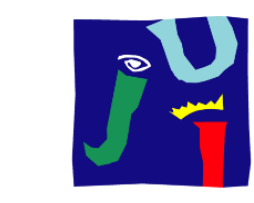

UNIVERSITAT

JAUME•I

Escola Superior de Tecnologia i Ciències Experimentals Departament Química Inorgànica i Orgànica

\title{
Functional Gels as Microreactors
}

Geles funcionales como microreactores

PhD Thesis

Nishant Singh

Supervisor:

Beatriu Escuder Gil

Castelló de la Plana, November, 2016 



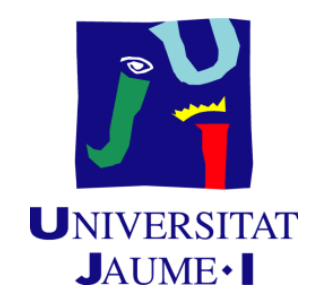

Beatriu Escuder Gil, Associate Professor at the Department of Inorganic and Organic Chemistry, Universitat Jaume I,

CERTIFY that the PhD thesis entitled "Functional Gels as Microreactors" presented by Nishant Singh, has been developed under her supervision at the Organic Chemistry Section of the Department of Inorganic and Organic Chemistry, Universitat Jaume I.

Castelló, November, 2016

Beatriu Escuder 



\section{PYר \\ $\mathbf{U}_{\text {NIVERSITAT }}$ \\ JAUME•I}

This work has been financed by the EU (Marie Curie ITN-SMARTNET). Nishant Singh thanks the EU for the ESR Marie Curie contract.

Publications related to the content of this thesis:

1) Towards supramolecular catalysis with small self-assembled peptides.

N. Singh, M. T. Solsona, J. F. Miravet, B. Escuder, Israel Journal of Chemistry, 2015, 55, 711 .

2) Insight into the esterase like activity demonstrated by an imidazole appended self-assembling hydrogelator.

N. Singh, M. P. Conte, R. V. Ulijn, J. F. Miravet, B. Escuder, Chemical Communications, 2015, 51, 13213.

3) Tandem reactions in self-sorted catalytic molecular hydrogels.

N. Singh, K. Zhang, C. A. A. Pachón, E. Mendes, J. H. van Esch, B. Escuder, Chemical Science, 2016, 7, 5568.

Highlighted as Working in tandem in Nature Nanotechnology, 11, 578, 2016, doi:10.1038/nnano.2016.130.

4) Peptide-based molecular hydrogels as supramolecular protein mimics, N. Singh, M. Kumar, J. F. Miravet, R. V. Ulijn, B. Escuder, Chemistry - A European Journal, 2016, DOI: $10.1002 /$ chem.201602624. 

The shortest answer is doing the thing....

Ernest Hemingway

Apparantly he never met a $\mathrm{PhD}$, you do things but you never get the answers....

The course of true love never did run smooth...

Said William Shakespeare... and every poor soul trying to finish his/her thesis.... 



\section{Acknowledgements:}

"Men, like nails, lose their usefulness when they lose their direction and begin to bend ", Bea has always been a torchbearer, a huge motivator and ofcourse the hammer, not letting me bend or lose my direction. Kudos Bea for making me work hard and party harder... with all my respect and love, words won't suffice my gratitude.

I would like to thanks Juan for all the interesting conversations we had and sometimes we did talk about science. Your coolness and support will always be cherished.

Santi now that you are "quitting smoking", I guess we will have to find a new addiction to talk about rock $\mathrm{n}$ roll, politics, science and what not. Cristina and Marta you guys have been an immense support in work and ofcourse for unforgettable parties that we have had. Cesar has always been a huge help from the beginning, muchas gracias "Parcero". The venomous jokes of Juanjo are worth mentioning with his bollywood moves, they always lighten your mood. Anna who is a sweetheart always inspiring us to eat our food slowly, all the best for your "European Style Thesis". Thanks and congratulations to Dr. Marco the new doctor in the family. And ofcourse this thankyou note cannot be complete without a worthy mention of Vicent Nebot, Maria dolores and Carlos. Anna marzo and Carlos for the padel matches, one day I will pay for all the beers that you were promised Anna for defending my smash shots, but I guess you are a better player now thanks to me ofcourse.

The "ciempies humano" family without whome my journey here in Spain would have been unimaginable. Thanks to Maria- La Jefa and Carmen-La Deputy Jefa for all the love and care, Diana and Ara-the amount of love and craziness in these two is unscalable, Gerrard, Campanilla, Elena, Fran, Hugo and Silvia, Omar, Dominika Marcos-el loco del tascas del pollo for visiting me in Holland from Castellon after a crazy car ride wih Hugo, Marta and Manolo-I guess no one shares my love for Indian food in Spain as much as Marta. We will never be forgetting our trips to India and the crazy memories will always be in my heart. Underneath is the list of "germans" who have always supported me in thick and thin-

Anupam, Shashwat and Arpit- Bhai se bhi badh kar

Ruben-sabes que te quiero un montón hermano.

Carles- Germà gràcies per tot- Com va això? -

Andrew pa mi Andre- tot begudet germà-

And Alba, " Sleepless nights, watching the sky, under the stars here we lie" need I say more?

Finally my maa you raised me all alone and gave me all you had and my brother "live your dreams, make your life, I will be there". And my papa "Wish you were here". 

Abbreviations

1D one dimensional

3D three dimensional

$\AA \quad$ angstrom

AFM atomic force microscopy

Ala(A) $\quad L$-alanine

ALP alkaline phosphatase

$\operatorname{Arg}(\mathrm{R}) \quad L$-arginine

Asn $(\mathrm{N}) \quad L$-asparagine

Asp(D) $\quad L$-aspartic acid

BOP (Benotriazol-1-yloxy)tris(dimethylamino)phosphonium

hexafluorophosphate

C concentration

calcd calculated

$\mathrm{Cbz}$ benzyloxycarbonyl

CD circular dichroism spectroscopy

CLSFM confocal laser scanning fluorescence microscopy

Cys $(\mathrm{C}) \quad L$-cysteine

DCC $\quad N, N^{\prime}$-dicyclohexylcarbodiimide

DCM dichloromethane

DCU $\quad N, N^{\prime}$-dicyclohexylurea

dd doublet of doublets

ddd doublet of doublet of doublets

DIPEA $\quad N, N$-Diisopropylethylamine

DME ethylene glycol dimethyl ether

DMF $\quad N, N$-dimethylformamide

DMSO dimethyl sulfoxide

DN double network

DNA deoxyribonucleic acid

DNPA dinitrophenyl acetate

$\mathrm{dq}$ doublet of quadruplets

DSC differential scanning calorimetry

e.e. enantiomeric excess

e.r. enantiomeric ratio

eq equivalent

$\mathrm{Et}_{3} \mathrm{~N} \quad$ triethylamine

exp experimental

Fmoc 9-fluorenylmethoxycarbonyl

FTIR fourier transform infrared spectroscopy

GdL glucono $\delta$-lactone

$\mathrm{G} \ln (\mathrm{Q}) \quad L$-glutamine

Glu(E) $\quad L$-glutamic acid

Gly(G) $\quad L$-glycine

h hexaplet

$\operatorname{His}(\mathrm{H}) \quad L$-histidine

hr hour

HPLC high performance liquid chromatography chromatography

HTBU $\quad N, N, N^{\prime}, N^{\prime}$-Tetramethyl-O-(1H-benzotriazol-1-yl)uronium hexafluorophosphate

H-bond hydrogen bond

Ile(I) $\quad L$-isoleucine

iPr isopropyl 


\begin{tabular}{|c|c|}
\hline $\mathrm{k}_{\text {cat }}$ & constant for turnover rate of enzyme substrate complex \\
\hline $\mathrm{K}_{\mathrm{M}}$ & Michaelis-Menten constant \\
\hline $\mathrm{K}_{\mathrm{sol}}$ & solubility constant \\
\hline Leu(L) & $L$-leucine \\
\hline LMWG & low molecular weight organic gelators \\
\hline Lys(K) & $L$-lysine \\
\hline $\mathrm{s}$ & singlet \\
\hline $\mathrm{m}$ & multiplet \\
\hline $\mathrm{MeOH}$ & methanol \\
\hline $\operatorname{Met}(\mathrm{M})$ & $L$-methionine \\
\hline MGC & minimum gelation concentration \\
\hline $\mathrm{mmol}$ & milimoles \\
\hline mol & moles \\
\hline MS & mass spectrometry \\
\hline NHS & $N$-hydroxysuccinimide \\
\hline NMR & nuclear magnetic resonance \\
\hline PA & polyamide \\
\hline $\mathrm{Pd} / \mathrm{C}$ & palladium on charcoal \\
\hline Phe(F) & $L$-phenylalanine \\
\hline$p$ NPA & para-nitrophenyl acetate \\
\hline Pro(P) & proline \\
\hline RNA & ribonucleic Acid \\
\hline r.t. & room temperature \\
\hline SEM & scanning electron microscopy \\
\hline $\operatorname{Ser}(\mathrm{S})$ & $L$-serine \\
\hline $\begin{array}{l}T_{\text {gel }} \\
\text { t-BOC }\end{array}$ & $\begin{array}{l}\text { highest temperature at which gel stays self-standing } \\
\text { tert-butyloxycarbonyl }\end{array}$ \\
\hline TEM & transmission electron microscopy \\
\hline TFA & trifluoroacetic acid \\
\hline THF & tetrahydrofuran \\
\hline $\operatorname{Thr}(\mathrm{T})$ & $L$-threonine \\
\hline TRIS & tris(hydroxymethyl)aminomethane \\
\hline $\operatorname{Trp}(\mathrm{W})$ & $L$-tryptophan \\
\hline $\mathrm{TsCl}$ & $p$-toluenesuphonyl chloride \\
\hline $\operatorname{Tyr}(Y)$ & $L$-tyrosine \\
\hline$V_{\max }$ & maximal rate of the reaction \\
\hline $\operatorname{Val}(\mathrm{V})$ & $L$-valine \\
\hline WAXD & wide angle $\mathrm{X}$-ray diffraction \\
\hline
\end{tabular}


<smiles>CC(C)[C@H](NC(=O)Cc1c[nH]cn1)C(=O)NCCCCCCCNC(=O)[C@@H](NC(=O)Cc1c[nH]cn1)C(C)C</smiles><smiles>O=C(Cc1c[nH]cn1)NCCCCCCCCNC(=O)Cc1c[nH]cn1</smiles><smiles>CC(C)[C@H](NC(=O)C1CCCN1)C(=O)NCCCCCCCNC(=O)[C@@H](NC(=O)[C@@H]1CCCN1)C(C)C</smiles><smiles>CC(C)[C@H](NC(=O)CCC(=O)O)C(=O)NCCCCCCCCNC(=O)[C@@H](NC(=O)CCC(=O)O)C(C)C</smiles><smiles>CCCCCCCCCCCCNC(=O)C(NC(=O)[C@@H]1CCCN1)C(C)C</smiles>

ProValDoc

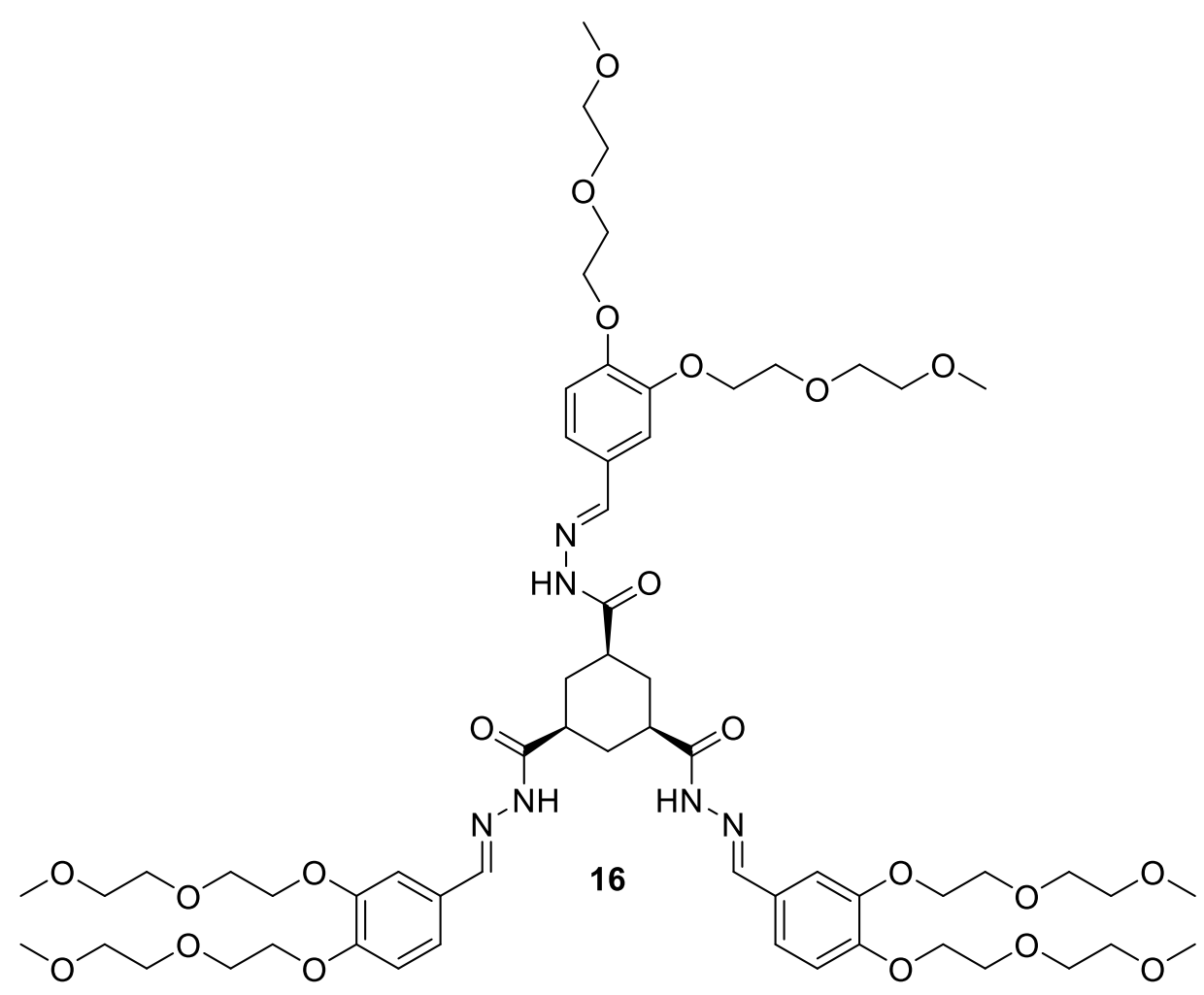



Chapter 1: Introduction

1.1.1. What is self-assembly though?

1.1.2. What is a gel?

1.1.3. Peptide based gels $\quad 8$

1.1.4. Applications 11

$\begin{array}{ll}\text { 1.1.4.1. Cell culture scaffolds } & 11\end{array}$

$\begin{array}{lr}\text { 1.1.4.2. Biomedical applications } & 12\end{array}$

$\begin{array}{ll}\text { 1.1.4.3. Energy harvest/electronics } & 14\end{array}$

$\begin{array}{ll}\text { 1.1.5. Application of suprmaolecular gels in catalysis } & 17\end{array}$

$\begin{array}{ll}\text { 1.1.5.1. Prior art } & 19\end{array}$

1.2. Summary and future prospects 31

1.3. References 33

Chapter 2: Objectives of the thesis

2.1. General objectives of the thesis $\quad 39$

2.2. Specific objectives

$\begin{array}{ll}\text { 2.3. References } & 42\end{array}$

Chapter 3: Insight into the esterase like activity demonstrated by an imidazole appended self-assembling hydrogelator

3.1. Introduction $\quad 47$

3.2. Result and discussion $\quad 48$

3.2.1. Design and synthesis $\quad 48$

3.2.2. Structural and morphological characterisation 51

3.2.2.1. Determination of minimum gel concentration $\quad 51$

$\begin{array}{ll}3.2 .2 .2 \text {. Solubility experiments } & 51\end{array}$

3.2.2.3. Potentiometric titration experiments $\quad 52$

$\begin{array}{ll}\text { 3.2.2.4. TEM } & 53\end{array}$

3.2.2.5. CD and IR $\quad 54$

3.2.2.6. Probing by 1-anilinonaphthalene-8-sulphonate (ANS) for
hydrophobicity of self-assembled fibres

$\begin{array}{ll}\text { 3.2.3. Catalysis } & 56\end{array}$

3.2.3.1 $p$ NPA hydrolysis $\quad 56$

3.2.3.2 Hydrolysis of inactivated $L$ - and $D$-phenylalanine methyl ester $\quad 62$

3.3. Conclusions

3.4. Experimental section $\quad 65$

3.5. References $\quad 76$

Chapter 4: Tandem reactions in self-sorted catalytic molecular hydrogel

$\begin{array}{ll}\text { 4.1. Introduction } & 79\end{array}$

4.2. Results and discussions $\quad 83$

4.2.1. Synthesis $\quad 83$

4.2.2. Structural and morphological analysis $\quad 86$

$\begin{array}{ll}\text { 4.2.2.1. Gel formation } & 86\end{array}$

$\begin{array}{ll}\text { 4.2.2.2. AFM and TEM } & 87\end{array}$

$\begin{array}{ll}\text { 4.2.2.3. WAXD } & 89\end{array}$

$\begin{array}{ll}\text { 4.2.2.4. } T_{\text {gel }} \text { experiments } & 91\end{array}$

4.2.2.5. Rheology, DSC and FTIR 92

4.2.3. Catalysis 95

4.3. Conclusions $\quad 98$

4.4. Experimental section $\quad 99$

4.5. References 112 
Chapter 5: A supramolecular self-sorted system as bifunctional catalyst for antiselective direct one pot Mannich reaction

5.1. Introduction $\quad 117$

5.2. Results and discussion $\quad 121$

$\begin{array}{ll}\text { 5.2.1 Catalysis } & 121\end{array}$

5.2.1.1 Direct three component Mannich reaction $\quad 121$

5.2.1.2. Three component Mannich reaction using benzaldimethyl acetal,
aniline and cyclohexanone

$\begin{array}{ll}\text { 5.3. Conclusion } & 127\end{array}$

5.4. Experimental Section $\quad 127$

5.5. References 133

Chapter 6: Catalytically controlled formation of a double network hydrogel 6.1. Introduction

6.2. Results and discussion $\quad 145$

$\begin{array}{ll}\text { 6.2.1. Synthesis } & 145\end{array}$

6.2.2. Individual and mixed gel system formation $\quad 145$

$\begin{array}{ll}\text { 6.2.3. Rheological experiments } & 146\end{array}$

$\begin{array}{ll}\text { 6.2.4. Kinetic studies } & 147\end{array}$

$\begin{array}{ll}\text { 6.2.5. Confocal microscopy } & 149\end{array}$

6.2.6. AFM and TEM 150

$\begin{array}{ll}\text { 6.2.7. WAXD } & 152\end{array}$

6.3. Conclusion 152

6.4. Experimental section 153

6.5. References 161

$\begin{array}{ll}\text { Summary (English) } & 167\end{array}$

$\begin{array}{ll}\text { Summary (Spanish) } & 173\end{array}$

$\begin{array}{lr}\text { Annex } & 179\end{array}$ 
Chapter 1

Introduction 


\subsection{Introduction}

It is known that the answer to origin of life lies somewhere on delicate thread linking the protein and DNA. But simple as it sounds, this DNA-protein system is too complex to be serendipitous, and to have come into existence at once by chance. So, clearly there lies a chicken-egg problem about which came first, the chicken (protein, phenotype), or the egg (DNA, genotype)? The answer though open to debate lies in the pre-existence of a RNA world before DNA and proteins. A set of RNA molecules able to self-replicate using complementary templating, being able to auto-catalyse/catalyse the synthesis of their own or other RNA molecules' and thus reproducing and sustaining their own kind is now most widely accepted theory supported by some experimental work. ${ }^{1-5}$

Let's give a slight twist to the stories of few movies and generate the outline of this chapter. Let's pick our favourite movie star and teleport him/her to 3 billion years from now when all forms of life are on the verge of extinction. Fortunately/unfortunately the science and technology has advanced so much that we can travel at the speed of light but still the chicken egg problem lingers in thin air which is now hard to breathe in. Finding it extremely hard to survive in the earth's environment, our hero is sent to far out galaxies with select team mates to find a planet where life exists or at least have better chances to support life. Unfortunately travelling at the speed of light they encounter some problem with their ship and have to execute an emergency landing on a planet "XYZ123". The planet is under continuous bombardment of asteroids and meteors bringing tonnes of organic matter to its surface. They find bodies of liquid most likely water with froth floating on the surface. They take samples of froth and water and after fixing their ship they continue their hunt for a new life supporting planet. Meanwhile visiting thousands of different solar systems and planets they studied the sample collected from the planet 
XYZ123. To their surprise they find some organic compounds in the samples which have now self-assembled into larger structures like polymers and macroscopic bubbles. Having lost their hope, in dismay they make a pit stop on this planet while going back to earth to find only to their surprise the planet brimming with micro-organisms and different forms of life. Everything started to fall in place, even though the planet was still under constant bombardment of meteors, the self-assembled structure were unaffected by extreme outer environment conditions. They observed that these structures could harbour light and nutrients to reproduce their structure, filling the planet with early form of life. But what puzzled them most was that in the absence of proteins or enzymes which require DNA and other complex chemicals, how was this evolution of living microorganisms possible.

As most forms of life today depend on the protein catalysts called enzymes responsible for enhancing the rates of different chemical reactions. Not until someone pointed out that certain kind of RNA called ribozymes also possess catalytic activity which can act as enzymes. This simplifies the perception of life where catalysis and life can be coined as synonymous and we can conceive the concept of the evolution of first form of life to the much simpler set of molecules for example RNA being able to catalyse, reproduce and grow, showing all the basic properties which can be attributed to a living form. Such selfassembly also directs the formation of larger self-organised structures/networks as DNA. Absence of genes or enzymes at the time of prebiotic earth also indicates that metabolism and reproduction shown by first forms of life must have occurred via spontaneously selfassembling molecules. ${ }^{6-10}$

We can thus understand that self-assembling networks and catalysis have existed since the beginning in the nature and are quite possibly responsible for all forms of life. 


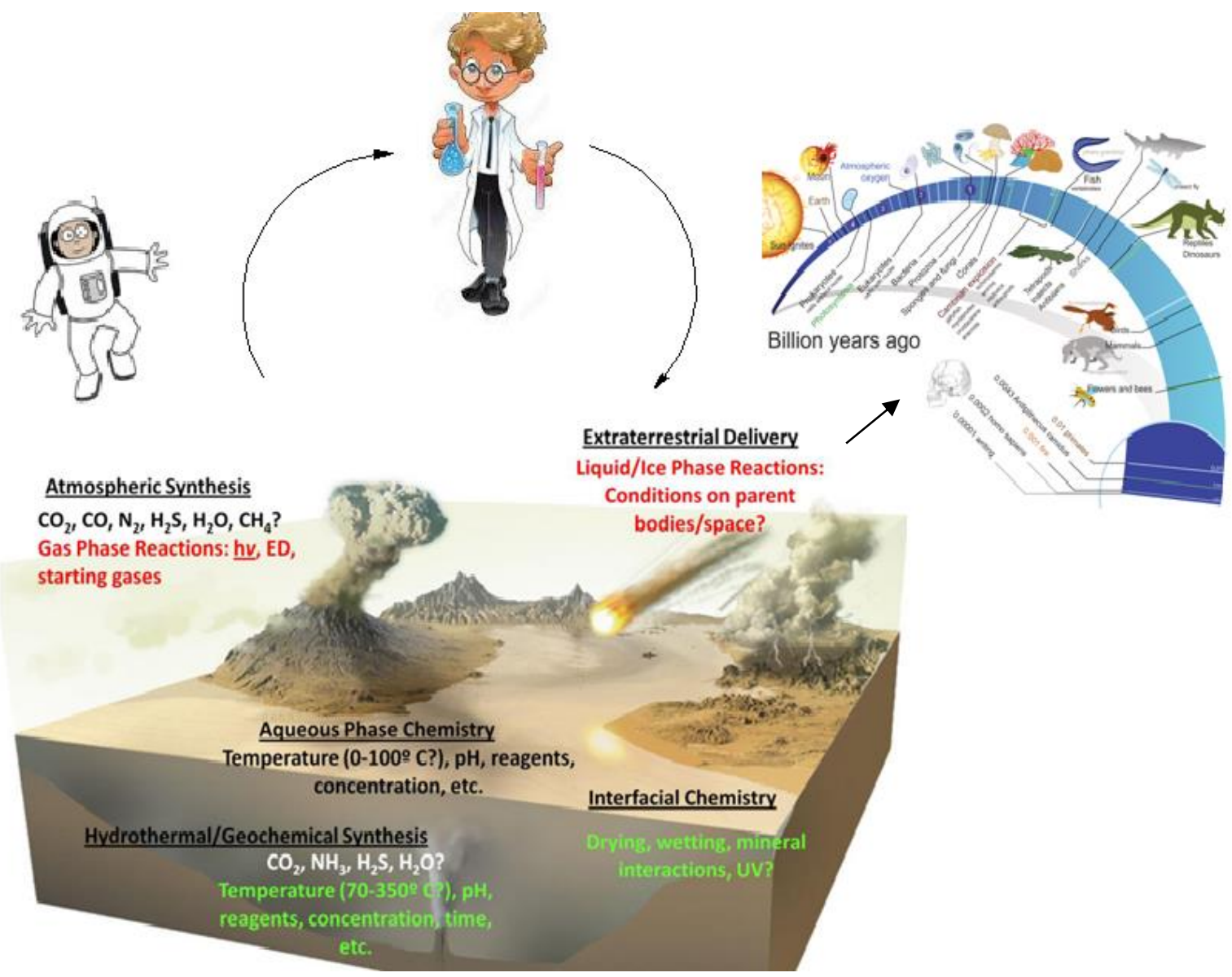

Figure 1.1: Cartoon depicting a probable way of evolution of life on prebiotic earth.

\subsubsection{What is self-assembly though?}

Certain organic compounds have the ability to react together and form simple sugars, hydrocarbons and amino acids which can spontaneously self-assemble into membrane structures or can polymerise into protein or nucleic acid type molecules. The process of self-assembly in itself is a counter intuitive process defying the law of entropy as per which everything leads to a more disordered state. It is impossible for a protein molecule or a soap bubble to be created by chance in the lifetime of universe even though we encounter plenty of soap bubbles or protein molecules every day. The self-assembly of such molecules leads to different shapes, structures and arrangements at the molecular level which give rise to different macroscopic aspects such as crystals, gels, etc. Even though we find numerous examples of self-assemblies in the nature, to design such 
molecules and predict them to self-assemble is a tricky business. Some advances have been made regarding the structure activity relationship of such molecules in recent years with the growing interest of the scientific community in this field owing to the numerous new useful applications related with such molecules. The self -assembling properties of such synthetic molecules depends on a very fine and tricky balance between the hydrophilic and hydrophobic groups present in the molecule. Such molecular selfassembly at microscopic level can lead to a very riveting macroscopic aspect commonly termed as gel which is our topic of interest here.

\subsubsection{What is a gel?}

Gel, a solid like material which mostly consists of a liquid and a solid as minor component has been defined or has been tried to be described in various ways. A definition as basic as "If it looks like a jelly then it is a gel" to "dilute mixtures of at least two components, in which both components form separate continuous phase throughout the system". It is not only limited to a solid component and a liquid component but also comprises of those composed of a solid and a gas phase termed as aerogels. In general the solid part is in minority which forms a three dimensional network in the liquid or gas medium. The solidliquid component gels are based on 3D network formed by solid preventing free flow of the liquid and the liquid preventing the $3 \mathrm{D}$ network from collapsing thus giving rise to the gel state. This coexistence of solid network with liquid gives rise to its unique elastic properties and distinguishes it from other forms like liquid crystals, solids or fluids. ${ }^{11,12}$

Gels are broadly classified as covalent or non- covalent gels. This classification comes from the interaction between the molecules that lead to the formation of gels. Covalent gels are based on covalent interactions between the individual molecules. In such gels the fibres or filaments of which the gel is made of and also the connections which connect 
different filaments are formed by covalent chemical bonds. These gels are independent of the properties of their individual components and are irreversible.

On the other hand the supramolecular gels are formed by low molecular weight molecules based on non-covalent interactions such as van der Waals forces, hydrogen bonding, $\pi-\pi$ interactions etc. between individual molecules which leads to a self-assembled fibrillar network able to percolate solvent. Such gels usually need a trigger or stimulus to nucleate the self-assembly process which could be temperature change, sonic waves, $\mathrm{pH}$ change, light, etc. These gels are usually reversible owing to the fact that since they are based on weak supramolecular interactions which are in orders of magnitude weaker than covalent interaction. Thus they can revert back to initial solution state on application of stimuli under moderate treatment of temperature / $\mathrm{pH}$ change, etc.

The viscoelastic behaviour or stability of these gels under various physical conditions is hugely based on the properties of their constituents and the forces governing their interactions. The reversibility of these gels and their ability to possess the properties of their constituents has been used to great advantages. The phenomenon of coming together of molecules in an ordered fashion to form gels by non-covalent interactions upon application of stimuli and their ability to revert back to the original state has allowed to find their application in different fields for e.g. drug delivery, photonics, catalysis, cell labelling, bio-templating, biomedicine, etc. ${ }^{13-20}$ Different kinds of bio-inspired building blocks based on sugars, amino acids etc. have been used for formation of such reversible low molecular weight hydrogelators owing to them being biocompatible and economical (Figure 1.2). ${ }^{21,22}$ 

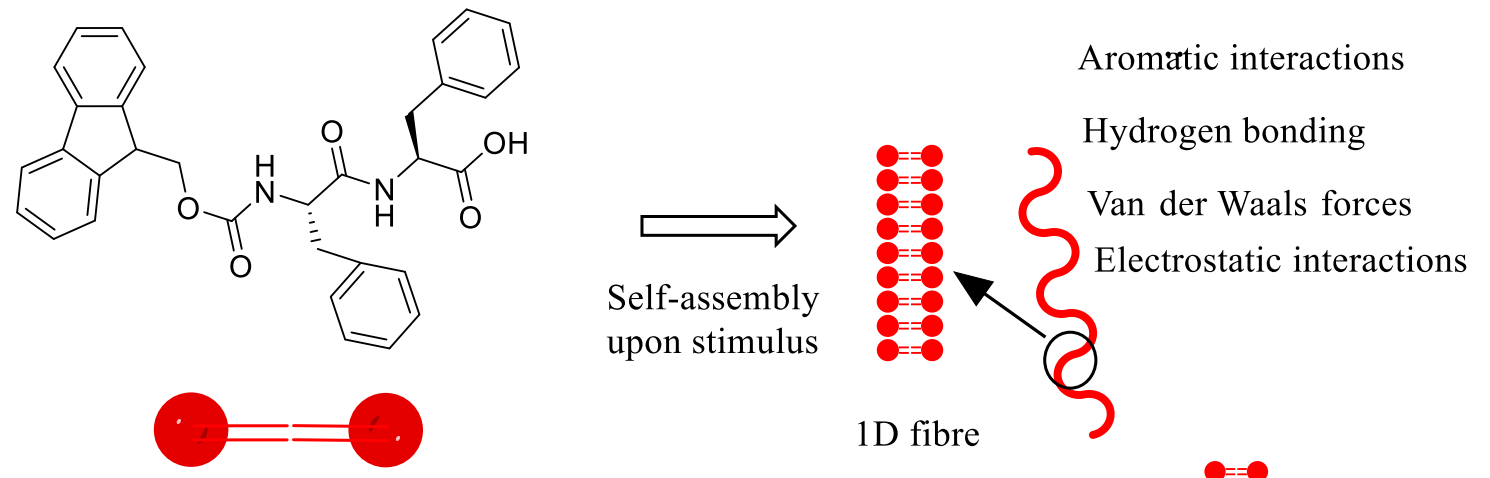

Bundles of fibres

Self-standing gel

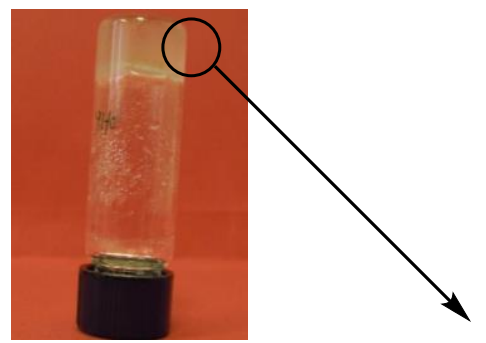

SEM image of dried gel
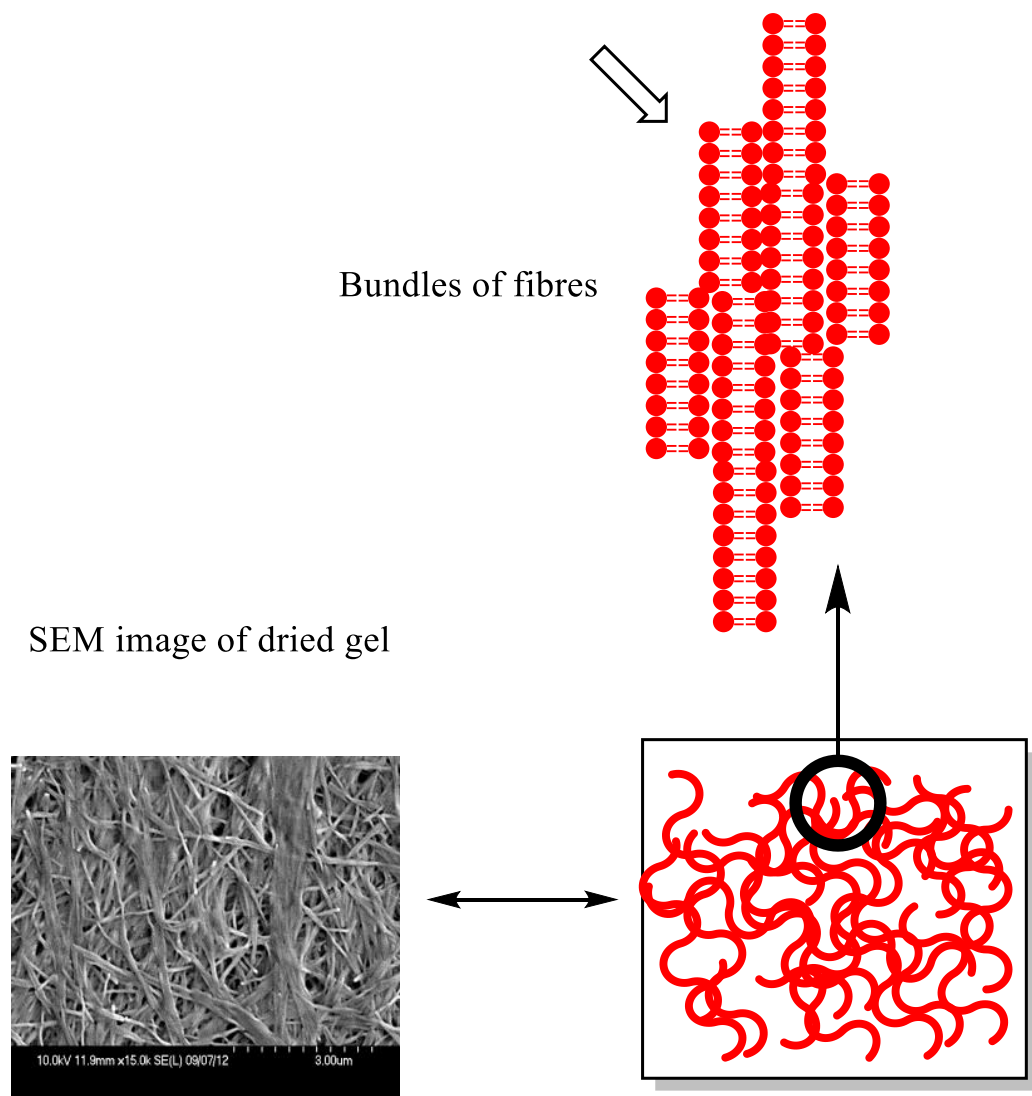
designed in such a manner so that they can self-assemble into a 1D aggregate which further form fibrils. These fibrils then can coil into larger fibres which cross link to form gels. The molecular design which has the information for the assembly is determined by the rigidity of the amide group as well as the size and polarity of the side chains. Thus the predetermination of the secondary structures of such peptidic hydrogelators is very important for them to assemble in a one-dimensional array. Different peptidic hydrogelators based on $\beta$ sheet, $\alpha$ helix, $\beta$ hairpin etc. have been reported. ${ }^{23}$ But for low molecular weight gelators with less than 10 amino acid residues $\beta$ sheet is the most abundant motif. Focusing in $\beta$-strand analogues, different designs of short peptides are found with their structures comprising of segregated polar and hydrophobic regions. These structures self-assemble in water driven by a combination of the screening of hydrophobic groups from water and the formation of 1D arrays of multiple H-bonds. Figure 1.3 collects some of the most common designs that include amphiphatic peptides, ${ }^{24}$ peptide-headed amphiphiles (either aromatic end-capped or lipidated) ${ }^{20,25}$ and bola-amphiphiles. ${ }^{19,22,26,27}$

$\mathrm{N}$-protected single amino acids (aromatic end capped peptides, Figure 1.3) are by far the simplest examples of peptide/amino acid based gelators. The $\mathrm{N}$-capping residue which usually are hydrophobic aromatic moieties for example Fmoc provide the $\pi-\pi$ interaction which is balanced with the hydrophilic polar parts of the amino acid to give the effective ability to form hydro/organogels. ${ }^{20,29,30}$ Bolamphiphilic and short lapidated peptides which are mostly discussed and used in this thesis usually have an alkyl chain providing hydrophobic interactions while the peptidic residues provide the necessary hydrogen bonding, ionic and aromatic interactions etc. together with several amide bonds contributing in hydrogen bonding to yield self-assembled nano/microscopic structures. Increasing the size of the molecule with extra amino acids gives a wider prospect to play 
with the design and to induce different new properties and microstructure based on the length, order and selection of the amino acids. As mentioned before the biocompatibility, reversibility and new/enhanced functionalities upon self-assembly make these molecules highly applicable in different fields. Few of the different functional properties which are observed upon self-assembly of peptidic molecules are discussed in the following section briefly with greater emphasis on catalytic properties.

\section{AMPHIPATHIC PEPTIDES}
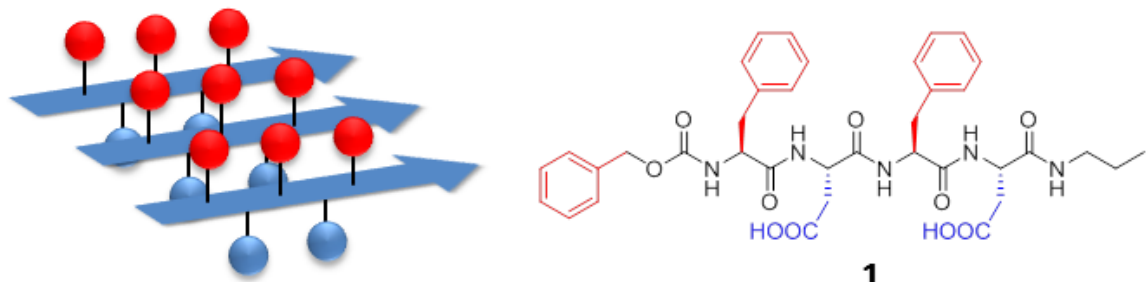

1

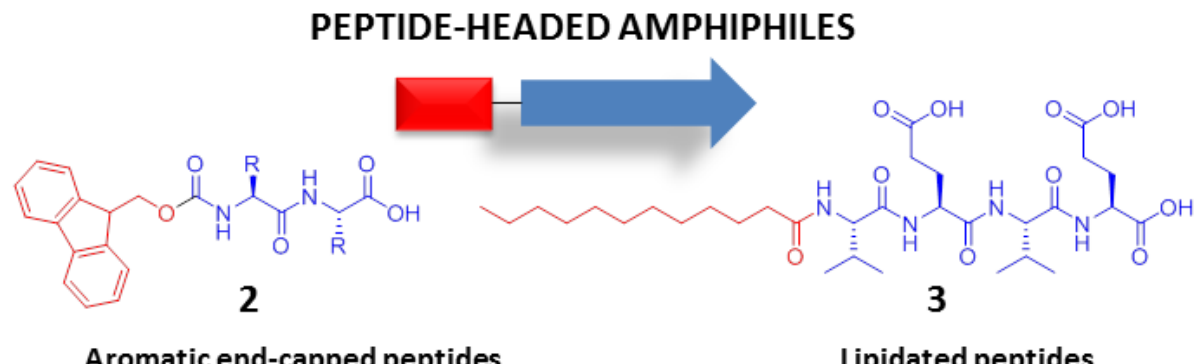

Aromatic end-capped peptides

Lipidated peptides

BOLAAMPHIPHILES

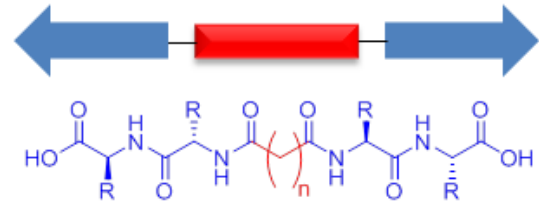

4

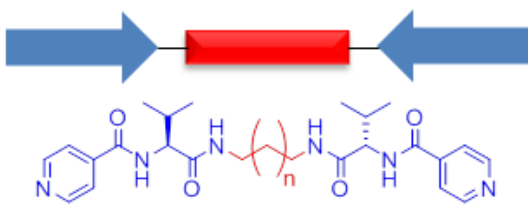

5
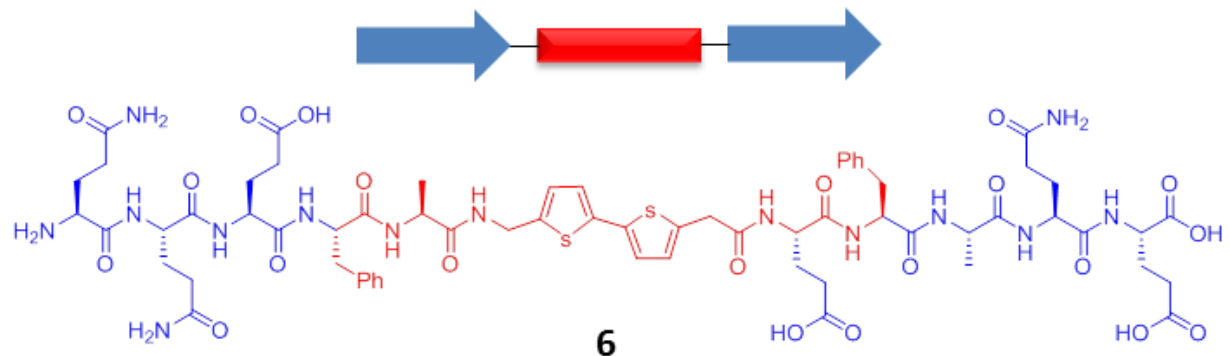

Figure 1.3: Different classes of peptidic gelators. ${ }^{28}$ 


\subsubsection{Applications of self-assembled peptides}

\subsubsection{Cell culture scaffolds}

The hydrogelation capabilities and biocompatibility of such peptidic molecules has driven a great amount of interest in their application as scaffolds for cell/tissue culture. An elaborate review has recently been published by $\mathrm{Xu}$ and co-workers about the same. ${ }^{31}$ For instance, a Fmoc-FF hydrogel has been found to be biocompatible 3D scaffold for the cell culture of mammalian cells including astrocytes, MDCK and COS7, with evident cell migration and proliferation observed in 5 days of incubation (Figure 1.4). ${ }^{32}$ RGD based hydrogels due to their intrinsic cell adhesion properties have shown to be ideal candidates for 3D cell culture. It has been also reported that Fmoc-GRDS with a biomimetic collagen gel, as a composite scaffold could enhance the adhesion and proliferation of viable human corneal stromal fibroblasts (hCSFs) by $300 \%$ compared to non-functionalized gels. ${ }^{33}$ Fmoc-RGD and Fmoc-FF coassembled hydrogel could support human dermal fibroblasts which could then deposit and form extra cellular matrices including fibronectin and collagen I in a controlled fashion. Interestingly when the RGD sequence was altered to RGE the deposition and formation of uECM was not observed. ${ }^{34}$
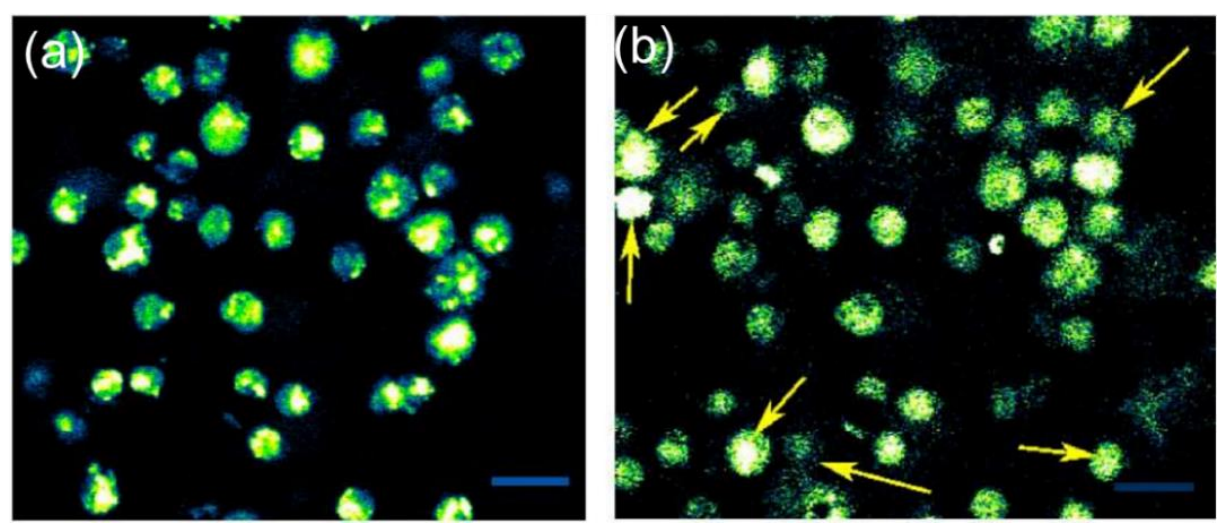

Figure 1.4: Laser confocal micrographs representing 3-D cultures of COS7 cells using in situ hydrogels self-assembled from Fmoc-FF as scaffolds: (a) 4 days and (b) 5 days of incubation. The arrows in (B) indicate the proliferated new cells. 32 


\subsubsection{Biomedical applications}

The self-assembly of such bio-insipired peptidic molecules have been widely used for biomedical applications ranging from controlled nano carriers for encapsulation and drug release, tissue engineering, diagnostic tool etc. ${ }^{35-37}$ Nano-fibrillar network of Fmoc-FD gelator was used to entrap low molecular-weight drugs, i.e., 3,5-dimethyl-1adamantanamine hydrochloride (AddMe) and 5-methyl-1-adamantanamine 3-carboxylic acid (Ada-MeC) which are inherently non-antigenic antiviral drugs, in the gel and injecting into rabbits, highly specific antibodies were efficiently produced. ${ }^{38}$ FmocTAEA known to form nanospheres could be stabilised by Fmoc-FY or Fmoc-FRGD. These nanoparticles were well-tolerated by cells (mouse embryonic fibroblast cells, NIH/3T3) and were capable of encapsulating hydrophobic dyes (Nile red) and targeting breast cancer cells (MDA-MB-435 cells) (Figure 1.5). ${ }^{39,40}$

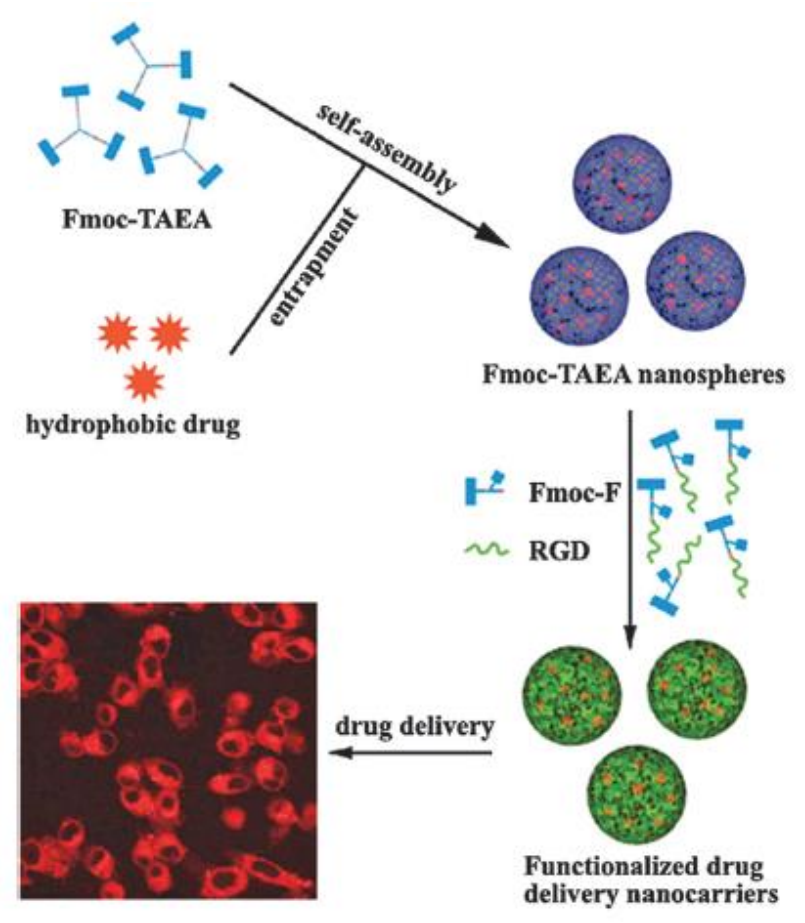

Figure 1.5: Schematic diagram of the construction of Fmoc-FRGD stabilized and functionalized FmocTAEA self-assembling nanospheres, along with the entrapment of hydrophobic molecules for drug delivery. 39 
Phenylacetyl-peptide amphiphiles are able to tranform from spherical to nanofibrillar aggregates by action of matrix metalloproteinases enzyme (MMP-9). An anticancer drug (Doxorubicin) was encapsulated in the spherical aggretaes and the structure transformation into 1D fibres by action of MMP-9 enzyme was utilised for slow release of the drug (Figure 1.6). ${ }^{41}$ In an another interesting example surface and secretory phosphatases, which are overexpressed around cancer cells were used to help dephosphorylate peptide derivatives leading to formation of nanofibrillar gel network around tumour cells. These hydrogel nanonets blocks cellular mass transport of proteins/enzymes across the cells leading to apoptosis even in multidrug-resistant cancer cells (Figure 1.7). ${ }^{42}$

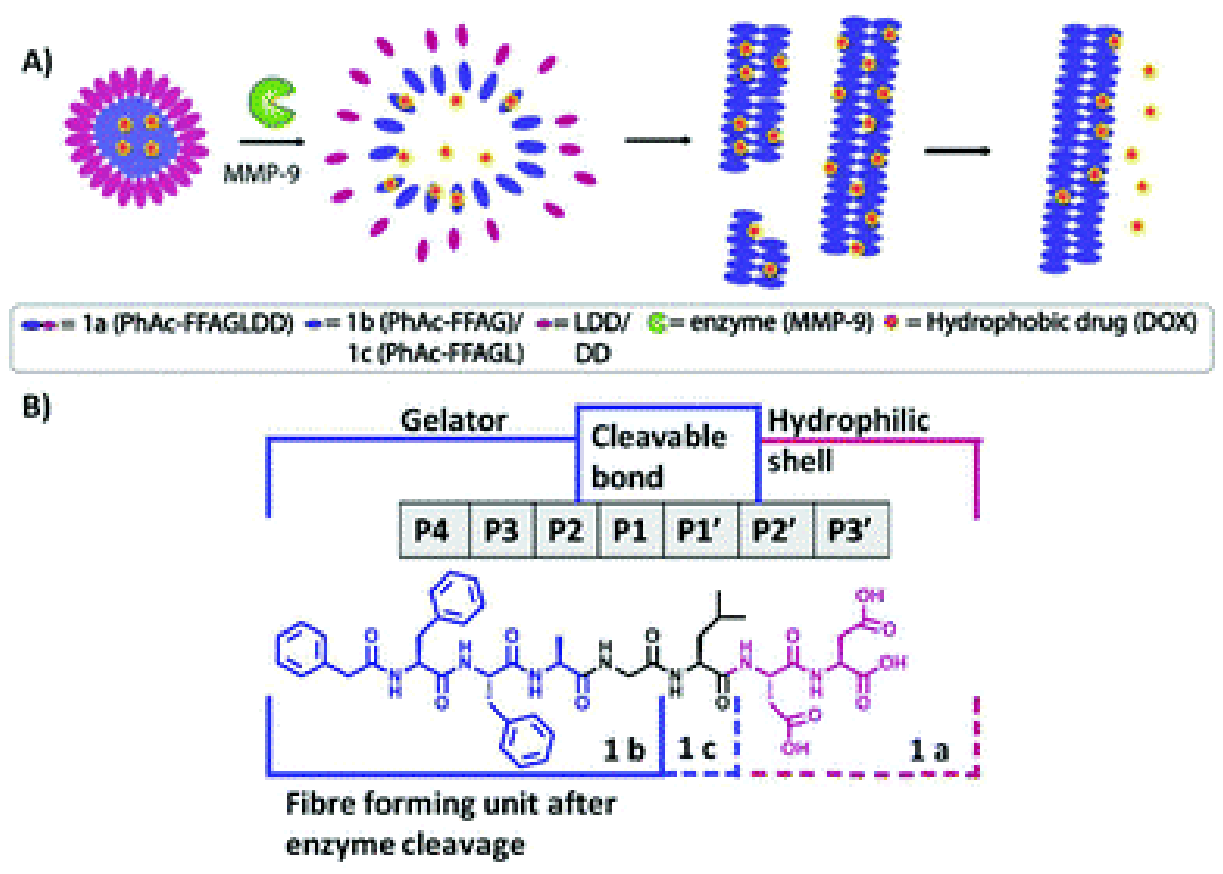

Figure 1.6: (A) Schematic representation of micelle to fiber transition induced by MMP-9 cleavage showing disassembl of micelles and the re-assembly into fibres after the removal of the hydrophilc group enabling prolonged drug release (B) Chemical structure of the biocatalytic gelation system and its components. $^{41}$ 

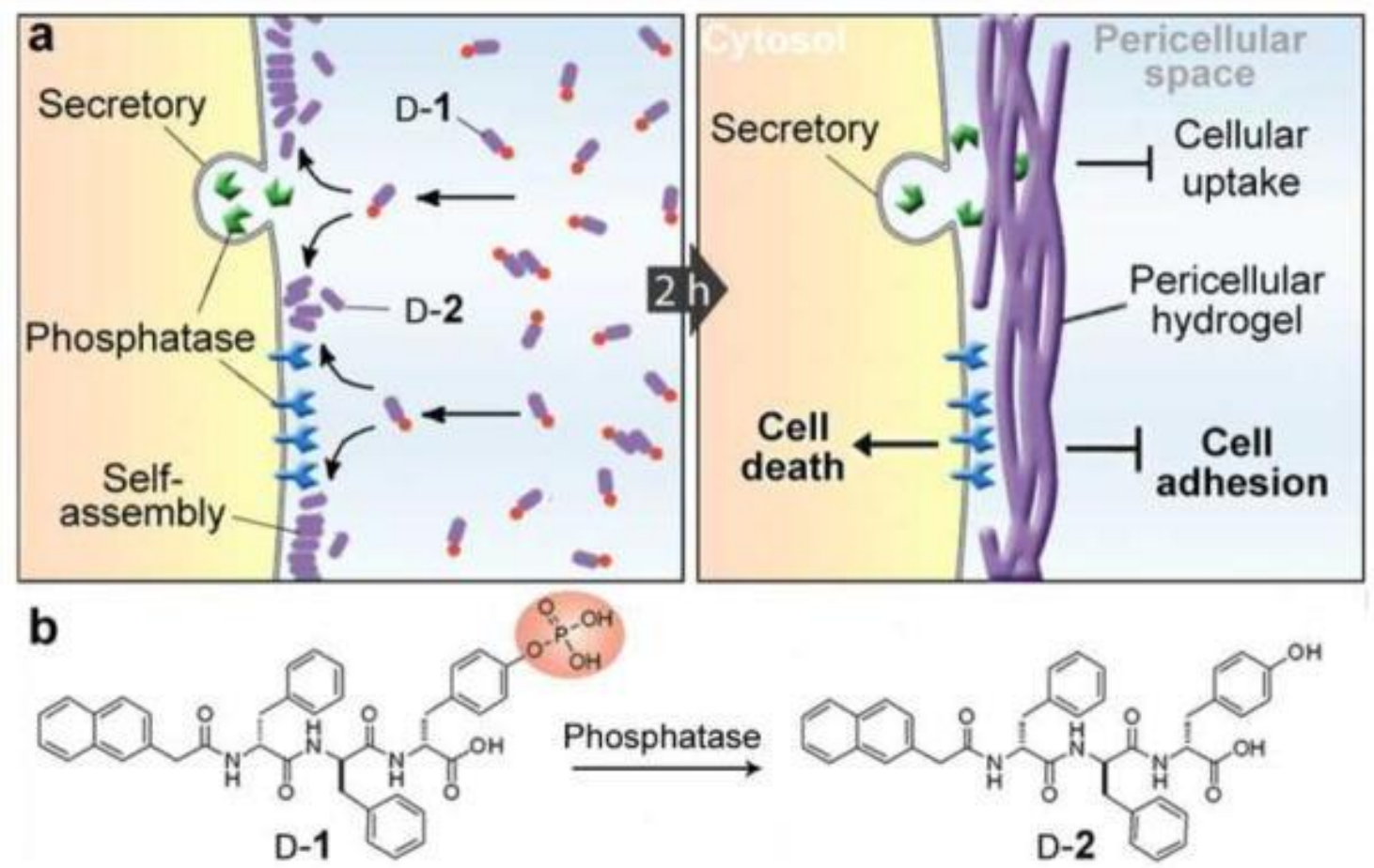

Figure 1.7: (A) Enzyme catalysed formation of pericellular hydrogel/nano-nets toinduce cell death. (B) molecular structures of the precursor (D-1)and the hydrogelator (D-2). ${ }^{42}$

\subsubsection{Energy harvest/electronics}

The organized molecular arrangement due to supramolecular interactions in the fibres of self-assembling peptidic molecules acting in conjugation or as template with electroactive molecules allows them to have long-range charge delocalization and transport. This makes them ideal candidate as an alternative organic option for greener energy. ${ }^{43}$

In a riveting example the acidic and polar moieties on the nanofibrillar surface of Fmoc -FF could be utilized to mineralize $\mathrm{FePO}_{4}$ by the sequential introduction of $\mathrm{Fe}^{3+}$ and $\mathrm{PO}_{4}$ ${ }^{-3}$. When heated to $350{ }^{\circ} \mathrm{C}$, the $\mathrm{FePO}_{4} /$ nanofibril conjugates transformed to form $\mathrm{FePO}_{4}$ nanotubes with the inner walls coated with a thin layer of conductive carbon due to carbonization of the peptides. These $\mathrm{FePO}_{4}$ nanotubes were found to be promising 
cathode materials for rechargeable Li ion batteries, with high reversible capacity and good stability during cycling (Figure 1.8). ${ }^{44}$

a)

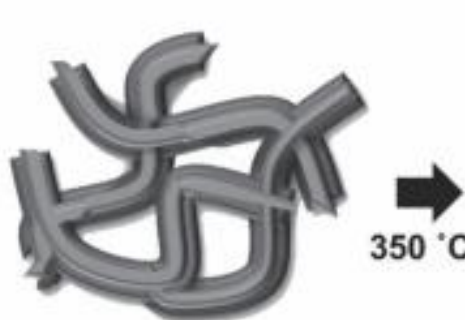

amorphous carbon

Mineralized hydrogel
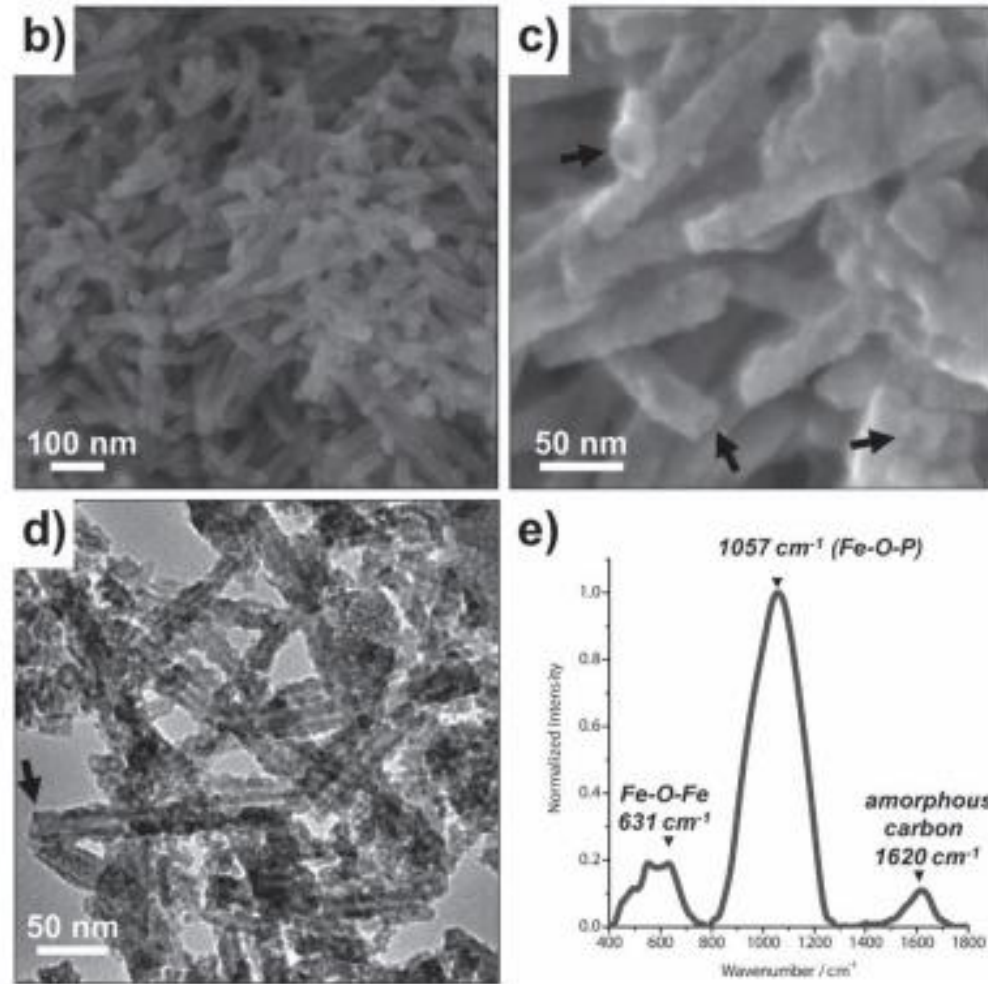

e)

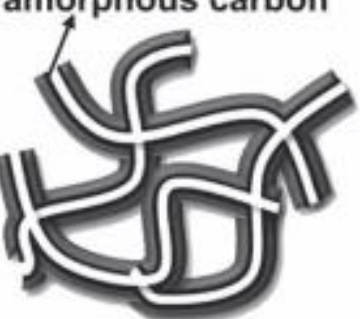

$\mathrm{FePO}_{4}$ nanotubes

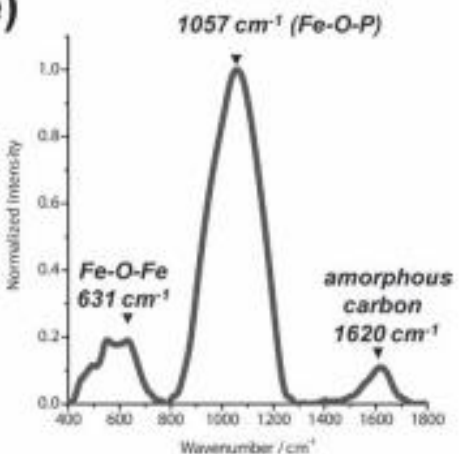

Figure 1.8: Synthesis of $\mathrm{FePO}_{4}$ nanotubes by heat treatment of Fmoc peptide/ $\mathrm{FePO}_{4}$ hybrid nanofibres. (a) Peptide nanofibres mineralized with $\mathrm{FePO}_{4}$ were treated at $350{ }^{\circ} \mathrm{C}$ to carbonize the peptide core and thus to fabricate hollow $\mathrm{FePO}_{4}$ nanotubes with inner walls coated with a thin layer of conductive carbon. Tubular structures are clearly visible in SEM (b-c) and TEM (d) micrographs. (e) FT-IR spectroscopy confirmed carbonization of the peptide core. Note that a peak at approximately $1620 \mathrm{~cm}^{-1}$ is attributed to vibrations of $\mathrm{sp}^{2}$ carbon, indicating the formation of amorphous graphitic carbon. Arrows indicate the openings of $\mathrm{FePO}_{4}$ nanotubes. ${ }^{44}$

In an another example 1,4-distyrylbenzene (an oligo-phenylenevinelene-OPV) derivative was attached to a variety of tetra peptides and their excitonic coupling could be controlled based on the nature of tetrapeptide sequence. A clear difference in the properties was noticed from a strongly excitonic coupling to excimer-like excited state, from an $\mathrm{H}$ - 
aggregate to a weakly coupled monomeric state. Altering the peptide sequeence resulted in different polymorphic states resuting in influencing the supramolecular ordering of $\pi$ conjugated chromophores (Figure 1.9A). ${ }^{45}$

Perylenebisimide (PBI) is a well-known chromophore for displaying photoconductivity. PBI molecules functionalized with peptides were shown to form one-dimensional (1-D) nanostructures with high photoconductivity. Detailed analysis revealed the formation of radical anions, which was remarkably stable in air and in presence of water. This example clearly demonstrates how a change of peptide sequence affects the morphology and in turn hampers the photoconductivity (Figure 1.9B). ${ }^{46}$
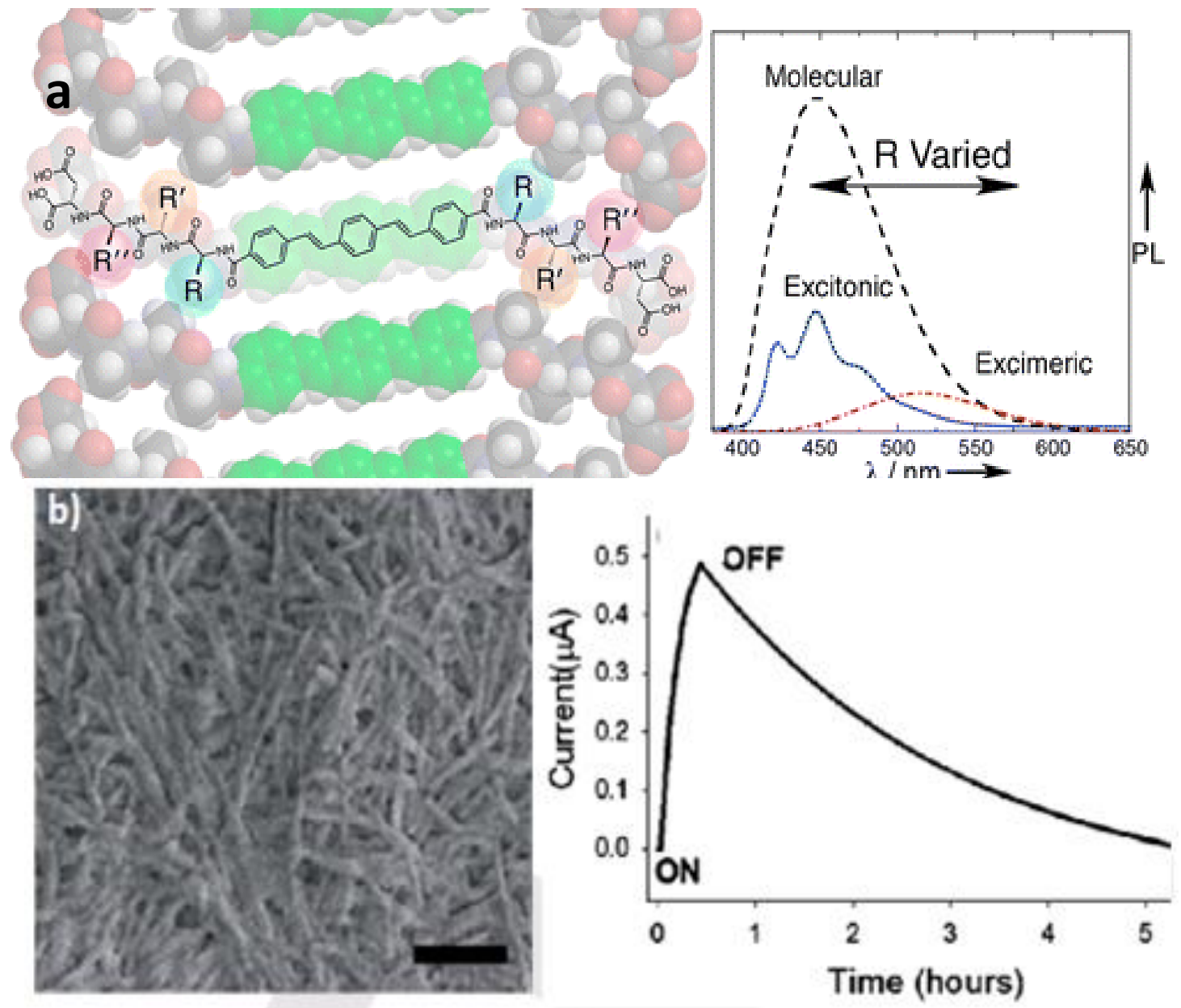

Figure 1.9: (A) Chemical structure of OPV peptide conjugate and the emission characterization of various

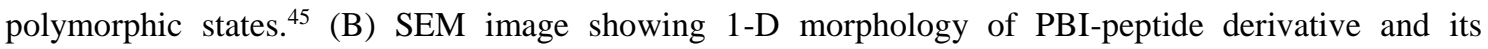
photoconductivity characterization. ${ }^{46}$ 
So far we have seen the basics in designs, synthesis and few of the many different applications of self-assembling peptidic molecules. The immense interest of the scientific community has led to high number of new findings and applications in this field making it almost impossible to sum up in the brief scope of this thesis. It could just be said that instead of taking the reader to the sea I have just brought a glass of water from the sea just to let it be known as how the water looks, tastes and feel like, trying to sum up the enormity of the sea, the potential and scope of the unchartered and unexplored waters in few words. As the title of the thesis "Functional Gels as Micro-reactors" suggests in the following section we will deal with the application of gels in catalysis trying to throw some light on the principles involved and a wider range of concerned prior art.

\subsubsection{Application of supramolecular gels in catalysis}

The use of supramolecular gels in catalysis is now a widely studied topic worldwide. As mentioned earlier the non-covalent interactions of the individual components leads to the formation of one dimensional fibres which lead to bundles of such fibres entrapping solvent, giving rise to physical gels. The question is how is the catalysis by gels if possible any different from conventional methods, what are the advantages which makes it any useful?
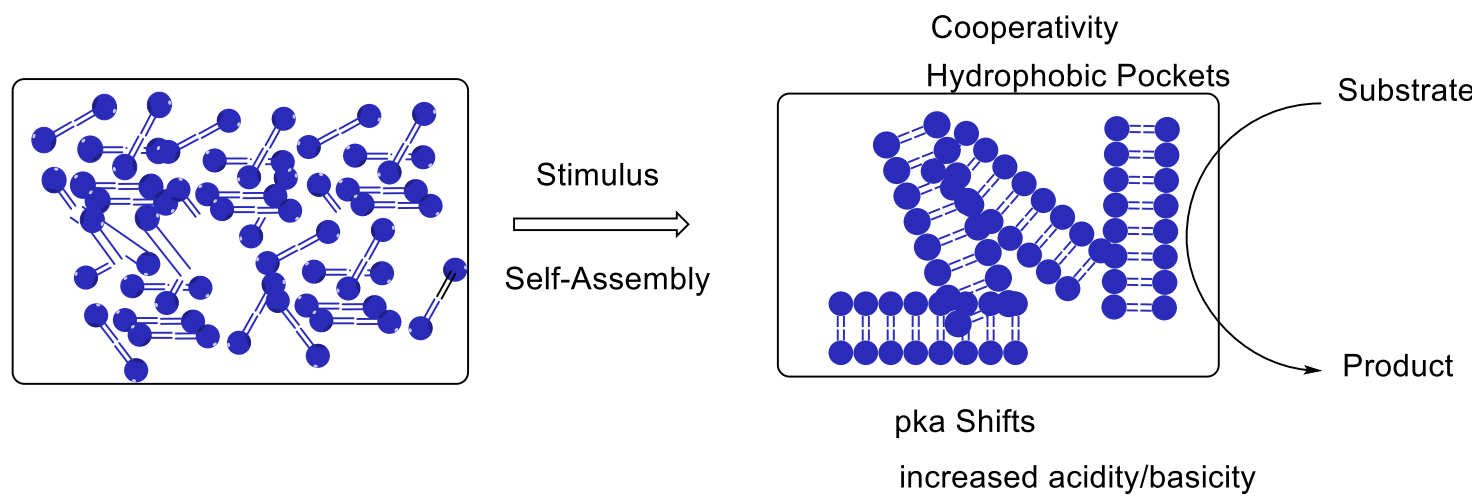

Figure 1.10: Cartoon depicting different new properties upon self-assembly making catalytic groups appended gelators as highly effective catalysts. 
Gel is composed of two different components the gelator (minor component) and the solvent (major component). It is necessary to dissolve the gelator completely in the solvent by heating, acidifying or basifying the solution based on the functional group of gelator, sonication, etc., this is as mentioned before coined as the stimulus which triggers the solubilisation of the gelator in the solvent. When eventually the heated solution comes at ambient temperature or the acidified/basified solution is neutralised it triggers the aggregation of the gelator molecules which causes the formation of 1D fibres responsible for gelation.

As discussed previously the secondary molecular structure of a potential gelator needs to have a balance between hydrophobic and hydrophilic parts. Such molecules if appended with catalytically active groups result in close proximity of the functional groups leading in increased concentration of the catalytic sites inducing cooperativity to work together among them. Upon aggregation the hydrophobic part is screened away from water molecules forming hydrophobic pockets which facilitate the approach of hydrophobic substrates in the close proximity of the catalytic groups. Moreover several other important features such as $p$ Ka shifts, increased binding affinity result in these molecules to perform enzyme like catalysis upon self-aggregation (Figure 1.10). The point to be noted here is that the gelator concentration required in general to form such supramolecular gels is very low sometimes as low as $0.1 \mathrm{wt} \%$. Apart from this since the gelator in gel are in the form of fibres (solid), thus they can be considered as heterogeneous catalysts. This makes the workup processes (especially in case of hydrogels when you can extract the product by organic solvents) very easy and also allows to use the same system multiple times for catalysis, as the organic products can be separated easily by organic phase wash. 


\subsubsection{Prior Art}

The use of gels in catalysis has been a relatively new field but with a promising future as publications highlighting the importance, feasibility and application of gels in catalysis are being added every day. ${ }^{11,19,20,22}$

The first mention of the presence of a supramolecular gel in an organocatalytic system was made by Inoue et al. by 1990 in their studies on the asymmetric addition of hydrogen cyanide to m-phenoxy benzaldehyde catalyzed by a histidine-based cyclodipeptide. ${ }^{47}$ They observed that low temperatures were accompanied by an increase in stereoselectivity. Later, Danda et al. showed that depending on the purification procedure of the catalyst either transparent or opaque gels or even solid suspensions were obtained in toluene. ${ }^{48}$ They observed that the viscosity depended directly on the rate of stirring and that faster stirring rates gave higher enantioselectivity. It was proposed that the process was second order with respect to the catalyst, with two imidazole residues necessary for the catalytic action. These catalytic gels were found by serendipity and the aggregation properties of the molecules were not seen as a helping factor.

The first designed catalytic gel was reported nearly a decade later by $\mathrm{Xu}$ et $a l .{ }^{49} \mathrm{In}$ this example a metallogel formed irreversibly in dimethylsulfoxide via the creation of crosslinked, three dimensional coordination polymer networks was applied. The crosslinking was achieved by using transition-metal ions with multiple sites available for coordination with multidentate ligands. They could catalytically oxidise benzyl alcohol to benzaldehyde by coordinating $\mathrm{Pd}(\mathrm{II})$ as the catalytic centres to the multidentate ligands. The best catalytic turnover of the metallogel was twice that of $\left[\mathrm{Pd}(\mathrm{OAc})_{2}\right]$.

One of the seminal works in the field of organocatalytic molecular gels was reported by Stupp et al. in 2007, where they demonstrated the hydrolysis of a model ester on the 
surface of nanofibres formed by aggregation of peptide amphiphiles (Figure 1.11). They explored the ability of the cylindrical supramolecular nanostructures formed by compound 1 for hydrolysis of 2,4-dinitrophenylacetate (DNPA). Histidine residues were incorporated into the peptide segment of PA molecules to mimic hydrolytic enzymes. The core peptide segment of the structures was KLLLAAA with histidine incorporated on the lysine amine side chain and N-terminus whilst an aliphatic tail was present to form cylindrical structures on self-assembly. They synthesised four different peptides aggregating into different structure to study their esterase activity. ${ }^{1-4}$ Peptide $\mathbf{1}$ was the amphiphile used to create self-assembled nanofibres. Peptide $\mathbf{2}$ formed spherical aggregates whilst peptides $\mathbf{3}$ and $\mathbf{4}$ had proline residues precluding the formation of $\beta$ sheet structures (Figure 1.11). Peptide 1 was found to have a $\mathrm{k}_{\text {cat }}$ of $(1.67 \pm 0.13) 10^{-2} \mathrm{~s}^{-1}$, three orders of magnitude greater than for peptides $\mathbf{2 - 4}$ for hydrolysis of substrate $(2,4$ dinitrophenyl acetate). (Figure 1.11)
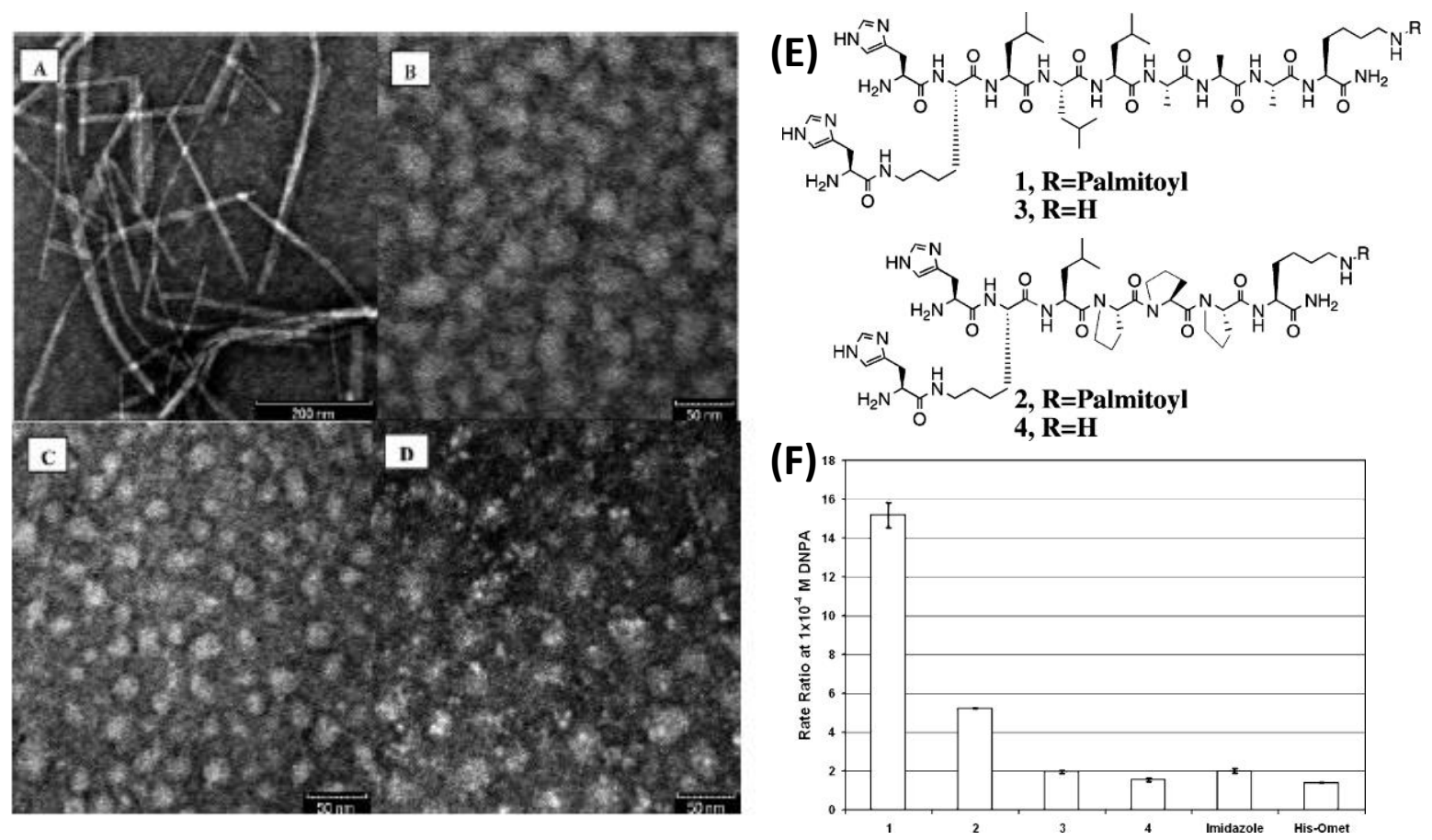

Figure 1.11: (A)-(D) Negatively stained TEM micrographs of 1 (A), 2 (B), 3 (C), and 4 (D) at pH 7.4. (E) Chemical structures of the molecules used to create nanostructures. (F) Observed rate increase in DNPA hydrolysis as the level of molecular organization in the catalytic particles is varied. ${ }^{50}$ 
They could thus conclude that the hydrolysis efficiency of DNPA was enhanced by a high density of reactive sites displayed on the surface of a supramolecular catalytic particle with significant internal order. Considerably higher hydrolysis rate was observed in the presence of internally ordered supramolecular nanofibres as the catalytic particles, compared to catalysts in solution and in spherical aggregates which should have less order.

These observations opened a new area in the design of supramolecular catalysts, suggesting that nanofibres of high aspect ratio and internal order are potentially interesting catalytic candidates. ${ }^{50}$ Liu et. al. reported functionalised nanotubes based on aromatic peptide amphiphiles as a hydrolase models. ${ }^{51}$ They took advantage of nanotube structures of Fmoc-FFH upon self-assembly, based on the well-known Fmoc-FF molecule, for hydrolysing the esterase substrate $p$-nitrophenyl acetate ( $p$ NPA) through catalytic centres (imidazole) present as a part of the molecule.

To enhance the hydrolysis rate they introduced guanidinium group as an electrostatic anchor for the transition state by incorporating Fmoc-FFR into the nanotubes through the method of co-assembly. They were able to form nanotubes by co-assembly of Fmoc-FFR and Fmoc-FFH giving rise to a $\beta$-sheet structure. Initial investigation into the Fmoc-FFH nanotubes proved to be efficient in the hydrolysis of the esterase substrate, $p$ NPA. Upon co-assembly of the two molecules the rate of hydrolysis increased confirming that the coassembled system is a more efficient catalytic system (Figure 1.12).

Liang et. al. also presented a similar work with a self-assembling peptide using histidine residue as a catalytic centre and arginine residues as binding probe. ${ }^{52}$ The self-assembling peptide named Q11 (QQKFQFQFEQQ) is salt-responsive and had the ability to selfassemble into a $\beta$-sheet nanostructure under mild conditions Using the Q11 as backbone 
and SG as flexible linker, peptides were synthesised with an $\mathrm{N}$-terminal histidine residue (peptide $\mathrm{Q} 11 \mathrm{H}$ ) and with an $\mathrm{N}$-terminal arginine residue as an electrostatic binding site (peptide Q11R).

(a)

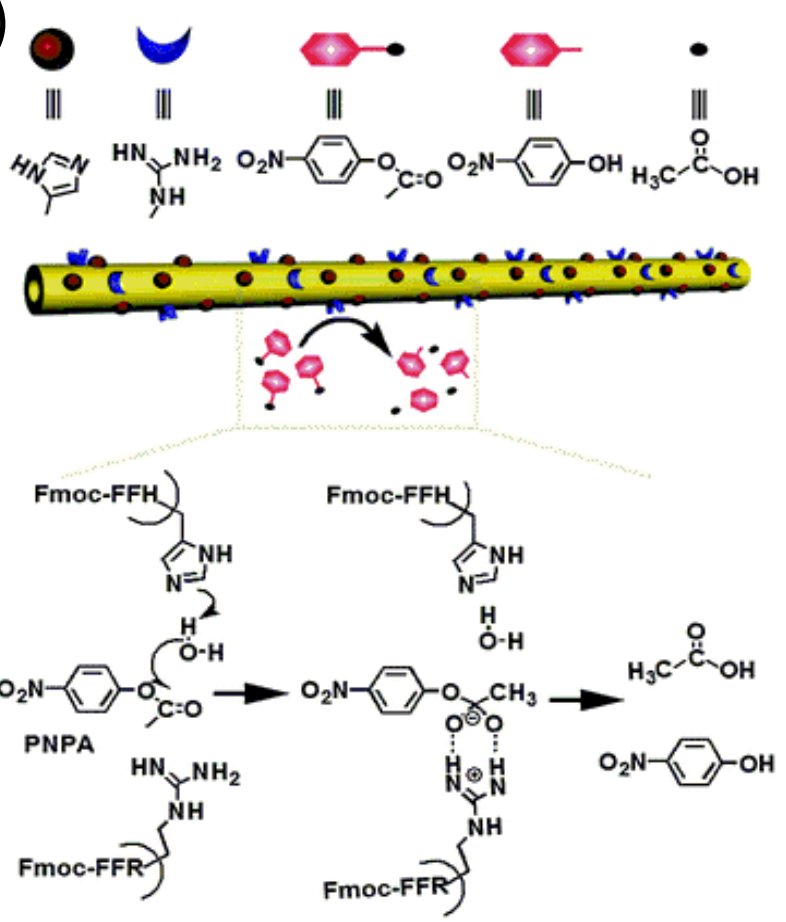

(b)

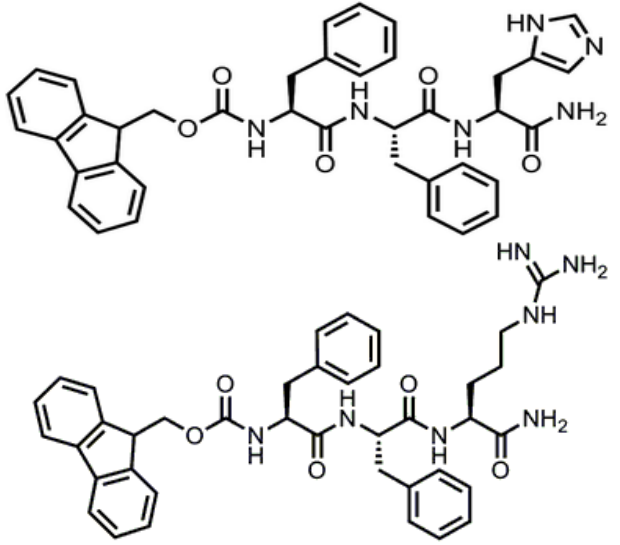

(d)

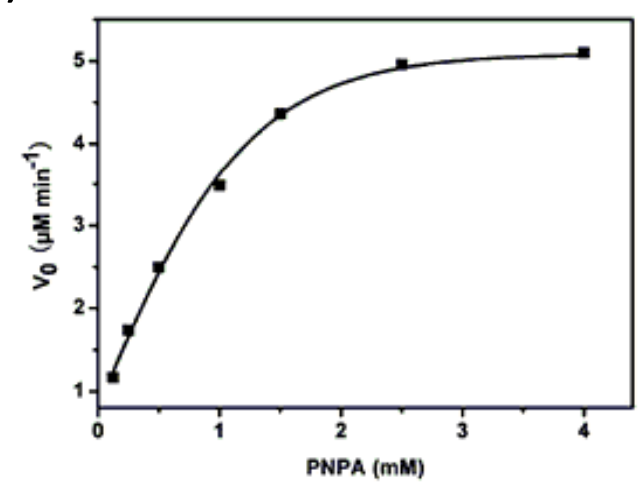

Figure 1.12: (a) Cartoon of proposed mechanism of hydrolysis of pNPA by self-assembled nanotube of Fmoc-FFH and Fmoc-FFR. Structures of (b) Fmoc-FFH (c) Fmoc-FFR. (d) Schematic of MichaelisMenten plot of initial catalytic reaction rate vs. concentration of substrate as seen in reported data. ${ }^{51}$

Another peptide Q11G with the same SG linker was synthesised to test for background reaction. Peptides Q11H and Q11R were then co-assembled to facilitate catalysis and substrate binding in the same sample. The presence of histidine as catalytic centre and arginine as electrostatic binding site facilitated hydrolysis of $p$ NPA. This increase in activity was proportional to catalyst concentration. The co-assembled system demonstrated an enhancement in hydrolysis. Q11H had a value of $1.96 \times 10^{-3} \mathrm{~s}^{-1}$ in comparison to $2.64 \times 10^{-3} \mathrm{~s}^{-1}$ for $\mathrm{Q} 11 \mathrm{R} / \mathrm{H}$. This suggests that the incorporation of an $\mathrm{R}$ 
residue is key to the increase in catalytic rate observed in the comparison of Q11H and Q11R/H (Figure 1.13). It was proposed that the imidazole group of histidine activates a water molecule to produce a hydroxide ion which in turn attacks the carbonyl group of the substrate. This transition state is stabilised by the guanidyl group, binding the oxide ions and activating the ester bond for cleavage before finally releasing the product. The $\mathrm{K}_{\mathrm{M}}$ for $\mathrm{Q} 11 \mathrm{R} / \mathrm{H}$ in comparison to $\mathrm{Q} 11 \mathrm{H}$ was higher demonstrating a stronger binding affinity for the substrate for Q11R. The incorporation of arginine resulted in increased catalytic rate for Q11R/H.

(a)

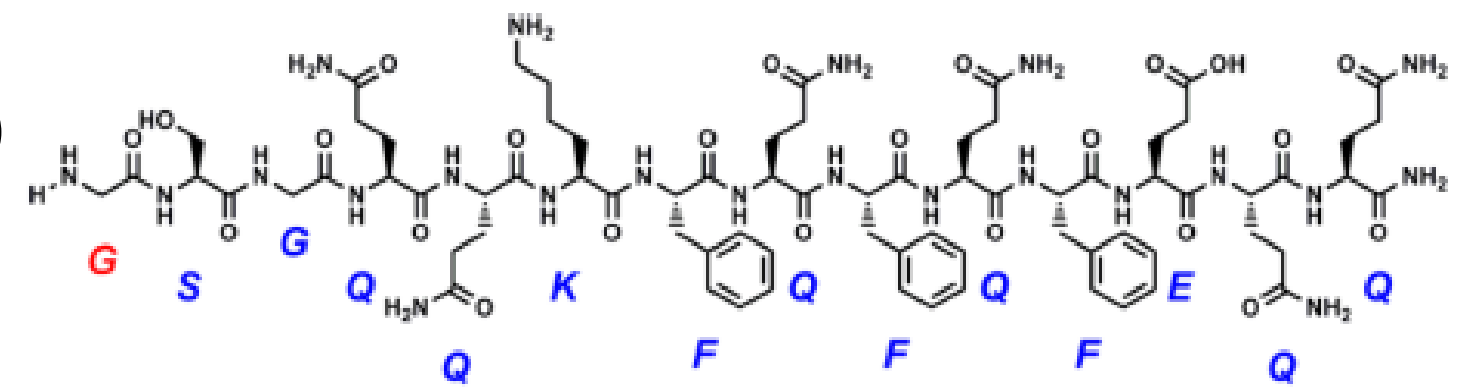

(b)

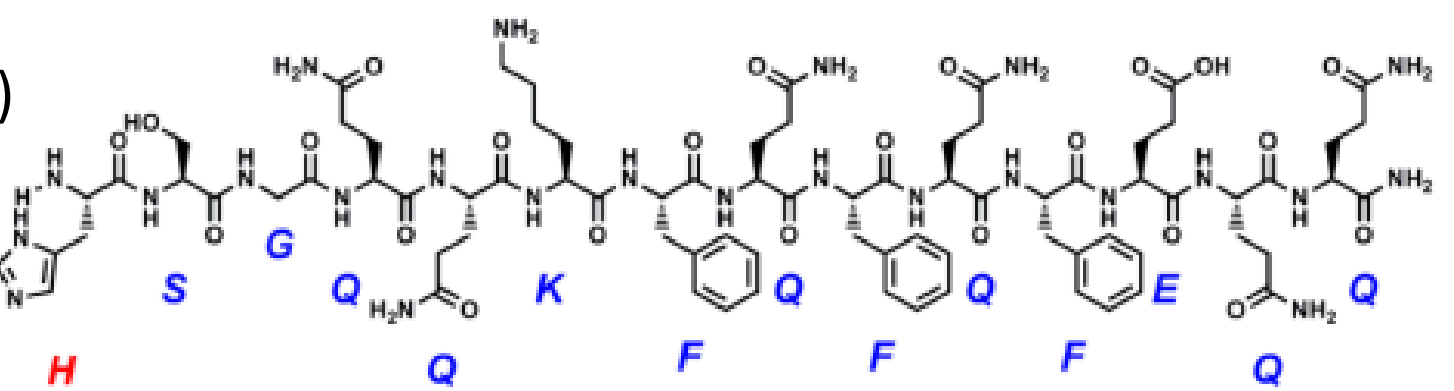

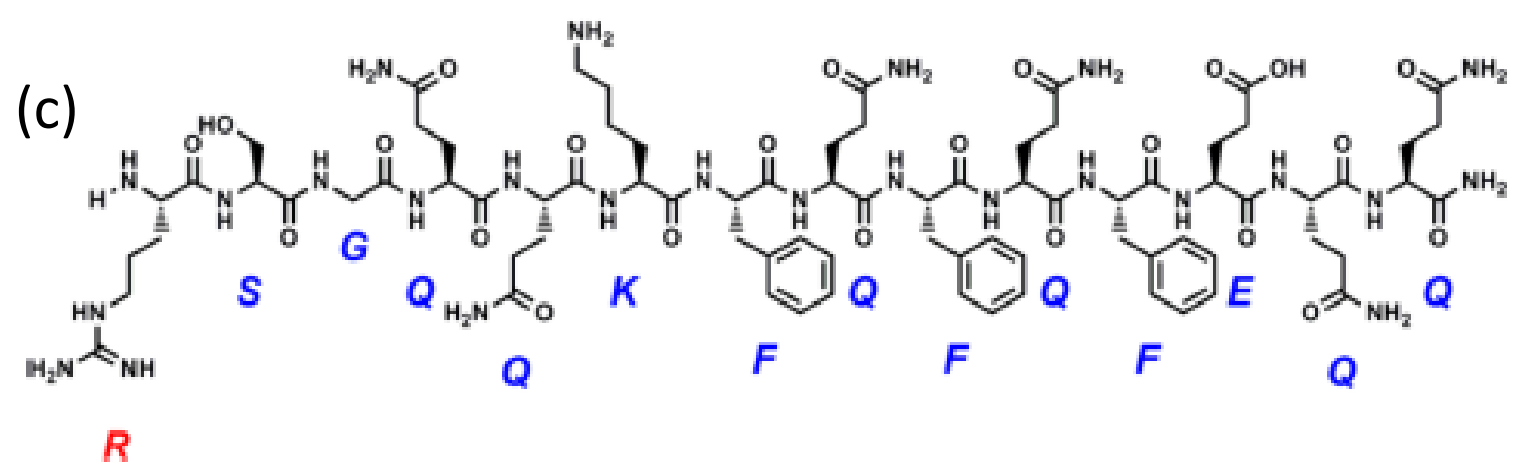

Figure 1.13: Peptide sequences used for hydrolase model (a) Q11G (b) Q11H (c) Q11R. All with flexible SG linker. ${ }^{52}$ 
Very recent work by Korendovych et al. dealt with heptapeptides formed from amyloid structures to show efficient ester hydrolysis in the presence of metal cofactors. They used sequence LKLKLKL as a template and later introduced different modifications in design such as alternating hydrophobic residues within the sequence and the ability of these to interact further by hydrophobic interactions with other $\beta$-sheets. The apolar residues induced the self- assembly process and the leucine side chain was decorated with different polar groups. Owing to these design mutations they were able to support transition metal binding in the molecules. The molecule with sequence Ac-LHLHLRL-CONH${ }_{2}$ showed esterase-like activity with $\mathrm{k}_{\text {cat }} 3.2 \pm 0.4 \times 10^{-2} \mathrm{~s}^{-1}$ which was dependent on $\mathrm{Zn}^{2+}$ ions being present in the role of a cofactor. Histidine residues within the sequence support a tetrahedral zinc coordination sphere. This catalytic activity is also dependent on the nature of the residue at position 6 , in this case arginine. The arginine residue plays a significant role in catalysis, related to the earlier described examples. When arginine was replaced by glutamine the catalytic activity increased further with respect to $\mathrm{k}_{\mathrm{cat}} / \mathrm{K}_{\mathrm{M}}$ and was most active amongst all sequences (Figure 1.14 and Figure 1.15).

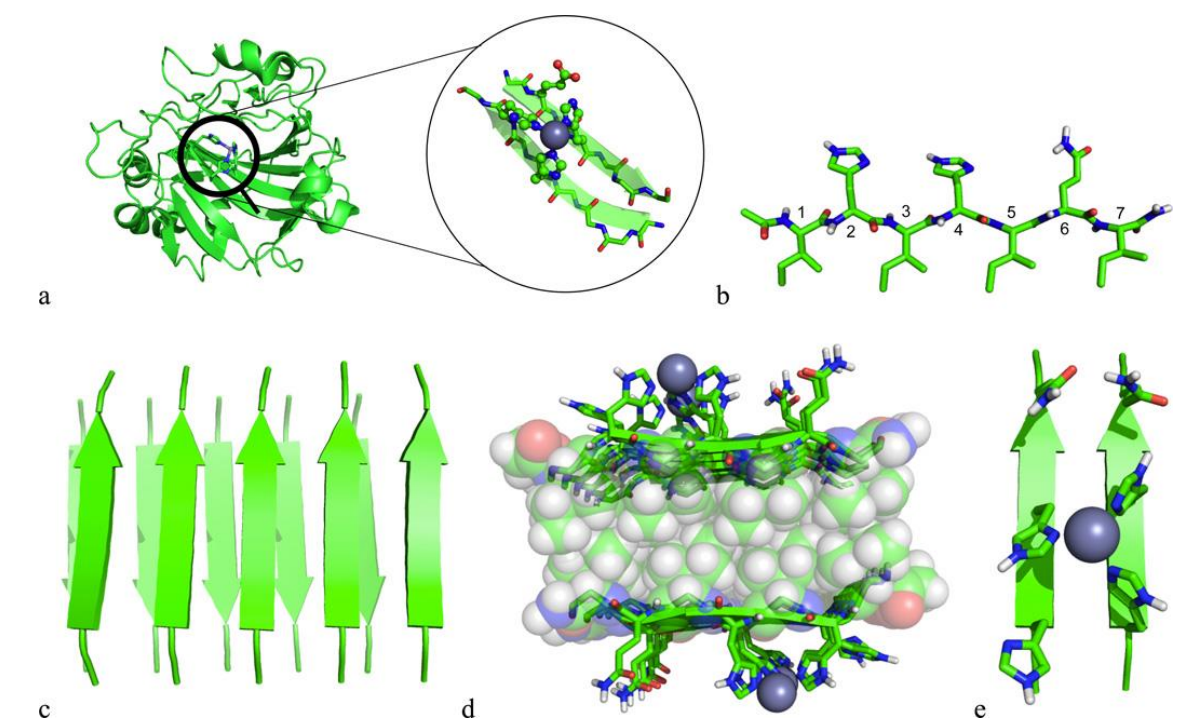

Figure 1.14: (a) Metal binding motif of a human carbonic anhydrase model. (b) A model for one of the designed peptides (Ac-IHIHIQI-CONH 2$)$ in the extended $\beta$-strand configuration showing positions of the residues in the sequence. Computationally derived model of fibrils formed by Ac-IHIHIQI-CONH${ }_{2}$, showing (c) folding (d), hydrophobic core packing and (e), zinc primary coordination sphere. ${ }^{53}$ 
The peptide showed negligible activity when aspartic acid, glutamic acid or histidine were at position 6 . The mutation of arginine with glutamine was intriguing due to an increase in observed catalytic activity. The sequence was changed further by replacing leucine residue with isoleucine or valine making it more susceptible to forming $\beta$-sheet structures. This resulted in the catalytic activity doubling in comparison to the original sequence AcLHLHLRL-CONH$H_{2}$ while the catalytic activity was reduced drastically on replacing leucine by alanine. The terminal acetyl and carboxamide groups were also reported to be important for catalysis to occur as upon the removal of these groups, the peptide is inactive for esterase activity. The coordination of zinc ions resulted in amplified catalytic activity of the peptides when compared to the previously reported metal free peptides showing esterase type activity. ${ }^{53}$

Apart from hydrolysis one of the many applications of the catalytic gels is for $\mathrm{C}-\mathrm{C}$ bond forming aldol reaction. ${ }^{54}$. In our group, we have designed an amphiphilic hydrogelator derived from $L$-proline (ProValDoc) (Figure 1.16). ${ }^{55}$ This compound self-assembled in water forming an almost transparent hydrogel that was tested for the direct aldol reaction between cyclohexanone and 4-nitrobenzaldehyde. Reagents were easily added on top of the gel dissolved in toluene and the reaction was quantitatively completed after $24 \mathrm{~h}$ at 5 ${ }^{\circ} \mathrm{C}$ with high stereoselectivity (anti/syn, 92/8, 88\% ee). Moreover, the catalytic hydrogel could be reused after decantation of the toluene phase for at least three times with the same efficiency and stereoselectivity. Very interestingly, in this system the hydrophobic effect plays a dual role: first as the driving force for gelator self-assembly and, secondly, conducting reagents to the hydrophobic pockets inside the gel fibres. 

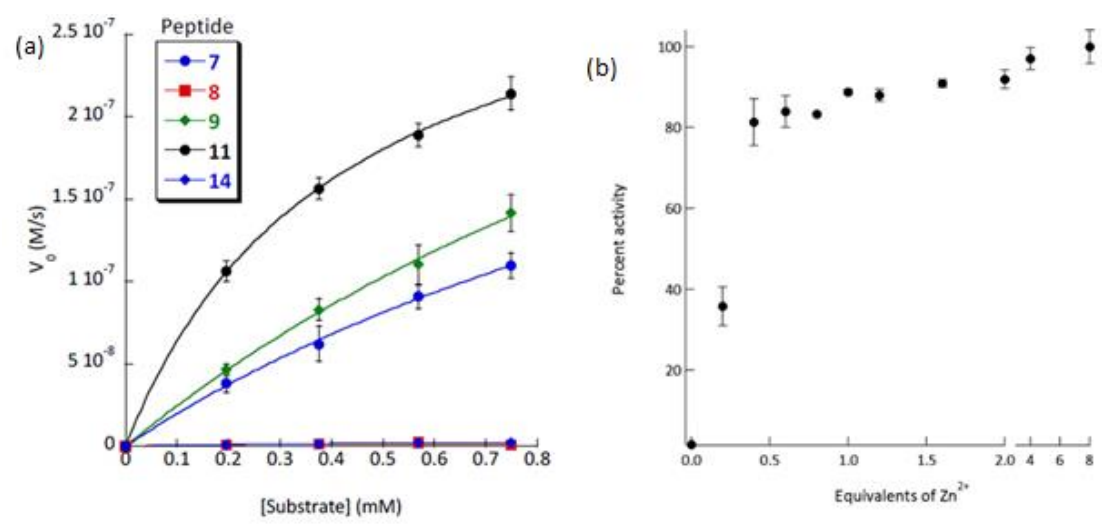

(c)

(d)
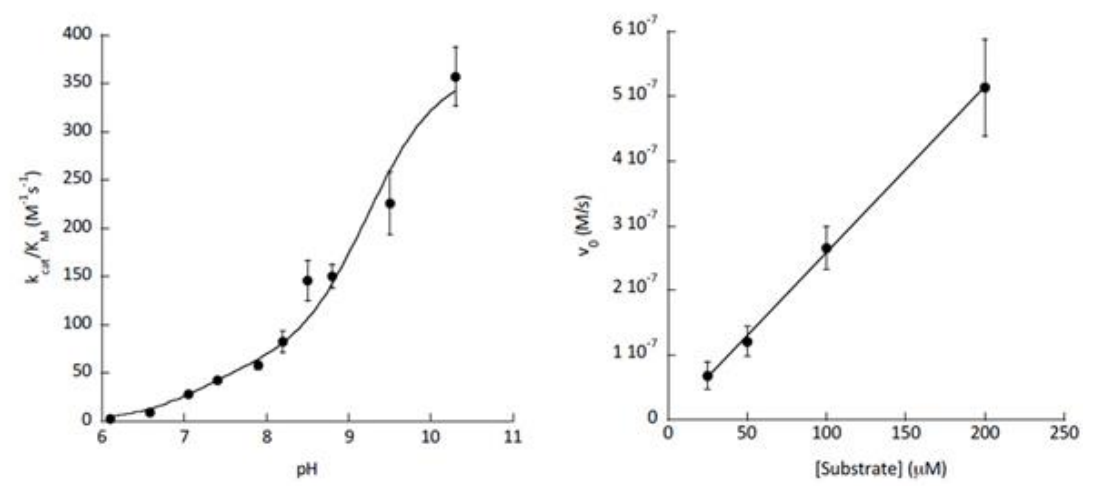

Figure 1.15: (a) Michaelis-Menten fit of catalysis for different peptides at $\mathrm{pH} 8$ in the presence of $1 \mathrm{mM}$ $\mathrm{Zn}^{2+}$. Peptide (Ac-IHIHIQI-CONH${ }_{2}$ ) shows an enzyme-like saturation at higher substrate concentrations. (b) A two-state protonation model of esterase activity by peptide Ac-IHIHIQI-CONH 2 . (c) Dependence of activity of Ac-IHIHIQI-CONH 2 on the concentration of $\mathrm{Zn}^{2+}$ shows a 2:1 peptide:metal stoichiometry. (d) Dependence of p-nitrophenyl acetate (pNPA) hydrolysis rate catalyzed by Ac-IHIHIQI-CONH ${ }_{2}$ on the concentration of monomeric peptide used to make fibrils. ${ }^{53}$

(a)<smiles>CCCCCCCCCCCCNC(=O)[C@H](NC(=O)C1CCCC1)C(C)C</smiles>

(b)<smiles>O=Cc1ccc([N+](=O)[O-])cc1</smiles>

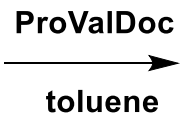<smiles>O=C1CCCCC1[C@H](O)c1ccc([N+](=O)[O-])cc1</smiles>

Figure 1.16: (a) L-Proline containing hydrogel ProValDoc (b) Aldol Reaction carried out by hydrogel ProValDoc. $^{55}$ 
Berdugo et al. have reported a clear trend in relation with this. Aldol reactions with the same hydrogelator (ProValDoc) were carried out with different ketones. It was observed that ketones with greater alkyl chain length showed better conversion rate for the aldol reaction when compared to less hydrophobic ketones. This highlighted the role of hydrophobic pockets upon self-assembly, allowing better access of the hydrophobic substrates near the catalytic centres (Figure 1.17). ${ }^{56}$

(a)

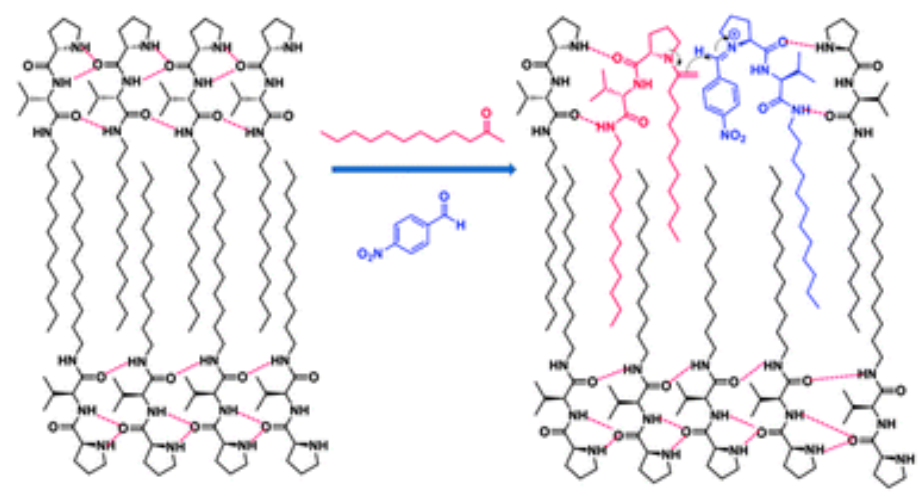

(b)

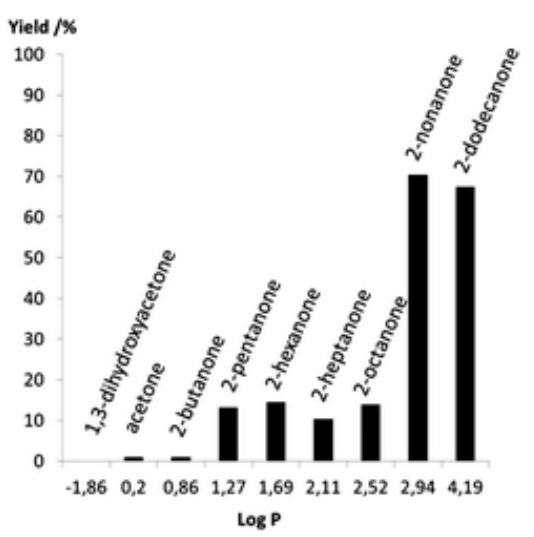

Figure 1.17: (a) Proposed scheme of hydrogel ProValDoc reaction site (b) Conversion (10hr) for different ketones depicting higher yields of conversion for more hydrophobic ketones due to the formation hydrophobic pockets on self-assembly. ${ }^{56}$

In a very recent article by Guler et al. a supramolecular catalyst is shown to have lower cytotoxicity and superior catalytic activity than molecular catalysts employed in bioorthogonal click reactions. ${ }^{57}$ They have constructed supramolecular one dimensional fibres using peptide amphiphiles decorated with copper (II) to construct a biocompatible and biodegradable method for live cell labelling. The supramolecular PA nanofibres treated with copper sulphate solution were tested for a typical Huisgen 1,3-dipolar cycloaddition reaction where phenylacetylene and benzylazide were chosen as reactants, sodium ascorbate as reducing agent, and water as biological solvent. Since L-histidinecopper complex (H-Cu(II)) has highest catalytic activity for this bio-orthogonal click reaction with conversion of $61 \%$, soluble dipeptide(Ac-HH-Am) complexed with $\mathrm{Cu}(\mathrm{II})$ 
ion (HH-Cu(II)) also showed a moderate conversion efficiency of $65 \%$, while PA-Cu(II) nanofibres demonstrated a tremendous conversion efficiency of $95 \%$ under the same conditions. The copper-catalysed click chemistry method offers a bio-orthogonal strategy that can label live cells in a complex environment, allowing the function and dynamics of target biomolecules to be monitored in living organisms (Figure 1.18). The oxidative damage is one major drawback of copper catalysts for bio-orthogonal labelling reactions. They figured out that owing to the stabilization of $\mathrm{Cu}(\mathrm{I})$, the peptide ligand can prevent the formation of undesired by products and minimize the oxidative damage against target biomolecules and cells, along with higher catalysis rate because of high surface-substrate interaction for the nanofibres. $\mathrm{PA}-\mathrm{Cu}(\mathrm{I})$ nanofibres were found to display significantly lower cytotoxicity compared to copper-alone samples for all copper concentrations. MCF-7 cells bearing alkyne sialic acid residues were reacted with biotin-azide for $6 \mathrm{~h}$ in the presence of $\mathrm{PA}-\mathrm{Cu}(\mathrm{I})$ nanofibres, using a reaction mixture composed of biotin azide, PA-Cu(II), and sodium ascorbate. They reported lower cytotoxicity and higher reaction rates with $\mathrm{PA}-\mathrm{Cu}(\mathrm{II})$ nanofibres. Thus providing with new method to efficiently label live cells using $\mathrm{Cu}(\mathrm{II})$ embedded nanofiber catalyst for bio-orthogonal click reactions (Figure 1.18).

In another recent work Guler et al. have reported high efficiency for bone regeneration by peptide nanofibres possessing both catalytic and matrix-regulatory functions of alkaline phosphatase (Figure 1.19 and 1.20) ${ }^{58}$ Alkaline phosphatase is a versatile enzyme that plays a critical role in bone formation by regulating phosphate homeostasis and calcifiable bone matrix formation. The peptide nanostructures were presented with histidine and had phosphatase like activity and thus served as bone-like nodule inducing scaffold. Alkaline phosphatase-like peptide nanofibres enabled osteogenesis for both osteoblast-like and mesenchymal cell lines. Multiple histidine residues were presented on 
the active sites of peptide amphiphile molecules forming the nanofibres to act as a mimic of natural Alkaline Phosphatase enzyme (Figure 1.20). The pPA (Lauryl-VVAGH-Am) nanofibres exhibited significant catalytic activity, with a $\mathrm{k}_{\text {cat }}$ value of $1.83 \times 10^{-5} \mathrm{~s}^{-1}$, EPA\K-PA combination showed slight activity, with a $\mathrm{k}_{\mathrm{obs}}$ of $6.87 \times 10^{-7} \mathrm{~s}^{-1}$ similar to free imidazole with $\mathrm{k}_{\mathrm{obs}}$ of $7.54 \times 10^{-7} \mathrm{~s}^{-1}$. Catalytic efficiency of the peptide nanofiber $\left(\mathrm{k}_{\mathrm{cat}} / \mathrm{K}_{\mathrm{M}}\right)$ was calculated as $0.69 \times 10^{-3} \mathrm{M}^{-1} \mathrm{~s}^{-1}$ while the effective phosphatase-like catalytic activity was demonstrated for both nanofibres in solution and nanofiber on surfaces. Thus they were able to induce efficient osteogenic differentiation of multiple cell types and facilitated the formation of bone-like nodules by the synthetic ALP mimetic nanostructures. 

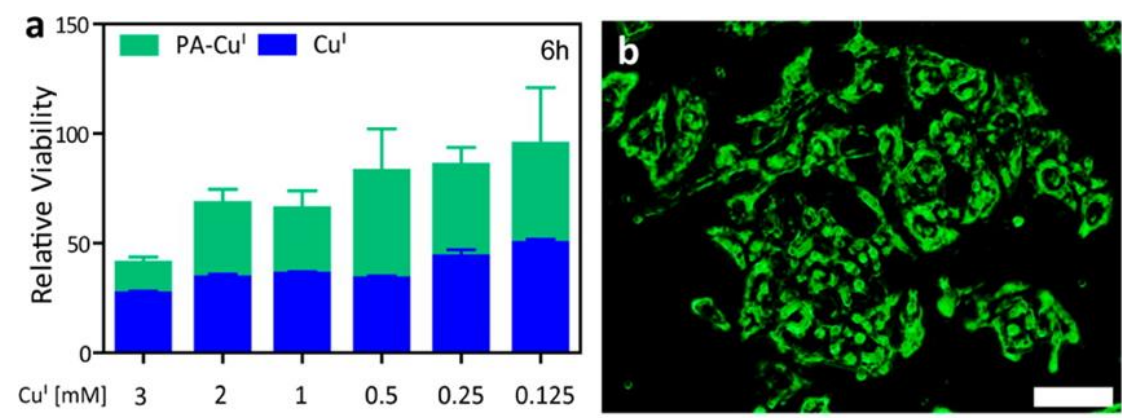

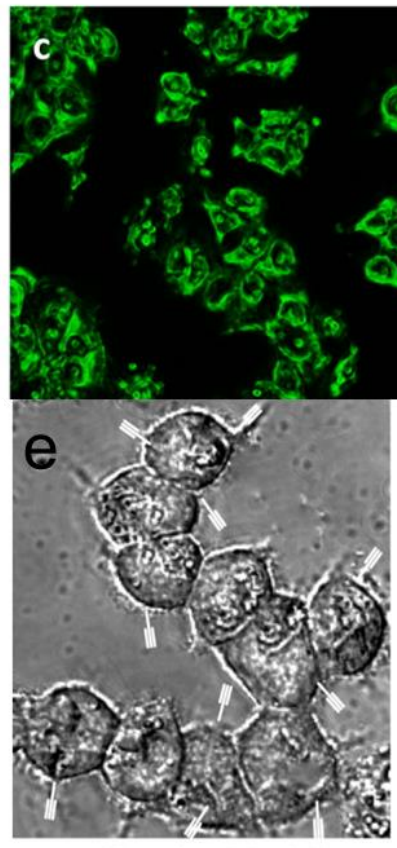

$\underline{=}$ Alkyne Containing Cells

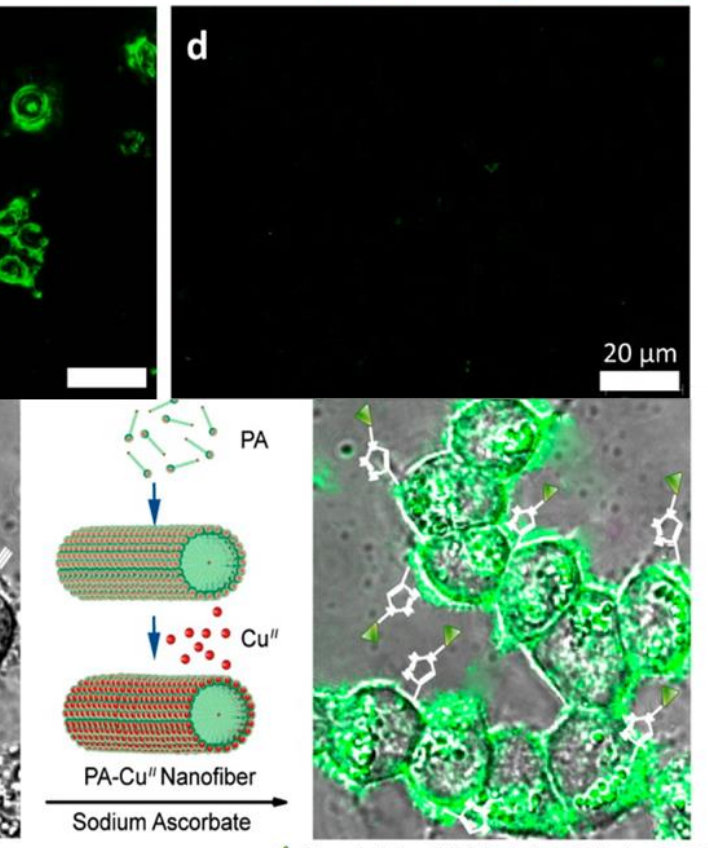

$\triangle$ Streptavidin- FITC Labeled Cells by CuAAC

Figure 1.18: Viability of MCF-7 cells in the presence of PA-CuI and $\mathrm{CuI}$ (a); microscopic analysis of fixed cells labeled with PA-CuI nanofibres after $6 \mathrm{~h}$ (b), and after $24 \mathrm{~h}$ reaction (c) and non treatment group after $24 \mathrm{~h}$ reaction $(\mathrm{d})$. (Scale bars $=20 \mu \mathrm{m}$. (e) Schematic representation of labeling live cells by PA-CuII nanofibres. 57

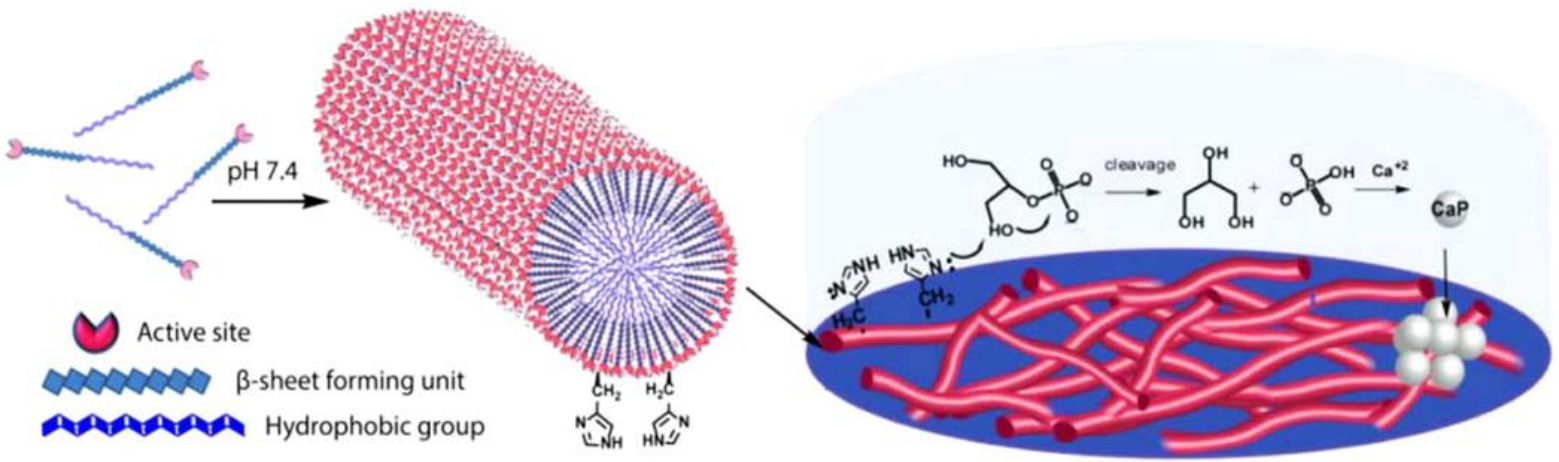

Figure 1.19: Cartoon representation of imidazole containing self-assembling peptide being able to catalyse phosphate hydrolysis and serve as bone-like nodule inducing scaffolds. ${ }^{58}$ 


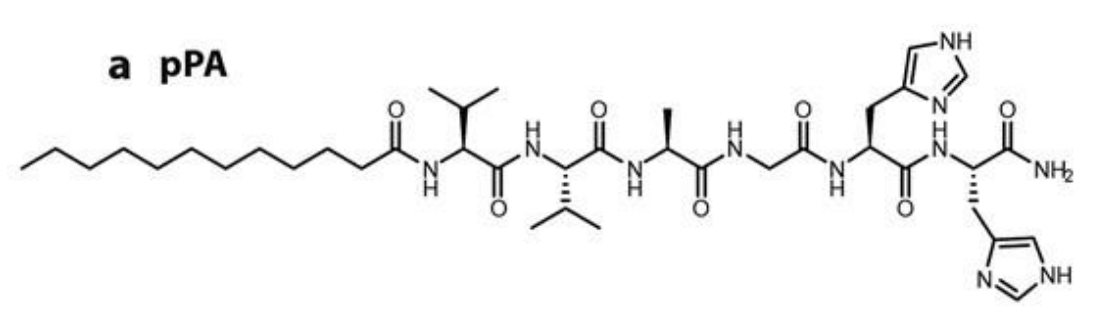

b E-PA<smiles>CCCCCCCCCCCCC(=O)NC(C(=O)N[C@H](C(=O)NC(C)C(=O)NCC(=O)NC(CCC(=O)O)C(=O)O)C(C)C)C(C)C</smiles>
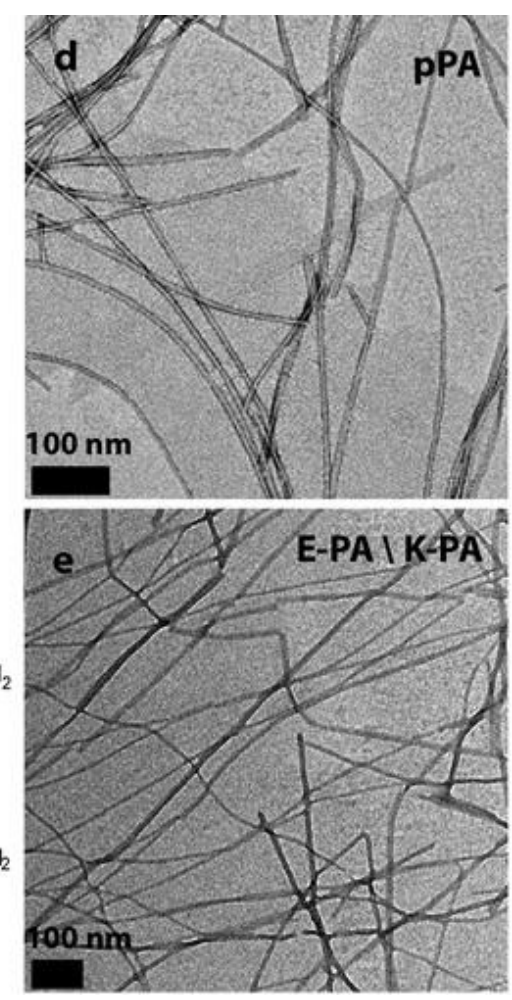

Figure 1.20: Chemical structures and TEM images of peptide amphiphile molecules. Chemical structure of (a) pPA (Lauryl-VVAGH-NH ${ }_{2}$ ) and control group peptide amphiphiles: (b) E-PA (Lauryl-VVAGE) and (c) K-PA (Lauryl-VVAGK- $\mathrm{NH}_{2}$ ). TEM images of (d) pPA and (e) E-PAIK-PA. ${ }^{58}$

\subsection{Summary and future prospects}

Bottom- up approach gives opportunity to get detailed information about the properties of the individual components forming the self-assembled network. We still lack the clear understanding of the influence, transfer and processing of the molecular level information into the dynamic overall behaviour of an enzyme, protein or a living cell, this can be solved by using the bottom- up approach for simple self-assembling bio-inspired molecules mimicking natural systems. It is not only the properties of the individual molecules but the non-linear dynamics and transfer process between the components that affect the new properties arising upon self-assembly. So a quantitative analysis and modelling is the need of the hour to better understand the underlying principles leading 
to the dynamics, information transfer among the individual components and observed properties of a complex self-assembled network.

The bioinspired peptidic buiding blocks which are able to self-assemble into different morphologies from nano-spheres to nanofibres exhibit immense application potential. In this introduction we saw various applications of self-assembled peptidic molecules from cell culture, energy harvest to catalysis. Focussing on the title of thesis, "Functional Gels as Microreactors" we saw applications of different hydrogels and metallogels in catalysis for different reactions. These hydrogels have been used for mimicking enzyme like catalysis for different range of reactions from $\mathrm{C}-\mathrm{C}$ bond forming aldol to hydrolysis of esters. We also saw few examples of direct applications of catalytic hydrogels in bone regeneration and live cell labelling. Such enhanced catalytic activity is a result of different new properties such as increased acidity/basicity, pKa shifts, hydrophobic pockets, cooperativity, etc. which arise upon self-assembly of such simple peptidic molecules. Even though undeniable progress has been made we still are miles away from attaining enzyme like catalytic activity, cooperativity among different functional groups, substrate recognition, selectivity and complexity. These desirable properties can be achieved by introducing multi-functionality in the self-assembling molecules and by increasing the complexity from just single component hydrogels to be able to control and program the co/ortho-assembly of more than one component in the same system. The following chapters will showcase some preliminary endeavours in this perspective dealing with esterase like catalytic hydrogel, tandem-cascade catalysis by orthogonal hydrogels and catalytic control over supramolecular organisation. 


\subsection{References}

1. W. Gilbert, Nature, 1986, 319, 618.

2. G. F. Joyce, Nature, 1989, 338, 217.

3. G. F. Joyce, Nature, 2002, 418, 214.

4. C. Anastasi, F. F. Buchet, M. A. Crowe, A. L. Parkes, M. W. Powner, J. M. Smith, Chem. \& Biodiversity, 2007, 4, 721.

5. W. Hordijk, J. Hein, M. Steel, Entropy, 2010, 12, 1733.

6. S. J. Carlson, Pal. Soc. Spec. Pub., 1999, 9, 4.

7. D. W. Deamer, Pal. Soc. Spec. Pub., 1999, 9, 7.

8. E. Anders, R. Hayatsu, M. H. Studier, Science, 1973, 182, 781.

9. S. Dawson, Pal. Soc. Spec. Pub., 1999, 9, 5.

10. E. M. Shoemaker, Ann. Rev. Ear. \& Plan. Sci., 1983, 11, 461.

11. B. Escuder, J. F. Miravet (Eds.), Functional Molecular Gels, RSC., 2013.

12. P. Terech, R. G. Weiss (Eds.), Molecular Gels, Springer., 2006.

13. E. M. Ahmed, J. Adv. Res., 2015, 6, 105.

14. T. R. Hoare, D. S. Kohane, Polymer, 2008, 49,1993.

15. J. Kopeček, J. Yang, Polymer Int., 2007, 56, 1078.

16. T. Vermonden, R. Censi, W. E. Hennink, Chem. Rev., 2012, 112, 2853.

17. E. A. Appel, J. del Barrio, X. J Loh, O. A. Scherman, Chem. Soc. Rev., 2012, 41, 6195.

18. R. J. Mart, R. D. Osborne, M. M. Stevens, R. V. Ulijn, Soft Matter, 2006, 2, 822.

19. K. L. Duncan, R. V. Ulijn, Biocatalysis, 2015, 1, 68.

20. K. Tao, A. Levin, L. A. Abramovich, E. Gazit, Chem. Soc. Rev., 2016, 45, 3935.

21. S. Datta, S. Bhattacharya, Chem. Soc. Rev., 2015, 44, 5596. 
22. N. Singh, M. Tena-Solsona , J. F. Miravet, B. Escuder, Isr. J. Chem., 2015, 55, 711.

23. A. Dasgupta, J. H. Mondal, D. Das, RSC Adv., 2013, 3, 9117.

24. M. Tena-Solsona , J. F. Miravet, B. Escuder, Chem. Eur. J., 2014, 20, 1023.

25. M. Ma, Y. Kuang, Y. Gao, Y. Zhang, P. Gao, B. Xu, J. Am. Chem. Soc., 2010, $132,2719$.

26. J. F. Miravet, B. Escuder, Chem. Commun., 2005, 46, 5796.

27. S. R. Diegelmann, J. M. Gorham, J. D. Tovar, J. Am. Chem. Soc., 2008, 130, 13840.

28. N. Singh, M. Kumar, J. F. Miravet, R. V. Ulijn, B. Escuder, Chem. Eur. J., 2016, DOI: $10.1002 / \mathrm{chem} .201602624$.

29. D. M. Ryan, S. B. Anderson, F. T. Senguen, R. E. Youngman, B. L. Nilsson, Soft Matter, 2010, 6, 475.

30. S. Sutton, N. L. Campbell, A. I. Cooper, M. Kirkland, W. J. Frith, D. J. Adams, Langmuir, 2009, 25, 10285.

31. X. Du , J. Zhou, J. Shi, B. Xu , Chem. Rev., 2015, 115, 13165.

32. T. Liebmann, S. Rydholm, V. Akpe, H. Brismar, BMC Biotechnol., 2007, 7, 1.

33. G. Cheng,V. Castelletto, R. R. Jones, C. J. Connon, I. W. Hamley, Soft Matter, 2011, 7, 1326.

34. M. Zhou, R. V. Ulijn, J. E. Gough, J. Tiss. Eng., 2014, 5, DOI: $10.1177 / 2041731414531593$.

35. T. M. Allen, P. R. Cullis, Science, 2004, 303, 1818

36. K. Kataoka, A. Harada, Y. Nagasaki, Adv. Drug Del. Rev., 2001, 47, 113.

37. S. S. Dharap, Y. Wang, P. Chandna, J. J. Khandare, B. Qiu, S. Gunaseelan, Proc. Natl. Acad. Sci., USA, 2005, 102, 12962. 
38. R. Vegners , I. Shestakova, I. Kalvinsh, R. M. Ezzell, P. A. Janmey, J. Pep. Sci., 1995, $1,371$.

39. W. Wang, Y. Chau, Chem. Commun., 2011, 47, 10224.

40. W. Wang, Y. Chau, Chem. Mater., 2012, 24, 946.

41. D. Kalafatovic, M. Nobis, N. Javid, P.W. J. M. Frederix, K. I. Anderson, B. R. Saunders, R. Brian, R. V. Ulijn, Biomater. Sci., 2015, 3, 246.

42. Y. Kuang, J. Shi, J. Li, D. Yuan, K. A. Alberti, Q. Xu , Angew. Chem., Int. Ed., 2014, 53, 8104.

43. H. A. M. Ardoña, J. D. Tovar, Biocon. Chem., 2015, 26, 2290.

44. J. Ryu, S-W. Kim, K. Kang, C. B. Park, Adv. Mater., 2010, 22, 5537.

45. B. D. Wall, A. E. Zacca, A. M. Sanders, W. L. Wilson, A. L. Ferguson, J. D. Tovar, Langmuir, 2014, 30, 5946.

46. E. R. Draper, J. J.Walsh, T. O. McDonald, M. A. Zwijnenburg, P. J. Cameron, A. J. Cowan, J. Mater. Chem. C, 2014, 2, 5570.

47. K. Tanaka, A. Mori, S. Inoue, J. Org. Chem., 1990, 55, 181.

48. H. Danda, Synlett., 1991, 4, 263.

49. B. Xing, M-F. Choi, B. Xu, Chem. Eur. J., 2002, 8, 5028.

50. M. O. Guler, S. I. Stupp, J. Am. Chem. Soc., 2007, 129, 12082.

51. Z. Huang, S. Guan, Y. Wang, G. Shi, L. Cao, Y. Gao, J. Mater. Chem. B, 2013, $1,2297$.

52. C. Zhang, X. Xue, Q. Luo, Y. Li , K. Yang, X. Zhuang X, ACS Nano, 2014, 8, 11715.

53. C. M. Rufo, Y. S. Moroz, O. V. Moroz, J. Stöhr, T. A. Smith, X. Hu, Nat. Chem., 2014, 6, 303.

54. N. Mase, Y. Nakai, N. Ohara, H. Yoda, K. Takabe, F. Tanaka, J. Am. Chem. Soc., 2006, 128,734 . 
55. F. Rodriguez-Llansola, J. F. Miravet, B. Escuder B, Chem. Commun., 2009, 47, 7303.

56. C. Berdugo, J. F. Miravet, B. Escuder, Chem. Commun., 2013, 49, 10608-10610.

57. M. A. Khalily, G. Gulseren, A. B. Tekinay, M. O. Guler, Bioconjugate. Chem., 2015, 26, 2371.

58. G. Gulseren, I. C. Yasa, O. Ustahuseyin, E. D. Tekin, A. B. Tekinay, M. O. Guler, Biomacromolecules, 2015, 16, 2198. 
Chapter 2

Objectives 


\subsection{General objectives of the thesis}

It is well known that the hierarchical organization of peptidic molecules into long physically cross-linked fibres often result in the formation of self-supported hydrogels. ${ }^{1,}$ ${ }^{2}$ Such materials, held by non-covalent interactions, exhibit certain properties including reversibility, self-healing or responsiveness to different physicochemical stimuli which make them extremely useful in many diverse fields like biomedicine, catalysis or materials science. ${ }^{3-6}$ The presented work focuses majorly on utilizing the self-assembly of these small peptidic molecules appended with catalytic groups for catalysis applications.

\subsection{Specific objectives}

Inspired by previous reports of histidine appended peptidic hydrogelators ${ }^{6-8}$ for esterase like activity the aim is to design a new metal free low molecular weight hydrogelator appended with imidazole residue. The expected $\mathrm{pKa}$ shifts of the imidazole upon aggregation and formation of hydrophobic pockets may render the hydrogel with enhanced hydrolytic activity (Figure 2.1a). ${ }^{9}{ }^{10}$ As in Chapter 3, we aim to check the hydrolase activity of this gelator for $p$-nitrophenyl acetate hydrolysis (Figure 2.1b) and for the hydrolysis of a non-activated ester, phenylalanine methyl ester (Figure 2.1c).

In Chapter 4 and 5, the aim is to use two structurally different gelators appended with mutually incompatible groups for orthogonal assembly without the self-quenching of the functional groups. The orthogonal system will then be used to activate electrophilic and nucleophilic centers simultaneously in the same pot to achieve different tandem and cascade reactions.

In Chapter 4 we tend to utilize a bolaamphilic gelator SucVal8 appended with acidic groups for deacetalisation reaction of benzaldimethyl acetaldehyde and an amphiphilic 
gelator ProValDoc with proline group to catalyze the subsequent aldol reaction of the obtained benzaldehyde with cyclohexanone in tandem in the same pot. We would also like to check the same set of reactions using SucVal8 with another structurally similar gelator-ProVal8. In this case on the contrary we expect them to co-assemble or selfquench each other rendering them catalytically inactive (Figure 2.2a and 2.2.b).

(a)<smiles>CC(C)[C@H](NC(=O)Cc1c[nH]cn1)C(=O)NCCCCCCCNC(=O)[C@H](NC(=O)Cc1c[nH]cn1)C(C)C</smiles>

(b)

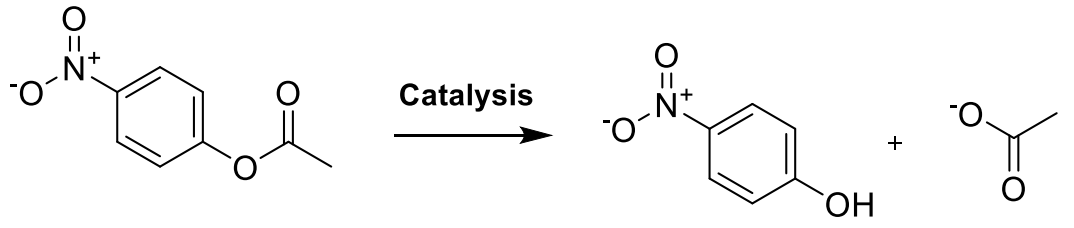

(c)

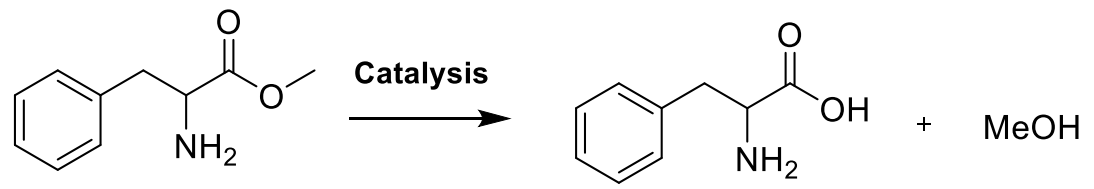

Figure 2.1: (a) Structure of imidazole appended hydrogelator and hydrolysis reactions of (b) $p$-nitrophenyl acetate (c) phenylalanine methyl ester to be carried out by the gelator.

Whereas in Chapter 5 we intend to use the two gelators: SucVal8 and ProValDoc individually for three component direct Mannich reaction (Figure 2.2c). We also expect them to catalyze the Mannich reaction in concert when present in one pot by simultaneously activating the electrophilic and nucleophilic centers. We also intend to utilize SucVal8 for a cascade reaction of deacetalisation of benzaldimethyl acetal and subsequently perform Mannich reaction of the obtained aldehyde with aniline and cyclohexanone. We then plan to use SucVal8 and ProValDoc together for the same reaction scheme in order to ProValDoc to assist in the second step of the cascade reaction i.e. Mannich and thus give a cascade-tandem reaction system (Figure 2.2a and 2.2d). 
(a)<smiles>CC(C)[C@H](NC(=O)CCC(=O)O)C(=O)NCCCCCCCNC(=O)[C@@H](NC(=O)CCC(=O)O)C(C)C</smiles><smiles>CCCCCCCCCCCNC(=O)C(NC(=O)C1CCCN1)C(C)C</smiles>

ProValDoc

(b)

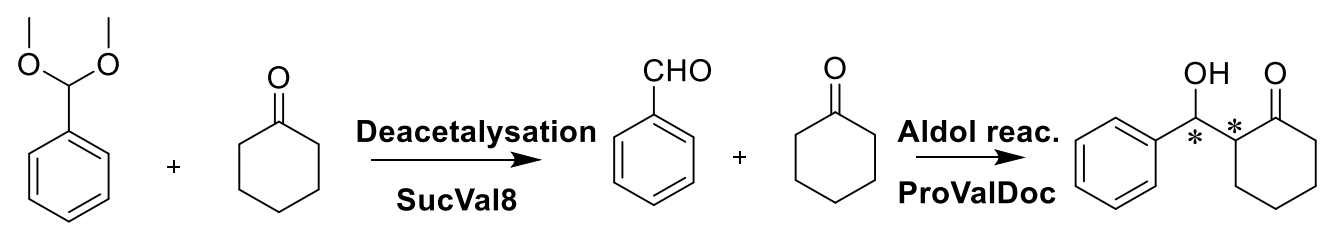

(c)

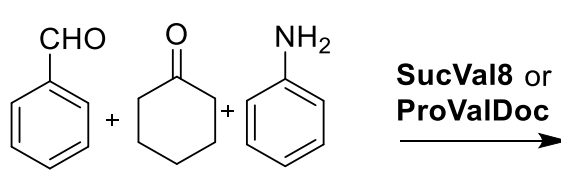

(d)<smiles>CC(C)C(NC(=O)[C@H]1CCCN1)C(=O)NCCCCCCCNC(=O)[C@@H](NC(=O)C1CCCN1)C(C)C</smiles>

) (1)

(c)

)

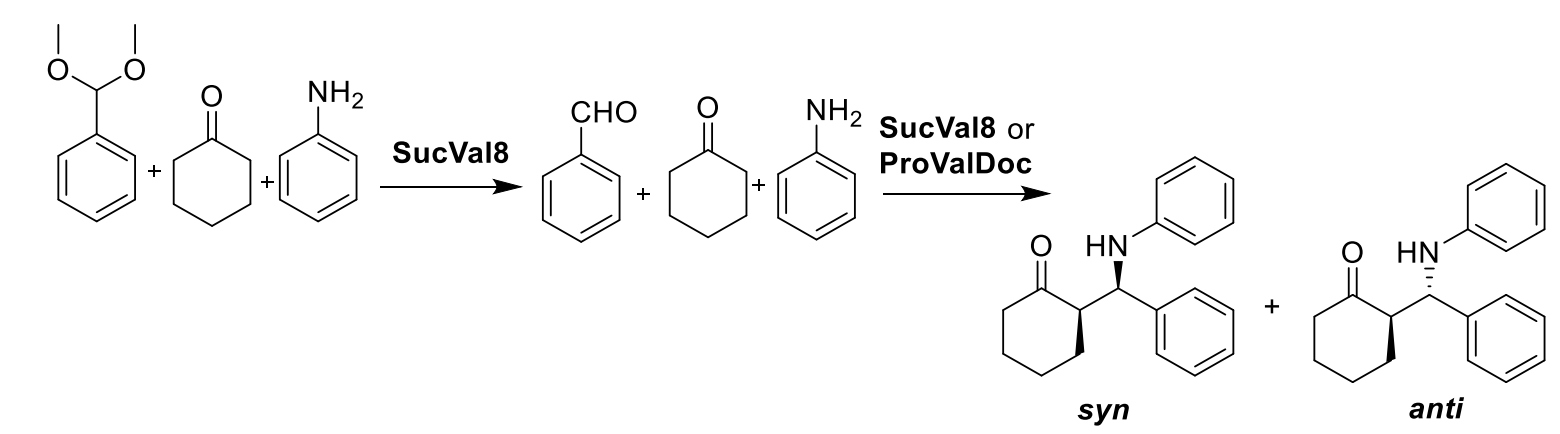<smiles>O=C1CCCCC1[C@H](Nc1ccccc1)c1ccccc1</smiles>

syn anti

Figure 2.2: (a) Structurally similar bolaamphiphilic gelators: SucVal8 and ProVal8 and structurally different amphilic gelator ProValDoc. (b) Tandem reactions to be tested by mixed systems of the gelators in one pot. (c) Mannich reaction to be carried out with SucVal8 and ProValDoc, (c) cascade reaction of deacetalysation and Mannich reaction to be carried out by SucVal8 and same reaction to be carried out by SucVal8 and ProValDoc as a cascade-tandem system.

It is quite common in nature for enzymes to catalytically control the supramolecular organization of different molecules giving a spatial and temporal handle over the newly formed structure. In Chapter 6 we tend to use SucVal8 hydrogel to mimic the same by 
catalytically controlling the kinetics of the formation of a new self-assembling molecule, by forming a hydrazone between its precursors with aldehyde and hydrazide functionality. We thus tend to achieve a double network hydrogel which retains the properties of the individual gelators with new properties arising from the synergy between the two networks (Figure 2.3).

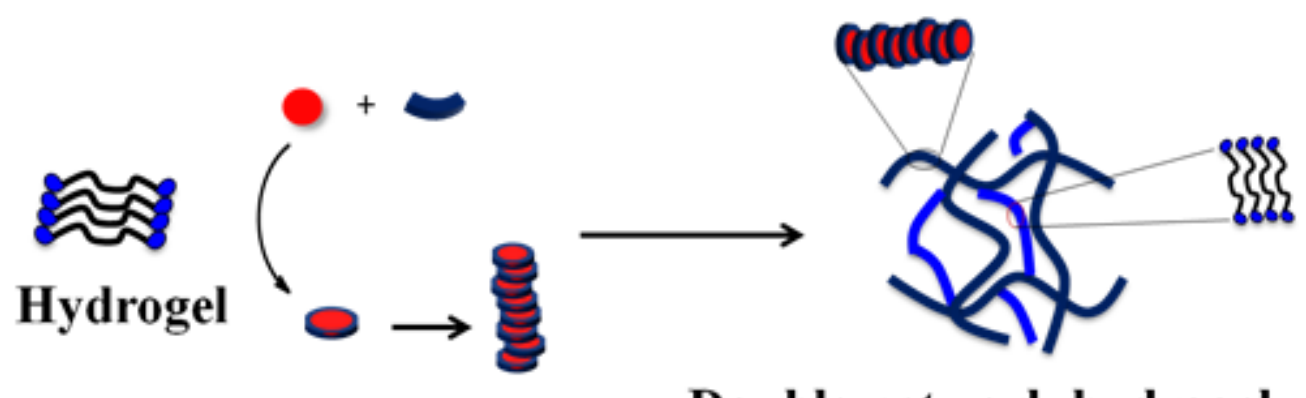

Double network hydrogel

Figure 2.3: Formation of a double network hydrogel by catalytic activity of one hydrogel to give a new second network.

\subsection{References}

1. A. Dasgupta, J. H. Mondal, D. Das, $R S C A d v$., 2013, 3, 9117.

2. A. M. Jonker, D. W. P. M. Löwik, J. C. M. van Hest, Chem. Mater. 2012, 24, 759.

3. G. Cheng, V. Castelletto, R. R. Jones, C. J. Connon, I. W. Hamley, Soft Matter, 2011, 7, 1326.

4. D. Kalafatovic, M. Nobis, N. Javid, P. W. J. M. Frederix, K. I. Anderson, B. R. Saunders, R. V. Ulijn, Biomater. Sci., 2015, 3, 246.

5. M. A. Khalily, G. Gulseren, A. B. Tekinay, M. O. Guler, Biocon. Chem., 2015, $26,2371$.

6. M. O. Guler, S. I. Stupp, J. Am. Chem. Soc., 2007, 129, 12082.

7. C. M. Rufo, Y. S. Moroz, O. V. Moroz, J. Stöhr, T. A. Smith, X. Hu, Nat. Chem., 2014, 6, 303. 
8. C. Zhang, X. Xue, Q. Luo, Y. Li , K. Yang, X. Zhuang X, ACS Nano, 2014, 8, 11715.

9. C. Berdugo, J. F. Miravet, B. Escuder, Chem. Commun., 2013, 49, 10608.

10. F. Rodríguez-Llansola, J. F. Miravet, B. Escuder, Chem. Commun., 2009, 7303. 


\section{Chapter 3}

Insight into the esterase like activity

demonstrated by an imidazole appended selfassembling hydrogelator 


\subsection{Introduction}

Mimicking enzymes by means of synthetic catalysts is currently an area of huge interest. ${ }^{1-}$

${ }^{2}$ Tertiary structure allows various functional groups to be precisely arranged in threedimensional space, creating sites to bind substrates and positioning chemical functional groups to enable catalysis. Enzyme like performance from de novo designed primary sequence able to fold and function accordingly is currently not possible. However it is possible to attain enzyme like activity by using smaller self-assembling molecules or peptides owing to the ordered arrangement of the catalytically active sites/functional groups. Several groups have demonstrated esterase-like activity using metal based nanoparticles, micelles or dendrimers with large molecular weights and mostly with spherical symmetry. ${ }^{3-6}$ Histidine-containing peptide nano-fibrillar systems have been reported recently as catalysts for activated ester hydrolysis (2,4-dinitrophenyl acetate and $p$-nitrophenyl acetate) and have revealed the role of the fibrillar nanostructure and multivalency on the catalytic performance. ${ }^{7-10}$ Here we report a metal free low molecular weight hydrogelator ImVal8 with covalently linked imidazole moieties demonstrating esterase like activity (Scheme 3.1). The ordered arrangement of the catalytic centres upon self-assembly of molecules into a fibrillar network is taken advantage of to attain improved catalytic activity when compared to a non-aggregating analogue. In contrast to previously reported examples, ImVal8 is a small synthetically simple compound that is able to hydrolyse not only activated but also non-activated aminoacyl esters. ${ }^{7-10}$ 


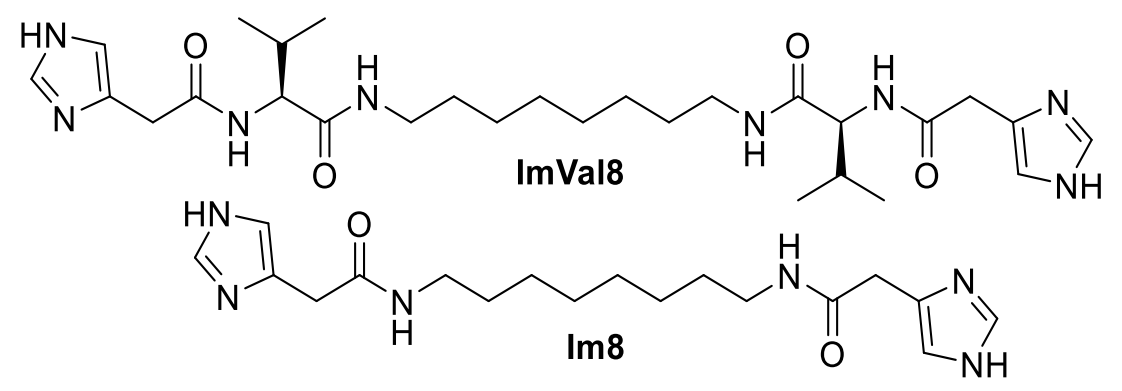

Scheme 3.1: Self-aggregating compound ImVal8 and non-aggregating analogue Im8.

\subsection{Results and discussion}

\subsubsection{Design and synthesis}

(A)
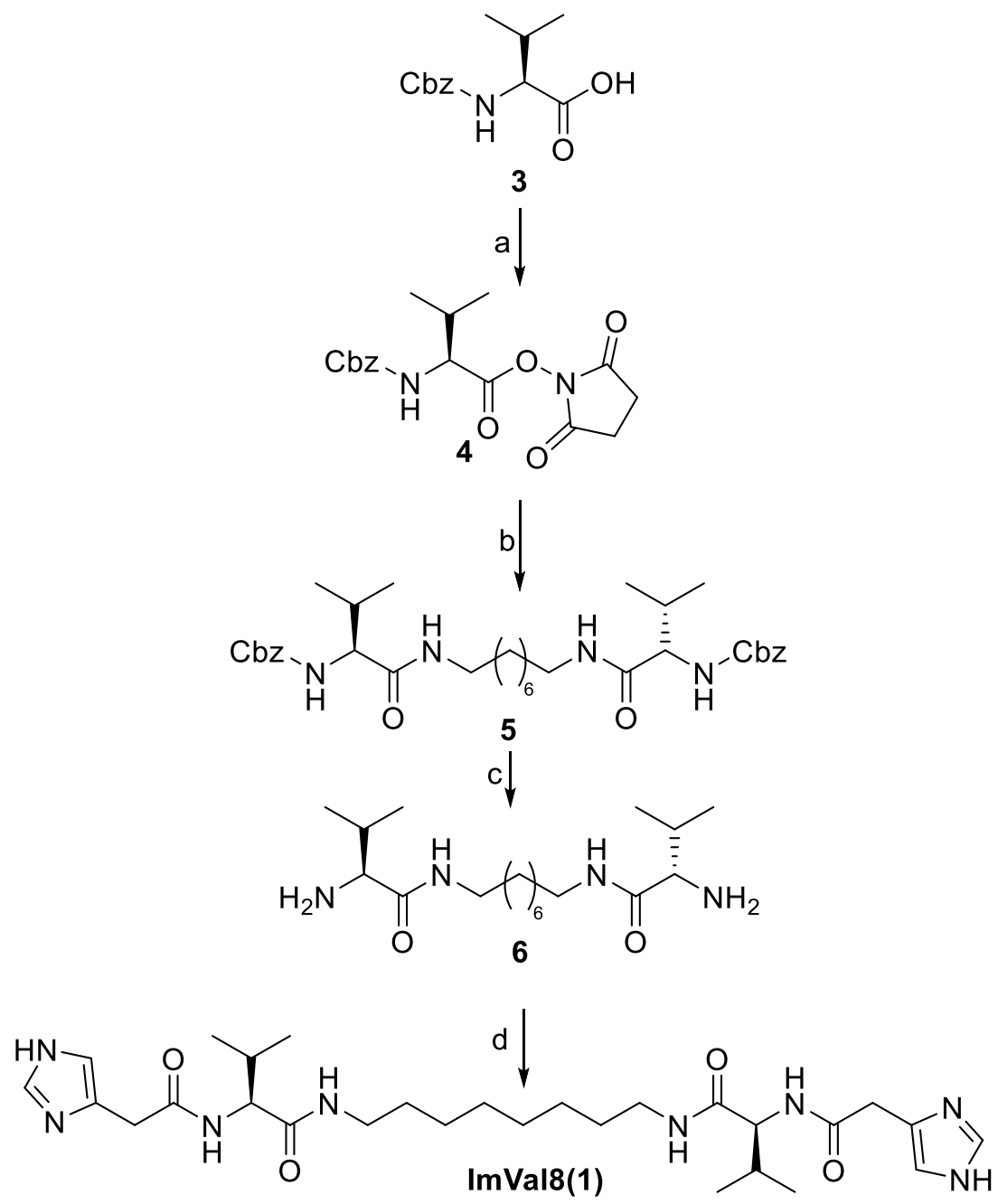
(B)<smiles>O=C(O)Cc1c[nH]cn1</smiles>

Scheme 3.2. Reagents and conditions:(A) (a) DCC, NHS, THF, $5^{\circ} \mathrm{C}, 3 \mathrm{hr}, 91 \%$; (b) 1,8-diamonooctane, DME, $55^{\circ} \mathrm{C}, 6 \mathrm{hr}, 95 \%$, (c) $\mathrm{Pd} / \mathrm{C}\left(5 \% \mathrm{wt}\right.$ ), $\mathrm{H}_{2}, \mathrm{MeOH}, 3 \mathrm{~h}, 99 \%$, (d) Imidazole 4-acetic acid, BOP, DIPEA, $\mathrm{CH}_{2} \mathrm{Cl}_{2}, 0^{\circ} \mathrm{C}$-R.T, $16 \mathrm{hr}, 70 \%$, (B) (e) BOP, 1,8-diaminooctane, DIPEA, $\mathrm{CH}_{2} \mathrm{Cl}_{2}, 0^{\circ} \mathrm{C}$-r.t., $12 \mathrm{hr}, 65 \%$.

(a)<smiles>CC(C)C(NC(C)(C)C)C(=O)O</smiles>

3

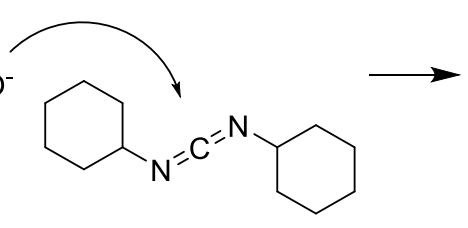

(c)

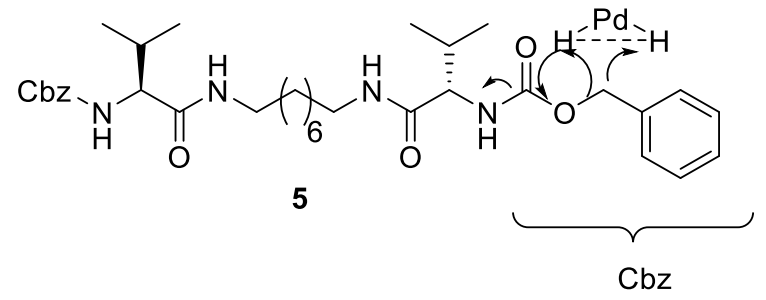

(b)

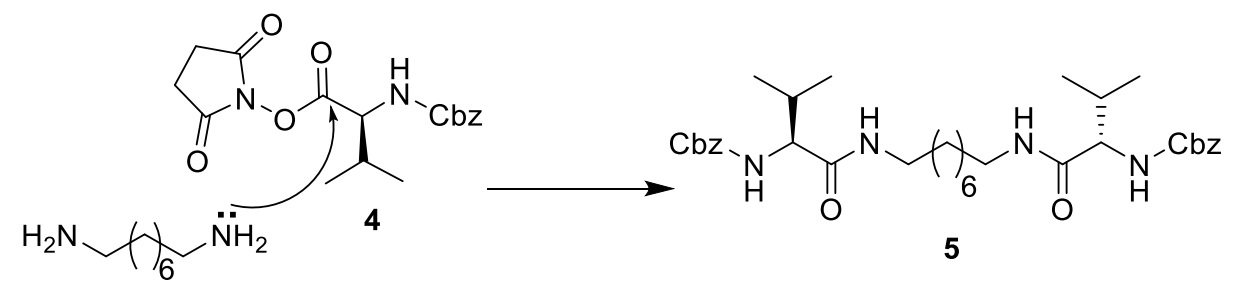<smiles>CC(C)C(NC(=O)OCc1ccccc1)C(=O)NCc1ccccc1</smiles><smiles>CC(C)C(NC(=O)OCc1ccccc1)C(=O)NCc1ccccc1</smiles><smiles>CC(C)C(NC(=O)OCc1ccccc1)C(=O)N[C@H](C(=O)ON1C(=O)CCC1=O)C(C)C</smiles>

4

Scheme 3.3: Reaction mechanism for (a) N-protected valine activation by NHS (b) coupling of 1,8diaminoctane with the activated $L$-valine (c) Deprotection of the $\mathrm{Cbz}$ group by $\mathrm{Pd} / \mathrm{C}$ to obtain the central backbone 6.

The steps carried out in the synthesis of ImVal8 and Im8 are shown in Scheme 2. The detailed reaction mechanism are depicted in the following Schemes 3 and 4 . Compound 
4, the activated ester of $\mathbf{3}$ is formed by a DCC/NHS coupling reaction. This activated ester is then made to react with the primary amines of 1,8-diaminoctane to form amide bond with the $\mathrm{N}$ - terminal of $L$-valine group still protected. The $\mathrm{Cbz}$ deprotection is carried out by $\mathrm{Pd} / \mathrm{C}$ hydrogenation reaction in methanol. The final compound ImVal8 is synthesized using BOP as a coupling reagent to form amide bond between free acid of Imidazole 4acetic acid and the terminal primary amines of $\mathbf{6}$. The last step of coupling the diamine with Imidazole 4-acetic acid using BOP follows the same mechanism as depicted in Scheme 4 for both ImVal8 and Im8.
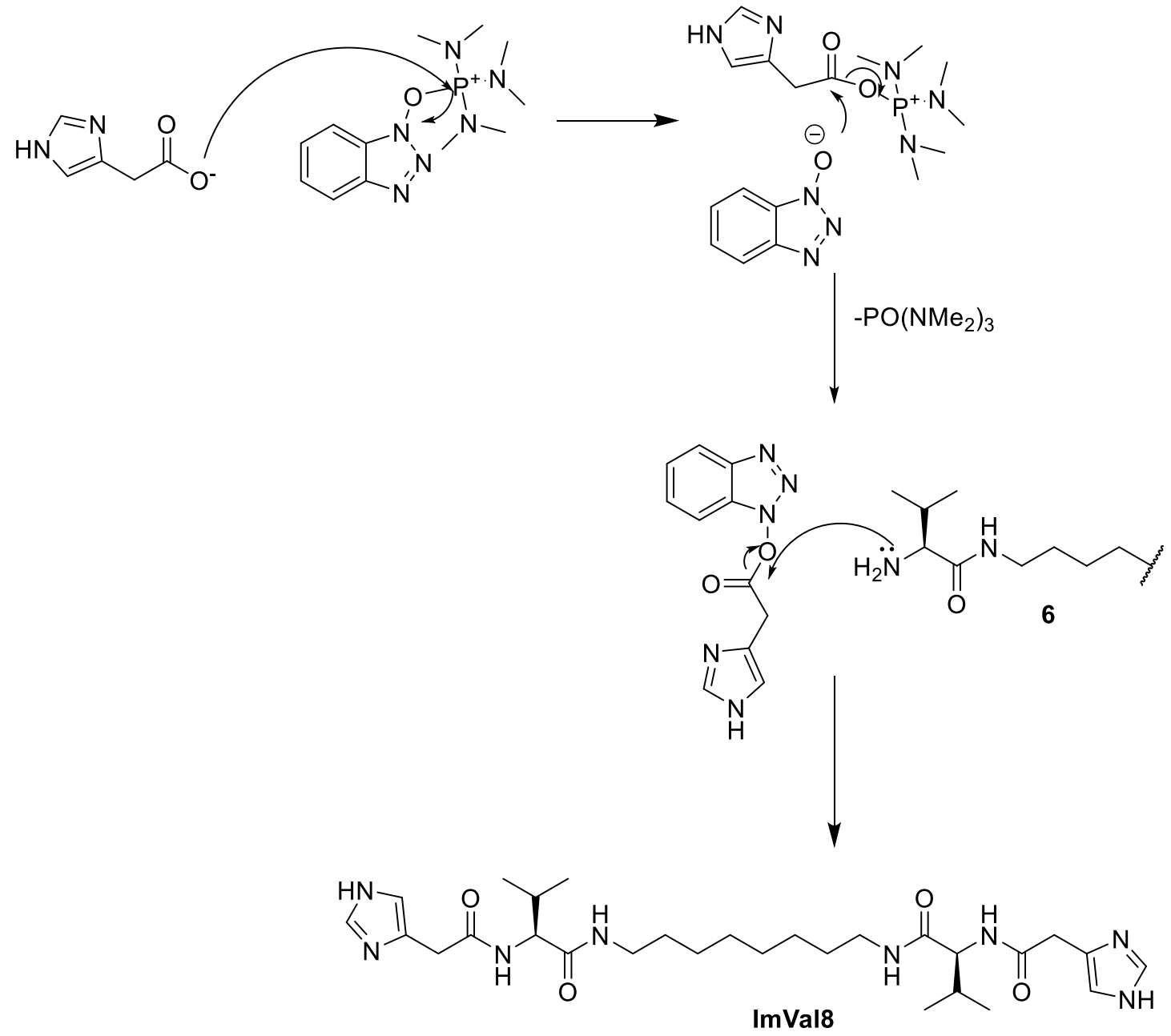

Scheme 3.4: Reaction mechanism for coupling of 6 with imidazole 4-acetic acid using BOP. The mechanism is same for the coupling reaction to obtain $\mathbf{I m 8 .}$ 


\subsubsection{Structural and morphological characterisation}

\subsubsection{Determination of minimum gel concentration}

The minimum gelation concentration of ImVal8 was roughly determined as $5.7 \mathrm{mM}$ using tube inversion method. ${ }^{21,22}$ The desired amount of ImVal8 was dissolved in $0.1 \mathrm{M}$ TRIS-HCl buffer of pH 7 and sonicated to get a suspension. This suspension was then heated to dissolve the compound to get a clear solution and then was allowed to stand for 1 hour to come to room temperature forming a hydrogel. $\operatorname{Im8}$ for the same and much higher concentrations was unable to form hydrogel or visible aggregates.

\subsubsection{Solubility experiments}

To find the amount of molecules present in solution when ImVal8 forms gel, NMR solubility experiments were performed. The molecules which contribute in fibre formation are not detected by ${ }^{1} \mathrm{H}$ NMR which allows only the molecule in solution to be detected by NMR. ${ }^{29}$ For each data point freshly prepared samples in NMR tubes of ImVal8 were used at different concentrations dissolved in buffered water by heating which were then allowed to stand for 24 hours. In this tube, another concentric NMR tube containing $50 \mathrm{mM}$ hydroquinone dissolved in $\mathrm{D}_{2} \mathrm{O}$ was introduced as an external reference. NMR spectra in water were recorded at different concentrations of ImVal8 ranging from completely soluble to gel state. The peak of water was presaturated to obtain the ${ }^{1} \mathrm{H}$ NMR spectra. The solubility constants at different $\mathrm{pH}$ values were obtained by plotting the relative integral of a chosen peak in the spectra against the concentration of ImVal8 for different concentrations. The solubility $\left(\mathrm{k}_{\mathrm{sol}}\right)$ of compound ImVal8 obtained by ${ }^{1} \mathrm{H}$ NMR experiments for $\mathrm{pH} 6$, pH 7 and $\mathrm{pH} 8$ were found to be $2.5 \mathrm{mM}, 1.3 \mathrm{mM}$ and $0.7 \mathrm{mM}$ respectively (Figure 3.1). 

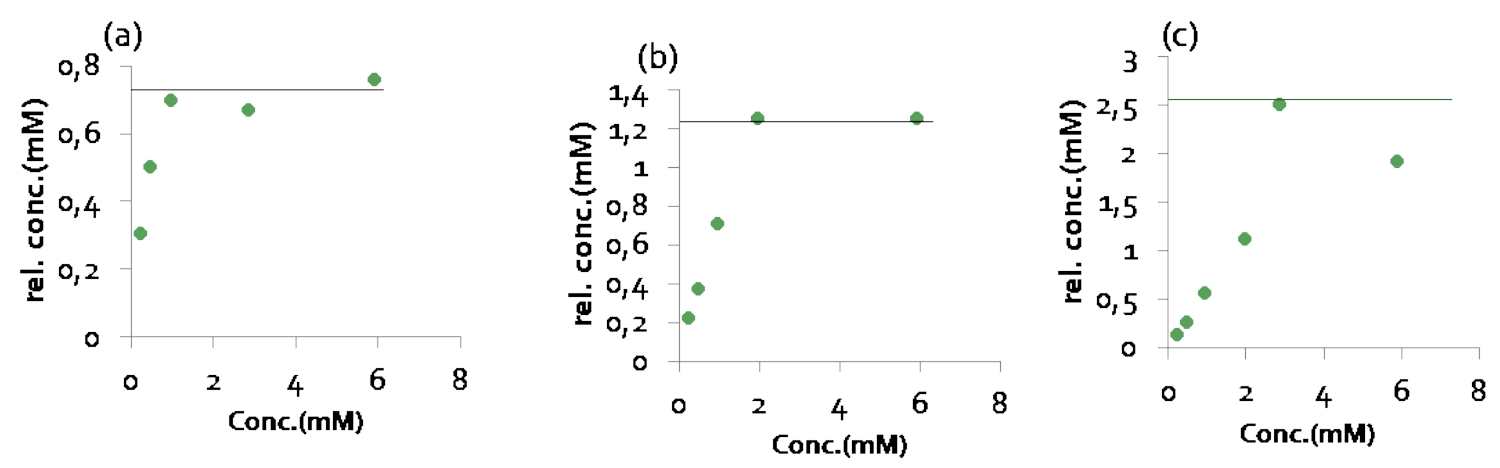

Figure 3.1: $500 \mathrm{MHz}{ }^{1} \mathrm{H}$ NMR solubility experiment graph for ImVal8 at (a) pH 8, (b) pH 7 and (c) pH 6. Relative integral are w.r.t to $50 \mathrm{mM}$ hydroquinone in $\mathrm{D}_{2} \mathrm{O}$ which was present in a concentric tube inside the NMR tube with the sample.

\subsubsection{Potentiometric Titration Experiment}

Potentiometric titration experiments were performed to check the distribution of protonated-deprotonated imidazole species with respect to $\mathrm{pH}$ and whether aggregation brought any unexpected changes in the pKa values. ${ }^{23-29}$ The see the effect of aggregation experiments were done at two different concentrations, $17 \mathrm{mM}$ (well above the MGC) and at $1.8 \mathrm{mM}$ when ImVal8 should not aggregate. Interestingly the pKa values for higher concentration of ImVal8 at which it was able to self-assemble were different for the two imidazole units (5.9 and 6.6), with an abundance of monoprotonated imidazole in this range. This difference in the pKa values was only observed for the aggregated form of ImVal8, as in solution the pKa values were comparable (6.2 and 6.3). This highlights the fact that aggregation induced a shift in the $p K a$ values resulting in the increased basicity of the imidazole moiety (Table 3.1, Figure ES 3.1). 
Table 1: $p K a$ values for ImVal8 at different concentrations.

\begin{tabular}{|c|c|}
\hline Concentration & $p K a$ \\
\hline $17.2 \mathrm{mM}$ & $6.6,5.9$ \\
\hline $1.8 \mathrm{mM}$ & $6.3,6.2$ \\
\hline
\end{tabular}

Calculated error less than $5 \%$

\subsubsection{Transmission electron microscopy studies}

The nanoscale structures of the self-assembled networks of gels as observed by TEM differ depending on $\mathrm{pH}$ values (Figure 3.2). TEM images reveal helical fibres of 15-20 $\mathrm{nm}$ width at $\mathrm{pH} 6$ and 6.5 . At $\mathrm{pH} 7$ and 8 the molecules aggregate in flat belt-like structures which are $0.5 \mu \mathrm{m}$ wide and several micrometres long, with lower aspect ratio. The variation in morphologies based on $\mathrm{pH}$ can be attributed to the change in number of protonated imidazole residues. The repulsion between higher number of protonated imidazole present at pH 6 and 6.5 may result in stacking of molecules with higher slip angle between them; this gives rise to the twists observed in the nanofibres. This is not seen further away from the $p K_{a}$ by increasing the $\mathrm{pH}$ due to the significantly lower number of protonated imidazole residues. 


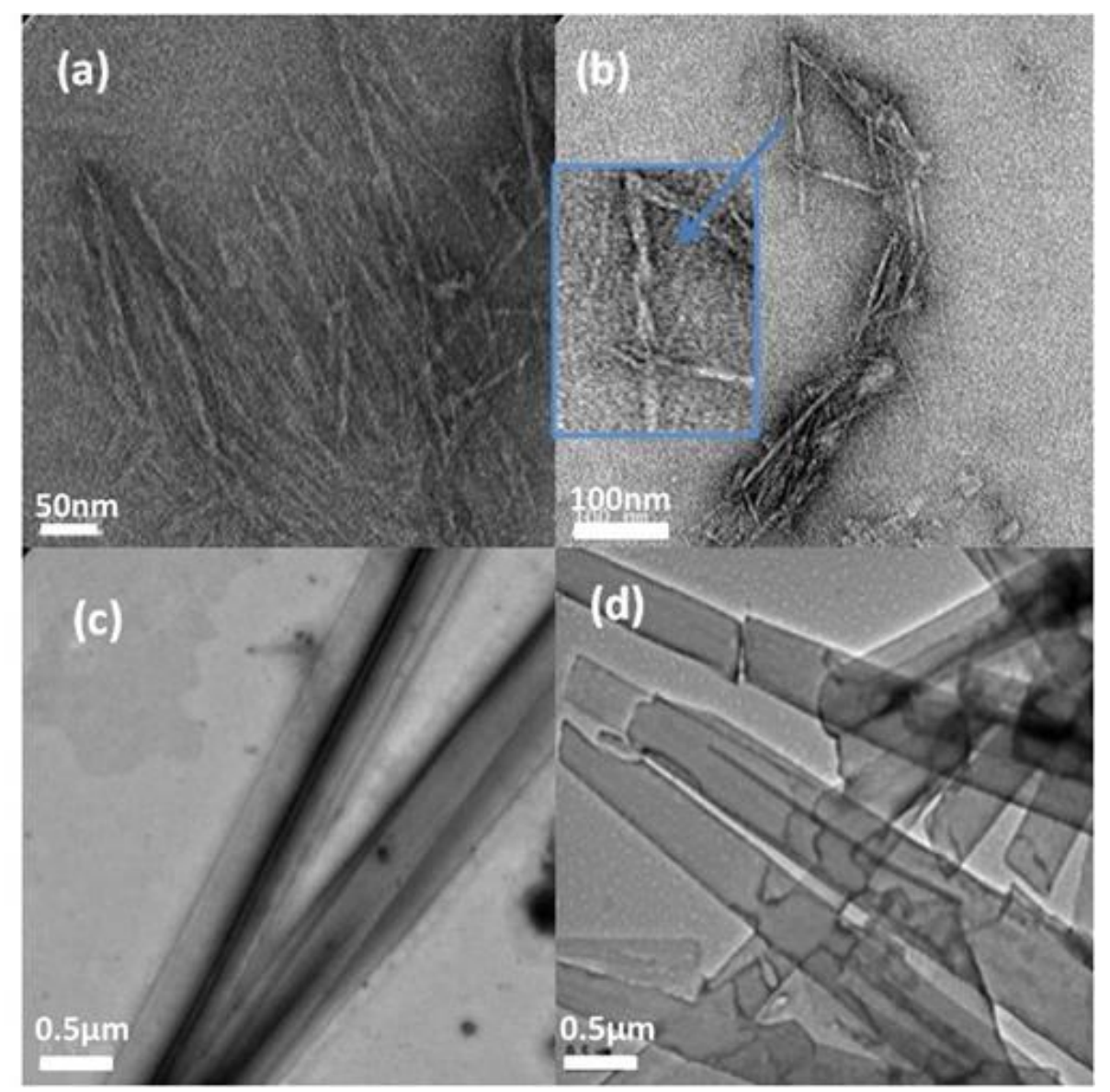

Figure 3.2: TEM images of gels at (a) pH 6 (b) pH 6.5 (Inset: zoomed image of twisted fibre) (c) pH 7 (d) pH 8.

\subsubsection{Circular dichroism and infrared spectroscopy}

The amide $\mathrm{I}^{\prime}$ band in the $1630-1638 \mathrm{~cm}^{-1}$ region of IR for different $\mathrm{pH}$ values denote the presence of $\beta$-sheet like structures, which is also evident from the circular dichroism (CD) contours (Figure 3.3, Figure ES 3.4 ). While moving from $\mathrm{pH} 8$ to $\mathrm{pH}$ 6, an increase in ellipticity together with an apparent red-shift is observed in the CD spectra. ${ }^{13,14,16}$ 


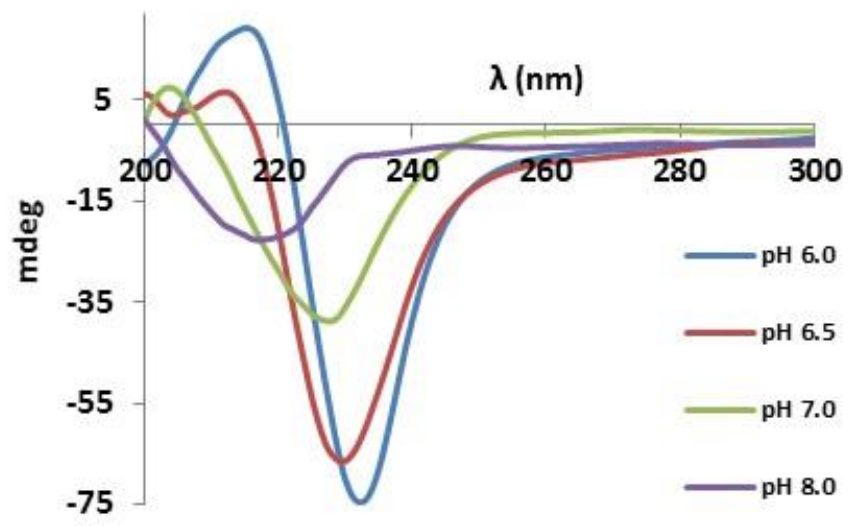

Figure 3.3: $\mathrm{CD}$ spectra obtained for gels at different $\mathrm{pH}$ values

These kinds of spectral shifts to longer wavelengths are reported for twisted fibres having $\pi-\pi^{*}$ transitions with larger dipole moments which is expected to be the case in the protonated imidazole more than the deprotonated ones. ${ }^{15}$ This information obtained from CD and IR are in agreement with the TEM images of the gels which switch from twisted helical fibres (pH 6 and 6.5) to flat belt like structures ( $\mathrm{pH} 7$ and 8).

\subsubsection{Probing by 1-anilinonaphthalene-8-sulphonate (ANS) for hydrophobicity of self-assembled fibres}

In order to evaluate the presence of hydrophobic binding pockets, we probed the gels at different $\mathrm{pH}$ values with 1-anilinonaphthalene-8-sulphonate (ANS), used extensively for this purpose in protein structure studies. ${ }^{17-18}$ When ANS was introduced in hydrogel of ImVal8, an apparent blue shift along with the rise in fluorescence was observed confirming the presence of hydrophobic pockets (Figure 3.4). These hydrophobic binding pockets could be formed by the central alkyl chain as well as by the $L$-valine isopropyl residues in ImVal8. 


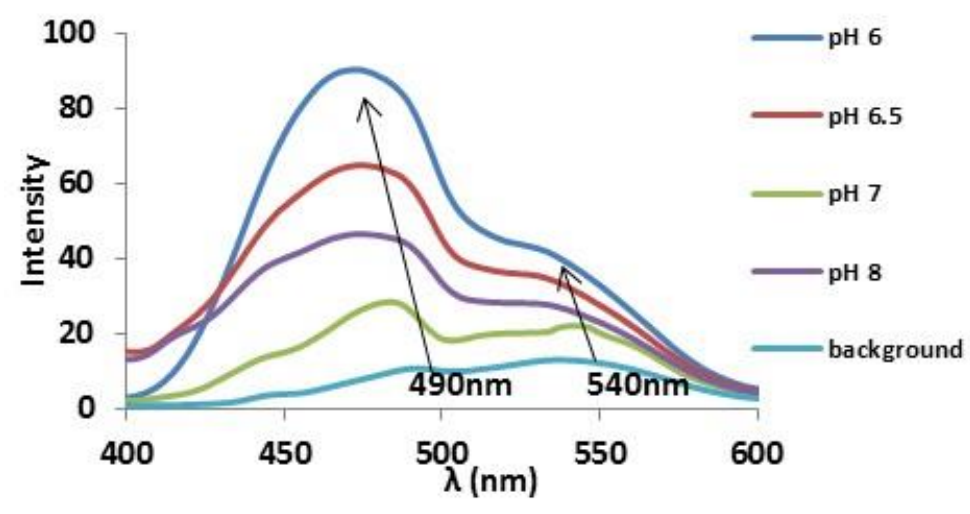

Figure 3.4: Fluorescence emission of ANS in gels and background at different pH values.

The molecular rigidity introduced by the two amide groups could be balanced by the flexibility of the alkyl spacer as well as the rotational freedom of the imidazole end fragments. Overall, a dynamic binding pocket could be confirmed in the vicinity of the catalytic fragment. It is also remarkable the effect of the $L$-valine residue as compound Im8 lacking this amino acid fragment does not even aggregate under similar conditions. Moreover, the fluorescence intensity at pH 6 and 6.5 is higher and more blue shifted (472 $\mathrm{nm}$ for $\mathrm{pH} 6$ and $474 \mathrm{~nm}$ for $\mathrm{pH} 6.5$ ) than for the rest of the $\mathrm{pH}$ values, suggesting stronger binding of the ANS.

\subsubsection{Catalysis}

\subsubsection{1.pNPA hydrolysis}

ImVal8 with a minimum gel concentration of $5.7 \mathrm{mM}$ was tested for the esterase like activity using $p$ NPA as substrate. The model substrate $p$ NPA upon hydrolysis yields chromogenic $p$-nitrophenolate anion which can be monitored at $400 \mathrm{~nm}$ using UV spectroscopy (Scheme 3.5). $800 \mu \mathrm{L}$ gel of ImVal8 at MGC in buffer of desired pH was vortexed with $1 \mathrm{~mL}$ of $0.1 \mathrm{M}$ TRIS- $\mathrm{HCl}$ buffer and $100 \mu \mathrm{L}$ of this was added to $1 \mathrm{~cm}$ quartz cell containing $1.8 \mathrm{~mL}$ of buffer. To this $100 \mu \mathrm{L}$ of substrate dissolved in acetonitrile was added from a freshly prepared stock solution. This system was then 
monitored at $400 \mathrm{~nm}$ to check the evolution of the $p$-nitrophenolate anion. The catalysis experiments were generally done in triplicate. Graph pad prism version 6.05 software was used for data fitting. ${ }^{30}$<smiles>CC(=O)Oc1ccc([N+](=O)[O-])cc1</smiles>

Scheme 3.5: Hydrolysis of $p$ NPA

The initial parts of the kinetic curves for hydrolysis at different concentrations of substrate were fitted to Michaelis-Menten equation for respective $\mathrm{pH}$ values. The obtained $\mathrm{K}_{\mathrm{M}}, \mathrm{k}_{\mathrm{cat}}$ and $\mathrm{V}_{\max }$ values and Michaelis-Menten fits are presented in Table 3.2 and Figure 3.5.

Table 3.2: Obtained $\mathrm{K}_{\mathrm{M}}, \mathrm{k}_{\mathrm{cat}}$ and $\mathrm{V}_{\max }$ values of hydrolysis of $p$ NPA by $\mathbf{I m V a l 8}$.

\begin{tabular}{|l|l|l|l|l|l|}
\hline & pH 6 & pH 6.5 & pH 7 & pH 7.5 & pH 8 \\
\hline $\mathbf{k}_{\text {cat }}\left(\mathrm{s}^{-1}\right) \times 10^{2}$ & $2.6 \pm 0.4$ & $2.5 \pm 0.6$ & $2.1 \pm 0.4$ & $2.4 \pm 0.7$ & $2.5 \pm 0.6$ \\
\hline $\mathbf{K}_{\mathbf{M}}(\mathrm{mM})$ & $3.3 \pm 1.1$ & $3.1 \pm 1.6$ & $4.0 \pm 1.5$ & $3.9 \pm 1.6$ & $3.7 \pm 1.3$ \\
\hline $\mathbf{V}_{\mathbf{m a x}}\left(\mu \mathrm{mols}^{-1}\right)$ & 8.8 & 8.6 & 7.3 & 8.1 & 8.3 \\
\hline
\end{tabular}

It is essential to find the catalytic activity of the molecules that are present in the solution to check if the fibres are catalytically active or not. The $\mathrm{k}_{\mathrm{sec}}$ (second order rate constant) values observed for $\mathrm{pH}$ 6, pH 7 and $\mathrm{pH} 8$ for non-aggregating concentrations of ImVal8, were $0.07 \mathrm{M}^{-1} \mathrm{~s}^{-1}, 0.23 \mathrm{M}^{-1} \mathrm{~s}^{-1}, 1.8 \mathrm{M}^{-1} \mathrm{~s}^{-1}$ respectively. These values are significantly lower than at the self-assembling concentration (Figure 3.6). Thus, highlighting the fact that observed catalysis is not by the molecules in solution but due to the catalytically active fibres. 
(a)

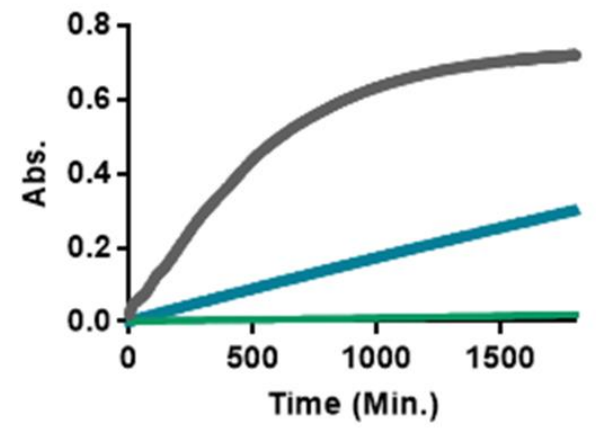

(c)

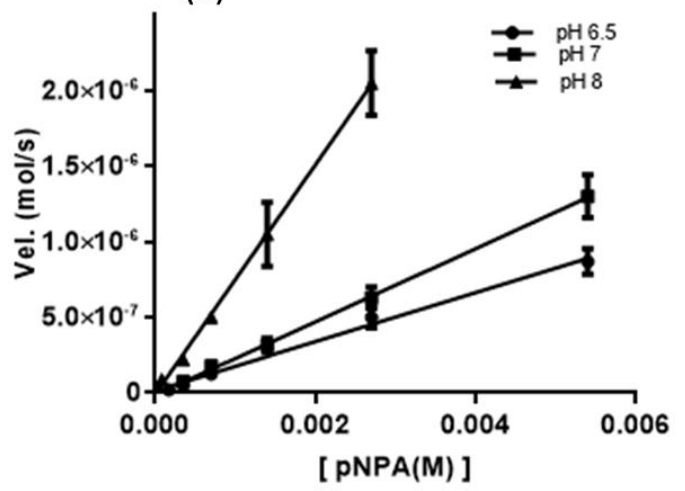

(b)
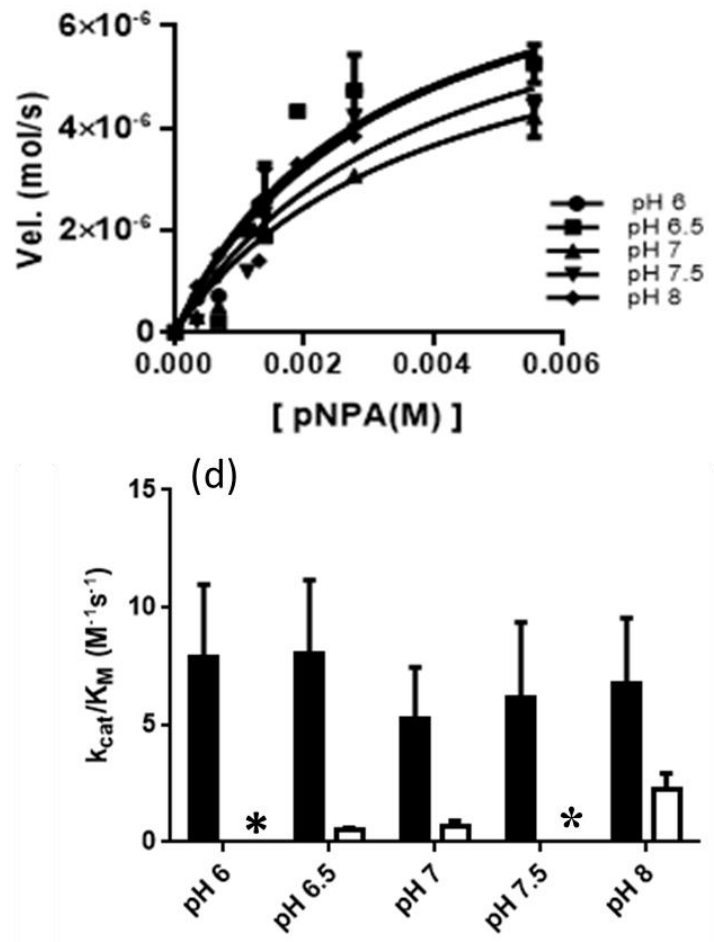

Figure 3.5: (a) UV-Vis kinetic profile of $p$ NPA $(1.4 \mathrm{mM})$ hydrolysis at $400 \mathrm{~nm}$ catalysed by $0.17 \mathrm{mM}$ of ImVal8 gel (grey), Im8 (blue) and background hydrolysis at pH 6.5 (green). (b) Michaelis-Menten graph for the hydrolysis of $p$ NPA by $\mathbf{I m V a l 8}$ for different $\mathrm{pH}$ values (c) Hydrolysis of $p$ NPA by $\mathbf{I m 8}$ for different $\mathrm{pH}$ values (d) $\mathrm{k}_{\text {cat }} / \mathrm{K}_{\mathrm{M}}$ values obtained by $\mathbf{I m V a l 8}$ at different $\mathrm{pH}$ values (black bars) and $\mathrm{k}_{\text {sec }}$ values for $\mathbf{I m 8}$ (white bars, * not determined).

To establish the effect of aggregation resulting in the enhanced catalytic activity, similar catalysis experiments were performed with $\mathbf{I m 8}$ which does not aggregate at same concentrations as $\mathbf{I m V a l 8}$. The $\mathrm{k}_{\mathrm{sec}}$ for $\mathbf{I m 8}$ at $\mathrm{pH} 6.5, \mathrm{pH} 7$ and $\mathrm{pH} 8$ were $0.5 \mathrm{M}^{-1} \mathrm{~s}^{-1}, 0.7$ $\mathrm{M}^{-1} \mathrm{~s}^{-1}$ and $2.2 \mathrm{M}^{-1} \mathrm{~s}^{-1}$ which are significantly lower than for ImVal8 under identical conditions. The obtained linear relationship between velocity of product formation and substrate concentration also reflected lack of any binding events unlike ImVal8 (Figure 3.5b-d). 
(a)

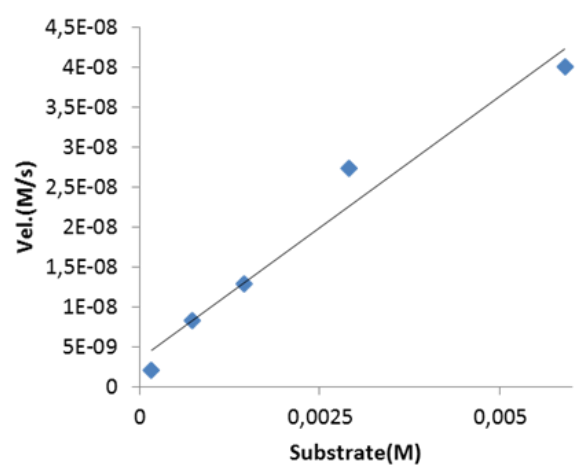

(b)

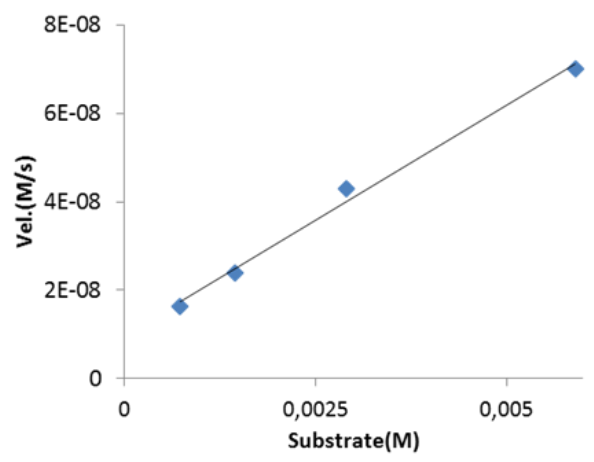

(c)

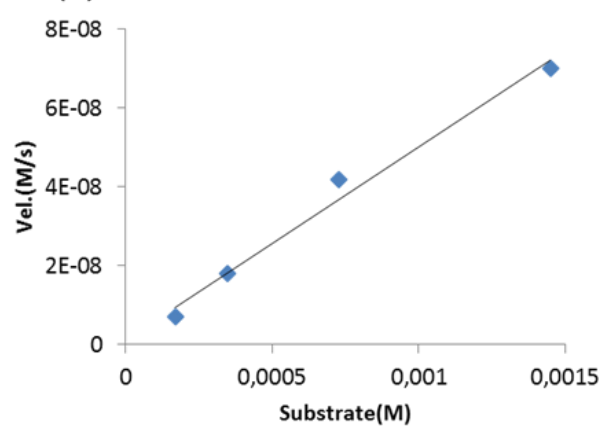

Figure 3.6: Observed hydrolysis rate by ImVal8 under non aggregating conditions for (a) $\mathrm{pH} 8$, (b) $\mathrm{pH} 7$ and (c) $\mathrm{pH} 6 . \mathrm{k}_{\mathrm{sec}}$ values for $\mathrm{pH} 6, \mathrm{pH} 7$ and $\mathrm{pH} 8$ are $0.07 \mathrm{M}^{-1} \mathrm{~s}^{-1}, 0.23 \mathrm{M}^{-1} \mathrm{~s}^{-1}$, and $1.8 \mathrm{M}^{-1} \mathrm{~s}^{-1}$ respectively.

The catalytic efficiency $\left(\mathrm{k}_{\mathrm{ca}} / \mathrm{K}_{\mathrm{M}}\right)$ for imidazole molecules in solution is known to drop significantly at lower $\mathrm{pH}$ values. ${ }^{3,7-11}$ The higher amount of protonated imidazole moieties are held responsible for this which normally are not catalytically active. To our surprise for the pH 6 and 6.5 we do not observe this drop with ImVal8, in fact a slight rise in the catalytic efficiency when compared to higher $\mathrm{pH}$ values like 7 and 7.5 (Figure 3.5d). This unusual catalytic efficiency around the $p k a$ values of self-assembling ImVal8 suggests the involvement of both protonated and deprotonated imidazoles in the catalysis, often referred to as a cooperative mechanism in the prior art (Figure 3.7)., 7-11

From the potentiometric titration curve we know that the mono-protonated imidazole is present in four-fold excess compared to the deprotonated imidazole at pH 6.5 (Figure ES 3.1). At $\mathrm{pH} 8$ (well above the $\mathrm{pK}_{\mathrm{a}}$ ) only the deprotonated imidazole residues are present and held responsible for the hydrolysis (Figure 3.7). The calculated catalytic efficiency 
at $\mathrm{pH} 8$ only due to the deprotonated imidazole groups was $7.37 \mathrm{M}^{-1} \mathrm{~s}^{-1}$. According to these values, the extrapolated catalytic efficiency of the deprotonated imidazole at $\mathrm{pH}$ 6.5 , assuming that the protonated imidazole is not active should be $1.65 \mathrm{M}^{-1} \mathrm{~s}^{-1}$ whereas that observed is $8.09 \mathrm{M}^{-1} \mathrm{~s}^{-1}$. Hence, based on these observations the catalytic efficiency at lower $\mathrm{pH}$ values 6 and 6.5 , cannot simply be attributed to the contribution of the fraction of deprotonated imidazole. Instead, cooperativity between both protonated and deprotonated imidazole groups is likely responsible (Figures 3.5 and 3.7). High $\mathrm{V}_{\max }$ values for $p$ NPA hydrolysis were obtained at lower $\mathrm{pH}$ values which can be attributed to the observed high aspect ratio fibres, allowing higher extent of substrate binding thus releasing more product (Figure 3.2). Moreover, the fluorescence intensity of ANS at pH 6 and 6.5 is higher and more blue shifted (472 nm for $\mathrm{pH} 6$ and $474 \mathrm{~nm}$ for $\mathrm{pH} 6.5$ ) than for the rest of the $\mathrm{pH}$ values, suggesting stronger binding of the ANS and supporting the lower $\mathrm{K}_{\mathrm{M}}$ values obtained for the $p$ NPA hydrolysis at these $\mathrm{pH}$ values (Figure 3.4). In summary, the $\mathrm{k}_{\mathrm{cat}}$ observed for $p$ NPA hydrolysis shows little variation with $\mathrm{pH}$, with the change in catalytic efficiency probably due to differences in substrate binding. Although the errors in $\mathrm{K}_{\mathrm{M}}$ are significant, a clear trend is observed. This behaviour can be attributed to the difference in availability of binding pockets for each morphology. 
(a)

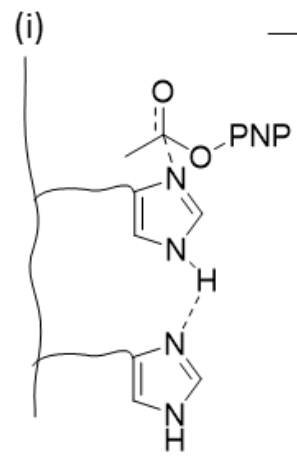

(i)

(b)

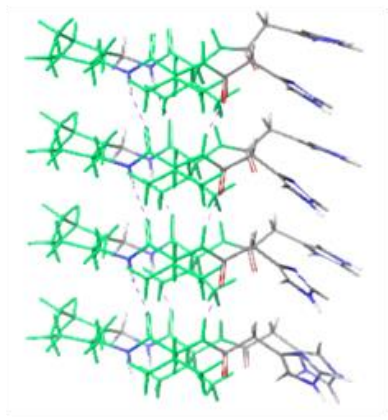

(i)

(c) (ii)

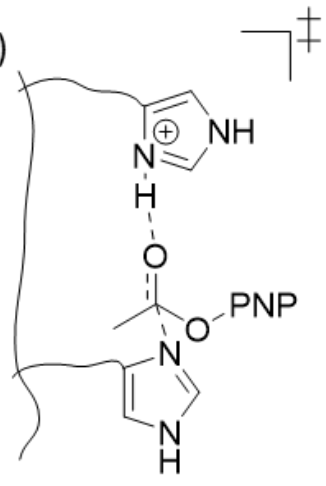

(ii)

Deprotonated residues: properly stacked

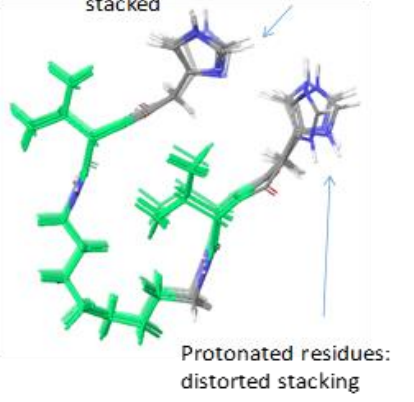

(iii)

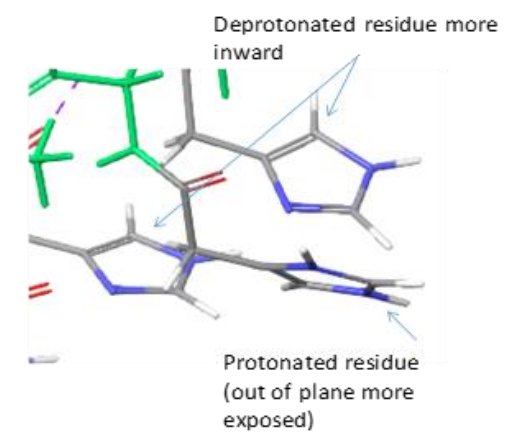

(ii)
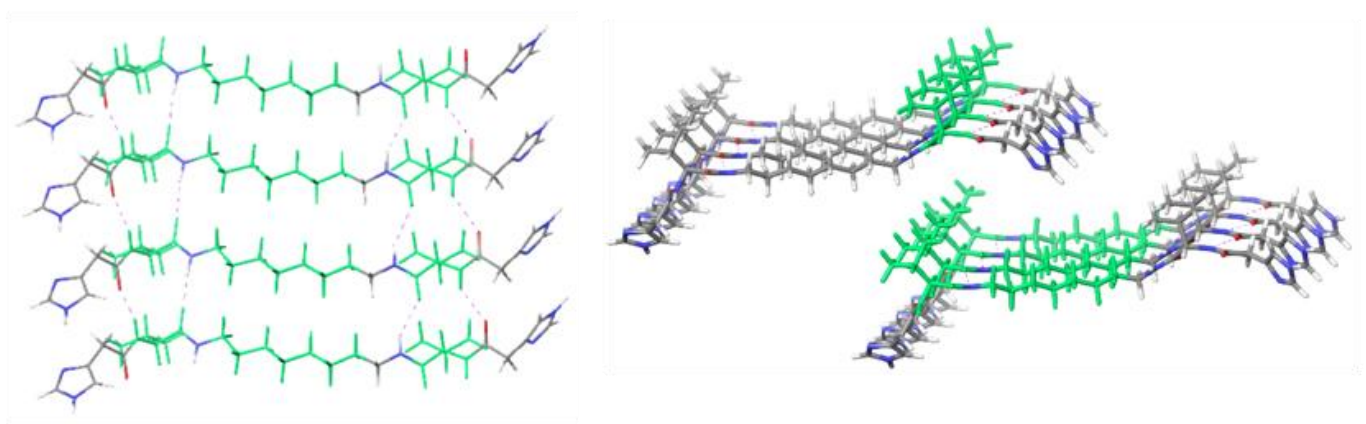

Stacking of molecules for the deprotonated case for higher $\mathrm{pH}$ The green parts depict the hydrophobic regions.

Figure 3.7: (a) Proposed transition states for the hydrolysis of $p$ NPA by (i) neutral imidazole residues and (ii) cooperation between protonated and neutral imidazole residues. (b) (i) Probable stacking of folded molecules in the case of lower $\mathrm{pH}$ values. For the sake of simplicity half of the imidazoles on one side of the molecules are taken as protonated. (ii) the distorted stacking between the protonated residues that gives rise to the twist in fibres as seen in TEM and confirmed by CD (iii) protonated residue depicted being outward and stacked with higher slip angle making them more exposed to the solvent and substrates. (d) (i) Proper stacking of molecules at higher $\mathrm{pH}$ values (ii) two such stacked fibres together forming hydrophobic regions. 


\subsubsection{Hydrolysis of inactivated $L$ and $D$-phenylalanine methyl ester}

Owing to the binding phenomenon and fast hydrolysis trend shown by ImVal8 we anticipated it to be capable of hydrolysing even stronger non activated ester linkages such as methyl esters. We chose $L$ - and $D$-phenylalanine methyl esters as our substrate and followed its hydrolysis by HPLC. As expected, these substrates did not undergo any noticeable background hydrolysis at pH 7 whereas, with 33 mol\% (5.7 mM) of ImVal8 as catalyst, we could observe commendable hydrolysis rate of the methyl esters. (Figure 3.9, Table 3.3). The calculated catalytic efficiency for the hydrolysis of $L$ - and $D$ phenylalanine methyl esters by ImVal8 are $1.2 \times 10^{-3} \mathrm{M}^{-1} \mathrm{hr}^{-1}$ and $1.7 \times 10^{-3} \mathrm{M}^{-1} \mathrm{hr}^{-1}$ respectively. The $\mathrm{K}_{\mathrm{sec}}\left(2.5 \times 10^{-4} \mathrm{M}^{-1} \mathrm{hr}^{-1}\right)$ for $\mathbf{I m 8}$ is an order of magnitude smaller than for ImVal8 exemplifying the aggregation effect, even though there does not seem to be any stereospecificity shown by ImVal8 (Table 3.3). Thus, the hydrolysis of non-activated ester at the physiological $\mathrm{pH}$, which to our knowledge has not been demonstrated before by a similar system, reflects the fact that aggregation can lead to new emergent catalytic abilities even in small molecules owing to the high local concentration of the catalytic sites, pKa shifts and formation of hydrophobic pockets.

Table 3.3: $\mathrm{k}_{\mathrm{cat}}$ and $\mathrm{K}_{\mathrm{M}}$ values for hydrolysis of unactivated $L$ - and $D$-phenylalanine methyl ester by $\mathbf{I m V a l 8 . ~}$

\begin{tabular}{|l|l|l|}
\hline & $\mathbf{k}_{\text {cat }}\left(\mathrm{hr}^{-1}\right) \times 10^{-5}$ & $\mathrm{~K}_{\mathrm{M}}(\mathbf{m M})$ \\
\hline L-phenylalanine methyl & $(3.7 \pm 0.3)$ & $(29 \pm 1.6)$ \\
\hline ester hydrochloride & $(1.5 \pm 0.1)$ & $(9 \pm 1.5)$ \\
\hline $\begin{array}{l}\text { D-phenylalanine methyl } \\
\text { ester hydrochloride }\end{array}$ & & \\
\hline
\end{tabular}



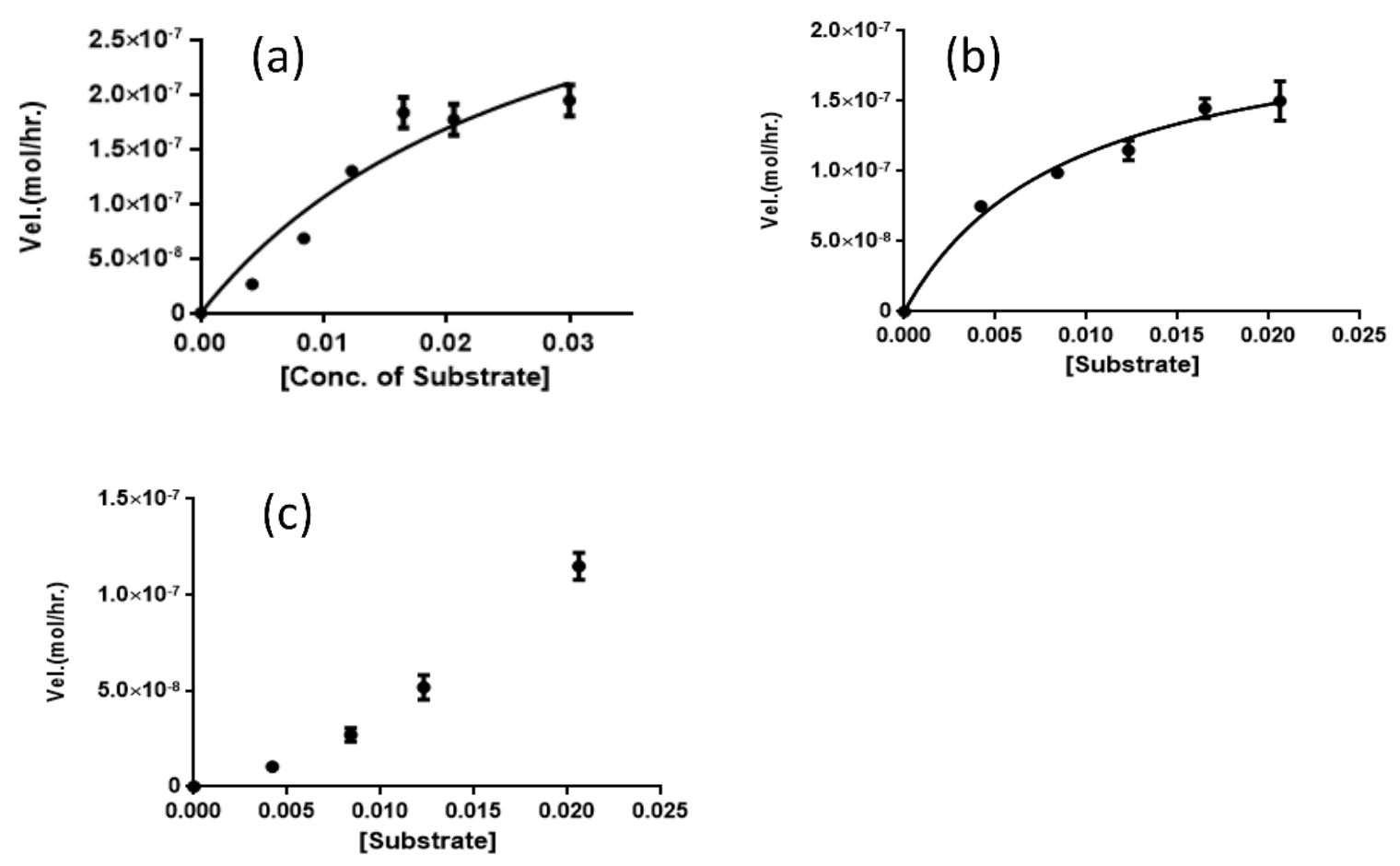

Figure 3.8: Michaelis-Menten fit for the hydrolysis of (a) $L$-phenylalanine methyl ester and (b) $D$ phenylalanine methyl ester by ImVal8 and (c) $L$-phenylalanine methyl ester by $\operatorname{Im8}$ at pH 7.

\subsection{Conclusions}

It is remarkable that a simple low molecular weight self-assembling compound bearing a minimal peptidic fragment is able to catalyse the hydrolysis of an activated ester as efficiently or even better than the few previously reported examples of longer selfassembled peptides. ${ }^{7-10}$ For instance, Stupp et al. ${ }^{7}$ reported a rate constant of $1.67 \times 10^{-2}$ $\mathrm{s}^{-1}$ and a $\mathrm{K}_{\mathrm{M}}$ of $0.4 \mathrm{mM}$ for a bis-histidine containing decapeptide and a less efficient tetradecapeptide containing one histidine residue was described by Liang et al. ${ }^{9}\left(\mathrm{k}_{\mathrm{cat}} 0.19\right.$ x $10^{-2} \mathrm{~s}^{-1}$ and $\mathrm{K}_{\mathrm{M}} 21.68 \mathrm{mM}$ ). The same group reported a shorter analogue (Fmoc-FFH$\left.\mathrm{CONH}_{2}\right)$ with lower reaction rate than in the case of $\mathbf{I m V a l 8}\left(\mathrm{k}_{\mathrm{cat}} 0.14 \times 10^{-2} \mathrm{~s}^{-1}\right)$ but with 
a stronger binding ability $\left(\mathrm{K}_{\mathrm{M}} 0.76 \mathrm{mM}\right) .{ }^{8}$ Related results have been also reported by Korendovych et al. for amyloidogenic heptapeptides bearing $\mathrm{H}$ residues that after selfassembly are able to coordinate $\mathrm{Zn}^{+2}$ and efficiently catalyse the hydrolysis of $p$ NPA. ${ }^{10}$ This example however follows a different catalytic mechanism based on metal ion Lewisacid catalysis. All these examples highlight the undoubtable link between self-assembly and emergence of catalysis which is also exemplified by ImVal8. In summary, we have reported an example of a catalytic supramolecular hydrogel in which binding and catalysis take place in reaction sites self-constructed solely with non-covalent interactions. We have been able to identify the probable structure-activity relationship between the different self-assembled structures and the subsequent catalytic performances of the gels. The results indicated that the presence of hydrophobic pockets, higher aspect ratio of fibres and the balance between the protonated and deprotonated imidazole can be the key factors for improved hydrolysis efficiency compared to related non-aggregating catalysts. It is remarkable the fact that enzyme-like catalytic behaviour emerges after self-assembly of small and simple molecular components. It is worth to mention that very simple low-molecular weight compounds can approach, although modestly by now, what evolution has achieved after millions of years. In fact, it has been proposed that short self- assembled peptides could have played a relevant role in the early stages of the origin of life. ${ }^{19}$ In this context, self-assembled catalytic peptides could have been potential precursors of enzymes. 


\subsection{Experimental section}

\subsubsection{Synthesis}

\section{Synthesis of compound 4}

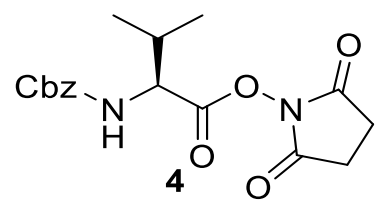

A solution of commercial available Carbobenzyloxy- $L$-valine $3(5.0 \mathrm{~g}, 19.90 \mathrm{mmol})$ and $N$-hydroxysuccinimide $(2.52 \mathrm{~g}, 21.89 \mathrm{mmol}, 1.1$ eq.) in dry THF (80 mL) was added dropwise under $\mathrm{N}_{2}$ at $0{ }^{\circ} \mathrm{C}$ with a dropping funnel to a solution of $N, N^{\prime}$ Dicyclohexylcarbodiimide (4.52 g, $21.89 \mathrm{mmol}, 1.1$ eq.) in dry THF (25 mL). The mixture was further stirred for $1 \mathrm{~h}$ at $0{ }^{\circ} \mathrm{C}$. The solution was then allowed to stand into refrigerator for $2 \mathrm{hr}$, which caused precipitation of $N, N^{\prime}$-Dicyclohexylurea. After this time, the mixture was filtered under vacuum, and the filtrate was removed under reduced pressure and the crude residue was purified by crystallization in isopropanol to yield $\mathbf{4}$ (91\%) as a white solid. The NMR spectra were consistent with those described in the literature. $^{20}$

${ }^{1} \mathbf{H}$ NMR $\left(300 \mathrm{MHz}, \mathrm{CDCl}_{3}\right) \delta(\mathrm{ppm}) 1.02(\mathrm{~d}, 6 \mathrm{H}, \mathrm{J}-7.4 \mathrm{~Hz}), 1.06(\mathrm{~d}, 6 \mathrm{H}, \mathrm{J}-7.7 \mathrm{~Hz})$, $2.31(\mathrm{~m}, 1 \mathrm{H}), 2.77(\mathrm{~s}, 4 \mathrm{H}), 4.66(\mathrm{dd}, 1 \mathrm{H}, \mathrm{J}-4.7 \mathrm{~Hz}), 5.13(\mathrm{~s}, 2 \mathrm{H}), 5.43(\mathrm{~d}, 1 \mathrm{H}, \mathrm{J}-9.5 \mathrm{~Hz})$, 7.28-7.41 (m, 5H)

${ }^{13} \mathrm{C}$ NMR $\left(126 \mathrm{MHz}, \mathrm{CDCl}_{3}\right) \delta(\mathrm{ppm})$ 17.2, 18.7, 25.5, 31.5, 57.4, 67.2, 128.0, 128.1, $128.3,135.8,155.6,167.5,168.6$. 


\section{Synthesis of compound 5}<smiles>CC(C)C(NC(=O)OCc1ccccc1)C(=O)NCCCNC(=O)C(NC(=O)OCc1ccccc1)C(C)C</smiles>

A solution of compound $4(6.31 \mathrm{~g}, 18.11 \mathrm{mmol})$ in DME (80 mL) was added dropwise under $\mathrm{N}_{2}$ at $25{ }^{\circ} \mathrm{C}$ with a dropping funnel to a solution of commercial available 1,8 diamino octano (2.88 g, $19.92 \mathrm{mmol}, 1.1$ eq.) in DME (50 mL). The mixture was further stirred for $5 \mathrm{~h}$ at $50{ }^{\circ} \mathrm{C}$. The white solid obtained was filtered under vacuum, and the residue was washed with $\mathrm{HCl} 0.1 \mathrm{M}(100 \mathrm{~mL})$ and water $(200 \mathrm{~mL})$. The compound was dried under reduced pressure at $50^{\circ} \mathrm{C}$ to yield $5(95 \%)$ as a white solid. The NMR spectra were consistent with those described in the literature. ${ }^{20}$

${ }^{1}$ H NMR (300 MHz, DMSO d 6 ) $\delta(\mathrm{ppm}) 0.81(\mathrm{~d}, 12 \mathrm{H}, J=6.3 \mathrm{~Hz}), 1.20(\mathrm{br} \mathrm{s}, 8 \mathrm{H}), 1.25$ (br s, 4H), $1.89(\mathrm{~m}, 2 \mathrm{H}), 2.95-3.08(\mathrm{~m}, 4 \mathrm{H}), 3.76(\mathrm{t}, 2 \mathrm{H}, J=8.0 \mathrm{~Hz}), 5.00(\mathrm{~s}, 4 \mathrm{H}), 7.13$ $(\mathrm{d}, 2 \mathrm{H}, J=8.4 \mathrm{~Hz}), 7.33$ (br s, 10H), 7.81 (br s, 2H)

${ }^{13}$ C NMR (126 MHz, DMSO d 6 ) $\delta$ (ppm) 18.4, 19.4, 26.4, 28.8, 29.1, 30.4, 38.5, 60.4, $65.4,127.6,127.7,128.3,137.1,156.0,170.8$.

\section{Synthesis of compound 6}<smiles>CC(C)C(N)C(=O)NCCCNC(=O)C(N)C(C)C</smiles> 
Palladium catalyst (5\% Pd/C, $526 \mathrm{mg})$ was suspended in $\mathrm{MeOH}(250 \mathrm{~mL})$ and stirred under $\mathrm{H}_{2}$ at room temperature for $10 \mathrm{~min}$. Subsequently, a solution of compound $\mathbf{5},(10.51$ $\mathrm{g}, 17.21 \mathrm{mmol})$ in $\mathrm{MeOH}(100 \mathrm{~mL})$ was added via syringe, followed by stirring under $\mathrm{H}_{2}$ at room temperature for $3 \mathrm{hr}$. The reaction mixture was then filtered through Celite ${ }^{\odot}$, and the solvent was removed under reduced pressure. The white solid obtained was filtered under vacuum, and the residue was washed with $\mathrm{NaOH} 0.1 \mathrm{M}(100 \mathrm{~mL})$ and water (200 $\mathrm{mL})$. The compound was dried under reduced pressure at $50{ }^{\circ} \mathrm{C}$ to yield $6(99 \%)$ as a white solid. The NMR spectra are consistent with those described in the literature. ${ }^{20}$

${ }^{1} \mathrm{H}$ NMR $\left(300 \mathrm{MHz}, \mathrm{CDCl}_{3}\right) \delta(\mathrm{ppm}) 0.72(\mathrm{~d}, 6 \mathrm{H}, J=6.8 \mathrm{~Hz}), 0.89(\mathrm{~d}, 6 \mathrm{H}, J=7.1 \mathrm{~Hz})$, $1.21(\mathrm{~s}, 8 \mathrm{H}), 1.38-1.43(\mathrm{~m}, 8 \mathrm{H}), 2.17(\mathrm{~m}, 2 \mathrm{H}), 3.09-3.18(\mathrm{~m}, 6 \mathrm{H}), 7.30$ (br s, 2H).

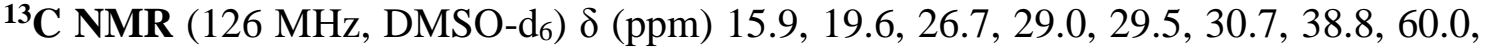
174.0 .

\section{Synthesis of compound ImVal8}

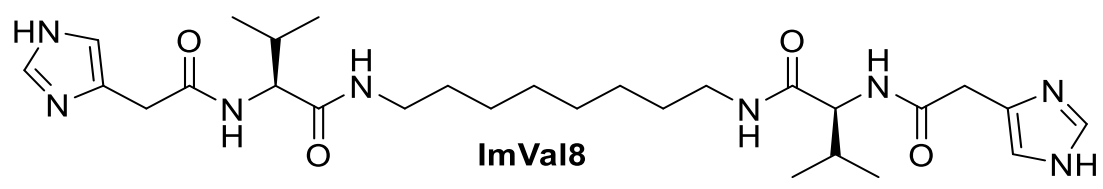

Imidazole-4 acetic acid hydrochloride (95 mg, $0.6 \mathrm{mmol}$.) was dissolved in dry DCM followed by addition of N,N-diisopropylethylamine $(0.2 \mathrm{~mL})$ and benzotriazol-1-yloxytris(dimethylamino)-phosphoniumhexafluorophosphate $(258 \mathrm{mg}, 0.6 \mathrm{mmol})$ at $0^{\circ} \mathrm{C}$. To this solution was added 6 (100 mg, $0.3 \mathrm{mmol})$, dissolved in DCM in a dropwise manner. The reaction mixture was monitored by TLC until completion. This mixture was then sonicated and washed with 3 batches of $10 \mathrm{~mL}$ of $0.1 \mathrm{M} \mathrm{NaOH}$ followed by washing with 
water and DCM over cintered funnel. The obtained solid was dried under vacuum to yield the final product in $70 \%$ yield.

${ }^{1}$ H NMR (500 MHz, DMSO-d $)$ ): $\delta(\mathrm{ppm}) 8.06(\mathrm{H} 14, \mathrm{t}, J=5.4 \mathrm{~Hz}, 2 \mathrm{H}), 7.90(\mathrm{H} 8, \mathrm{~d}, J=$ $8.9 \mathrm{~Hz}, 2 \mathrm{H}), 7.60(\mathrm{H} 2, \mathrm{~s}, 2 \mathrm{H}), 6.88(\mathrm{H} 4, \mathrm{~s}, 2 \mathrm{H}), 4.10(\mathrm{H} 9, \mathrm{dd}, J=8.9,6.5 \mathrm{~Hz}, 2 \mathrm{H}), 3.44$ $(\mathrm{H} 6, \mathrm{~d}, 2 \mathrm{H}, J=5.8 \mathrm{~Hz}), 3.40\left(\mathrm{H6}^{\prime}, \mathrm{d}, 2 \mathrm{H}, J=5.8 \mathrm{~Hz}\right), 3.02(\mathrm{H} 15, \mathrm{~m}, 2 \mathrm{H}), 2.98\left(\mathrm{H}^{\prime} 5^{\prime}, \mathrm{m}\right.$, 2H), 1.95 (H10, oct., 2H, $J=6.5 \mathrm{~Hz}), 1.37$ (H16, t, 4H, J=6.5 Hz), 1.22 (H17, H18, broad singlet, $8 \mathrm{H}), 0.80(\mathrm{H} 11, \mathrm{~d}, J=6.5 \mathrm{~Hz}, 6 \mathrm{H}), 0.78(\mathrm{H} 12, \mathrm{~d}, J=6.5 \mathrm{~Hz}, 6 \mathrm{H})$ (See annexe for assignment).

${ }^{13}$ C NMR (126 MHz, DMSO-d 6 ): $\delta$ (ppm) 171.0, 170.3, 135.4, 135.1, 113.8, 58.1, 38.8, $35.8,30.8,29.4,29.0,26.7,19.6,18.2$.

HR ESMS: m/z: $[\mathrm{M}+\mathrm{H}]^{+} \mathrm{Calcd}$ for $\mathrm{C}_{28} \mathrm{H}_{46} \mathrm{~N}_{8} \mathrm{O}_{4}$ : 559.3676; found: 559.3721; $\delta=0.2 \mathrm{ppm}$.

\section{Synthesis of $\operatorname{Im8}$}

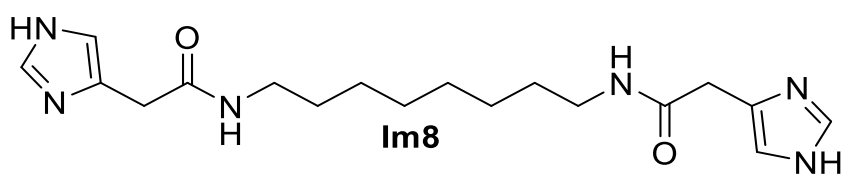

7 (221 mg, 1.4 mmol.) was dissolved in dry DCM followed by addition of N,Ndiisopropylethylamine (0.5 $\mathrm{mL}$.$) and Benzotriazol-1-yloxy-tris(dimethylamino)-$ phosphoniumhexafluorophosphate $(616 \mathrm{mg}, 1.4 \mathrm{mmol})$ at $0^{\circ} \mathrm{C}$. To this solution was added a suspension of 1,8-diaminooctane( $90 \mathrm{mg}, 0.6 \mathrm{mmol})$ in DCM in a dropwise manner. The reaction mixture was monitored by TLC until completion. This mixture was then sonicated and washed with 3 batches of $10 \mathrm{~mL}$ of $0.1 \mathrm{M} \mathrm{NaOH}$ followed by washing with water and DCM over cintered funnel. The obtained solid was dried under vacuum to yield the final product in $65 \%$ yield. 
${ }^{1}$ H NMR (500 MHz, DMSO-d $)$ : $\delta$ (ppm)11.81 (H1, broad s, 2H), 7.79 (H8, broad s, 2H), $7.49(\mathrm{H} 2, \mathrm{~s}, 2 \mathrm{H}), 6.85(\mathrm{H} 5, \mathrm{~s}, 2 \mathrm{H}), 3.42$ (H6, 2H(with water of DMSO)), $3.02(\mathrm{H} 9, \mathrm{~m}$, 4H), 1.44 (H10, m, 4H), 1.21 (H11, H12, m, 8H). (See annexe for assignment).

${ }^{13}$ C NMR (126 MHz, DMSO-d 6 ): $\delta$ (ppm) 170.9, 135.4, 135.2, 117.5, 39.4, 39.2, 34.7, 29.0, 26.4 .

HR ESMS: m/z: $[\mathrm{M}+\mathrm{H}]^{+} \mathrm{Calcd}$ for $\mathrm{C}_{18} \mathrm{H}_{28} \mathrm{~N}_{6} \mathrm{O}_{2}: 361.2307$; found: $361.2350 ; \delta=0.6 \mathrm{ppm}$.

\subsubsection{Potentiometric titration experiments}

ImVal8 was dissolved in an excess of aqueous $\mathrm{HCl}(0.1 \mathrm{M})$ and then titrated with aqueous $\mathrm{NaOH}(0.1 \mathrm{M})$. The $\mathrm{pH}$ was recorded with a glass $\mathrm{pH}$ electrode and the data analysed with HYPERQUAD2008 and HYSS2009 to afford acidity constants. ${ }^{31}$
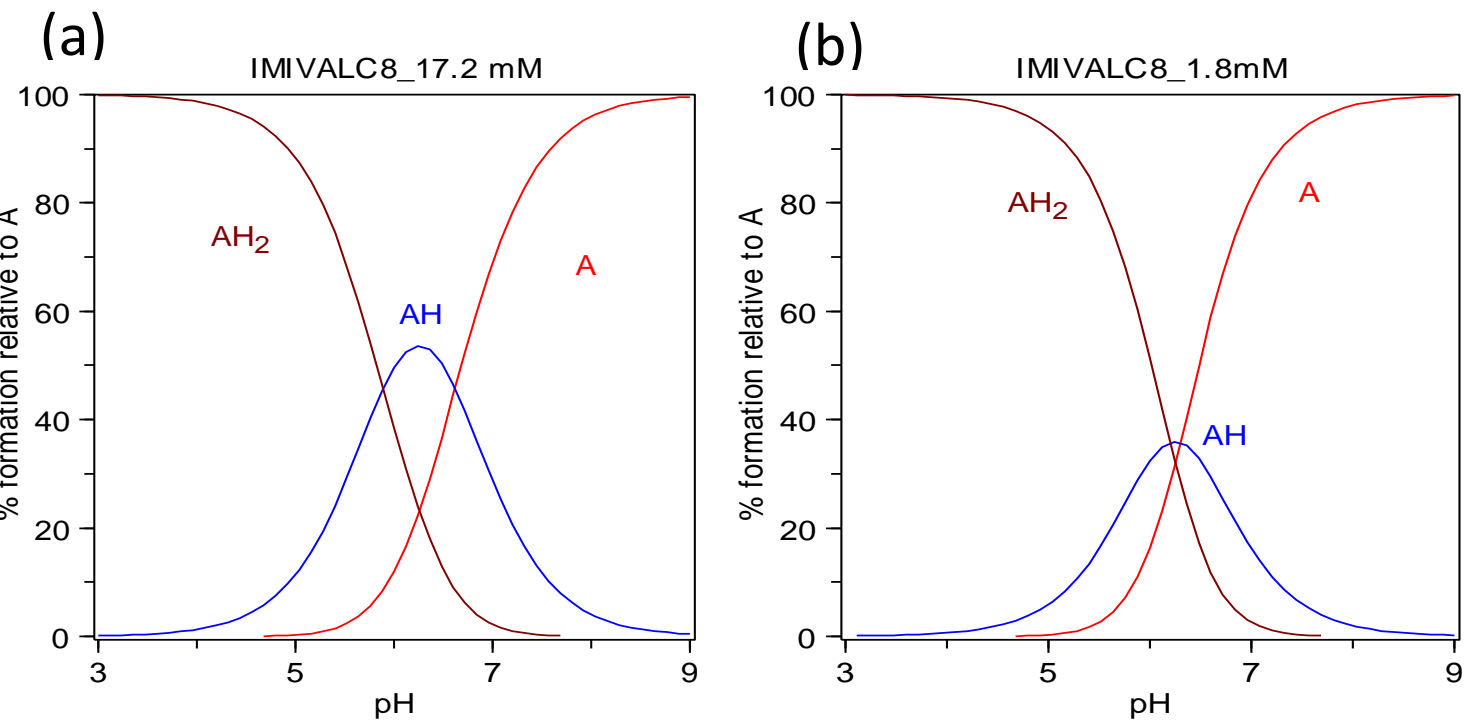

Figure ES 3.1: Relative abundance of different protonated and deprotonated species of ImVal8 with respect to $\mathrm{pH}$ at (a) $17.2 \mathrm{mM}$ (b) $1.8 \mathrm{mM}$. 


\subsubsection{UV kinetics experiment and Michaelis-Menten fitting}

Kinetics of hydrolysis was measured using a JASCO FP-8300 spectrometer by recording the absorbance at $400 \mathrm{~nm}$. The $800 \mu \mathrm{L}$ of a known concentration of catalyst was vortexed with $1 \mathrm{~mL}$ of $0.1 \mathrm{M}$ TRIS-HCl buffer and $100 \mu \mathrm{l}$ of it was added to $1 \mathrm{~cm}$ quartz cell containing $1.8 \mathrm{~mL}$ of buffer. To this $100 \mu \mathrm{l}$ of substrate dissolved in acetonitrile was added from a freshly prepared stock solution. The final concentration of ImVal8 under self-assembled state or $\mathbf{I m 8}$ used for hydrolysis was $17 \times 10^{-5} \mathrm{M}$. The catalysis experiments were generally done in triplicate. Similar procedure was followed for hydrolysis by non-aggregating concentrations of ImVal8 with final concentrations of $0.09 \mathrm{mM}, 0.045 \mathrm{mM}, 0.025 \mathrm{mM}$ at $\mathrm{pH}$ 6, $\mathrm{pH} 7$ and $\mathrm{pH} 8$ respectively. Graph pad prism version 6.05 software was used for data fitting. Undergiven is the Michaelis-Menten equation-

$$
\mathrm{V}_{0}=\mathrm{V}_{\max }\left\{[\text { Substrate }] /\left([\text { Substrate }]+\mathrm{K}_{\mathrm{M}}\right)\right\}
$$

$\mathbf{V}_{\mathbf{0}}$ is the velocity of the reaction.

$\mathbf{V}_{\max }$ is the maximal rate of the reaction.

[Substrate] is the concentration of the substrate.

$\mathbf{K}_{\mathbf{M}}$ is the Michaelis-Menten constant which shows the concentration of the substrate when the reaction velocity is equal to one half of the maximal velocity for the reaction.

\subsubsection{Circular dichroism}

CD experiments were performed using JASCO J-810 spectrometer for gels of ImVal8 prepared directly in $1 \mathrm{~mm}$ path length quartz cells. Measurements were performed at room temperature and spectra were recorded from $180 \mathrm{~nm}$ to $450 \mathrm{~nm}$ with $1.0 \mathrm{~nm}$ step and 1.0 $\mathrm{nm}$ bandwidth. 


\subsubsection{NMR solubility experiment}

All the NMR experiments were performed on Varian $500 \mathrm{MHz}$ spectrometer. For each data point freshly prepared samples were used by pouring hot solution of compound dissolved in buffered water into NMR tubes which were then allowed to stand for 24 hours. In this tube, another concentric NMR tube containing $50 \mathrm{mM}$ hydroquinone dissolved in $\mathrm{D}_{2} \mathrm{O}$ was introduced as an internal reference. NMR spectra in water were recorded at different concentrations of ImVal8 ranging from completely soluble to gel state. The peak of water was presaturated to obtain the spectra. The solubility constants at different $\mathrm{pH}$ values were obtained by plotting the relative intergral of a chosen peak in the spectra against the concentration of ImVal8 for different concentration.

\subsubsection{ANS experiment}

From a stock solution of concentration $0.8 \mathrm{mM}$ ANS in $\mathrm{H}_{2} \mathrm{O}, 100 \mu \mathrm{L}$ solution was introduced in the $0.8 \mathrm{~mL}$ of the vortexed gels at different $\mathrm{pH}$ values. An aliquot of $15 \mu \mathrm{L}$ from this was diluted to $215 \mu \mathrm{L}$ in the TRIS-HCl buffer of respective $\mathrm{pH}$ and the fluorescence spectrum was recorded.

\subsubsection{Transmission electron microscopy}

TEM micrographs were obtained using a JEOL 2100 transmission electron microscope.

The TEM samples were prepared by directly applying gels at MGC on carbon coated TEM grid. A $5 \mu \mathrm{L}$ droplet of purified water was used to remove the salts and the excess solution was wicked off using filter paper. The samples were immediately stained using $5 \mu \mathrm{l}$ droplet of $1 \%$ phosphotungstic acid and was allowed to stand for $5 \mathrm{~min}$. The excess solution was removed using a filter paper. The grids were then left under covered petri dish to dry before obtaining images. 


\subsubsection{HPLC analysis for $L$ - and $D$-phenylalanine methyl ester catalysis}

$400 \mu \mathrm{L}$ of gels and solutions of ImVal8 and $\mathbf{I m 8}$ respectively, were prepared in TRIS$\mathrm{HCl}$ buffer at $\mathrm{pH} 7$ and were allowed to stand for 24 hours. The gels were then vortexed in which $50 \mu \mathrm{L}$ of $L$ - or $D$-phenylalnine methyl ester hydrochloride of respective concentrations prepared in the same buffer were introduced. The reaction vessels were then analysed by CHIRAL OD-H HPLC coloumn using a gradient of 5\% to $95 \%$ acetonitrile (containing 1\% TFA) w.r.t to water in 45 minutes.
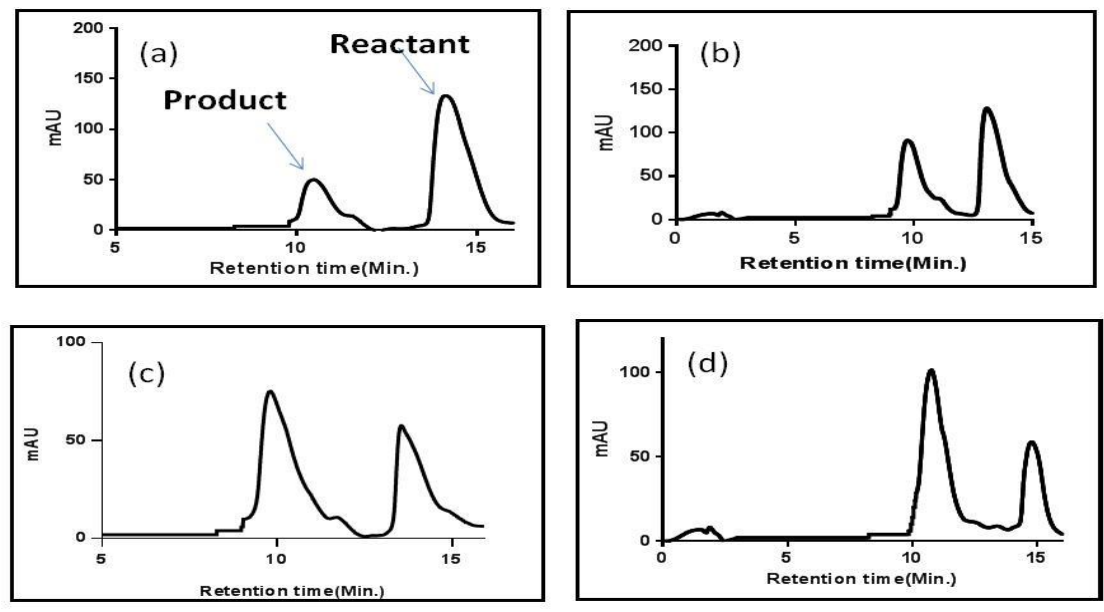

Figure ES 3.2: HPLC chromatogram of the hydrolysis of phenylalanine methyl ester hydrochloride [12.3mM] using ImVal8 [5.6mM] for (a) 8 hours (b) 30 hours (c) 60 hours (d) 72 hours.

The peak at 13.8 minutes corresponds to phenylalanine methyl ester and the peak at 10 minutes corresponds to the product formed after hydrolysis. 

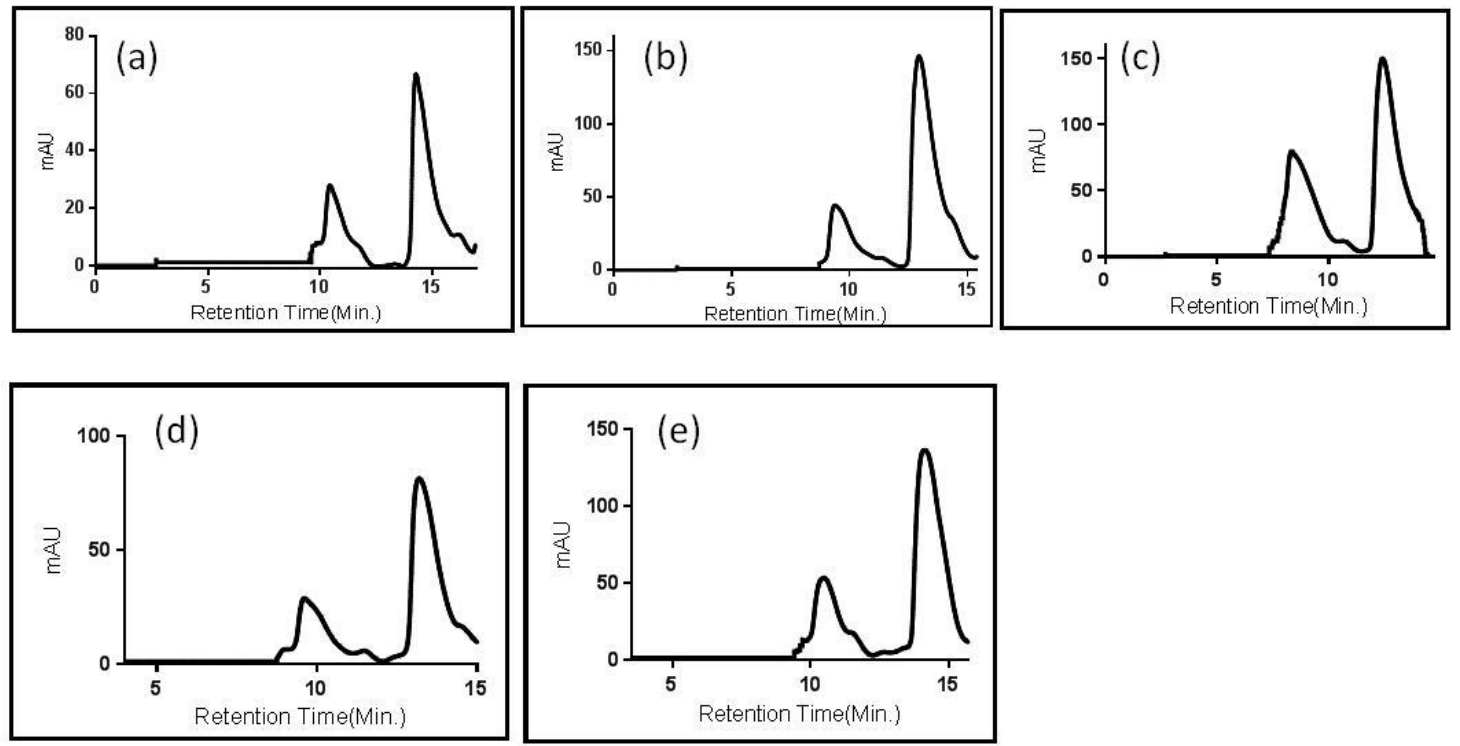

Figure ES 3.3: HPLC chromatogram of the hydrolysis of different concentrations of $L$-phenylalanine methyl ester using ImVal8 [5.7 mM] for 12 hours (a) $4.2 \mathrm{mM}$ (b) $8.2 \mathrm{mM}$ (c) $12.3 \mathrm{mM}$ (d) $16.5 \mathrm{mM}$ (e) $20.7 \mathrm{mM}$.

\subsubsection{Fourier transform infrared spectroscopy}

The gels at MGC were washed with water to remove salts and non-aggregating parts and then lyophilized. The resultant dry solid was diluted with $200-300 \mathrm{mg}$ of $\mathrm{KBr}$ in an agate mortar and then was compressed at 10 ton c.a. 2-3 minutes to make pellets. JASCO FTIR6200 spectrometer was used to obtain the IR spectra. 


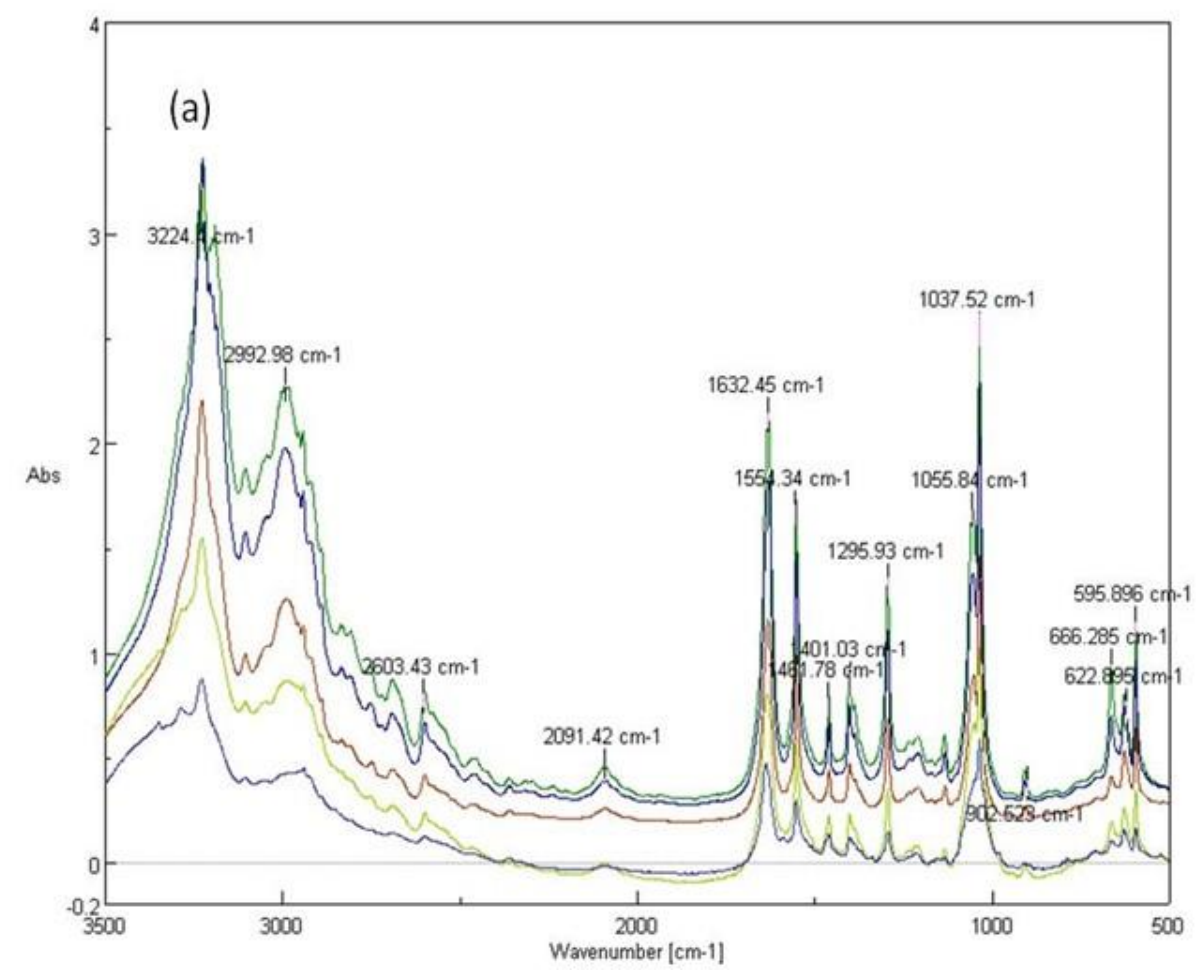

Figure ES 3.4: (a) IR spectra for gels of ImVal8 at different $\mathrm{pH}$ values.

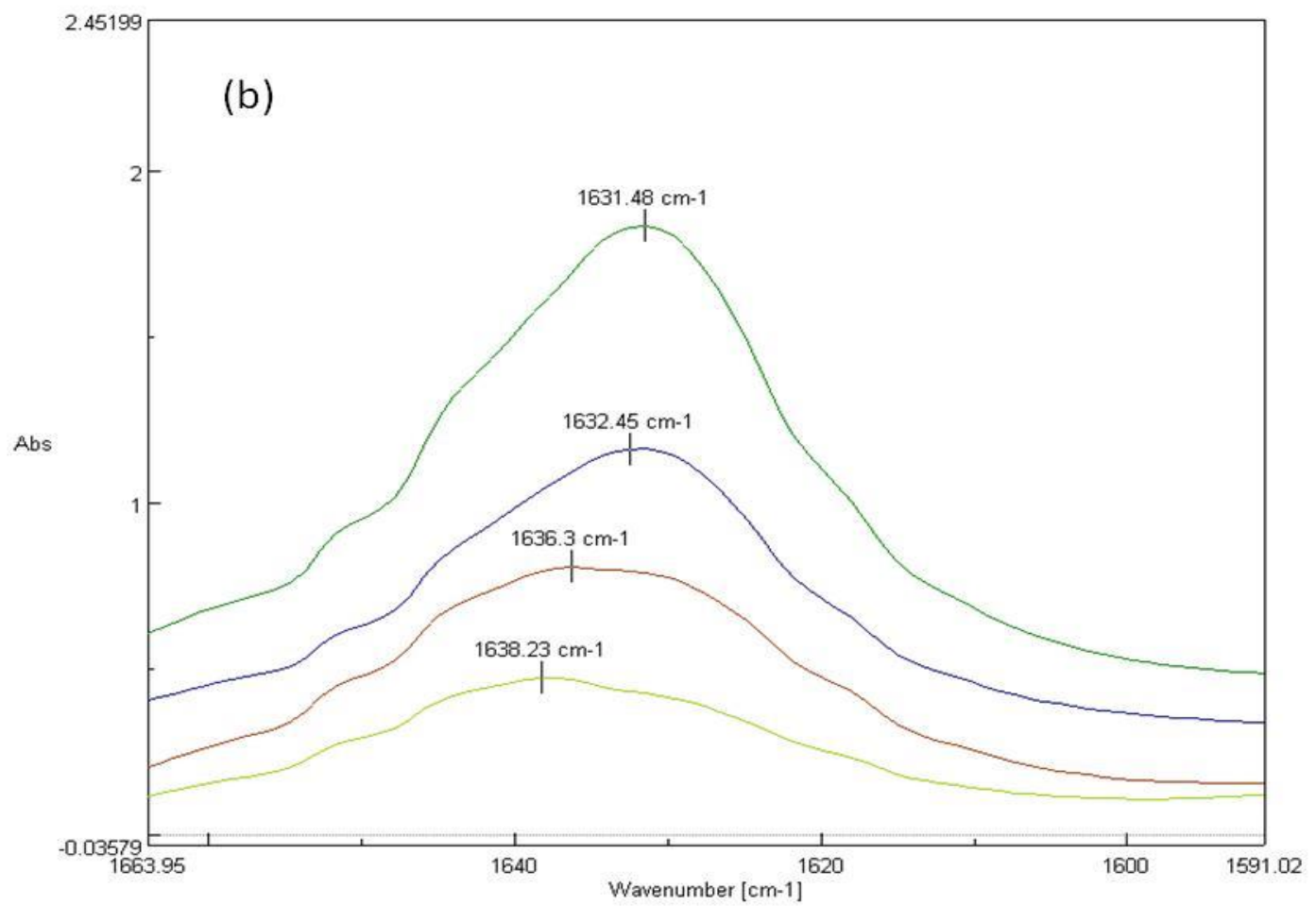

Figure ES 3.4: (b) Expanded amide I band region for $\beta$ sheet: $\mathrm{pH} 8$ (light green), $\mathrm{pH} 7.5$ (red), $\mathrm{pH} 7$ (blue), pH 6 (dark green). 


\subsubsection{Other NMR experiments}

\section{a. Temperature dependent NMR experiment}

To establish the retainment of molecules in aggregated state upon dilution, as used for catalysis, a temperature dependent NMR experiment was performed. An aliquot from the gel of ImVal8 was diluted to $0.17 \mathrm{mM}$ following the same method as used in catalysis. This sample was transferred to an NMR tube containing a concentric tube with an internal standard, hydroquinone $(50 \mathrm{mM})$. The tube was subjected to rise in temperature and respective ${ }^{1} \mathrm{H}$ NMR integrals were recorded. With subsequent rise in temperature the relative integral of ImVal8 rose w.r.t the fixed integral of hydroquinone (set as 100). Thus it can be deduced that the molecules which were in aggregated state (NMR invisible), on application of heat disintegrated and started getting solubilised into the solution (NMR visible).

\section{b. Comparison of amount of molecules in solution for gel and diluted aliquot of gel by NMR}

A gel of ImVal8 was prepared in an NMR tube with an internal standard of hydroquinone (50 mM). The concentration of molecules in solution was found to be $2.3 \mathrm{mM}$. Subsequently an aliquot of gel was diluted to $0.17 \mathrm{mM}$ and the concentration of ImVal8 in solution was found to be $0.08 \mathrm{mM}$. The ratio of molecules in solution for gel and aliquot is 1.17 which confirms that $\mathbf{I m V a l 8}$ still retains most of its aggregate form upon dilution. 


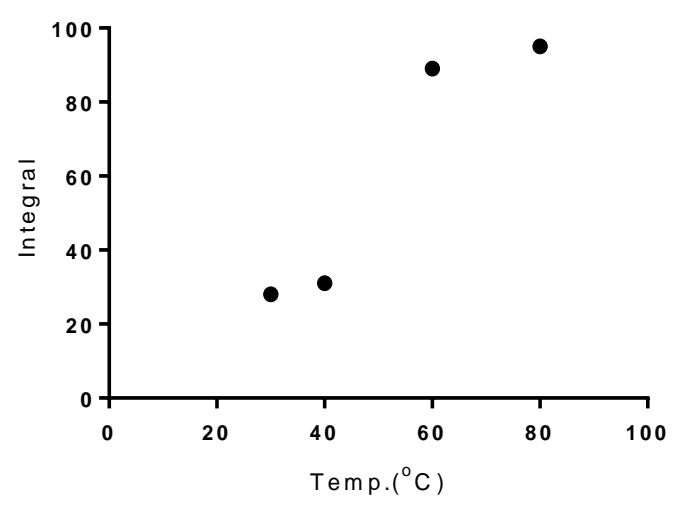

Figure ES 3.5: Integral of a selected peak of ImVal8 with respect to the fixed integral of hydroquinone versus temperature. $\left(500 \mathrm{mMHz}{ }^{1} \mathrm{H} \mathrm{NMR}\right)$

\subsection{References}

1. M. Raynal, P. Ballester, A. Vidal-Ferran, P. W. N. M. van Leeuwen, Chem. Soc. Rev., 2014, 43, 1660.

2. M. Raynal, P. Ballester, A. Vidal-Ferran, P. W. N. M. van Leeuwen, Chem. Soc. Rev., 2014, 43,1734.

3. D. Zaramella, P. Scrimin, L. J. Prins, J. Am. Chem. Soc., 2012, 134, 8396

4. G. Pieters, L. J. Prins, New J. Chem., 2012, 36, 1931.

5. G. Chadha, Y. Zhao, Org. Biomol. Chem., 2013, 11, 6849.

6. G. Chadha, Y. Zhao, Chem. Commun., 2014, 50, 2718.

7. M. O. Guler, S. I. Stupp, J. Am. Chem. Soc., 2007, 129, 12082.

8. Z. P. Huang, S. W. Guan, Y. G. Wang, G. N. Shi, L. N. Cao, Y. Z. Gao, Z. Y. Dong, J. Y. Xu, Q. Luo, J. Q. Liu, J. Mater. Chem. B, 2013, 1, 2297.

9. C. Zhang, X. Xue, Q. Luo, Y. Li, K. Yang, X. Zhuang, Y. Jiang, J. Zhang, J. Liu, G. Zou, X.-J. Liang, ACS Nano, 2014, 8, 11715. 
10. C. M. Rufo, Y. S. Moroz, O. V. Moroz, J. Stohr, T. A. Smith, X. Z.Hu, W. F. De Grado, I. V. Korendovych, Nat. Chem., 2014, 6, 303.

11. K. S. Broo, H. Nilsson, J. Nilsson, A. Flodberg, L Baltzer, J. Am. Chem. Soc., 1998, 120, 4063.

12. C. Guarise, F. Manea, G. Zuapa, L. Pasquato, L. J. Prins, P. Scrimin, J. Pept. Sci., 2008, 121,174.

13. B. A. Wallace, J. G. Lees, A. J. W. Orry, A. Lobley and R. W. Janes, Prot. Sci., 2003, 12, 875 .

14. E .T Pashuck, H. Cui, S. I. Stupp, J. Am. Chem. Soc., 2010, 132, 6041.

15. U. Anand, M. Mukherjee, Langmuir, 2013, 29, 2713.

16. S. M. Kelly, N. C. Price, Curr.Prot. Pept. Sci., 2000, 1, 349.

17. E. Schönbrumm, S. Eschenburg, K. Luger, W. Kabsch, N. Amrhein, Proc. Natl. Acad. Sci., USA, 2000, 97, 6345.

18. G. Chadha, Y. Zhao, J. Coll. Inter F. Sci., 2013, 390, 151.

19. O. Carny, E. Gazit, FASEB J., 2005, 19, 1051.

20. J. Becerril, M. Bolte, M.I. Burguete, F. Galindo, E. García-España, S.V. Luis, J. F. Miravet, J. Am. Chem. Soc., 2003, 125, 6677.

21. K.W. Kwon, M. J. Park, J. Hwang, K. Char, Polym. J., 2001, 33, 404.

22. M. M. Smith, W. Edwards, D. K. Smith, Chem. Sci., 2013, 4, 671.

23. J. R. Kanicky, D. O. Shah, Langmuir, 2003, 19, 2034.

24. D. Matulis, V.A. Bloomfield, Biophys. Chem., 2001, 93, 37.

25. M. Solsona, B. Escuder, J. F. Miravet, Chem. Mater., 2015, 27, 3358.

26. D. J. Adams, L. M. Mullen, M. Berta, L. Chen, W. J. Frith, Soft Matter, 2010, 6, 1971. 
27. C. Tang, A. M. Smith, R. F. Collins, R. V. Ulijn, A. Saiani, Langmuir, 2009, $25,9447$.

28. C. Tang, R. V. Ulijn, A. Saiani, Langmuir, 2011, 27, 14438.

29. M. Wallace, J. A. Iggo, D. J. Adams, Soft Matter, 2015, 11, 7739.

30. Michaelis-Menten curve fittting was performed using GraphPad Prism version 6.05 for Windows, GraphPad Software, La Jolla California USA, www.graphpad.com

31. L. Alderighi, P. Gans, A. Ienco, D. Peters, A. Sabatini, A. Vacca, Coord. Chem. Rev., 1999, 184, 311. 


\section{Chapter 4}

\section{Tandem reactions in self-sorted catalytic molecular hydrogels}




\subsection{Introduction}

Tandem catalysis is receiving increased attention in the last years due to process simplicity, economy of time and energy and waste reduction among other practical advantages associated to one-pot procedures. In particular, orthogonal tandem catalysis is a one-pot reaction in which sequential catalytic processes occur through two or more functionally distinct and non-interfering catalytic cycles. ${ }^{1}$ Excellent examples are found in multi-enzymatic complexes present in biosynthetic pathways in which a substrate is sequentially transformed towards a product in an effective and selective manner. ${ }^{2}$ Multifunctional catalysts have been prepared based on the spatial separation of catalytic groups in nanostructured materials such as star polymers, silicas, zeolites and MOFs among others requiring quite often tedious preparation procedures. ${ }^{3-7}$ Some of these systems are based on the controlled organization of incompatible acidic and basic catalytic groups into non-interacting locations. In this context, self-assembly of discrete functional components into multifunctional self-organized materials by bottom-up noncovalent synthesis could represent a powerful strategy incorporating both functional diversity as well as synthetic economy. Catalytic supramolecular nanomaterials can be prepared by self-assembly of tailor-made low molecular weight functional building blocks. ${ }^{8,9}$ In this respect, several examples of catalytic molecular gels have been reported in which catalytic activity has emerged as a consequence of the supramolecular organization of functional groups. ${ }^{10-14}$ These reported examples were based on a single catalytic component. However, supramolecular tandem catalysis often requires the spatial separation of two incompatible catalytic moieties. One way to achieve spatial separation by self-assembly is self-sorting, a relevant phenomenon in complex supramolecular systems that can be defined as a high fidelity recognition between molecules based on non-covalent interactions and structural complementarity. ${ }^{15}$ 
(a)

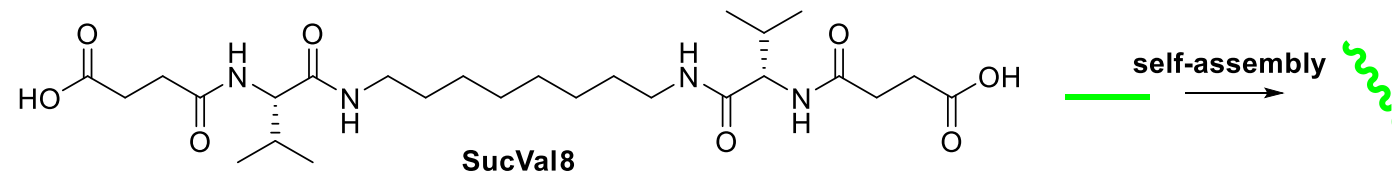<smiles>CCCCCCCCCCCCNC(=O)[C@H](NC(=O)[C@@H]1CCCN1)C(C)C</smiles><smiles>CC(C)[C@H](NC(=O)C1CCCN1)C(=O)NCCCCCCCNC(=O)[C@@H](NC(=O)[C@@H]1CCCN1)C(C)C</smiles>

(b)

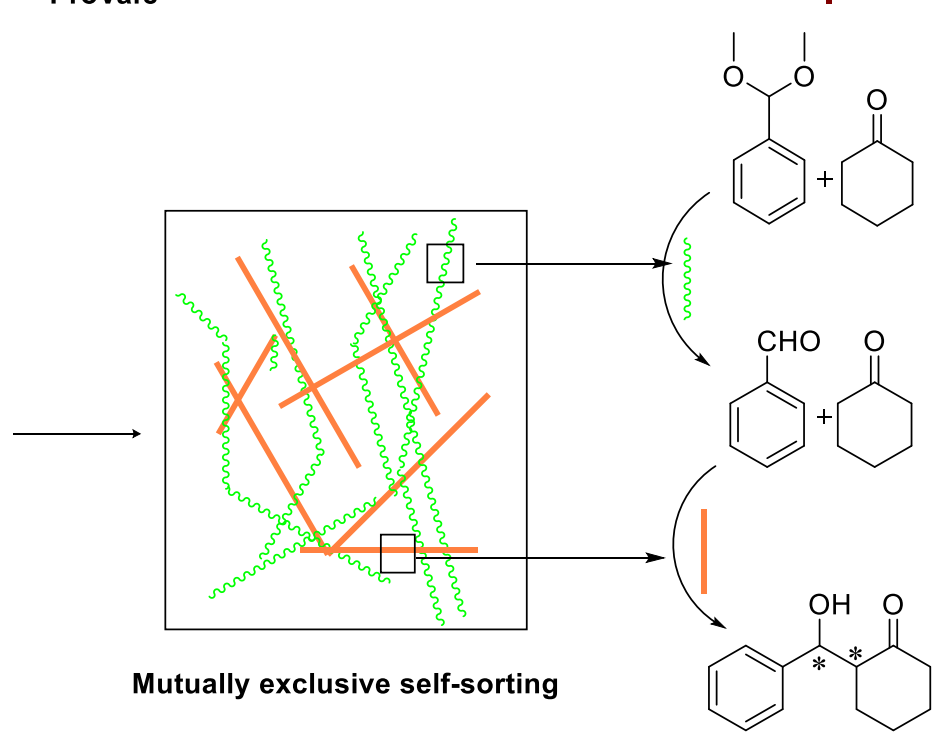

(c)
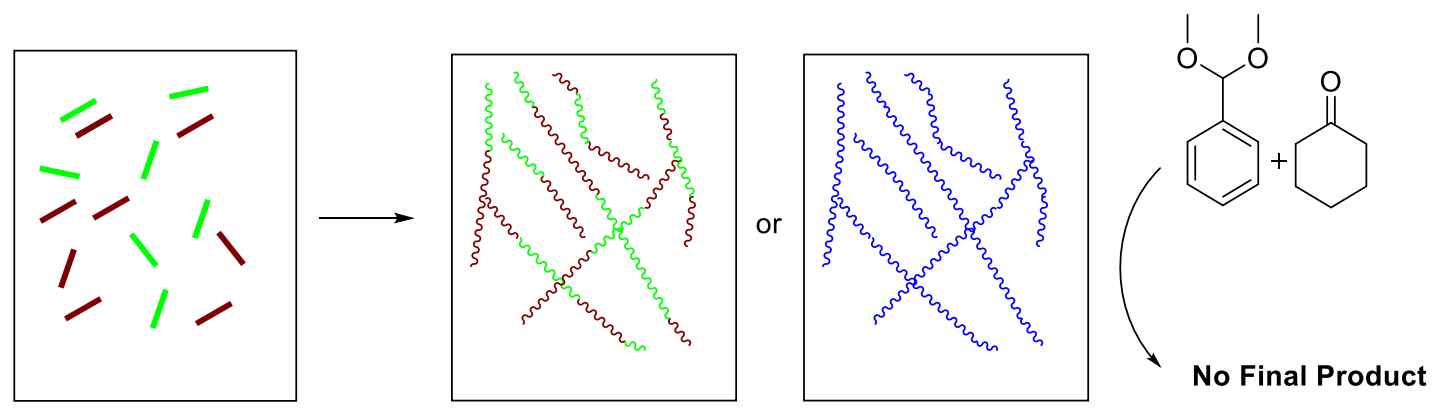

Disruptive co-assembly

Scheme 4.1. (a) Structures of hydrogelators SucVal8, ProValDoc and ProVal8. (b) Mutually exclusive self-sorting of structurally different hydrogelators and reaction scheme (c) Disruptive co-assembly of structurally similar hydrogelators with mutually incompatible groups (two possible scenarios: when the fibres form random/ordered block co-assembly (green-orange) or a completely new type of fibre formation(blue) based on the degree of interaction and recognition amongst themselves. 
Seminal work in this field was reported by Menger et al. showing self-sorting of fibres and microcrystallites based upon side chain differences of related compounds as well as by van Esch et al. who reported orthogonal self-assembly of surfactants and hydrogelators into co-existing fibres and vesicles. ${ }^{16-18}$ Since then, several groups have studied this phenomenon in depth in order to prepare spatially and temporally resolved multicomponent nanoscale materials. ${ }^{19-23}$

In this chapter we present for the first time the use of two orthogonally self-assembled catalytic molecular hydrogel networks for performing one-pot tandem catalysis (Scheme 4.1b). In contrast, an analogous co-assembled network is shown to be catalytically inactive (Scheme 4.1c). For this purpose, we selected three low-molecular weight hydrogelators with different catalytic groups and different self-assembly motives, which are previously described in our group (Scheme 4.1a). Compounds SucVal8 and ProVal8 present a bolaamphiphilic structure of similar molecular dimensions bearing carboxyl groups and $L$-proline residues respectively as end-groups ${ }^{24,} 25$ whereas compound ProValDoc is an amphiphilic dipeptide with an $L$-proline residue at the N-terminus. ${ }^{11}$

SucVal8 was chosen for the deacetalisation reaction since the use of Brønsted acids for deprotection of acetal groups is well known. ${ }^{26}$ ProValDoc and ProVal8 were chosen as the proline group is well known as a catalyst for the aldol reaction and these hydrogelators have been used in the past for the same by our group. ${ }^{10-14,24,25,27}$

\subsection{Results and discussion}

\subsubsection{Synthesis}

The three hydrogelators- ProValDoc, ProVal8 and SucVal8 were synthesized as shown in Scheme 4.1. The backbone 6 for ProVal8 and SucVal8 was synthesized using the 
same procedure as is Chapter 3. The mechanism for last step in formation of SucVal8 using 6 and succinic anhydride is shown in Scheme 4.3a. The mechanism for formation amide bond between activated ester and primary amine is shown in Scheme $\mathbf{4 . 3 b}$ and that for t-BOC deprotection is depicted in Scheme 4.3c.

(A)<smiles>CC(C)C(N)C(=O)NCCCNC(=O)C(N)C(C)C</smiles><smiles>CC(C)[C@H](NC(=O)CCC(=O)O)C(=O)NCCCCCCCCNC(=O)[C@@H](NC(=O)CCC(=O)O)C(C)C</smiles>

(B)<smiles>CC(C)C(N)C(=O)NCC1CCC(NC(=O)[C@@H](N)C(C)C)C1</smiles>

8<smiles>[Y]C(C)C</smiles><smiles>[10BH]</smiles><smiles>CC(=O)N1CCC[C@H]1C(=O)N[C@H](C(=O)NCCCCCCCCNC(=O)[C@H](NC(=O)C1CCCN1C(=O)OC1CC1)C(C)C)C(C)C</smiles>

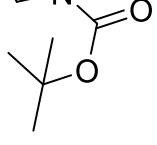
c<smiles>CC(C)[C@H](NC(=O)C1CCCN1)C(=O)NCCCCCCCNC(=O)[C@@H](NC(=O)[C@H]1CCCN1)C(C)C</smiles>

Scheme 4.1: Reagents and conditions (A) THF, reflux, overnight, $90 \%$ (B) (b) DME, r.t. (24 hr) followed by heating for $4 \mathrm{hr}$ at $40{ }^{\circ} \mathrm{C}$ (c) DCM, $15 \mathrm{~mL}$ TFA, r.t., $2 \mathrm{hr}$. 

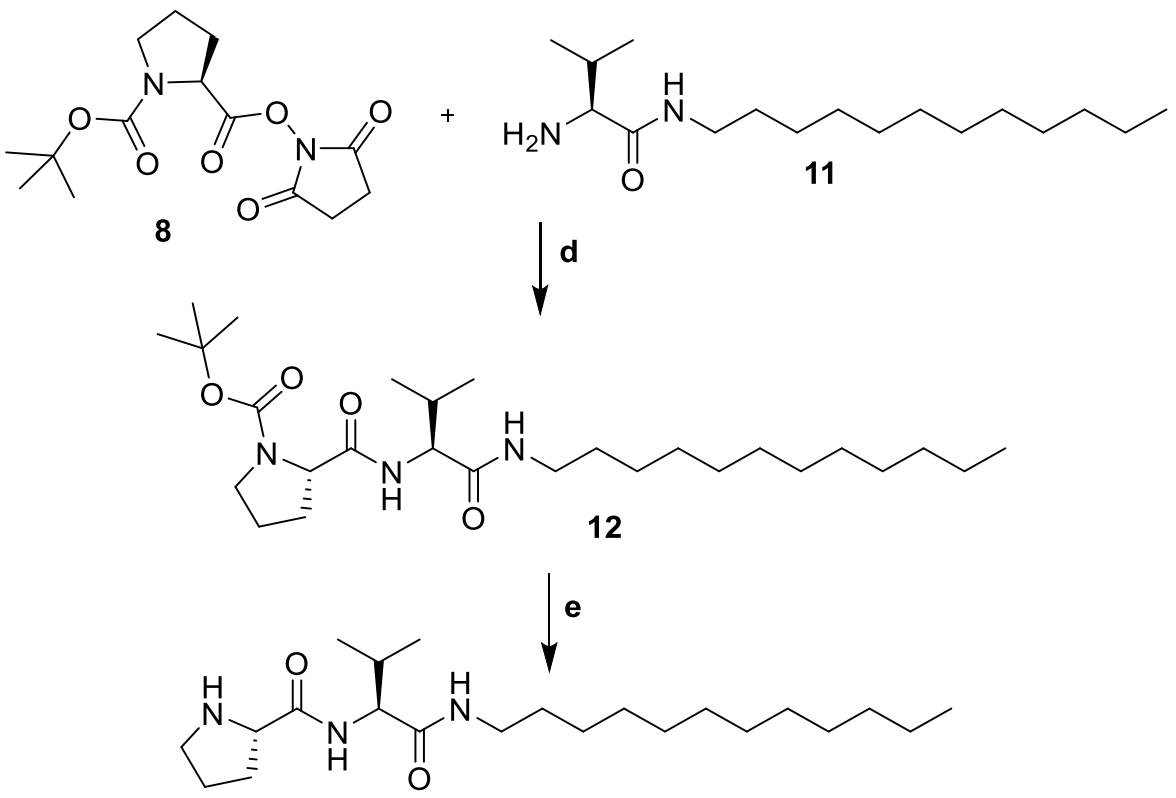

ProValDoc

Scheme 4.2: Reagents and conditions (d): DME, r.t. ( $24 \mathrm{hr}$ ) followed by heating for $4 \mathrm{hr}$ at $40^{\circ} \mathrm{C}$. (e): DCM, $15 \mathrm{~mL}$ TFA, r.t., $2 \mathrm{hr}$.

(a)

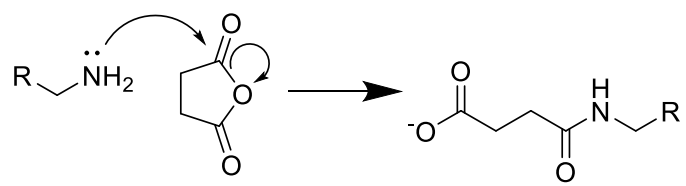

(b)

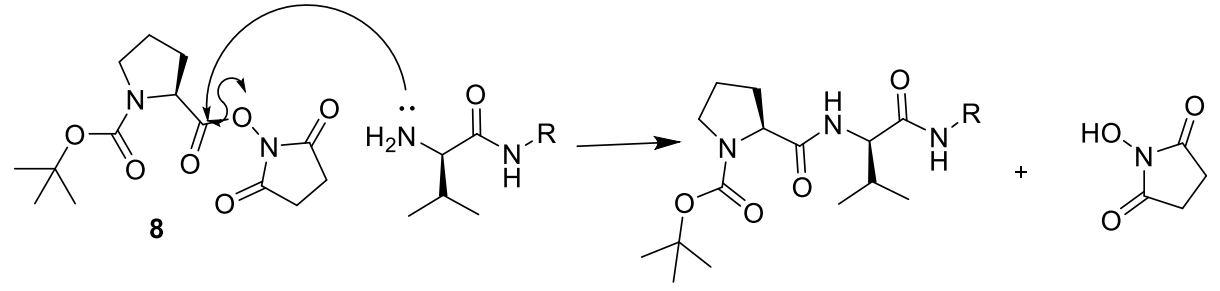

(c)

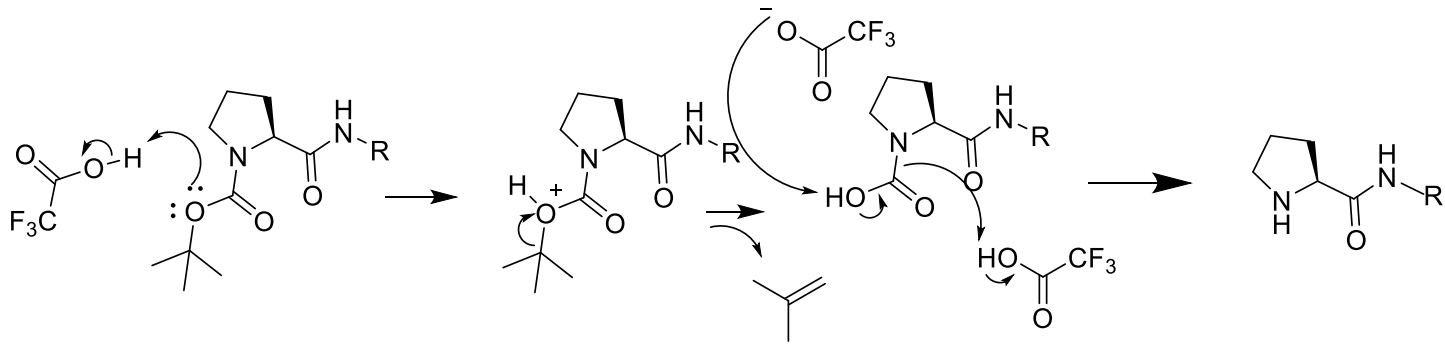

Scheme 4.3: Reaction mechanisms for formation of (a) amide using a primary amine and succinic anhydride (b) amide between an activated acid and primary amine (c) t-BOC deprotection by TFA. 


\subsubsection{Structural and morphological analysis}

\subsubsection{Gel formation}

All the gels were prepared by gentle heating to completely dissolve the compounds in water followed by sonication for $1 \mathrm{~min}$ and left to stand overnight at $25^{\circ} \mathrm{C}$. The hydrogels of ProValDoc on the one hand are white turbid looking gels with minimum gel concentration (MGC) of $5.7 \mathrm{mM}$ and temperature for the gel to solution transition, $\mathrm{T}_{\text {gel }}=40$ ${ }^{\circ} \mathrm{C}$. On the other hand, SucVal8 is a bolaamphiphilic hydrogelator with carboxylic acid groups at the two ends able to form transparent self-standing hydrogels showing a MGC of $7 \mathrm{mM}$ with $\mathrm{T}_{\text {gel }}=70{ }^{\circ} \mathrm{C} .{ }^{25}$ The mixed gel systems of (SucVal8+ProValDoc) and (SucVal8+ProVal8) were prepared by method described above using gelators at their respective MGC in the same vial. The mixed systems of SucVal8+ProValDoc formed a transparent white gel and SucVal8+ProVal8 formed a weak turbid white gel (Figure 4.2).

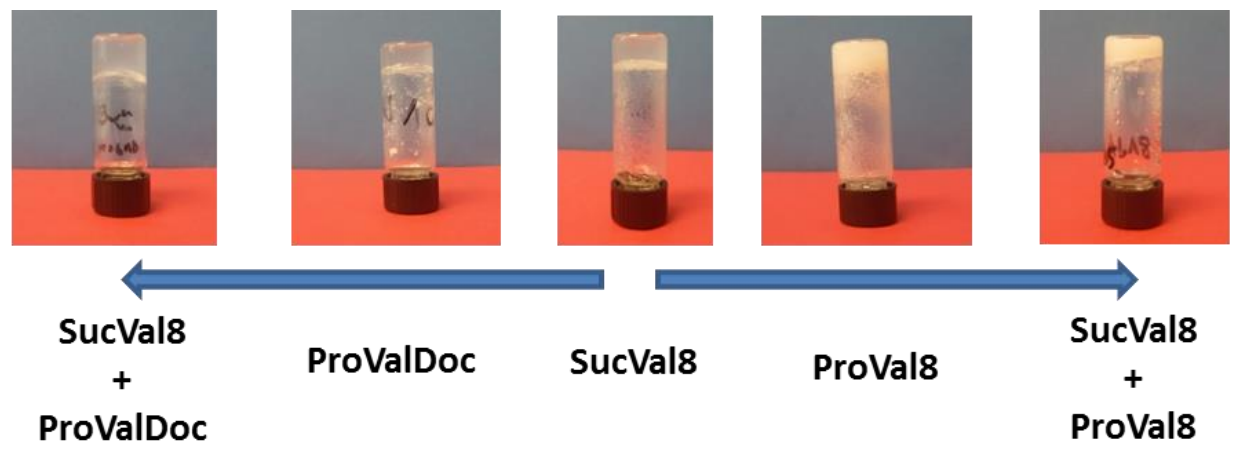

Figure 4.2. Macroscopic aspect of the different gels at their respective minimum gel concentration (MGC). 


\subsubsection{Atomic force microscopy and transmission electron microscopy studies}

After macroscopic confirmation of the formation of gel by mixing the three gelators we went on to check if the structural similarity/difference does give rise to a co-assembled or orthogonal network respectively. We implied AFM and TEM microscopic techniques to see the fibres present in the systems.

As seen from the AFM and TEM images, ProValDoc forms fibres around 40-50 nm in width and several micrometers long while ProVal8 also forms similar large crystalline fibres with a width varying from $40-50 \mathrm{~nm}$. On the other hand SucVal8 forms completely distinct twisted fibres 8-10 $\mathrm{nm}$ in width and several micrometers in length (Figure 4.3).

However, the TEM images of the mixed gel SucVal8+ProVal8 revealed a homogeneous system of only one kind of fibres with a width of 20-30 nm (Figure 4.3). On the other hand, AFM of the mixture showed the presence of twisted thin fibrils. A closer analysis of the AFM images revealed that the fibrils in the mixture (SucVal8 + ProVal8) had a pitch value of $70 \mathrm{~nm}$, which is almost twice the value of the pure SucVal8 (45 nm) (Figure 4.4). Therefore, fibres of the mixture were different from fibres constituting the individual gels, alluding towards the co-assembly of the two molecules to form a different kind of homogenous network.

The AFM and TEM images of the SucVal8+ProValDoc gel revealed the presence of two different kinds of fibres (Figure 4.3). The larger more crystalline fibres were attributed to

ProValDoc whereas the coexisting twisted thinner fibres were assigned to SucVal8, based on their similarity with the fibre morphologies observed for the single component gels. The height and width profile are provided in the ES (Figure ES 4.2) which show presence of two different kinds of fibres with profiles similar to the individual gelators. 

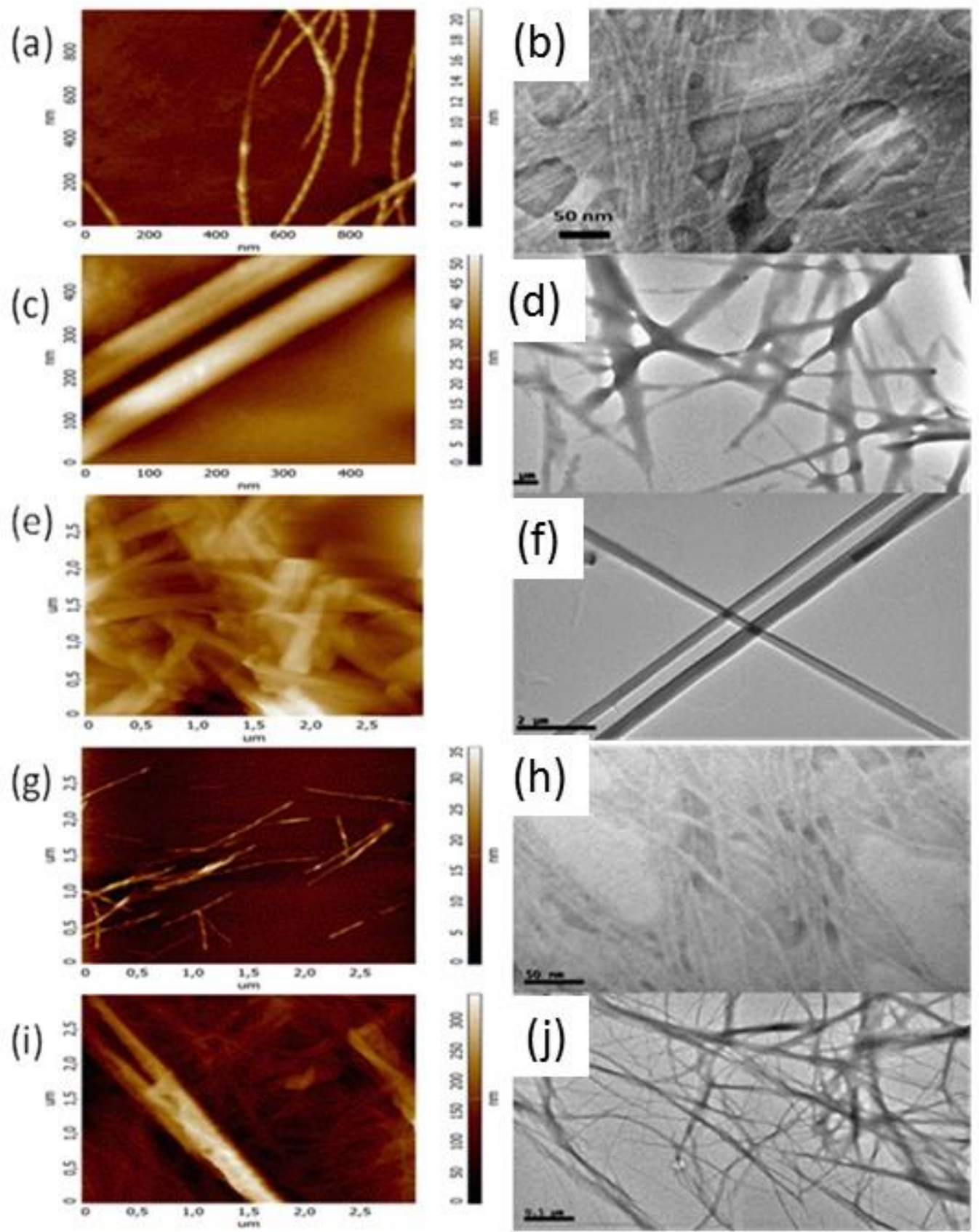

Figure 4.3: AFM images of hydrogels of (a) SucVal8 (c) ProValDoc (e) ProVal8 (g) ProVal8+SucVal8 (i) ProValDoc+SucVal8. TEM images of hydrogels of (b) SucVal8 (d) ProValDoc (f) ProVal8 (h) ProVal8+SucVal8 (j) ProValDoc+SucVal8. 
(a)
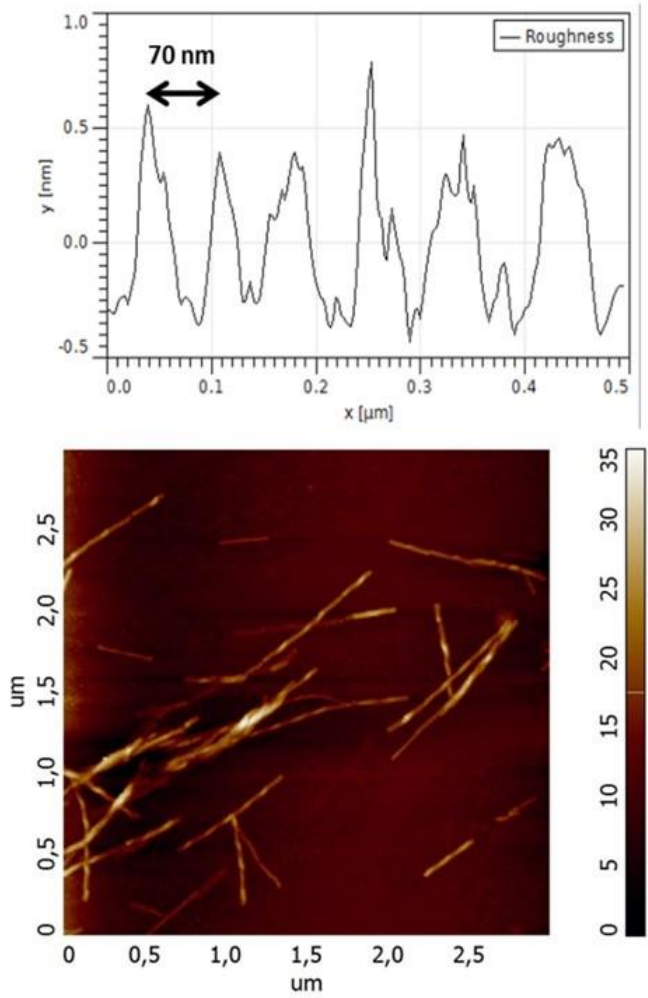

ProVal8+SucVal8 (b) SucVal8
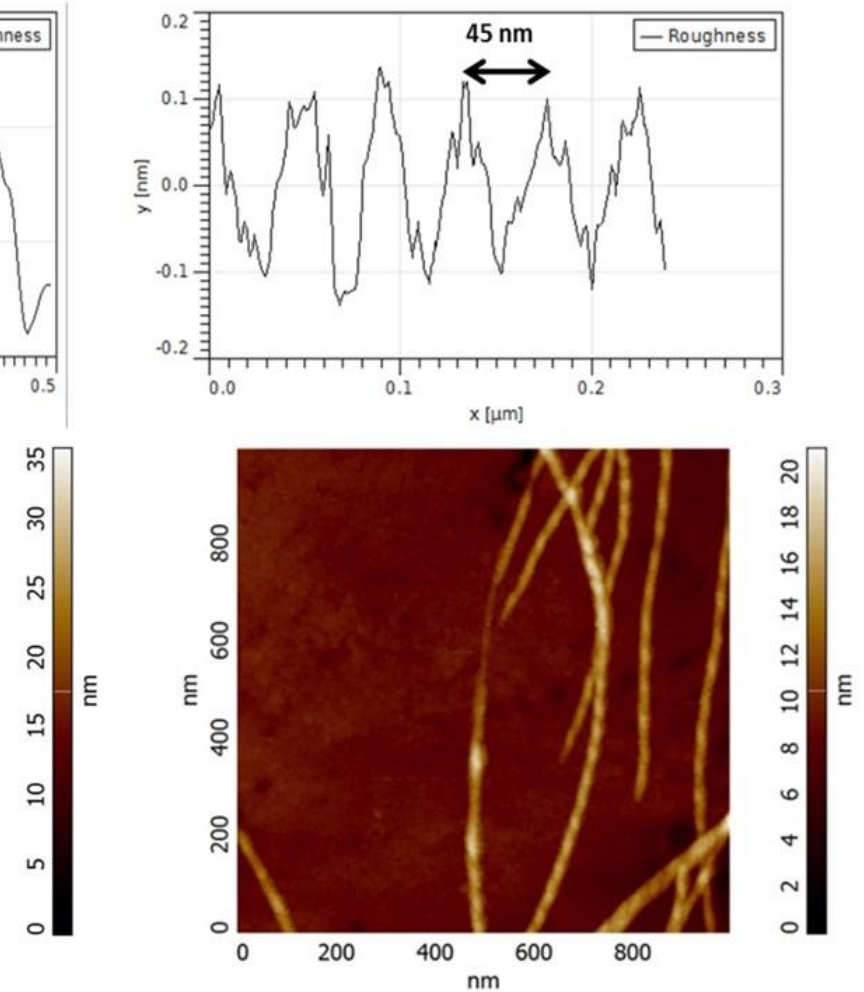

SucVal8

Figure 4.4: Pitch and AFM images of (a) ProVal8+SucVal8 (b) SucVal8.

\subsubsection{Wide angle $X$-ray diffraction analysis}

To further confirm the orthogonal self-assembly of the catalytic network components we performed wide angle powder X-ray diffraction (WAXD) of the xerogels of the two different gelators at their MGC and of their mixture. The WAXD data for SucVal8 reflected an amorphous structure with no crystallinity (Figure 4.5a) whereas that for ProValDoc alone showed more crystallinity which can be attributed to one of the previously described polymorphs of this compound, the most thermostable one (Figure 4.5b) ${ }^{27}$ Interestingly, the WAXD of the mixture showed an overlap of the patterns of amorphous SucVal8 and a different polymorph of ProValDoc, which is dominant when gels are formed by $\mathrm{pH}$ change from acidic solutions (Figure 4.5c and 4.5d). Even though gels of this compound 
alone and in the mixture of two hydrogelators were both prepared by heating followed by sonication, we obtained different polymorphs. This result suggests, as already mentioned in our previous report, a seeding effect caused by a small amount of protonated ProValDoc crystals which could be formed in the presence of the acidic counterpart. Nevertheless, as we reported before, all the polymorphs are catalytically active with only a slight differences on the respective reaction rates. ${ }^{27}$ While the WAXD of the xerogel of ProVal8+SucVal8 mixture showed a different pattern of packing than the individual hydrogelators falling in line with the new kind of fibres as seen from TEM and AFM images, further confirming the co-assembly between these two hydrogelators (Figure 4.5a, e, f).


Figure 4.5: WAXD patterns of the xerogels of (a) SucVal8 (b) ProValDoc and (c) SucVal8+ProValDoc. (d) ProValDoc gel formed by $\mathrm{pH}$ change (e) ProVal8 (f) SucVal8+ProVal8 


\subsubsection{4. $T_{\text {gel }}$ experiments}

Proline and acid groups are mutually incompatible. So we suspected them to react and form salt bridges in case of co-assembly when they are in close vicinity to each other while be spatially separated in the case of orthogonal assembly. This should have some effect on over $T_{\text {gel }}$ of the system and also the mechanical strength. So subsequent $T_{\text {gel }}$ experiments were performed which are reported below.

For the $\mathrm{T}_{\text {gel }}$ experiments the gels were slowly heated and temperature at which the solvent started seeping out was recorded as the $\mathrm{T}_{\text {gel }}$. As reported earlier we know that SucVal8 forms thermally more stable gels than ProValDoc. So we formed different gels by mixing the two gelators by varying the concentration of ProValDoc to see if it induces an effect on the overall thermal stability of the gelator (Figure 4.6).

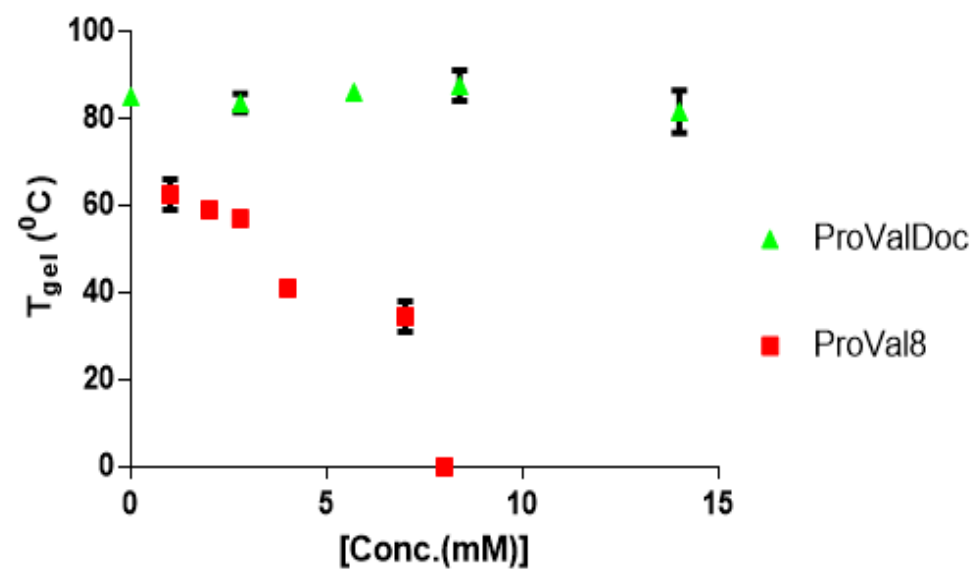

Figure 4.6: $\mathrm{T}_{\text {gel }}$ of the different gels of SucVal8 + ProValDoc and SucVal8 + ProVal8 by varying the concentration of proline component. SucVal8 was present in the mixtures at its MGC.

The gels of the mixture proved to be thermally slightly more $\left(5^{\circ} \mathrm{C}\right.$ higher but within the experimental error range) stable than SucVal8, probably due to the higher density of 
fibres in the system owing to the presence of two different self-sorted fibre networks, making the gel stiffer and more stable. Since the $T_{\text {gel }}$ of the mixed system (SucVal8+ProValDoc) did not vary much from the gelator with higher $\mathrm{T}_{\text {gel }}$ (SucVal8) we could say that the fibres were self-sorted and did not interfere with the fibre formation of one another. ${ }^{21,28}$ For the other mixed system of ProVal8+SucVal8 already had a weaker visual appearance than SucVal8 alone. This was further confirmed by $\mathrm{T}_{\text {gel }}$ experiments by varying the concentration of ProVal8 in the mixture. With increase in the concentration of ProVal8 a decrease in $T_{\text {gel }}$ was observed. On increasing the concentration of ProVal8 above $7 \mathrm{mM}$ in the mixture we could no longer obtain selfstanding gels but only suspended aggregates. This alludes that the two structurally similar gelators due to the reaction between proline and acid groups tend to lose their gelation ability and form weaker gels. Though, solely $\mathrm{T}_{\text {gel }}$ experiments cannot be labeled as conclusive.

\subsubsection{Rheology, DSC and FTIR}

To further confirm the self-sorting of the two fibres rheological experiments were done which revealed the $\mathrm{G}_{\max }^{\prime}$ for the mixed system (SucVal8+ProValDoc) as $11430 \mathrm{~Pa}$ which is one order in magnitude higher than the individual gelators SucVal8 $\left(\mathrm{G}^{\prime}{ }_{\max }\right)=$ $1578 \mathrm{~Pa}$ and ProValDoc $\left(\mathrm{G}_{\max }^{\prime}\right)=650 \mathrm{~Pa}$ (Figure 4.7). This falls in line with the previous reports of orthogonal systems being mechanically stronger than the individual hydrogelators owing to the higher density of fibres. ${ }^{13}$ Additionally DSC experiments revealed the thermal imprints of both SucVal8 and ProValDoc in the mixed system suggesting the self-sorted assembly of both the hydrogelators (Figure 4.8). The disruptive co-assembly of ProVal8 and SucVal8 was further vindicated by rheology and DSC experiments. The $\mathrm{G}^{\prime}$ max for ProVal8+SucVal8 was measured to be $290 \mathrm{~Pa}$ which was 
lower than that of SucVal8 (1578 Pa) and slightly higher than ProVal8 (138 Pa) (Figure 4.7). The thermal imprint of the mixed system was also different from the individual systems (Figure 4.8). All of the above experiments suggest that the molecules of SucVal8 with ProVal8 showed a disruptive co-assembly that interferes with the gelation ability of each other while with ProValDoc it forms a self-sorted fibre system. FTIR did not show significant differences in the position of bands between the different samples however broad bands were obtained for the xerogel of the mixture SucVal8+ProVal8 suggesting the formation of ammonium salts to a higher extent (Figure ES 4.5). Thus, the orthogonal and co-assembly of the molecules in two different mixtures were established by AFM,

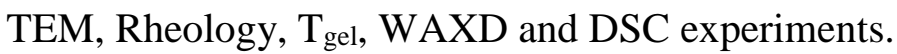



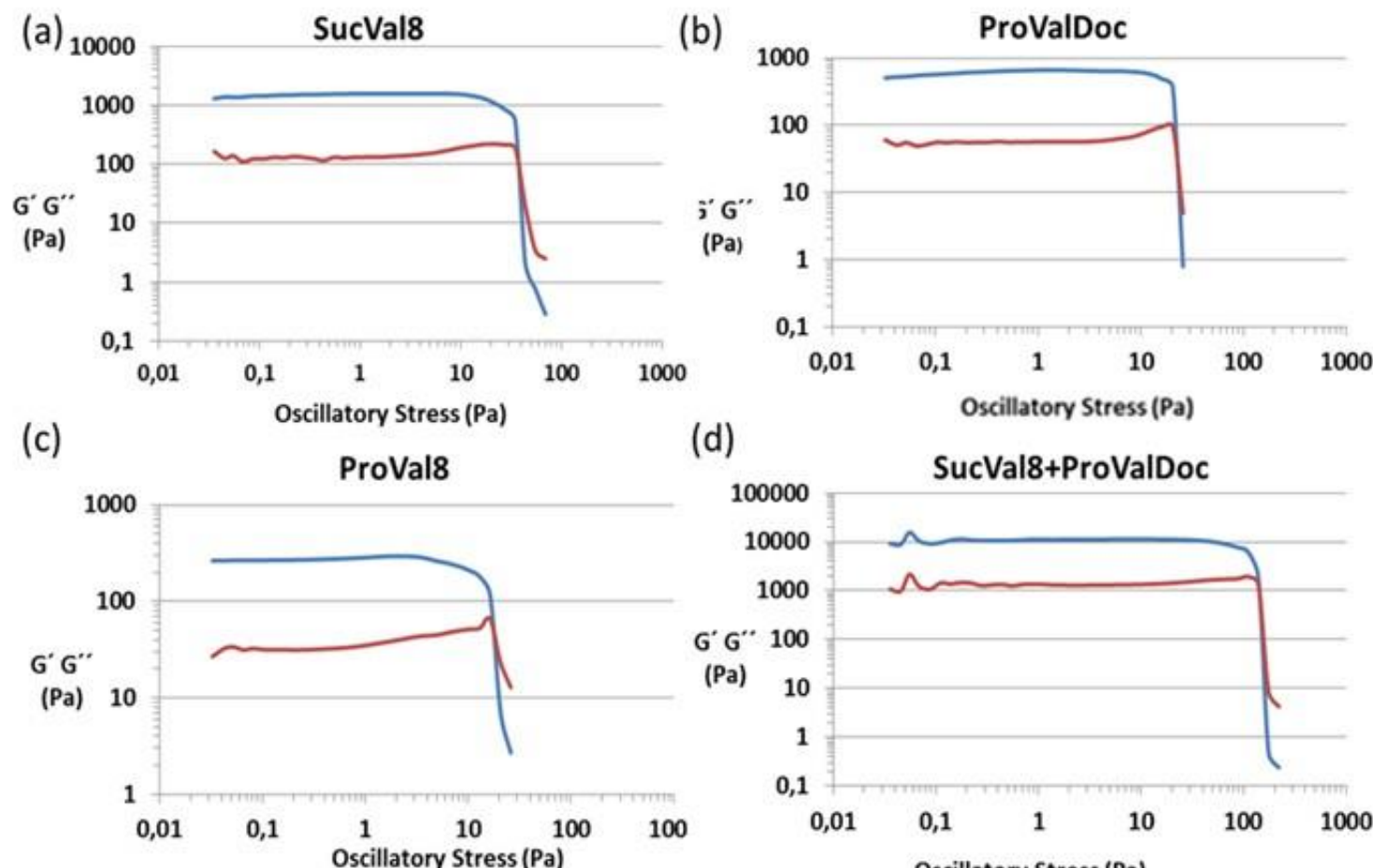

(d)

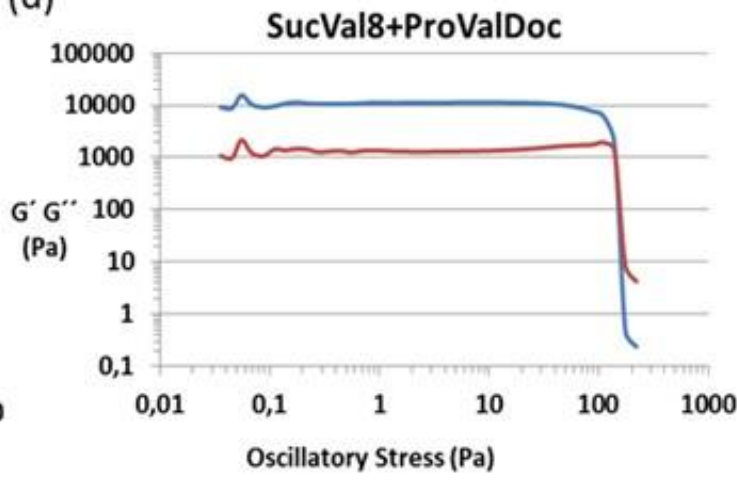

(e)
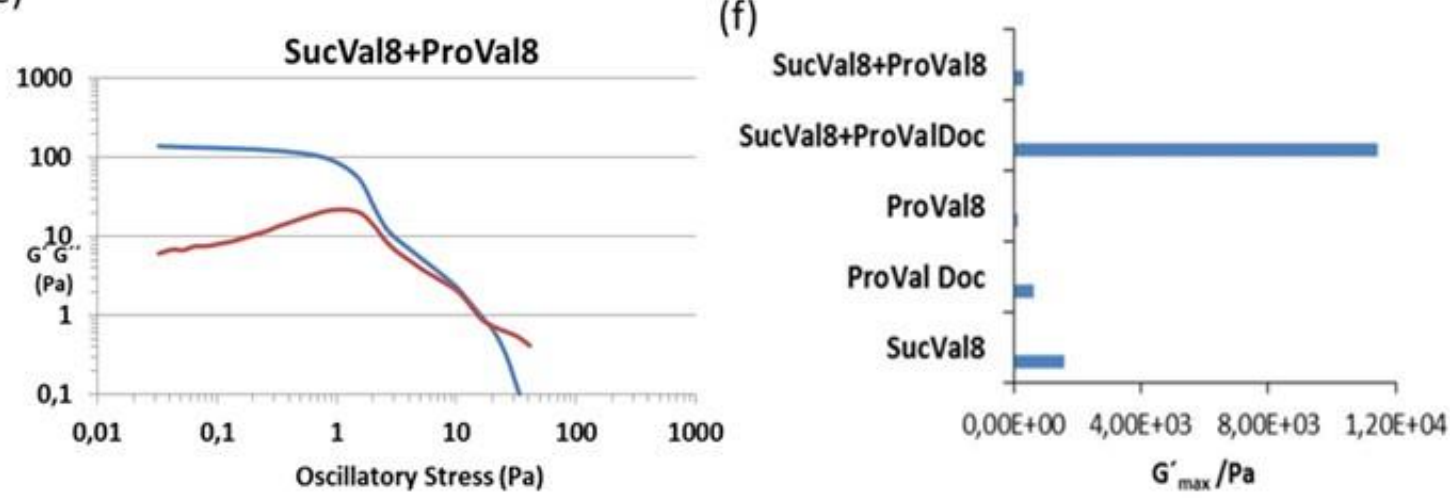

Figure 4.7: (a-e) Rheology contours of the different hydrogels and (f) the comparison of the $\mathrm{G}^{\prime}{ }_{\max }$ values of the different hydrogelators. 

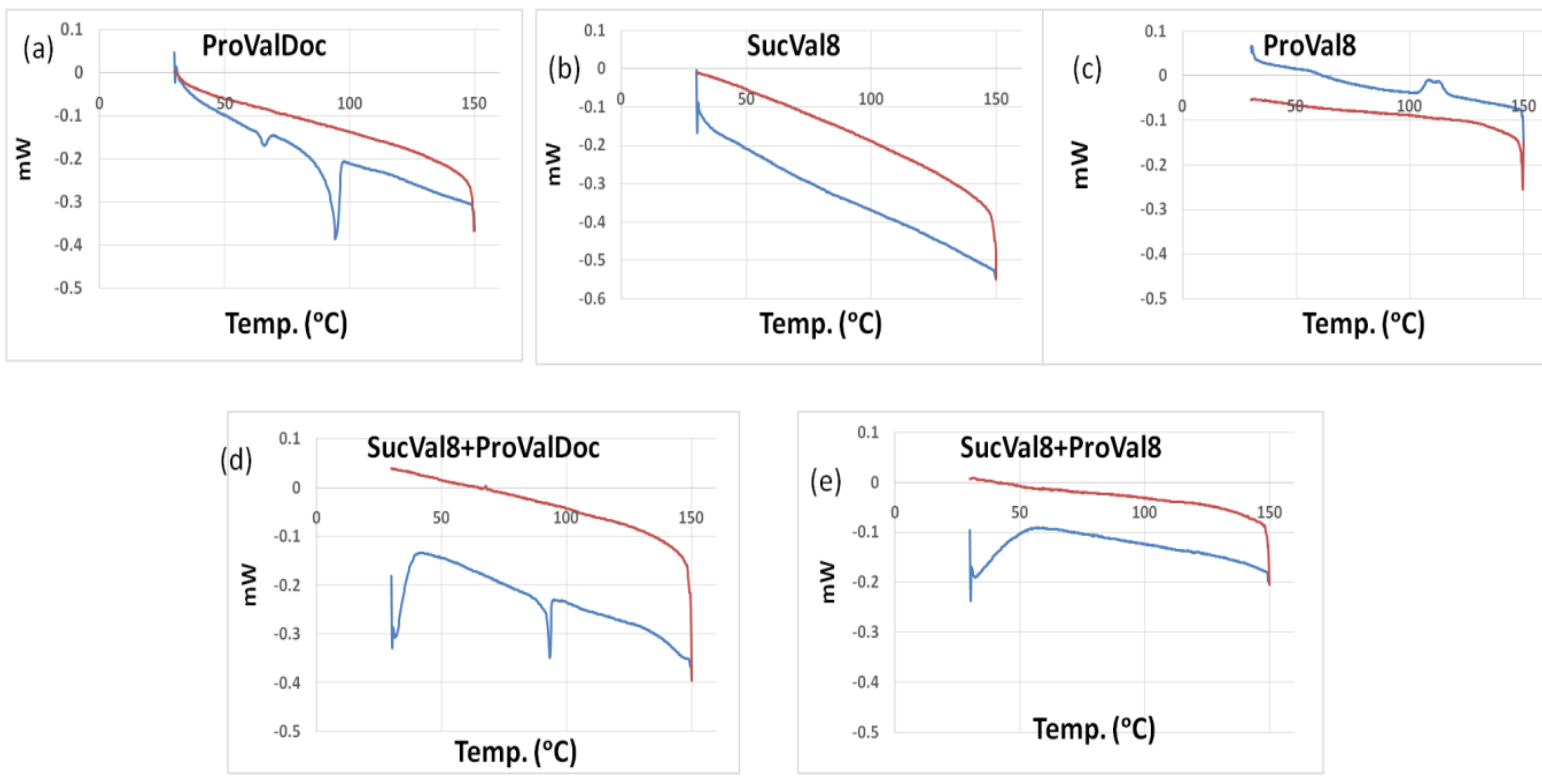

Figure 4.8: DSC patterns of the xerogels of different hydrogelators.

\subsubsection{Catalysis}

After establishing the orthogonality and co-assembly in the two different mixed systems we checked the hydrogelators for catalysis for deacetalisation and direct aldol conversions (Scheme 4.1).

For catalysis the reactants as mentioned in the following text were added in the gels and vortexed. Upon reaction the products were extracted at desired time by extraction with $1 \mathrm{~mL} \mathrm{CDCl} 3$ twice and dried over $\mathrm{MgSO}_{4}$ and observed by ${ }^{1} \mathrm{H} \mathrm{NMR}$.

First, we checked the catalytic activity of SucVal8 fibres for the deacetalisation reaction. Complete conversion of $35 \mathrm{mM}$ benzaldehyde dimethyl acetal into benzaldehyde was observed in 10 hours when $20 \mathrm{~mol} \%$ ( $7 \mathrm{mM}$ gel) of catalyst was used, while lower $\mathrm{k}_{\mathrm{obs}}$ was observed in samples of SucVal8 in solution (Table 4.1). This difference in catalytic activity between solution and gel arises from the formation of the hydrophobic pockets facilitating the approach of substrates near the functional groups and cooperation in the 
catalytic groups due to their increase in local concentration upon self-assembly. The

ProValDoc did not catalyse this reaction neither in solution nor as a gel.

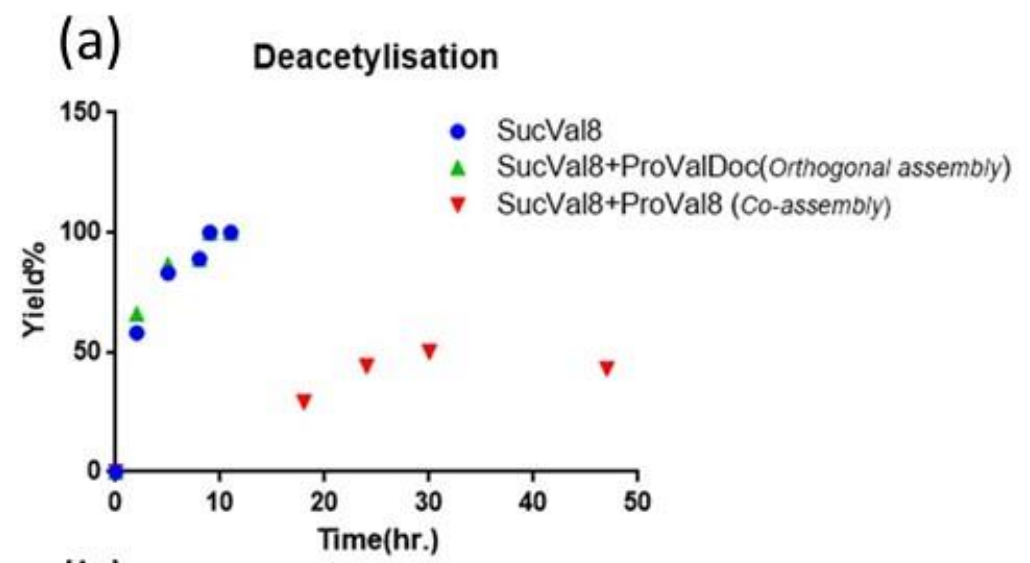

(b)

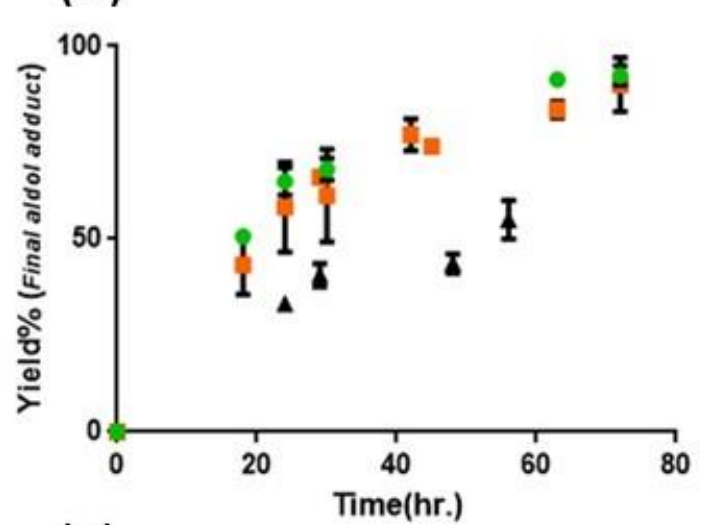

Direct aldol by

orthogonal assembly

( $\mathrm{K}_{\text {obs }}: 2.1 \times 10^{-5} \pm 4 \times 10^{-6} \mathrm{~s}^{-1}$ )

Tandem reactions by

orthogonal assembly

= (Kobs: $2.1 \times 10^{-5} \pm 8 \times 10^{-6} \mathrm{~s}-1$, ee: $90 \%)$

\section{Aldol by only ProVal8}

- $\left(K_{\text {obs }}: 1.61 \times 10^{-5} \pm 8 \times 10-7 \mathrm{~s}^{-1}\right)$

(c)

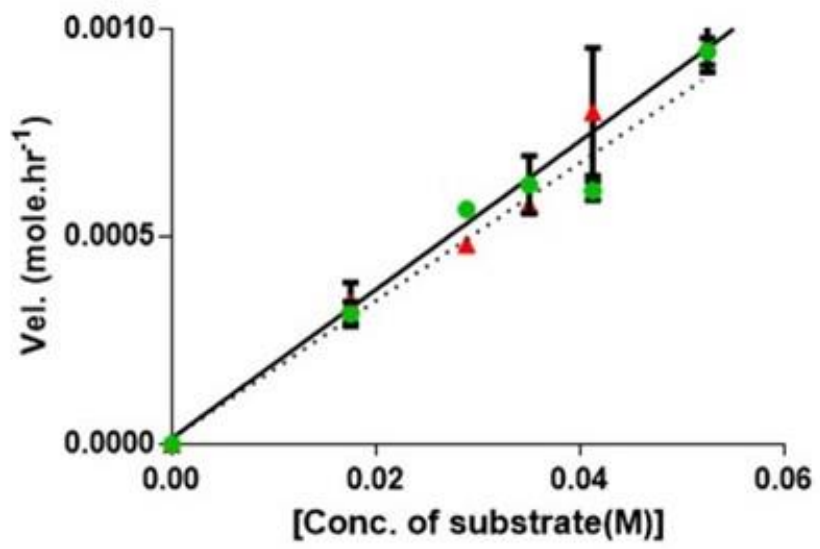

- Tandem

$\mp$ direct Aldol

Figure 4.9: (a) Kinetics of first step deacetalysation reaction (b) Kinetics of the tandem (॰) and direct aldol reaction (4) by the mixture of SucVal8 + ProValDoc at their respective MGC (c) Velocity of product formation versus substrate concentration of the tandem and direct aldol reaction. 
Table 4.1: Catalysis summary.

\begin{tabular}{|c|c|c|c|c|c|c|c|}
\hline \multirow[b]{2}{*}{ Catalyst } & \multirow[b]{2}{*}{$\begin{array}{l}\text { Gel(g)/ } \\
\text { Solution } \\
\text { (s) }\end{array}$} & \multicolumn{2}{|c|}{ Separate Reactions } & \multirow[b]{2}{*}{ (e.r.) } & \multicolumn{2}{|c|}{ Tandem Reactions } & \multirow[b]{2}{*}{ (e.r.) } \\
\hline & & $\begin{array}{l}\text { Acetal } \\
\text { deprotectio } \\
\text { n }\end{array}$ & Aldol & & $\begin{array}{l}\text { Acetal } \\
\text { deprotection }\end{array}$ & Aldol & \\
\hline \multirow[t]{2}{*}{ ProVal8 } & $\mathrm{g}$ & No Product & $\begin{array}{l}1.61 \times 10^{-5} \\
\pm 8 \times 10^{-7}\end{array}$ & $75: 25$ & No Product & $\begin{array}{c}\text { No } \\
\text { Product }\end{array}$ & \\
\hline & s & No Product & $\begin{array}{l}9.1 \times 10^{-6} \\
\pm 5 \times 10^{-7} \mathrm{~s}^{-1}\end{array}$ & & No Product & $\begin{array}{l}\text { No } \\
\text { Product }\end{array}$ & \\
\hline \multirow[t]{2}{*}{ ProValDoc } & g & No Product & $\begin{array}{l}2.23 \times 10^{-5} \\
\pm 3 \times 10^{-6} \mathrm{~s}^{-1}\end{array}$ & $91: 9$ & No Product & $\begin{array}{c}\text { No } \\
\text { Product }\end{array}$ & \\
\hline & s & No Product & $\begin{array}{l}5.7 \times 10^{-6} \\
\pm 9 \times 10^{-6} \mathrm{~s}^{-1}\end{array}$ & & No Product & $\begin{array}{c}\text { No } \\
\text { Product }\end{array}$ & \\
\hline \multirow[t]{2}{*}{ SucVal8 } & g & $\begin{array}{l}1.5 \times 10^{-4} \\
\pm 3 \times 10^{-5} \mathrm{~s}^{-1}\end{array}$ & No Product & & $\begin{array}{l}1.2 \times 10^{-4} \\
\pm 4 \times 10^{-5} \mathrm{~s}^{-1}\end{array}$ & $\begin{array}{l}\text { No } \\
\text { Product }\end{array}$ & \\
\hline & s & $\begin{array}{l}4.1 \times 10^{-5} \\
\pm 1 \times 10^{-6} \mathrm{~s}^{-1}\end{array}$ & No Product & & $\begin{array}{l}5.0 \times 10^{-5} \\
\pm 3 \times 10^{-6} \mathrm{~s}^{-1}\end{array}$ & $\begin{array}{l}\text { No } \\
\text { Product }\end{array}$ & \\
\hline \multirow[t]{2}{*}{$\begin{array}{r}\text { ProVal8 } \\
+ \text { SucVal8 }\end{array}$} & $\mathrm{g}$ & $\begin{array}{l}8.3 \times 10^{-6} \\
\pm 4 \times 10^{-7} \mathrm{~s}^{-1}\end{array}$ & No Product & & $\begin{array}{l}8.3 \times 10^{-6} \\
\pm 5 \times 10^{-7} \mathrm{~s}^{-1}\end{array}$ & $\begin{array}{l}\text { No } \\
\text { Product }\end{array}$ & \\
\hline & s & $\begin{array}{l}2.23 \times 10^{-6} \\
\pm 2 \times 10^{-7} \mathrm{~s}^{-1}\end{array}$ & No Product & & $\begin{array}{l}1.9 \times 10^{-6} \\
\pm 8 \times 10^{-7} \mathrm{~s}^{-1}\end{array}$ & $\begin{array}{l}\text { No } \\
\text { Product }\end{array}$ & \\
\hline \multirow[t]{2}{*}{$\begin{array}{l}\text { ProValDoc } \\
\text { +SucVal8 }\end{array}$} & g & $\begin{array}{l}1.4 \times 10^{-4} \\
\pm 4 \times 10^{-5} \mathrm{~s}^{-1}\end{array}$ & $\begin{array}{l}2.2 \times 10^{-5} \\
\pm 3 \times 10^{-6} \mathrm{~s}^{-1}\end{array}$ & & $\begin{array}{l}1.4 \times 10^{-4} \\
\pm 2 \times 10^{-5} \mathrm{~s}^{-1}\end{array}$ & $\begin{array}{l}2.1 \times 10^{-5} \\
\pm 4 \times 10^{-6} \mathrm{~s}^{-1}\end{array}$ & $90: 10$ \\
\hline & s & $\begin{array}{l}4.1 \times 10^{-5} \\
\pm 3 \times 10^{-6} \mathrm{~s}^{-1}\end{array}$ & No Product & & $\begin{array}{l}5 \times 10^{-5} \\
\pm 6 \times 10^{-6} \mathrm{~s}^{-1}\end{array}$ & $\begin{array}{l}\text { No } \\
\text { Product }\end{array}$ & \\
\hline
\end{tabular}

The orthogonally assembled catalytic fibres were then examined for the catalytic activity for the two previously mentioned reactions in tandem in one pot. The SucVal8+ProValDoc gel was first checked for deprotection of the acetal group. A quantitative yield of benzaldehyde from benzaldehyde dimethyl acetal $(35 \mathrm{mM})$ was obtained in $10 \mathrm{hr}$ using $7 \mathrm{mM}$ (20 mol\%) of the catalyst. To examine the viability of the SucVal8+ProValDoc gel for the tandem reaction, the two substrates, benzaldehyde dimethyl acetal and cyclohexanone, were simultaneously introduced in the system at $\mathrm{t}=0$. In 72 hours more than $85 \%$ of the aldehyde obtained by deacetalysation was converted to the final aldol product with an anti:syn ratio of $84: 16(90: 10$ e. r. $)$. The $\mathrm{k}_{\mathrm{obs}}=(2.1 \pm 0.4)$ $\times 10^{-5} \mathrm{~s}^{-1}$ for the tandem reaction. No final product was observed when both the gelators were mixed when completely soluble. These results confirm that both the networks 
maintain their catalytic activity without interfering with each other. Moreover, when the direct aldol reaction between benzaldehyde and cyclohexanone was performed in the SucVal8+ProValDoc gel a 91\% yield was obtained in 72 hours (anti:syn ratio of 90:10; 91:9 e. r., $\mathrm{k}_{\mathrm{obs}}=(2.2 \pm 0.3) \times 10^{-5} \mathrm{~s}^{-1}$ suggesting that the acetal deprotection was not the rate limiting step. Similar reactions were performed to check if the tandem reaction was carried out with the mixed gel system formed by disruptive co-assembly (SucVal8+ProVal8).

Single component gels of ProVal8 were able to catalyze the aldol condensation of benzaldehyde and cyclohexanone in water with a yield of 55\% in 96 hours. However, when the tandem deacetalization/aldol reaction was tested with the mixture of SucVal8+ProVal8, only $58 \%$ conversion of benzaldehyde dimethyl acetal to benzaldehyde was observed in 96 hours and no final aldol product was obtained even after much longer times. These results suggests a specific interaction between the acidic and proline groups of the two molecules while coassembling, presumably involving a salt bridge, and thus rendering them catalytically inactive for the enamine-based aldol reaction which is hampered if proline amino group is protonated.

\subsection{Conclusions}

In conclusion, we have reported for the first time two catalytic molecular hydrogelators that owing to their structural differences are able to orthogonally self-assemble into a two network gel and perform two reactions in one-pot which would be otherwise incompatible as exemplified by a related co-assembled network. We have shown that it is possible, by the sole use of molecularly instructed non-covalent interactions, to construct spatially separated catalytic sites able to work in tandem mimicking multi-enzymatic complexes found in cells. This work is an example of a tailored design of self-assembled 
supramolecular catalysts for one-pot tandem reactions, which is not often easy to achieve when working in homogeneous catalysis, and that could be extended to other subsets of incompatible reactions. ${ }^{31}$

\subsection{Experimental section}

\subsubsection{Synthesis}

The hydrogelators SucVal8, ProValDoc, ProVal8 were synthesized following the protocols as described in the literature. ${ }^{11,24,25}$

\section{Synthesis of SucVal8}<smiles>CC(C)[C@H](NC(=O)CCC(=O)O)C(=O)NCCCCCCCNC(=O)[C@@H](NC(=O)CCC(=O)O)C(C)C</smiles>

A solution of compound 6 (2.92 g, $8.57 \mathrm{mmol})$ in dry THF $(150 \mathrm{~mL})$ was added dropwise under $\mathrm{N}_{2}$ at $25^{\circ} \mathrm{C}$ with a dropping funnel to a solution of commercial available succinic anhydride ( $855 \mathrm{mg}, 8.57 \mathrm{mmol}, 1.0$ eq.) in dry THF (100 mL). The mixture was further stirred for $16 \mathrm{hr}$ at reflux. After this time, the solution was concentrated under reduced pressure and the crude residue was purified by washing with $\mathrm{HCl} 0.1 \mathrm{M}(100 \mathrm{~mL})$ and water $(200 \mathrm{~mL})$. The compound was dried under reduced pressure at $50{ }^{\circ} \mathrm{C}$ to yield SucVal8 ( $90 \%$ ) as a white solid.

${ }^{1} \mathrm{H}$ NMR $\left(\mathrm{DMSO}-d_{6}\right): \delta(\mathrm{ppm})=12.37-11.73(\mathrm{br} \mathrm{s}, 2 \mathrm{H}), 7.84-7.76(\mathrm{brm}, 4 \mathrm{H}), 4.07(\mathrm{dd}$, $J=8.9,7.0 \mathrm{~Hz}, 2 \mathrm{H}), 3.07(\mathrm{dt}, J=13.0,6.8 \mathrm{~Hz}, 2 \mathrm{H}), 2.96(\mathrm{td}, J=13.0,6.8 \mathrm{~Hz}, 2 \mathrm{H}), 2.40(\mathrm{~d}$, $J=4.8,8 \mathrm{H}), 1.91-1.86(\mathrm{~m}, 4 \mathrm{H}), 1.41-1.18(\mathrm{~m} .10 \mathrm{H}), 0.81(\mathrm{dd}, J=6.8 \mathrm{~Hz}, 2.3 \mathrm{~Hz}, 12 \mathrm{H})$; 
${ }^{13} \mathrm{C}$ NMR $(126 \mathrm{MHz})\left(\mathrm{DMSO}-d_{6}\right): \delta(\mathrm{ppm})=174.3(\mathrm{x} 2), 171.5(\mathrm{x} 2), 171.2(\mathrm{x} 2), 58.3$ (x2), 30.8, 30.4 , 38.8 (x2), 29.7 (x2), 29.4 (x2), 29.1 (x2), 26.7 (x2), 19.6 (x2), 18.6 (x2).

HR ESMS: m/z: calcd for $\mathrm{C}_{26} \mathrm{H}_{46} \mathrm{~N}_{4} \mathrm{O}_{8}$ : 541.3237; found: $541.3246\left[M-\mathrm{H}^{+}\right]^{-} \delta=0.2 \mathrm{ppm}$.

\section{Synthesis of compound 9}

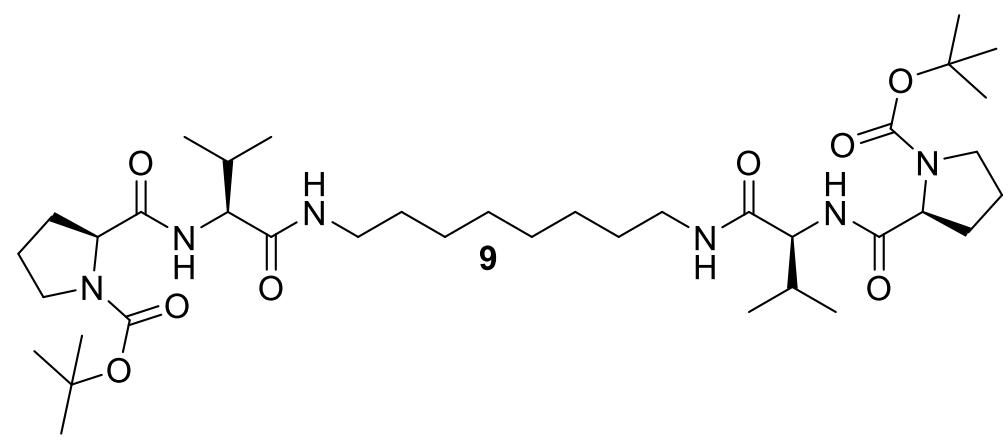

A solution of 6 (5.51 mmol) in $100 \mathrm{~mL}$ of dry DME was added dropwise over a solution of compound $8(11.50 \mathrm{mmol})$ in $100 \mathrm{~mL}$ of dry DME. The mixture was stirred at room temperature for $24 \mathrm{~h}$ and then at $40{ }^{\circ} \mathrm{C}$ for $5 \mathrm{~h}$. Solvent was evaporated under vacuum and the resulting white solid was dissolved in $50 \mathrm{~mL}$ of dichloromethane and washed with $\mathrm{NaHCO}_{3}(3 \times 15 \mathrm{~mL})$. Afterwards the organic layers were dried $\left(\mathrm{Na}_{2} \mathrm{SO}_{4}\right)$ and the solvent was evaporated under vacuum to yield 9 as a white solid in $85 \%$ yield.

${ }^{1} \mathrm{H}$ NMR (500 MHz, DMSO-d $): \delta(\mathrm{ppm})=0.90(12 \mathrm{H}, \mathrm{br}, \mathrm{m}), 1.25-1.50(30 \mathrm{H}, \mathrm{br}, \mathrm{m})$, 1.75- 2.20 (10H, br, m), 2.98-3.16 (4H, br, m), 3.29-3.47 (4H, br, m), 4.13 (2H, dd, J = 8.0, 7.8 Hz), 4.22-4.29 (2H, br, m), 7.67 (2H, br, d, J = 7.9 Hz), 7.87-8.05 (2H, br, m) ppm; 13C NMR (126 MHz, DMSO-d $): \delta(p p m)=19.1,19.8,23.6,26.9,28.6,29.3,29.6$, $31.3,31.7,38.9,47.2,58.4,60.1,79.1,154.0,171.2,172.7$.

$\operatorname{ESI-MS}(\mathrm{m} / \mathrm{z})=737.6[\mathrm{M}+\mathrm{H}]^{+}, 759.6[\mathrm{M}+\mathrm{Na}]^{+}, 775.7[\mathrm{M}+\mathrm{K}]^{+}$. 


\section{Synthesis of ProVal8}

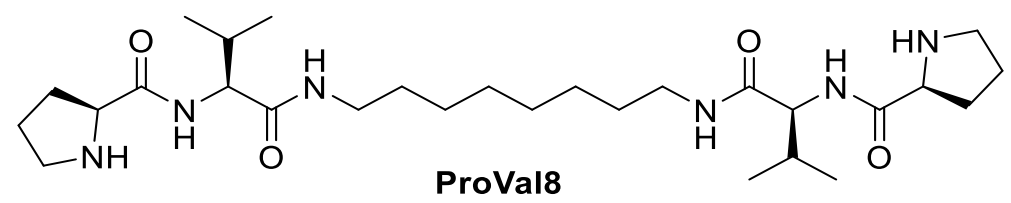

Compound 9 (3.00 mmol) was dissolved in dichloromethane and after addition of $15 \mathrm{~mL}$ of TFA the mixture was stirred at room temperature for $2 \mathrm{~h}$. The solvent was evaporated under vacuum and then the resulting crude oil was dissolved in water $(50 \mathrm{~mL})$. The solution was treated with $\mathrm{NaOH}(\mathrm{pH}=12)$, and extracted with $(3 \times 15 \mathrm{~mL})$. The organic layers were washed with water and dried $\left(\mathrm{Na}_{2} \mathrm{SO}_{4}\right)$. Solvent was evaporated under vacuum to yield ProVal8 as white solid in $80 \%$ yield.

${ }^{1} \mathrm{H}$ NMR $\left(500 \mathrm{MHz}, \mathrm{CD}_{3} \mathrm{CN}\right): \delta(\mathrm{ppm})=0.90(12 \mathrm{H}, \mathrm{dd}, \mathrm{J}=19.4,6.9 \mathrm{~Hz}), 1.25-1.36(8 \mathrm{H}$, m), 1.41-1.50 (4H, m), 1.65-1.72 (4 H, m), 1.78-1.85 (2H, m), 2.03-2.10 (4 H, m), 2.29 (2H, br, s), 2.83-2.88 (2H, m), 3.00-3.04 (2H, m), 3.12-3.19 $(4 \mathrm{H}, \mathrm{m}) 3.67(2 \mathrm{H}, \mathrm{dd}, \mathrm{J}=$ 4.6, $9.3 \mathrm{~Hz}), 4.01(2 \mathrm{H}, \mathrm{dd}, \mathrm{J}=9.0,6.2 \mathrm{~Hz}), 6.77(2 \mathrm{H}, \mathrm{br}, \mathrm{s}), 8.08(2 \mathrm{H}, \mathrm{br}, \mathrm{d}, \mathrm{J}=9.04 \mathrm{~Hz})$ ppm; 13C NMR (126 MHz, $\left.\mathrm{CD}_{3} \mathrm{CN}\right): \delta(\mathrm{ppm})=17.2,19.0,22.7,26.2,26.4,28.8,29.2$, $30.8,31.4,38.9,47.2,57.7,60.8,171.1,175.1$.

$\operatorname{ESI-MS}(\mathrm{m} / \mathrm{z})=269[\mathrm{M}+2]^{2+}$.

\section{Synthesis of ProValDoc}

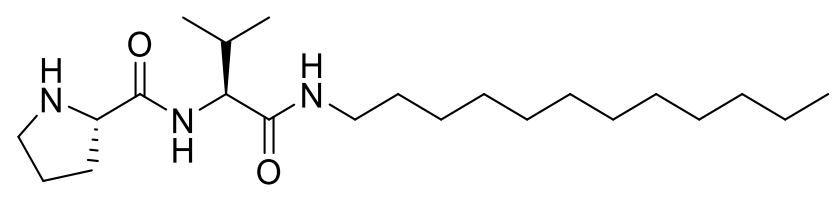

ProValDoc 
For the synthesis of ProValDoc, commercially available N-(t-butyloxycarbonyl)- $L$ Proline succinimide ester $(1.83 \mathrm{~g}, 7.75 \mathrm{mmol})$ was dissolved in $100 \mathrm{~mL}$ of dry dimethoxyethane (DME) and then amide 11 (1.28 g, $4.5 \mathrm{mmol})$ dissolved in $25 \mathrm{~mL}$ of dry DME was added dropwise. The reaction was stirred $16 \mathrm{hr}$ at room temp under a $\mathrm{N}_{2}$ atmosphere. After an additional period of $4 \mathrm{~h}$ at $50{ }^{\circ} \mathrm{C}$, DME was evaporated and a waxy white solid was obtained. This material was dissolved in $50 \mathrm{~mL}$ of $\mathrm{CH}_{2} \mathrm{Cl}_{2}$, washed with saturated sodium bicarbonate $(2 \times 25 \mathrm{~mL})$, dried over anhydrous sodium sulfate and filtered on a $100 \mathrm{~mL}$ round-bottom flask. To the obtained compound $\mathbf{1 2}, 15 \mathrm{~mL}$ of trifluoroacetic acid was slowly added over the dissolution and stirred overnight. Then, solvent was evaporated under vacuum and residue was dissolved with $50 \mathrm{~mL}$ of water, basified and extracted with chloroform ( $3 \times 25 \mathrm{~mL})$. After drying with sodium sulfate anhydrous solvent was evaporated to yield a white solid (86\%).

${ }^{1} \mathrm{H}-\mathrm{NMR}\left(500 \mathrm{MHz}, \mathrm{DMSO}-\mathrm{d}_{6}\right): \delta(\mathrm{ppm})=0.75-0.92(9 \mathrm{H}, \mathrm{m}), 1.18-1.30(18 \mathrm{H}, \mathrm{m}), 1.34-$ $1.42(2 \mathrm{H}, \mathrm{m}), 1.54-1.64(2 \mathrm{H}, \mathrm{m}), 1.66-1.72(1 \mathrm{H}, \mathrm{m}), 1.85-2.00(3 \mathrm{H}, \mathrm{m}), 2.72-2.79(2 \mathrm{H}$, m), 3.07-3.18 $(2 \mathrm{H}, \mathrm{m}), 3.52-3.58(1 \mathrm{H}, \mathrm{m}), 4.09-4.16(1 \mathrm{H}, \mathrm{m}), 8.00-8.05(1 \mathrm{H}, \mathrm{br}, \mathrm{m}), 8.05-$ $8.12(1 \mathrm{H}, \mathrm{br}, \mathrm{d}, 8 \mathrm{~Hz}) ; 13 \mathrm{C}-\mathrm{NMR}\left(126 \mathrm{MHz}, \mathrm{DMSO}-\mathrm{d}_{6}\right): \delta(\mathrm{ppm})=14.3,18.1,19.5$, 22.5, 26.3, 26.8, 29.1, 29,4, 29.4, 31.0, 31.7, 31.9, 38.7, 47.1, 56.9, 60.6, 170.8, 174.3.

$\operatorname{ESI-MS}(\mathrm{m} / \mathrm{z})=382.3[\mathrm{M}+\mathrm{H}]^{+} \delta=0.2 \mathrm{ppm}$

\subsubsection{Gels formation}

ProValDoc: $5.7 \mu \mathrm{mol}$ of the compound was dissolved in $1 \mathrm{~mL}$ of water in a screwed tight vial by heating at $100^{\circ} \mathrm{C}$ followed by sonication for 1 minute and left to stand at $25^{\circ} \mathrm{C}$.

SucVal8: $7 \mu \mathrm{mol}$ of the compound was dissolved in $1 \mathrm{~mL}$ of water in a screwed tight vial by heating at $100^{\circ} \mathrm{C}$ followed by sonication for 1 minute and left to stand at $25^{\circ} \mathrm{C}$. 
ProVal8: $6.5 \mu \mathrm{mol}$ of the compound was dissolved in $0.8 \mathrm{~mL}$ of water in a screwed tight vial by heating at $100^{\circ} \mathrm{C}$ followed by sonication for $1 \mathrm{~min}$ and left to stand at $25^{\circ} \mathrm{C}$.

ProValDoc+SucVal8 and ProVal8+SucVal8: Each component at their respective MGC was taken and dissolved in $1 \mathrm{~mL}$ of water in a screwed tight vial by heating at $100{ }^{\circ} \mathrm{C}$, followed by sonication for 1 minute and left to stand at $25^{\circ} \mathrm{C}$.

\subsection{3. $T_{\text {gel }}$ measurement}

Prepared gels were subjected to controlled heating in an oil bath and $\mathrm{T}_{\text {gel }}$ was determined by inverted vial method to check if the gel still was self-standing. Temperature at which solvent started to liberate from the gel was taken as $\mathrm{T}_{\text {gel. }}$. Experiments were done in triplicate.

\subsubsection{Wide angle $X$-ray Diffraction}

Data collection was performed at room temperature with a BrukerD4 Endeavor X-ray powder diffractometer by using $\mathrm{Cu}-\mathrm{K} \alpha$ radiation. Xerogels were obtained by freezedrying and lyophilization.

\subsubsection{Transmission electron microscopy}

TEM micrographs were obtained using a JEOL 2100 transmission electron microscope. The TEM samples were prepared by directly applying gels at MGC on formvar-carbon coated TEM grids. A $5 \mu \mathrm{L}$ droplet of purified water was used to remove the salts and the excess solution was wicked off using filter paper. The samples were immediately stained using $5 \mu 1$ droplet of $1 \%$ phosphotungstic acid and was allowed to stand for $5 \mathrm{~min}$. The excess solution was removed using a filter paper. The grids were then left under covered petri dish to dry before obtaining images. 


\subsubsection{Atomc force microscopy}

In order to visualize the individual fibre structure, atomic force microscopy (AFM) measurements were performed in the tapping mode using a commercial instrument (NTEGRA Prima, NT-MDT Co., Moscow, Russia). Topographic and phase images were recorded simultaneously at scanning rate of $0.4 \mathrm{~Hz}$ using a rectangular silicon cantilever (NSG03 series) with a resonant frequency of $100 \mathrm{kHz}$ (in the air) and force constant of $6.566 \mathrm{~N} / \mathrm{m}$, which was determined by the thermal fluctuation method. ${ }^{19}$ For samples preparation, diluted fibre solution was spin-coated on the surface of silicon wafers $(5 \times 7 \mathrm{~mm})$. Before spin coating, these small pieces of silicon wafers were cleaned by water, ethanol, and sonication in acetone followed by plasma treatment for $2.5 \mathrm{~min}$. 

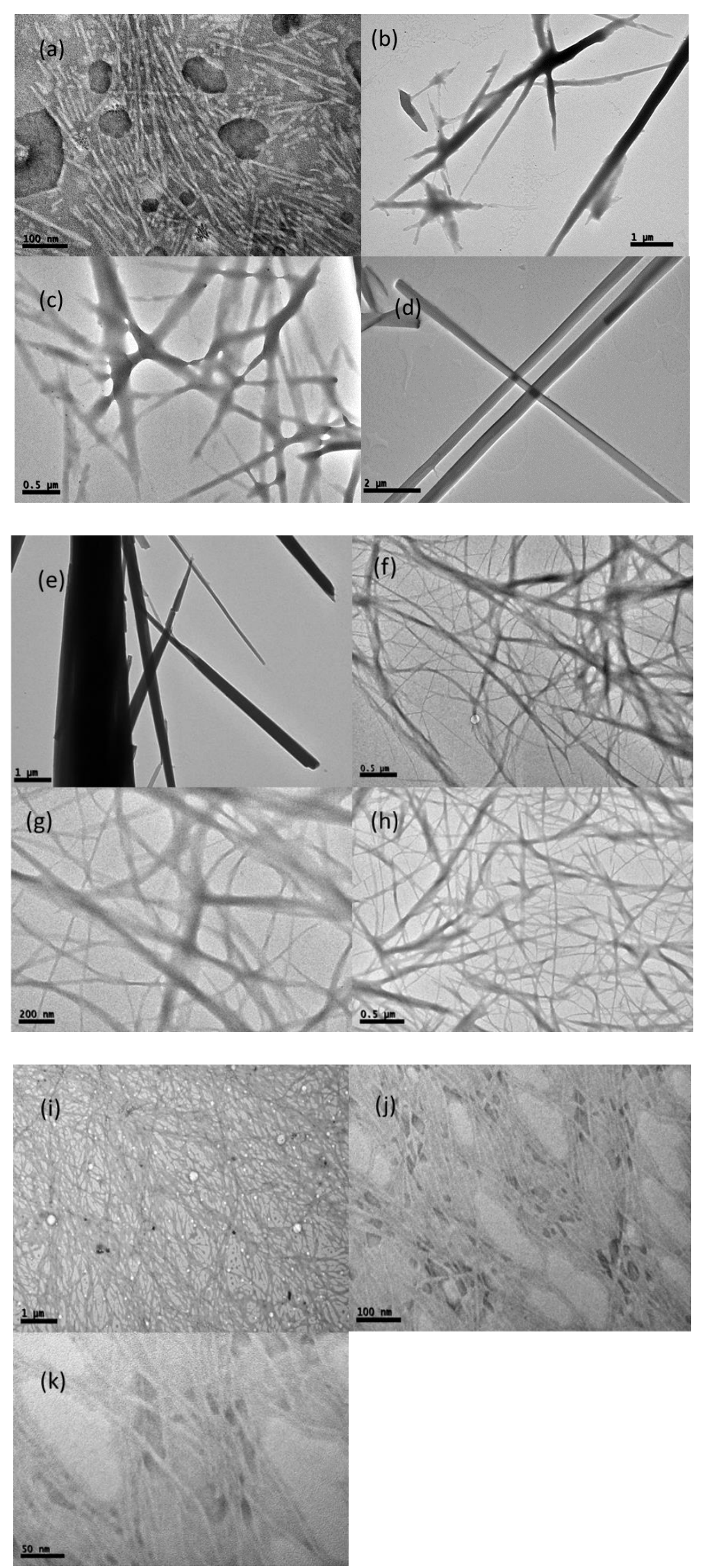

Figure ES 4.1: TEM images of (a) SucVal8 (b-c) ProValDoc (d-e) ProVal8 (f-h) SucVal8+ProValDoc (i-k) SucVal8+ProVal8 

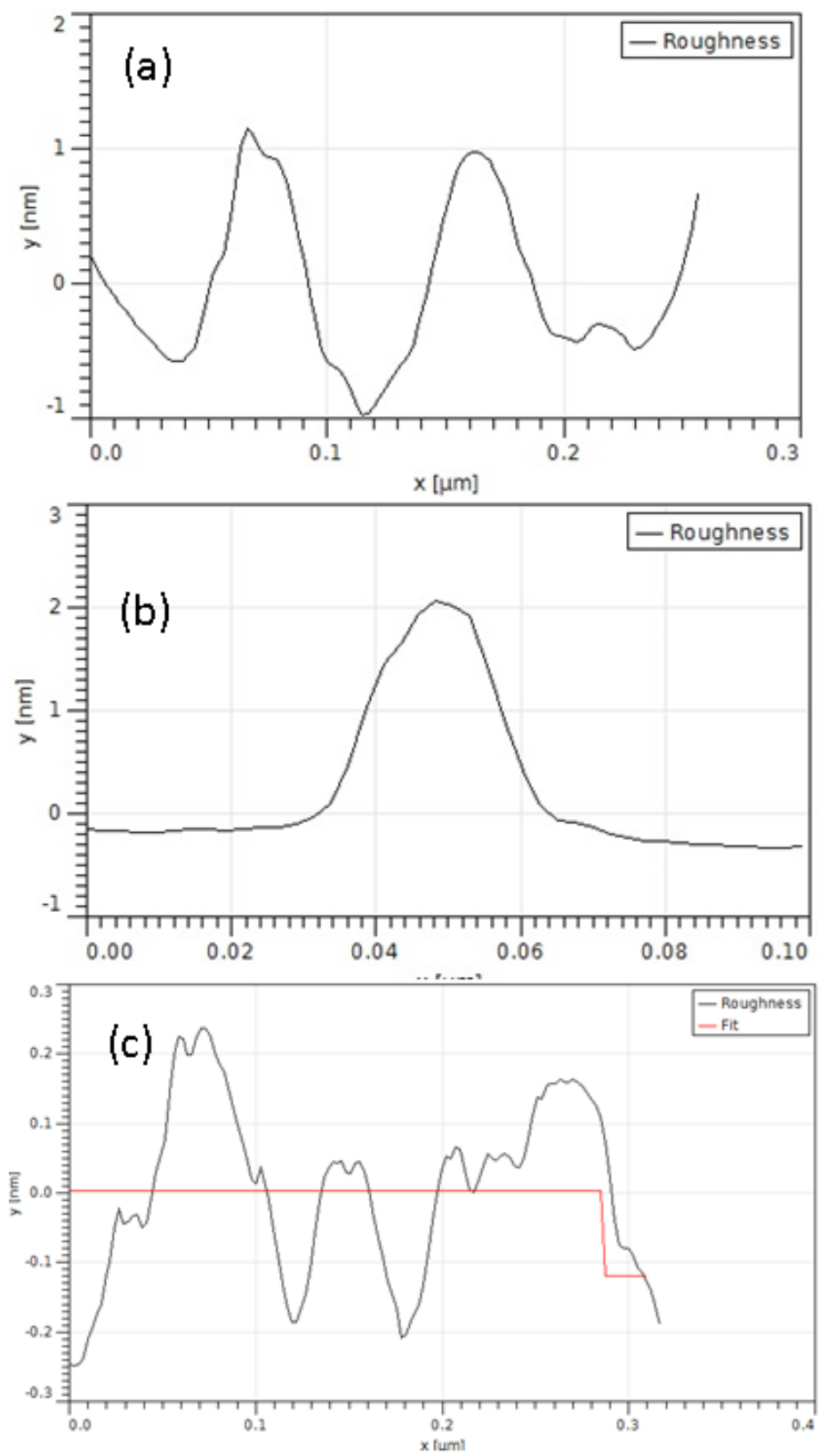

Figure ES 4.2: Height and width profile of (a) ProValDoc (Fibre width of 50nm) (b) ProVal8 (Fibre width of around $35 \mathrm{~nm}$ ) (c) SucVal8+ProValDoc (two different widths of 50nm and 10-15nm corresponding to ProValDoc and SucVal8 respectively)

\subsubsection{Differential scanning calorimetry}

Measurements were done using a Mettler Toledo 822e differential scanning calorimeter.

Heating and cooling rates of $2{ }^{\circ} \mathrm{C} \mathrm{min}^{-1}$ were employed over a range of $30-150{ }^{\circ} \mathrm{C}$ for the xerogels of each sample. 


\subsubsection{Catalysis}

Different concentrations of benzaldehyde dimethyl acetal and $200 \mu \mathrm{L}$ (10 equivalents or more) of cyclohexanone were mixed and added simultaneously in the hydrogel and left to react at room temperature. The reaction was extracted twice with $2 \mathrm{~mL}$ of $\mathrm{CDCl}_{3}$ and analysed by ${ }^{1} \mathrm{H}$ NMR in order to determine the yield. All the measurements were done in triplicate.

Determination of the yield of benzaldehyde: Yield of benzaldehyde was determined by emergence of aldehyde proton of benzaldehyde at ( $\delta(\mathrm{ppm}): 9.98(\mathrm{~s}))$ and comparing it by decrease in the intensity of the tertiary proton of the acetal $(\delta(\mathrm{ppm}): 5.43(\mathrm{~s}))$.

Determination of the aldol product: The product of the aldol condensation, 2(hydroxyphenylmethyl)-cyclohexan-1-one is a known compound and the diastreoselectivity was determined by comparison with previously reported literature. ${ }^{35,36}$ $($ syn: $5.39 \mathrm{ppm}(\mathrm{d}))(\mathrm{J}=2.4 \mathrm{~Hz})$ and $($ anti:4.79 ppm $(\mathrm{d}))(J=8.8 \mathrm{~Hz})$

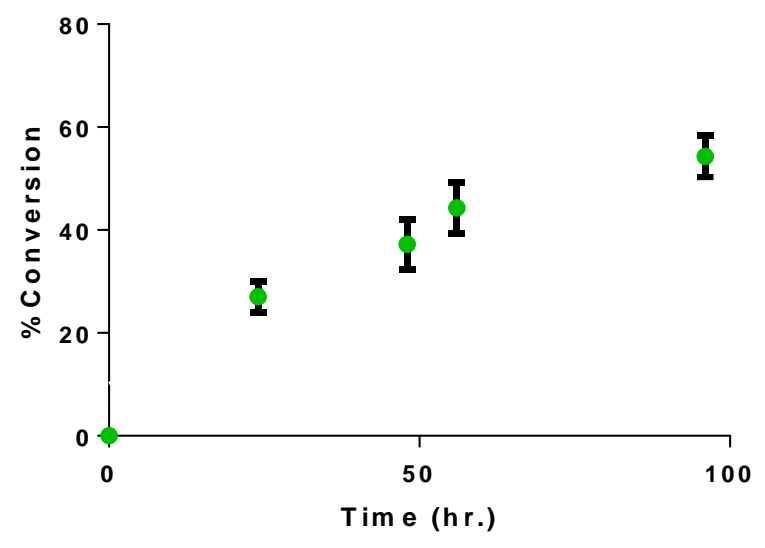

Figure ES 4.3: Tandem reaction of acetal deprotection and aldol condensation carried out in one pot by the mixture of ProVal8+SucVal8 only yielded the product from the first reaction i.e. deprotection of acetal (58\% in 96 hours) and no final aldol product. 


\subsubsection{Determination of enantiomeric ratio}

The enantiomeric ratio of the aldol adduct was determined by chiral HPLC with a Daicel

Chiralcell OD-H column using a previously reported method ${ }^{37}$ [eluent: 98:2 Hex:IPA;

$0.8 \mathrm{~mL} / \mathrm{min}$ flow rate; detection $\lambda=210 \mathrm{~nm} . \mathrm{t}_{\mathrm{R}}=20.3 \mathrm{~min}($ syn - minor $), \mathrm{t}_{\mathrm{R}}=22.9 \mathrm{~min}($ synmajor), $\mathrm{t}_{\mathrm{R}}=28.6 \min \left(\right.$ anti- major). $\mathrm{t}_{\mathrm{R}}=45.4 \min ($ anti- minor) $]$

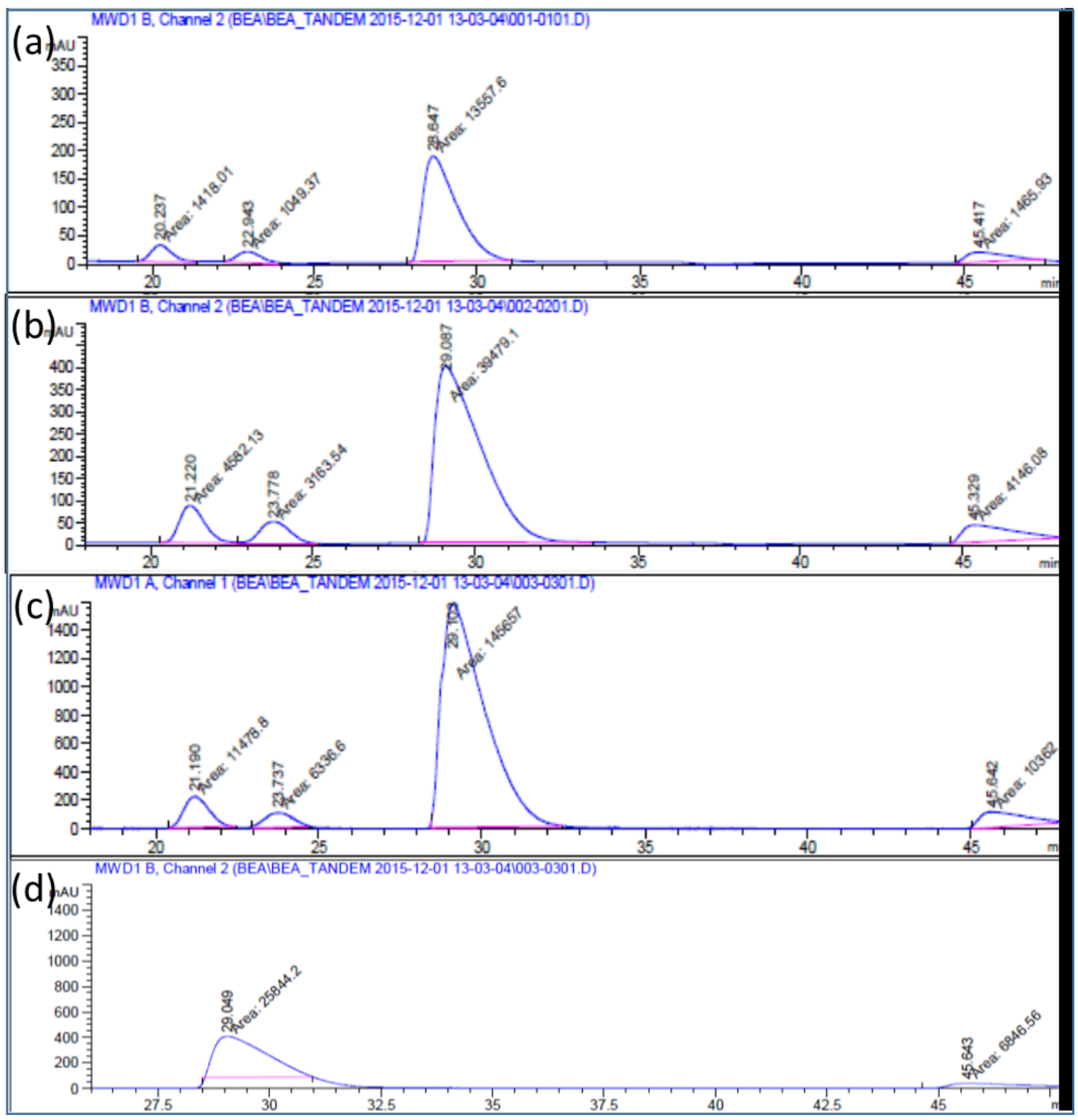

Figure ES 4.4 (a-d): HPLC chromatograms for enantiomeric ratio of final aldol adduct in (a) tandem reaction by SucVal8+ProvalDoc, (b) Direct aldol by SucVal8+ProValDoc, (c) Direct aldol by ProValDoc, (d) Direct aldol by ProVal8. 


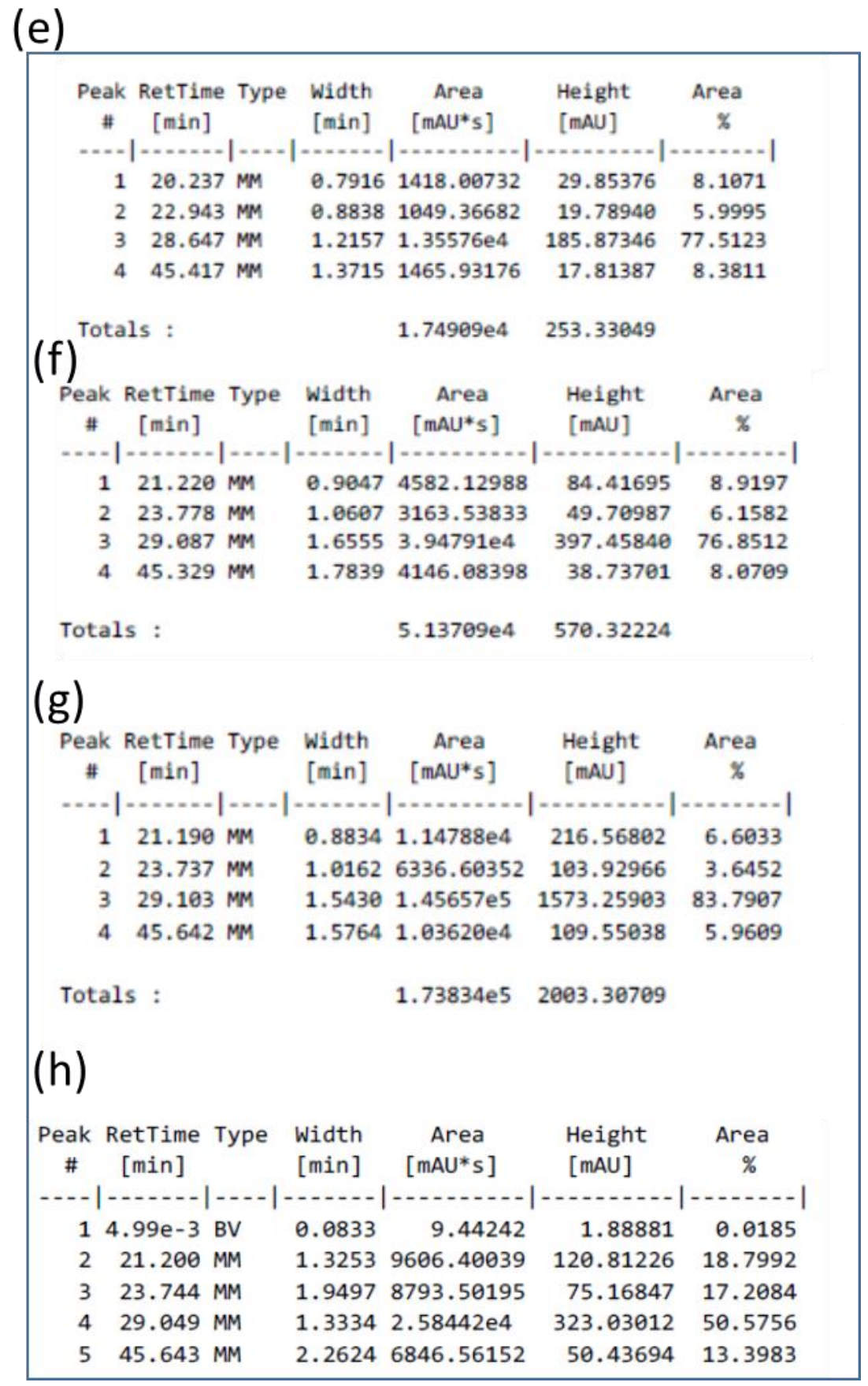

Figure ES 4.4 (e-h): Area distribution charts for enantiomeric ratio of final aldol adduct in (e) tandem reaction by SucVal8+ProvalDoc, (f) Direct aldol by SucVal8+ProValDoc, (g) Direct aldol by ProValDoc, (h) Direct aldol by ProVal8. 


\subsubsection{Solubility experiments}

It is essential to know the amount of molecules present in the solution phase for different gelators, and thus check the catalysis carried out at this concentration to see the difference with catalysis by gel. The amount of molecules present in soluble state can be determined by NMR as molecules in gel are NMR silent. Using an internal standard of known concentration (hydroquinone) at $30{ }^{\circ} \mathrm{C}$ the amount of molecules in solution was determined. Detailed procedure for previously reported solubility constant of the molecules can be found in the literature. ${ }^{11,32,33}$ The solubility constant of ProValDoc was below the detection limit of $500 \mathrm{MHz}{ }^{1} \mathrm{H}$ NMR so experiments were done at $0.1 \mathrm{mM}$. (SucVal8: $1.0 \mathrm{mM}$, ProValDoc $<: 0.2 \mathrm{mM}$ (experiments were done at $0.1 \mathrm{mM}$ for solution state), ProVal8: $1.5 \mathrm{mM})$.

\subsubsection{FTIR of xerogels}

The gels at MGC were washed with water to remove salts and non-aggregating parts and then lyophilized. The resultant dry solid was diluted with $200-300 \mathrm{mg}$ of $\mathrm{KBr}$ in an agate mortar and then was compressed at 10 ton c.a. 2-3 minutes to make pellets. JASCO FTIR6200 spectrometer was used to obtain the IR spectra. 

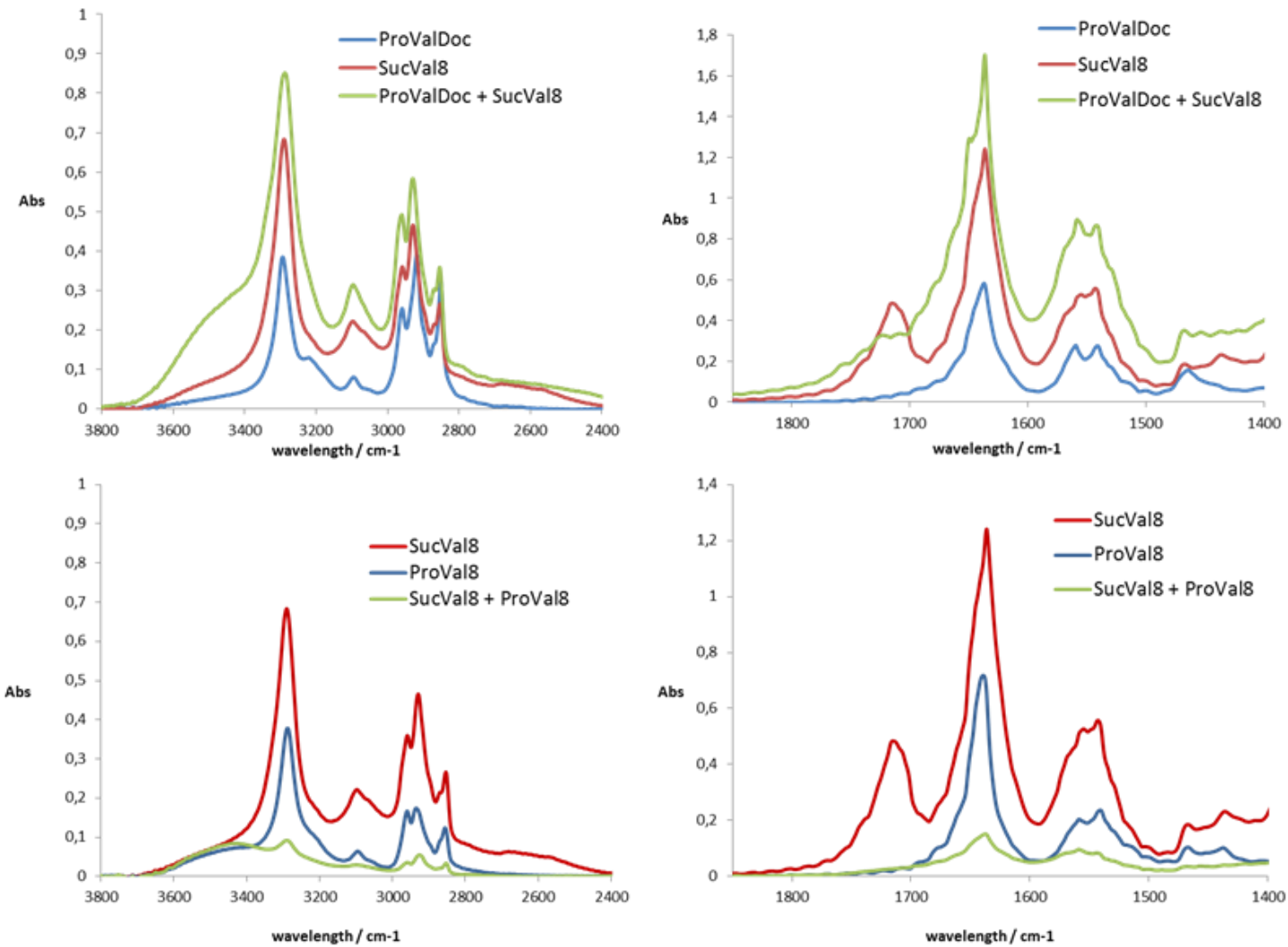

Figure ES 4.5: FTIR of freeze-dried xerogels of one-component and mixed samples (KBr pellets). 


\subsection{References}

1. T. L. Lohr, T. J. Marks, Nat. Chem., 2015, 7, 477.

2. D. Voet, J. G. Voet, C.W. Pratt, Fundamentals of Biochemistry: Life at the Molecular Level, $2^{\text {nd }}$ Ed, Wiley, 2006.

3. B. Helms, S. J. Guillaudeu, Y. Xie, M. McMurdo, C. J. Hawker, J. M. J. Fréchet, Angew. Chem. Int. Ed., 2005, 44, 6384.

4. P. Li, C.-Y. Cao, Z. Chen, H. Liu, Y. Yu, W. G. Song Chem. Commun., 2012, $48,10541$.

5. D. Vernekar, D. Jagadeesan, Cat. Sci. Tech.., 2015, 5, 4029.

6. J. Gao, X. Zhang, Y. Lu, S. Liu, J. Liu, Chem. Eur. J., 2015, 21, 7403.

7. L. M. Aguirre-Díaz, F. Gandara, M. Iglesias, N. Snejko, E. Gutierrez-Puebla, M. A. Monge, J. Am. Chem. Soc., 2015, 125, 6132.

8. M. Raynal, P. Ballester, A. Vidal-Ferran, P. W. N. M. van Leeuwen, Chem. Soc. Rev., 2014, 43, 1660.

9. M. Raynal, P. Ballester, A. Vidal-Ferran, P. W. N. M. van Leeuwen, Chem. Soc. Rev. , 2014, 43, 1734.

10. F. Rodríguez-Llansola, B. Escuder, J. F. Miravet, J. Am. Chem. Soc., 2009, $131,11478$.

11. F. Rodríguez-Llansola, J. F. Miravet, B. Escuder, Chem. Commun., 2009, 7303.

12. B. Escuder, F. Rodríguez-Llansola, J. F. Miravet, New J. Chem., 2010, 34, 1044.

13. C. Berdugo, J. F. Miravet, B. Escuder Chem. Commun., 2013, 49, 10608.

14. N. Singh, M. Tena-Solsona, J. F. Miravet, B. Escuder, Isr. J. Chem., 2015, 55, 711. 
15. M. M. Safont-Sempere, G. Fernández, F. Würthner, Chem. Rev., 2011, 111, 5784.

16. M. Kölbel, F. M. Menger, Langmuir, 2001, 17, 4490.

17. A. Heeres, C. van der Pol, M. Stuart, A. Friggeri, B. L. Feringa, J. van Esch, J. Am. Chem. Soc. 2003, 125, 14252.

18. A. Brizard, M. Stuart, K. van Bommel, A. Friggeri, M. de Jong, J. van Esch, Angew. Chem. Int. Ed., 2008, 47, 2063.

19. D. K. Kumar, J. W. Steed, Chem. Soc. Rev., 2014, 43, 2080.

20. J. R. Moffat, D. K. Smith, Chem. Commun., 2009, 316.

21. M. M. Smith, D. K. Smith, Soft Matter, 2011, 7, 4856,

22. K. L. Morris, L. Chen, J. Raeburn, O. R. Sellick, P. Cotanda, A. Paul, P. C. Griffiths, S. M. King, R. K. O'Reilly, L. C. Serpell, D. J. Adams, Nat. Commun., 2013, 4, 1480.

23. J. Raeburn, B. Alston, J. Kroeger, T. O. McDonald, J. R. Howse, P. J. Cameron, D. J. Adams, Mater. Horiz., 2014, 1, 241.

24. F. Rodríguez-Llansola, B. Escuder, J. F. Miravet, Org. Biomol. Chem., 2009, 7, 3091.

25. M. Fontanillo, C. A. Angulo-Pachón, B. Escuder, J. F. Miravet, J. Coll. Interf. Science, 2013, 412, 65.

26. P. G. M. Wuts, T. W. Greene, Protection for the Carbonyl Group, in Greene's Protective Groups in Organic Synthesis, John Wiley \& Sons: Hoboken, 2006, 431.

27. S. Díaz-Oltra, C. Berdugo, J. F. Miravet, B. Escuder, New J. Chem., 2015, 39, 3785. 
28. C. Colquhoun, E. R. Draper, E. G. B. Eden, B. N. Cattoz, K. L. Morris, L. Chen, T. O. McDonald, A. E. Terry, P. C. Griffiths, L. C. Serpell, D. J. Adams, Nanoscale, 2014, 6, 13719.

29. B. Escuder, S. Martí, J. F. Miravet, Langmuir, 2005, 21, 6776.

30. S. Fleming, S. Debnath, P. W. J. M. Frederix, N. T. Hunt, R. V. Ulijn, Biomacromolecules, 2014, 15, 1171.

31. J. Lu, J. Dimroth, M. Weck, J. Am. Chem. Soc., 2015, 137, 12984 and references cited therein.

32. B. Escuder, M. Llusar, J. F. Miravet, J. Org. Chem., 2006, 71, 7747.

33. A. R. Hirst, I. A. Coates, T. R. Boucheteau, J. F. Miravet, B. Escuder, V. Castelletto, I. W. Hamley, D. K. Smith, J. Am. Chem. Soc, 2008, 130, 9113.

34. J. L. Hunter, J. Bechhoefer, Rev. Sci. Instr., 1993, 64, 1868.

35. N. Mase Y. Nakai, N. Ohara, H Yoda, K. Takabe, F. Tanaka, C. F. Barbas, J. Am. Chem. Soc., 2006, 128, 734.

36. A. J. A. Cobb, D. M. Shaw, D. A. Longbottom, J. B. Gold, S. V. Ley, Org. Biomol. Chem, 2005, 3, 84.

37. S. Rossi, M. Benaglia, A. Genoni, T. Benincori, G. Celentano, Tetrahedron, 2011, $67,158$. 


\section{Chapter 5}

\section{A supramolecular self-sorted system as bifunctional catalyst for anti-selective direct one pot Mannich reaction}




\subsection{Introduction}

The $\beta$-amino carbonyl compounds obtained by Mannich reactions are very useful for natural product, pharmaceuticals and plant growth regulators synthesis among others (Figure 5.1). ${ }^{1-3}$ Lewis and Brønsted acid chemistry has been extensively used for such highly important $\mathrm{C}-\mathrm{C}$ bond formation reactions. ${ }^{4-6}$

(a)

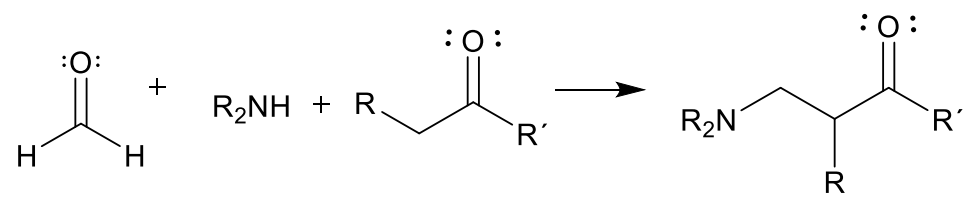

(b)

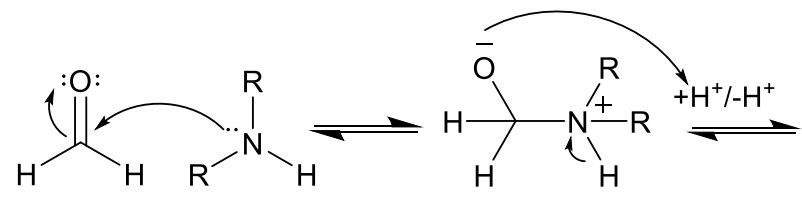

(c)
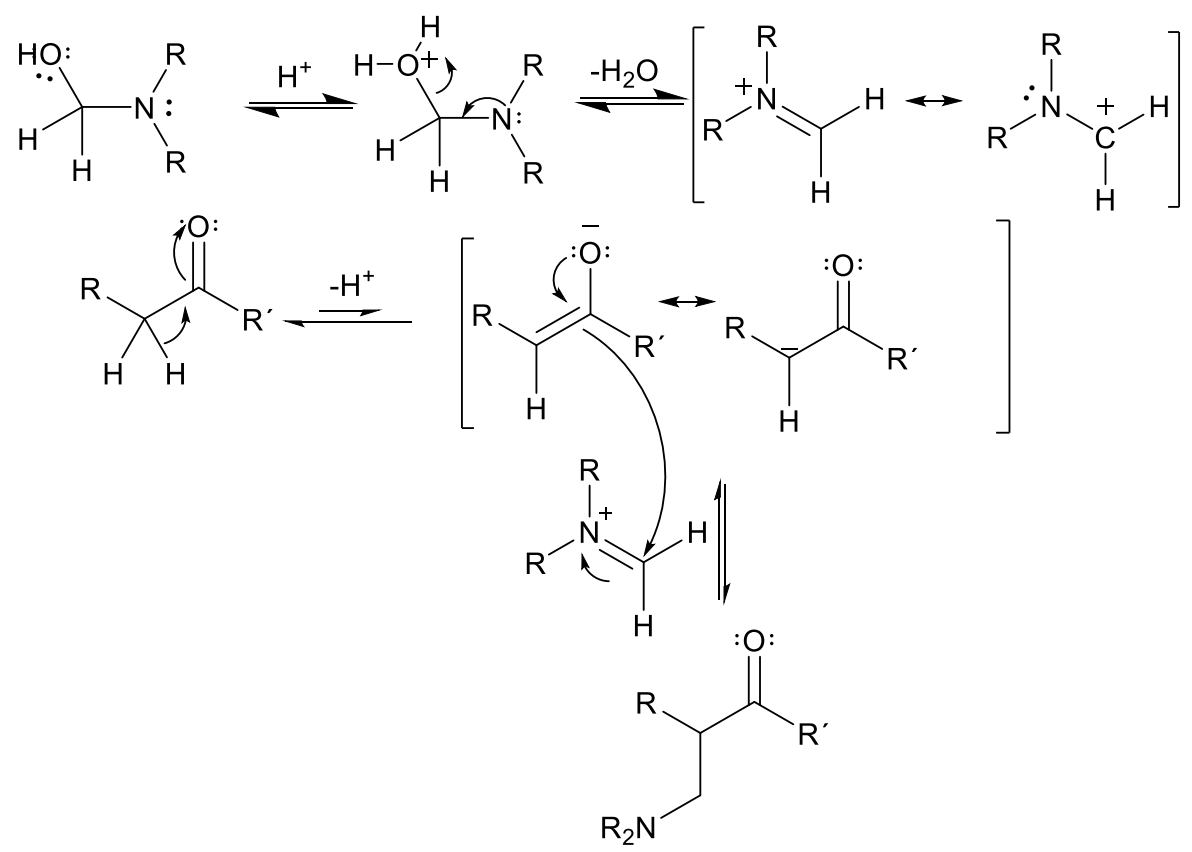

Figure 5.1: (a) An example of an acid catalyzed Mannich reaction, (b) mechanism of imine formation, and (c) addition of imine to ketone to give the final Mannich product.

These catalysts cannot be used for direct Mannich reaction as they get inactivated in presence of amine or by the water formed during imine formation. ${ }^{7}$ The obtained stereoselectivity is usually below par as a single Lewis acid centre is not effective to attain 
high streoselectivity. ${ }^{8}$ On the other hand the use of proline and other chiral organo catalysts has made it possible to attain better stereoselectivity but at the cost of lower yields, high catalyst loading and use of toxic organic solvents due to their low solubility in water (Figure 5.2). ${ }^{9-11,27}$

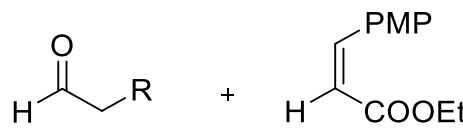

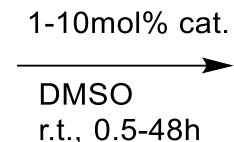<smiles>[R]C(C(C)=O)[C@H](N=[NH2+])C(=O)OCC</smiles><smiles>[R]C(C)CCCCCC(=O)O</smiles>

Figure 5.2: Anti-mannich-type reactions of aldehydes catalyzed by proline derived catalysts. ${ }^{27}$

Such problems are common in catalysis and asymmetric synthesis which has driven the scientific community to work on bifunctional systems, in which different parts of a catalyst or different catalyst work in a concert to promote one or more reactions simultaneously (Figure 5.3). ${ }^{12,31}$

(a)

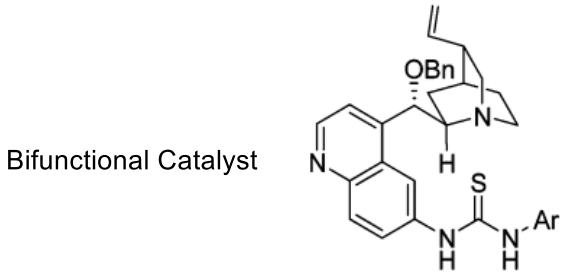

(b)

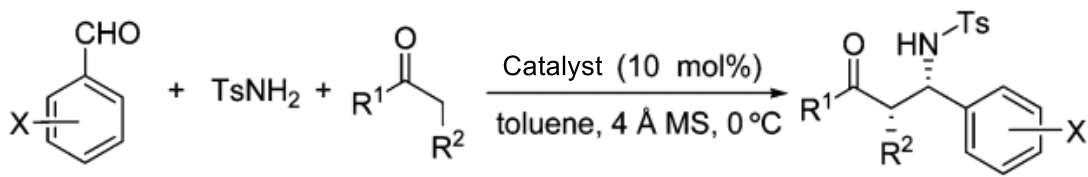

Figure 5.3: (a) A bifunctional quinidine thiourea catalyst (b) Mannich reaction between aromatic aldehyde, unfunctionalized ketone and p-toluene sulfonamide carried out by the catalyst. ${ }^{31}$

Developing such catalyst are either result oriented or in quest of emulating enzymes' selectivity and efficiency. Such bifunctional systems in theory can activate electrophilic and nucleophilic sites simultaneously but face problems on execution such as poor optical induction, instability in air and water, tedious synthetic procedures etc. ${ }^{12}$ They come with an inevitable risk of self-quenching meaning a Lewis acid can react with Lewis base or 
with nucleophilic reagent rendering the catalyst inactive. ${ }^{12}$ Hence, the development of low-cost bifunctional systems being able to demonstrate high catalytic activity and stereoselectivity is a major issue in asymmetric catalysis. ${ }^{4-6,9-12}$

An interesting concept is to bring supramolecular chemistry, catalysis and asymmetric synthesis together to overcome such hurdles avoiding tedious synthetic routes. The bottom-up approach can enable us to spatially confine the self-assembly of hydrogelators bearing mutually incompatible catalytic groups without inactivating each other. Such self-assembling molecules with catalytic groups have been demonstrated to show enzyme like catalysis for wide range of reactions such as ester hydrolysis, Michael addition, aldol reaction, Henry reaction, etc. ${ }^{13-15}$

The supramolecular organisation and molecular packing of these molecules upon selfassembly results, as mentioned before in several new properties such as hydrophobic pockets, cooperativity amongst the functional groups, $\mathrm{pKa}$ shifts, increased acidity/basicity etc. enabling them to perform reactions efficiently at high rates. ${ }^{16-19}$ Here we demonstrate the use such a self-sorted system where two different catalystsSucVal8 and ProValDoc with mutually incompatible groups can work together in the same pot to carry out a highly atom efficient direct Mannich reaction (Scheme 5.1, 5.2). SucVal8 is a bolaamphiphilic hydrogelator bearing acidic groups with MGC of $6 \mathrm{mM}$ and ProValDoc is an amphiphilic gelator with proline group with an MGC of $5.7 \mathrm{mM}$. Both the gelators form self-standing transparent gels on heating followed by sonication and left to stand at room temperature. These hydrogelators have the tendency to self-sort under thermodynamic equilibrium when mixed together due to their structural differences, which has been previously used to attain tandem reactions (deacetalisation- 
aldol, see Chapter 4) in the same pot (Scheme 5.1). ${ }^{20}$ As represented in Scheme 5.2a we tend to utilise both the acid appended and proline appended hydrogelators individually for catalysis of one pot direct Mannich reaction between aniline, benzaldehyde and cyclohexanone. When present in one pot owing to their self-sorting we expect them to activate the nucleophilic and electrophilic sites simultaneously without deactivating each other to catalyse the reaction in concert. Scheme $\mathbf{5 . 2 b}$ represents a more complex reaction when benzaldehyde replaced by benzaldehyde dimethyl acetal is expected to be deprotected by SucVal8 and further undergo a cascade reaction with aniline and cyclohexanone catalysed by SucVal8 to give the final Mannich product. For the mixed system of SucVal8+ProValDoc we expect a better stereoselectivity owing to the contribution by ProValDoc for Mannich reaction.

(a)

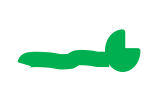<smiles>CCCCCCCCCCCNC(=O)[C@@H](NC(=O)[C@H]1CCCN1)C(C)C</smiles>

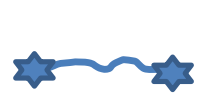<smiles>CC(C)[C@H](NC(=O)CCC(=O)O)C(=O)O</smiles>

(b)
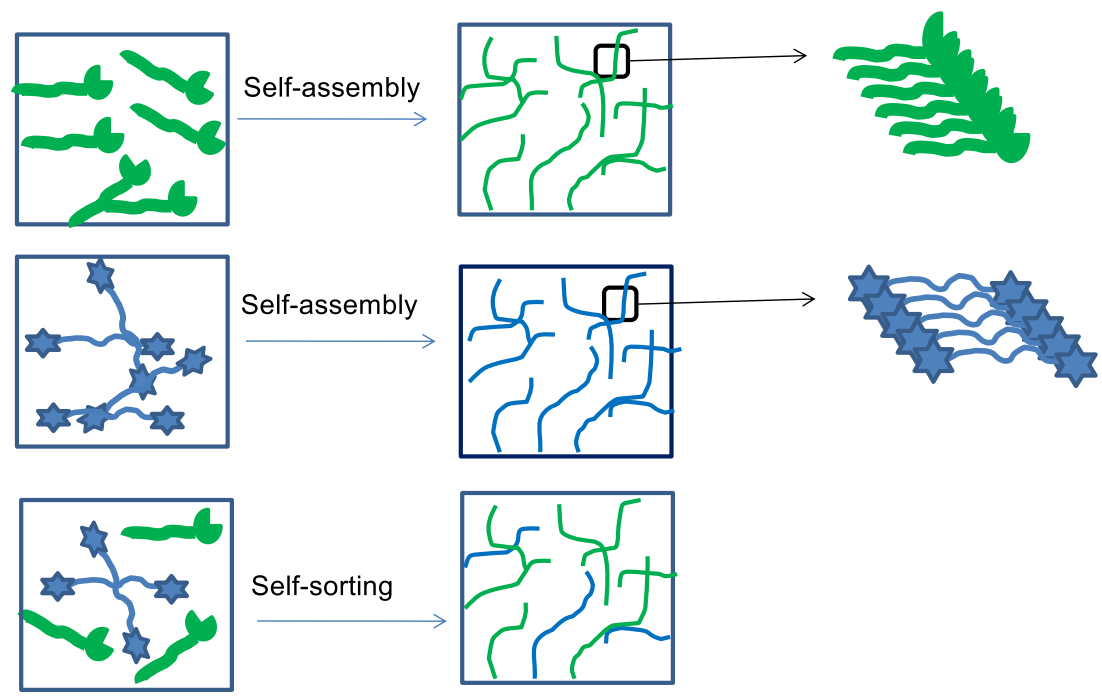

Scheme 5.1: (a) Molecular structures of the two catalytic hydrogelators (b) Cartoon representation of the independent self-assembly and self-sorting of the hydrogelators. 
(a)

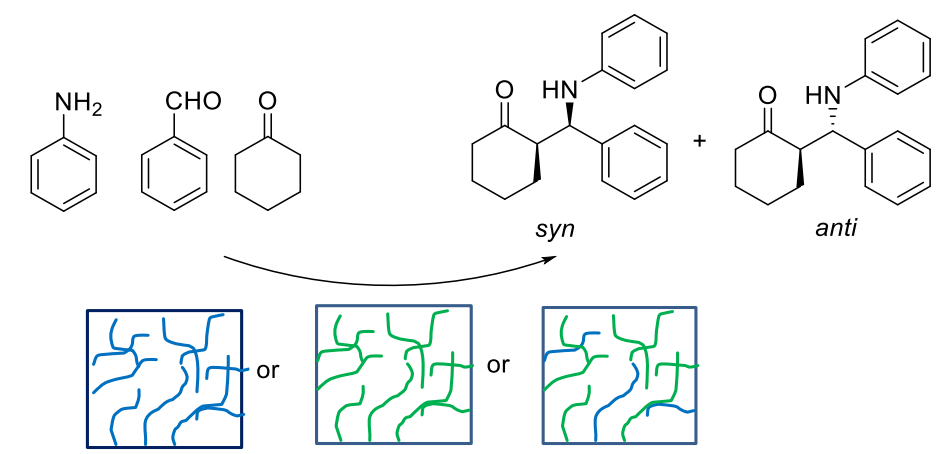

(b)

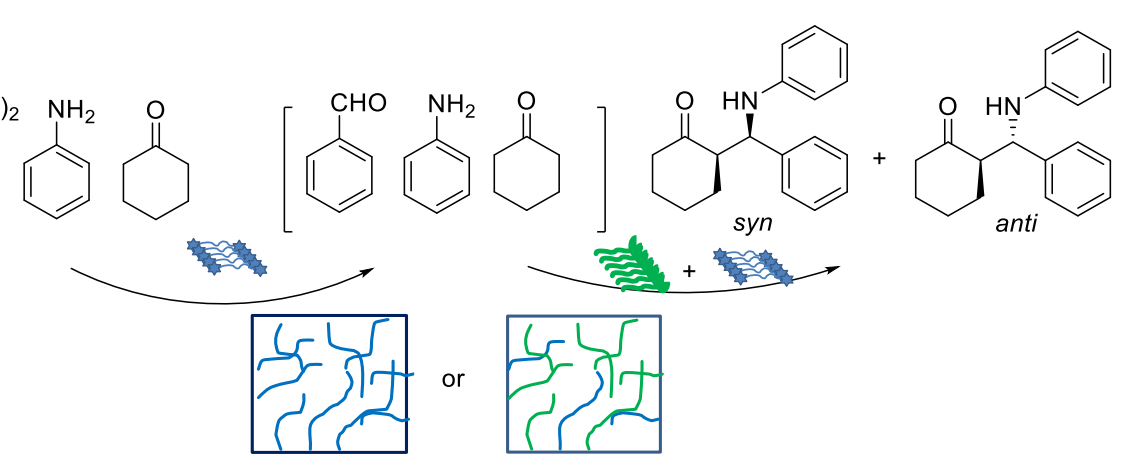

Scheme 5.2: (a) Direct three component Mannich reaction performed by the three different assembling systems (b) Cascade reaction performed by SucVal8 and the double network hydrogel of SucVal8 and ProValDoc.

\subsection{Results and discussion}

Both the gelators have been synthesized using the procedure stated in Chapter 4. Both the gelators at their respective MGC form transparent white hydrogels, both when mixed together at their MGC give a transparent hydrogel as well. See Chapter 4 for more details.

\subsubsection{Catalysis}

\subsubsection{Direct three component Mannich reaction}

We thus decided to check the catalytic activity of the gelators for one pot-direct three component Mannich reaction with unmodified aldehyde and ketone (benzaldehyde and cyclohexanone) and aniline. (Scheme 5.2a). (For direct Mannich reaction $113 \mathrm{mM}$ 
benzaldehyde, $114 \mathrm{mM}$ aniline and $1 \mathrm{M}$ cyclohexanone were added to the vortexed gels of SucVal8, ProValDoc, and SucVal8+ProvalDoc at their MGC). The kinetics for the progress of reaction was monitored using ${ }^{1} \mathrm{H}$ NMR as shown in Figure ES 5.1. The yields, $\mathrm{k}_{\mathrm{obs}}$, diastreoselectivity and enantiomeric ratio are shown in Table 5.1.

Table 5.1: Yield, diastereomeric ratio, enantiomeric ratio and the $k_{o b s}$ for direct Mannich reaction by different gelators.

\begin{tabular}{|l|l|l|l|l|}
\hline $\begin{array}{l}\text { Direct Mannich } \\
\text { Reaction }\end{array}$ & Yield \% & anti-syn & e.r. & kobs.(hr-1) \\
\hline SucVal8 (gel) & $84(12 \mathrm{hr})$ & $67: 33$ & $54: 46$ & 0.66 \\
\hline SucVal8 (sol.) & $54(12 \mathrm{hr})$ & $60: 30$ & $50: 50$ & 0.37 \\
\hline ProValDoc(gel) & $89(24 \mathrm{hr})$ & $85: 15$ & $73: 27$ & 0.69 \\
\hline $\begin{array}{l}\text { SucVal8+ProVaIDoc } \\
\text { (gel) }\end{array}$ & $82(16 \mathrm{hr})$ & $79: 21$ & $60: 40$ & 0.59 \\
\hline
\end{tabular}

Yield and diastreoselectivity calculated by ${ }^{1} \mathrm{H}$ NMR, enantiomeric ratio determined by chiral-OJ HPLC column.

The $\mathrm{k}_{\mathrm{obs}}$ for ProValDoc and SucVal8 were found to be comparable. SucVal8 was not highly diastereoselective (67:33) and the obtained enantiomeric ratio (53:47) was also poor. Concentration $(1 \mathrm{mM})$ at which molecules of SucVal8 are unable to form fibres was also tested for catalysis, the obtained reaction rate, diastereomeric ratio and enantiomeric ratio were even lower than that for the gel. The relatively higher selectivity and activity shown by the gel of SucVal8 could be explained by the cooperativity of different acid groups working together when SucVal8 forms fibres. The hydrophobic pockets formed by valine in the vicinity of the active site can facilitate the approach of hydrophobic substrates. The enolate ion and the imine can be easily stabilised in the transition state by the closely held acid groups and thus drive the reaction at a faster rate. Although the 
nucleophilic enolate ion can attack the imine from both the sides resulting in poor stereoselectivity (Figure 5.4).

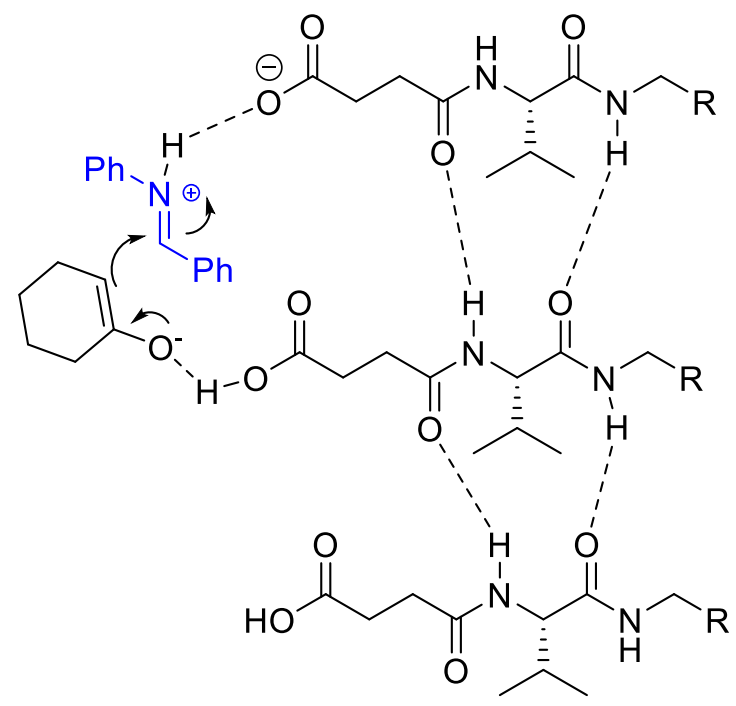

Figure 5.4: Mechanistic model of the Mannich reaction catalysed by SucVal8.

ProValDoc on the other hand yielded the final Mannich product in a high diastereomeric ratio (anti:syn-85:15) and enantiomeric ratio (72:28). Although when proline and related pyrrolidine derivatives that possess acidic groups are used as catalysts for Mannich-type reactions, typically syn-isomers are obtained as the major products. ${ }^{21-26}$ Having a bulky group and a proton donating group on or near the proline group can result in yielding an anti-selective reaction. ${ }^{27}$ Similarly here, capping the acid group of proline in ProValDoc with $L$-valine allowed not only to have access to hydrophobic pockets upon aggregation, but also provided a steric group in the same plane as proline. This steric hindrance could orient the enamine in a way allowing a preferable attack by the Re face of imine group on the $S i$ face of the enamine giving anti isomer in excess. The proton transfer from a neighbouring proline working in cooperation to the nitrogen of imine can stabilise the hydrogen bonded transition state making it more stereoselective and can also accelerate the reaction rate by increasing the electrophilicity of the imine (Figure 5.5a).The solubility constant of ProValDoc was below the detection limit of ${ }^{1} \mathrm{H}$ NMR (500MHz) 
so it was assumed that majority of the molecules (>97\%) were incorporated in the fibres and were responsible for catalysis. The gel comprised of self-sorted fibres of SucVal8 and ProValDoc did not show any improvement in the rate of conversion per catalytic site but in spite the presence of the poorly diastreoselective catalyst SucVal8 the net diastereoselectivity (79:21) was comparable to ProValDoc alone. We could consider the reaction proceeding not only by the two aforementioned transition states but a third transition state where the two catalysts are working as a typical bifunctional system activating the nucleophilic and electrophilic centres simultaneously. The imine can be stabilised by hydrogen bonding and the nitrogen gets a proton from the acid groups making it more electrophilic to attack on the chiral enamine formed by cyclohexanone and proline group (Figure 5.5b). 
(a)

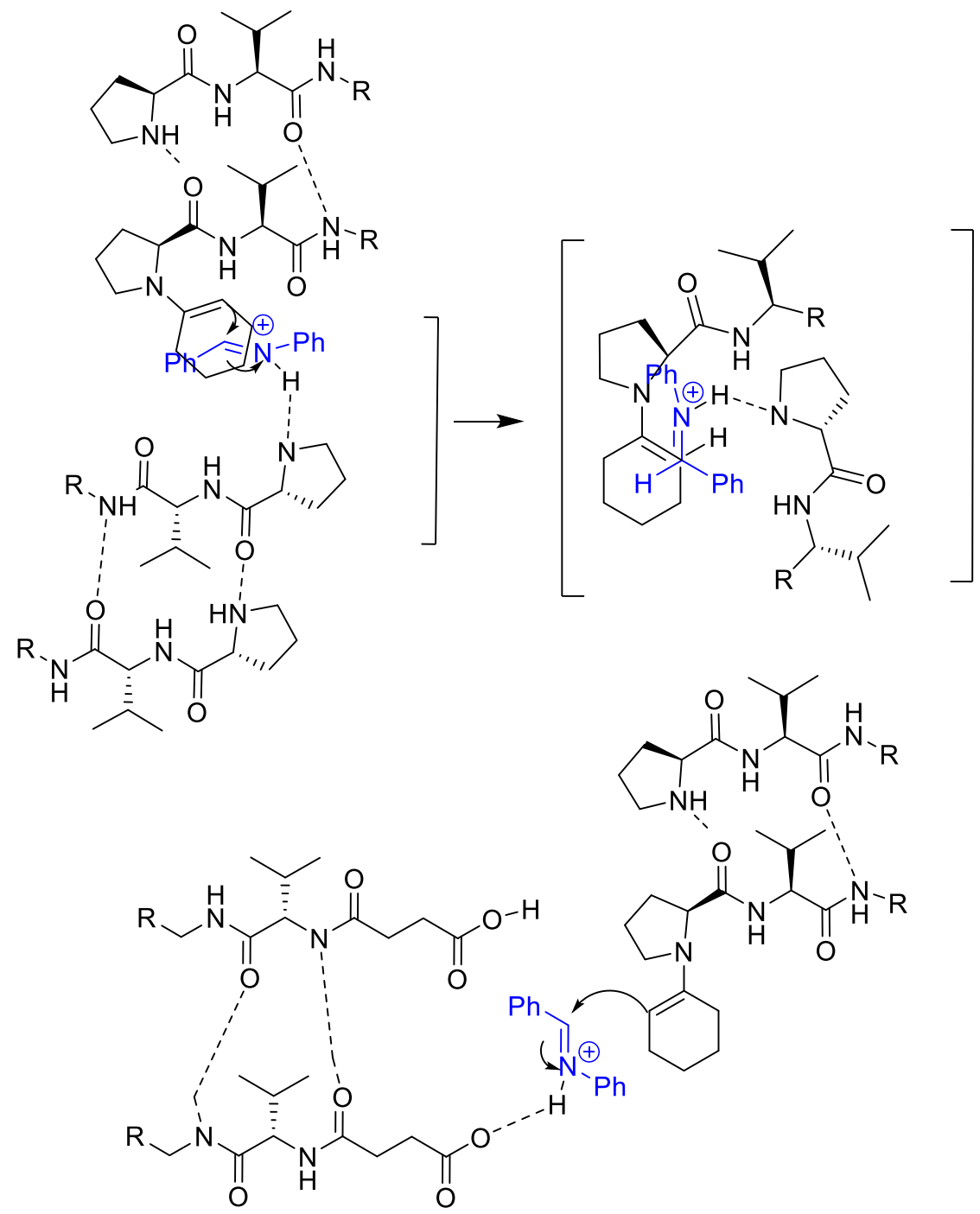

Figure 5.5: Mechanistic model for the Mannich reaction catalysed by (a) ProValDoc, (b) A bifunctional system in which SucVal8 activates the electrophilic centre and ProValDoc activates the nucleophilic centre in the mixed gel.

\subsubsection{Three component Mannich reaction using benzaldehyde dimethyl acetal,}

\section{aniline and cyclohexanone}

The direct one pot Mannich reaction in itself is a complex three component reaction but we decided to increase the complexity of the same system by using a protected aldehyde but without changing or adding any new catalysts to the system to carry out the extra step. We decided to use benzaldehyde dimethyl acetaldehyde knowing the ability of acid based catalysts in this case SucVal8 to be able to perform its deacetalisation into subsequent aldehyde (see Chapter 4). We first checked SucVal8 for the cascade reaction of 
deacetalisation followed by mannich reaction. To a vortexed $0.8 \mathrm{~mL}$ gel of $6 \mathrm{mM}$ SucVal8 was added $113 \mathrm{mM}$ benzaldimethyl acetaldehyde, $114 \mathrm{mM}$ aniline and $1 \mathrm{M}$ cyclohexanone. $83 \%$ of final mannich product was observed in $118 \mathrm{hr}$ with a poor diastereoselectivity of 66:34 anti:syn (e.r. (anti).-52:48). On the other hand just using ProValDoc gave the final product in a very low yield of $14 \%$ in the same time (Table

\section{2)}

Table 5.2: Yield, diastereomeric ratio and enantiomeric ratio for final mannich product obtained using benzaldehyde dimethyl acetal, aniline and cyclohexanone by catalysis from different hydrogelators.

\begin{tabular}{|l|l|l|l|}
\hline Cascade Reaction & Yield \% & anti:syn & e.r. \\
\hline SucVal8 (gel) & $83(118 \mathrm{hr})$ & $66: 34$ & $52: 48$ \\
\hline SucVal8 (sol.) & $51(118 \mathrm{hr})$ & $62: 38$ & $50: 50$ \\
\hline ProValDoc(gel) & $14(118 \mathrm{hr})$ & $76: 24$ & $65: 35$ \\
\hline $\begin{array}{l}\text { SucVal8+ProValDoc } \\
\text { (gel) }\end{array}$ & $77(110 \mathrm{hr})$ & $76: 24$ & $61: 39$ \\
\hline
\end{tabular}

Yield and diastreoselectivity calculated by ${ }^{1} \mathrm{H}$ NMR, enantiomeric ratio determined by chiral-OJ HPLC column.

Under the same reaction conditions using SucVal8+ProValDoc we could obtain $77 \%$ of the final product in $110 \mathrm{hr}$ with an improved diastereoselectivity of 76:24 (anti:syn) and enantiomeric ratio (anti)- 61:39 (Table 5.2). This improved streoselectivity of the final product could be attributed to the contribution of ProValDoc in the final step to give the Mannich product forming a cascade-tandem reaction system with SucVal8 in the same pot. 


\subsection{Conclusion}

In conclusion we have demonstrated the use of bottom-up approach to form a self-sorted system of catalytic hydrogelators to perform asymmetric catalysis avoiding selfquenching or deactivation. The hydrogelators with mutually incompatible groups could be employed for electrophilic and nucleophilic activation at the same time to give the final Mannich product in good yields and stereoselectivity. Utilising this concept the same system could be used for a complex cascade- tandem system. The acidic hydrogelator could perform the first step of deacetalisation followed by a sequential Mannich reaction in one pot. Though the final diastreomeric and enantiomeric ratios were not satisfactory. This could be improved by the use of mixed gel system in which the proline appended gelator could contribute to the second step and thus improving the final stereoselectivity and enantiomeric ratio of the Mannich product. Application of such supramolecular systems in asymmetric catalysis can allow to perform several complex reactions avoiding complex synthetic routes, stability issues and self-quenching issues faced by modern day catalysts.

\subsection{Experimental Section}

\subsubsection{Gels formation}

ProValDoc: A concentration of $6 \mathrm{mM}$ was dissolved in $0.8 \mathrm{~mL}$ of water in a screwed tight vial by heating at $100{ }^{\circ} \mathrm{C}$ followed by sonication for 1 minute and left to stand at 25 ${ }^{\circ} \mathrm{C}$.

SucVal8: A concentration of $6 \mathrm{mM}$ was dissolved in $0.8 \mathrm{~mL}$ of water in a screwed tight vial by heating at $100{ }^{\circ} \mathrm{C}$ and left to cool at $25^{\circ} \mathrm{C}$. 
ProValDoc+SucVal8: A concentration of $6 \mathrm{mM}$ of both the gelators was dissolved in $0.8 \mathrm{~mL}$ of water in a screwed tight vial by heating at $100{ }^{\circ} \mathrm{C}$, followed by sonication for 1 minute and left to stand at $25^{\circ} \mathrm{C}$.

\subsubsection{Catalysis}

To a gel of SucVal8 prepared at $6 \mathrm{mM}$ in $0.8 \mathrm{~mL}$ water, ProValDoc prepared at $6 \mathrm{mM}$ in $0.8 \mathrm{~mL}$ water was added Benzaldehyde/benzaldimethylacetal, aniline, cyclohexanone.

For the mixed gel of SucVal8 and ProValDoc both prepared at $6 \mathrm{mM}$ each was added benzaldehyde/benzaldehyde dimethyl acetal, aniline and cyclohexanone.

\subsubsection{Determination of the Mannich product}

Yield and the absolute stereochemistry of the final Mannich product was determined by comparison with previously reported literatures $4.64 \mathrm{ppm}(\mathrm{d}, J=7 \mathrm{~Hz}, \mathrm{CH}$, anti isomer), $4.82 \mathrm{ppm}(\mathrm{d}, J=4.2 \mathrm{~Hz}, \mathrm{CH}$, syn isomer $) .{ }^{28-30}$

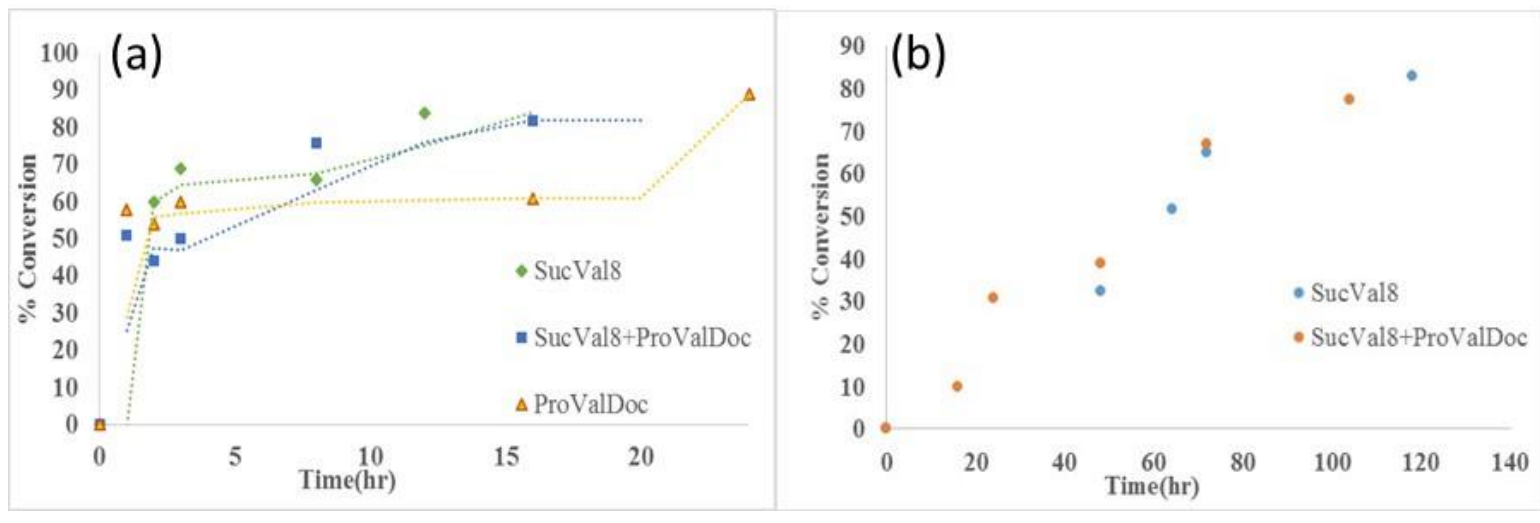

Figure ES 5.1: Comparison of kinetics of the formation of final Mannich product for different systems. 


\subsubsection{Determination of enantiomeric ratio}

The anti-product of the Mannich reaction by ProValDoc was purified by coloumn chromatography $\left(\mathrm{CHCl}_{2}: \mathrm{MeOH}\right.$ - 10:90) and crystallisation (MeOH:Hexane - 1:99). The enantiomeric ratio of the anti-isomer of the Mannich product was determined by chiral HPLC with a Daicel Chiral/cell OJ-H column using a eluent: 80:20 (Hex:IPA); $0.75 \mathrm{~mL} / \mathrm{min}$ flow rate; $\left.t_{R}=15.9 \mathrm{~min}, t_{R}=23.5 \mathrm{~min}\right]$

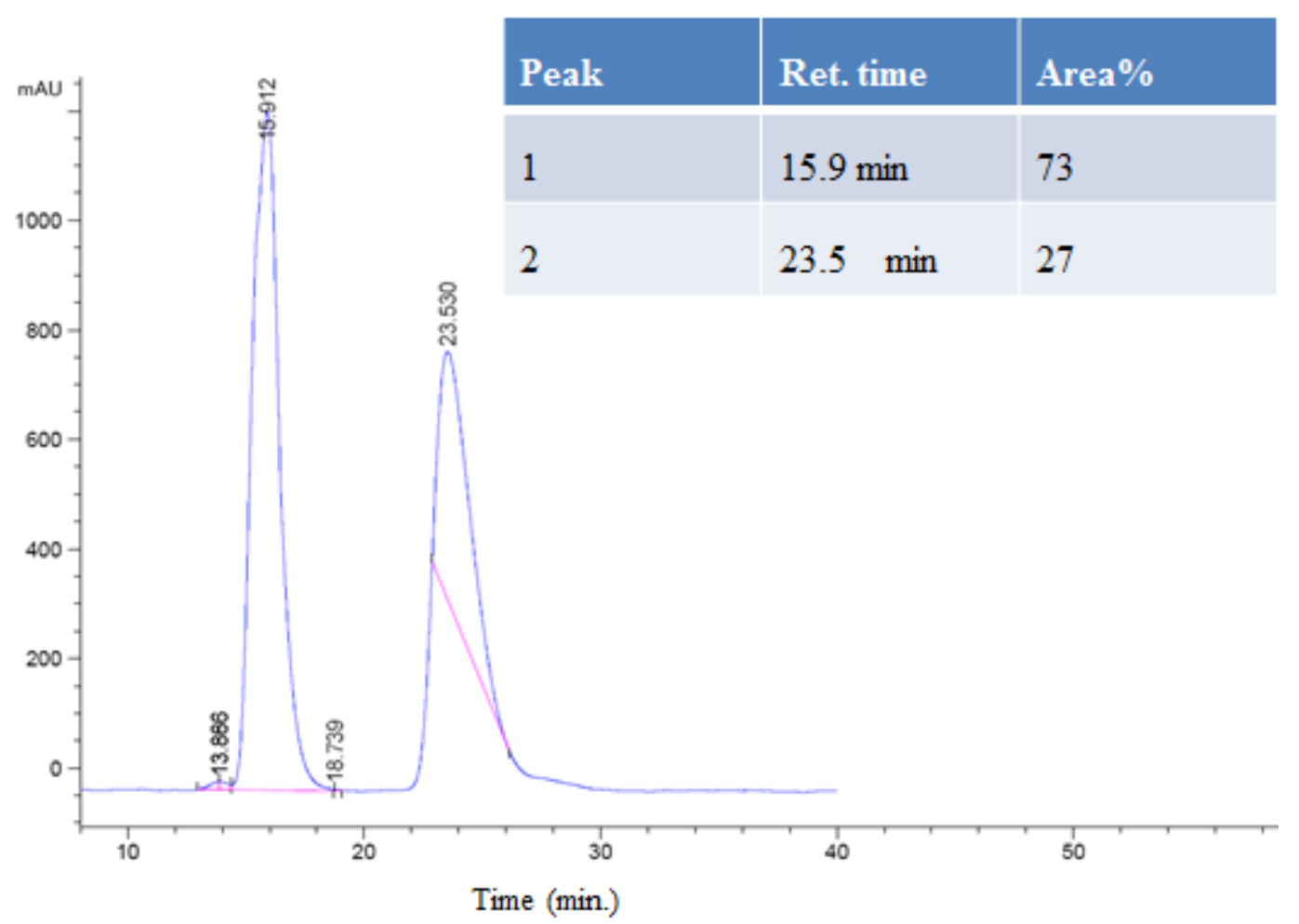

Figure ES 5.2: Enantiomers of anti-isomer obtained by direct Mannich reaction catalyzed by ProValDoc, inset showing area distribution. 


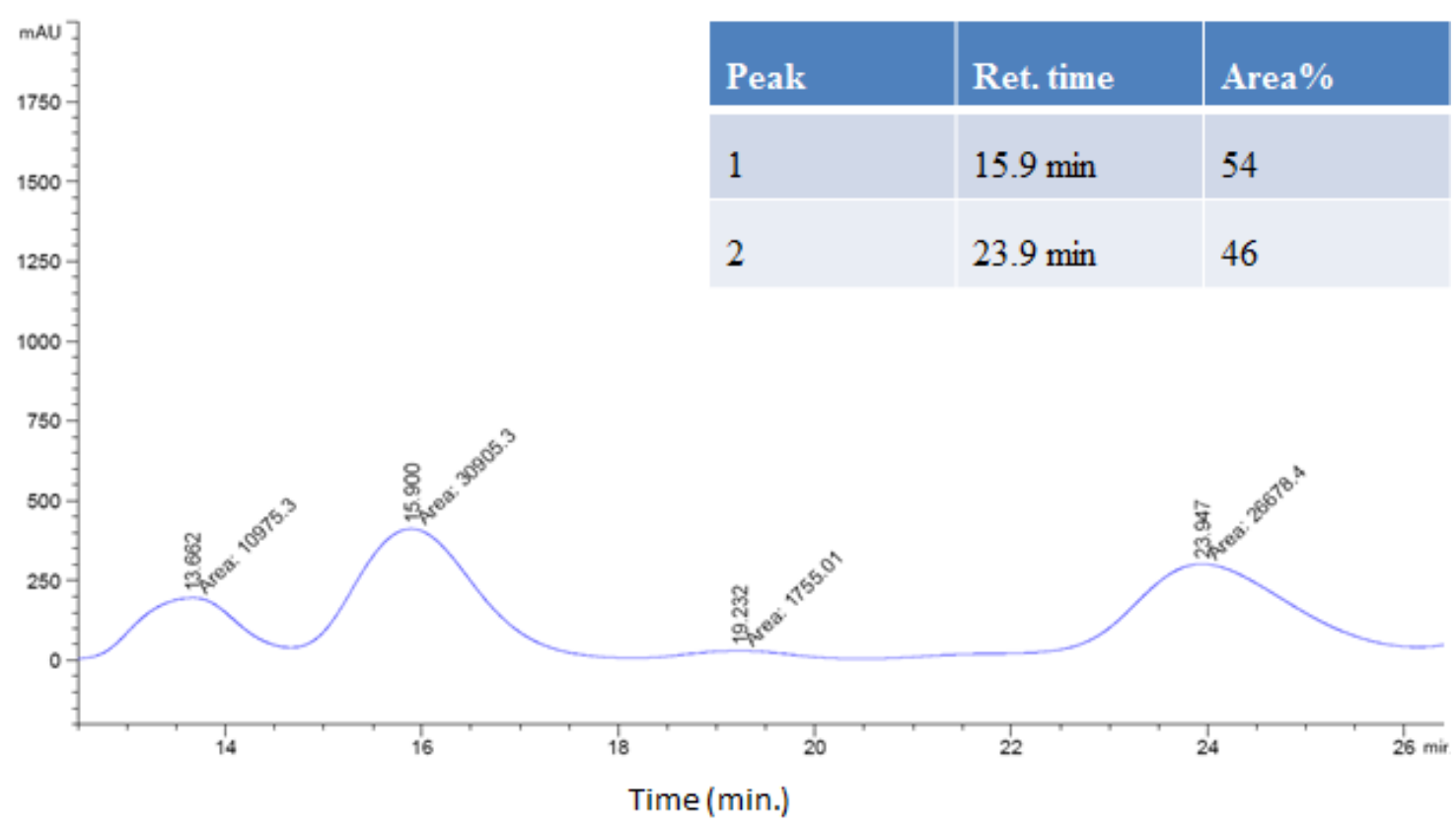

Figure ES 5.3: Diastreomers obtained by direct mannich reaction catalyzed by SucVal8, inset showing area distribution.

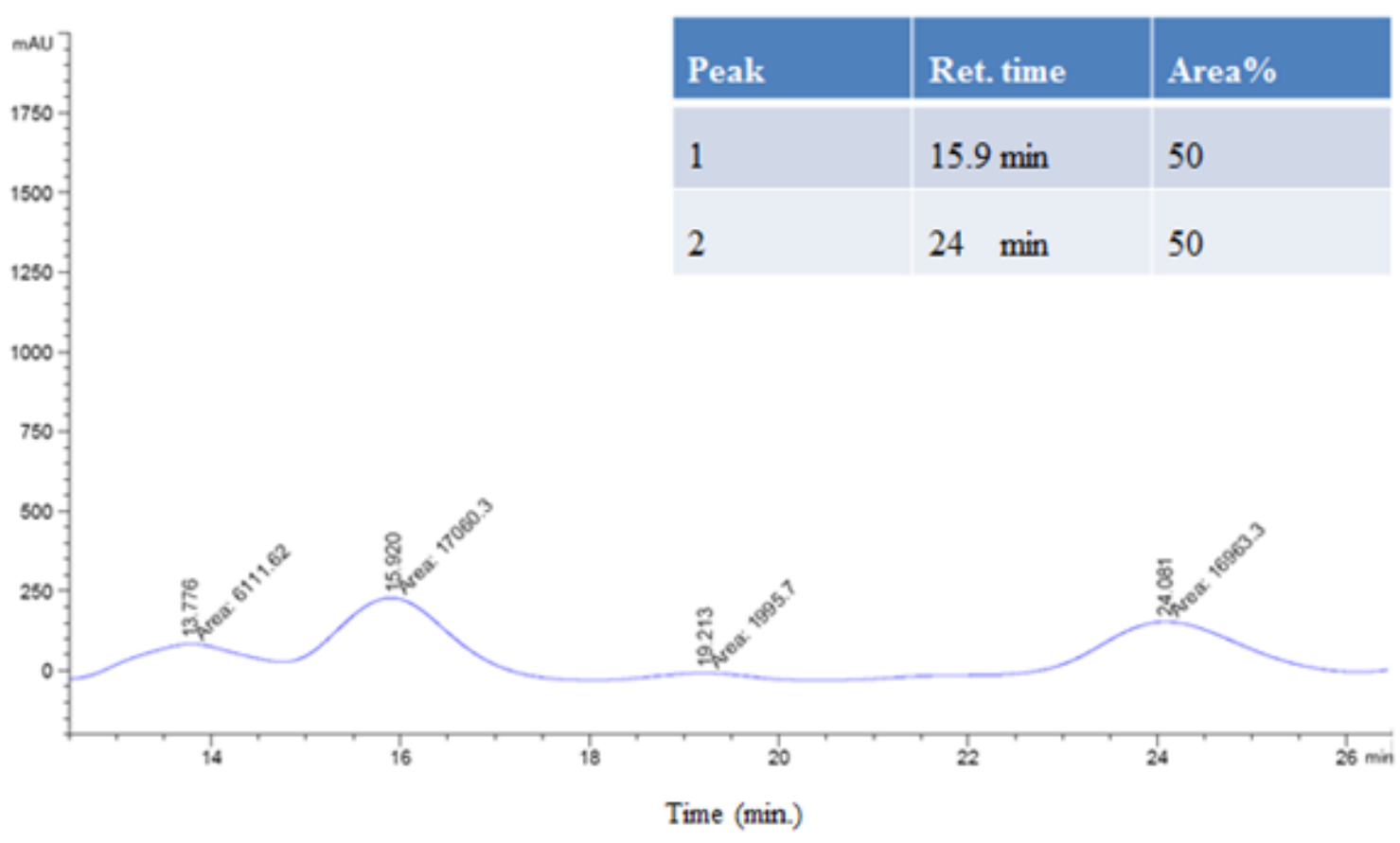

Figure ES 5.4: Diastreomers obtained by direct Mannich reaction catalyzed by SucVal8 solution, inset showing area distribution. 


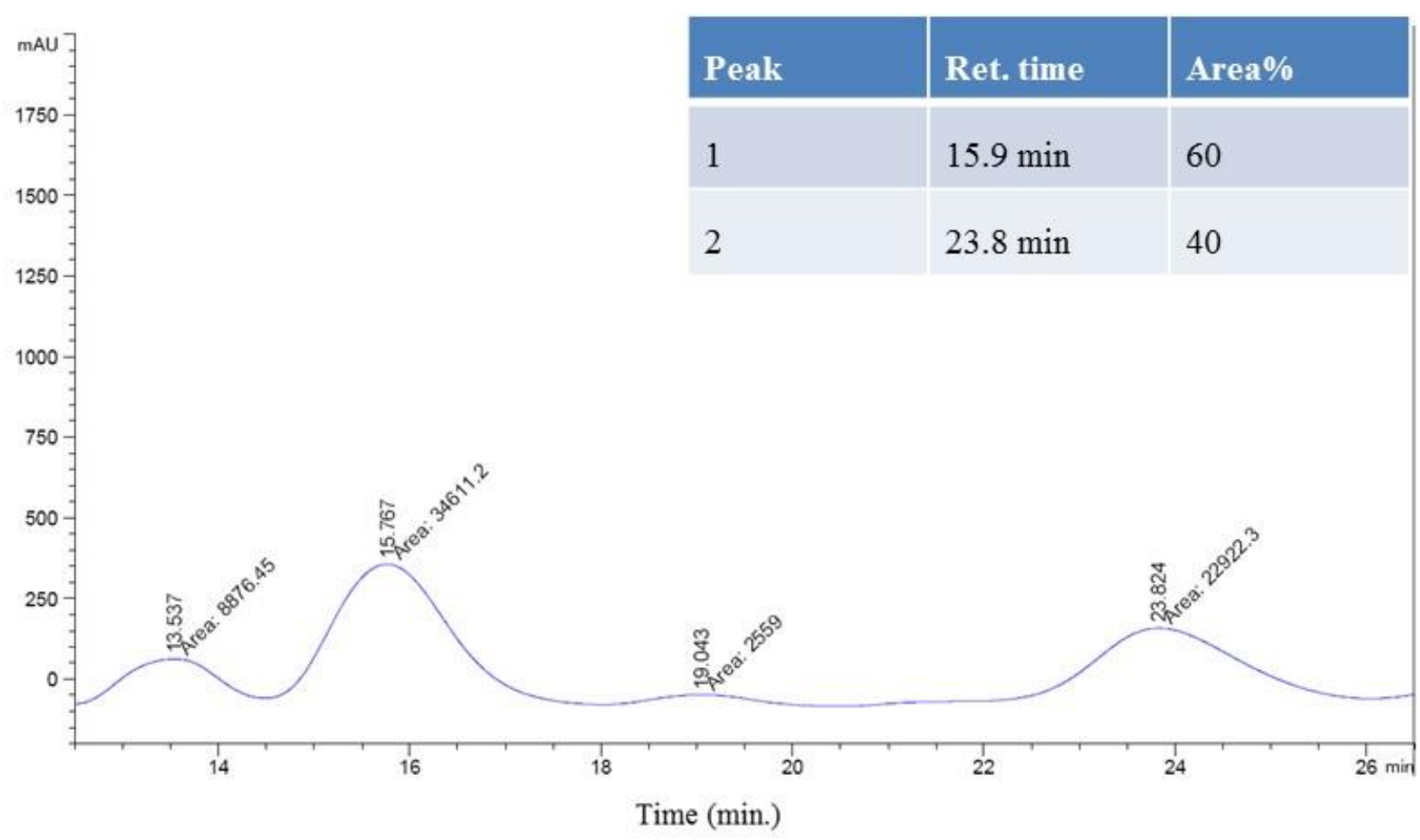

Figure ES 5.5: Diastreomers obtained by direct Mannich reaction catalyzed by SucVal8+ProValDoc, inset showing area distribution.

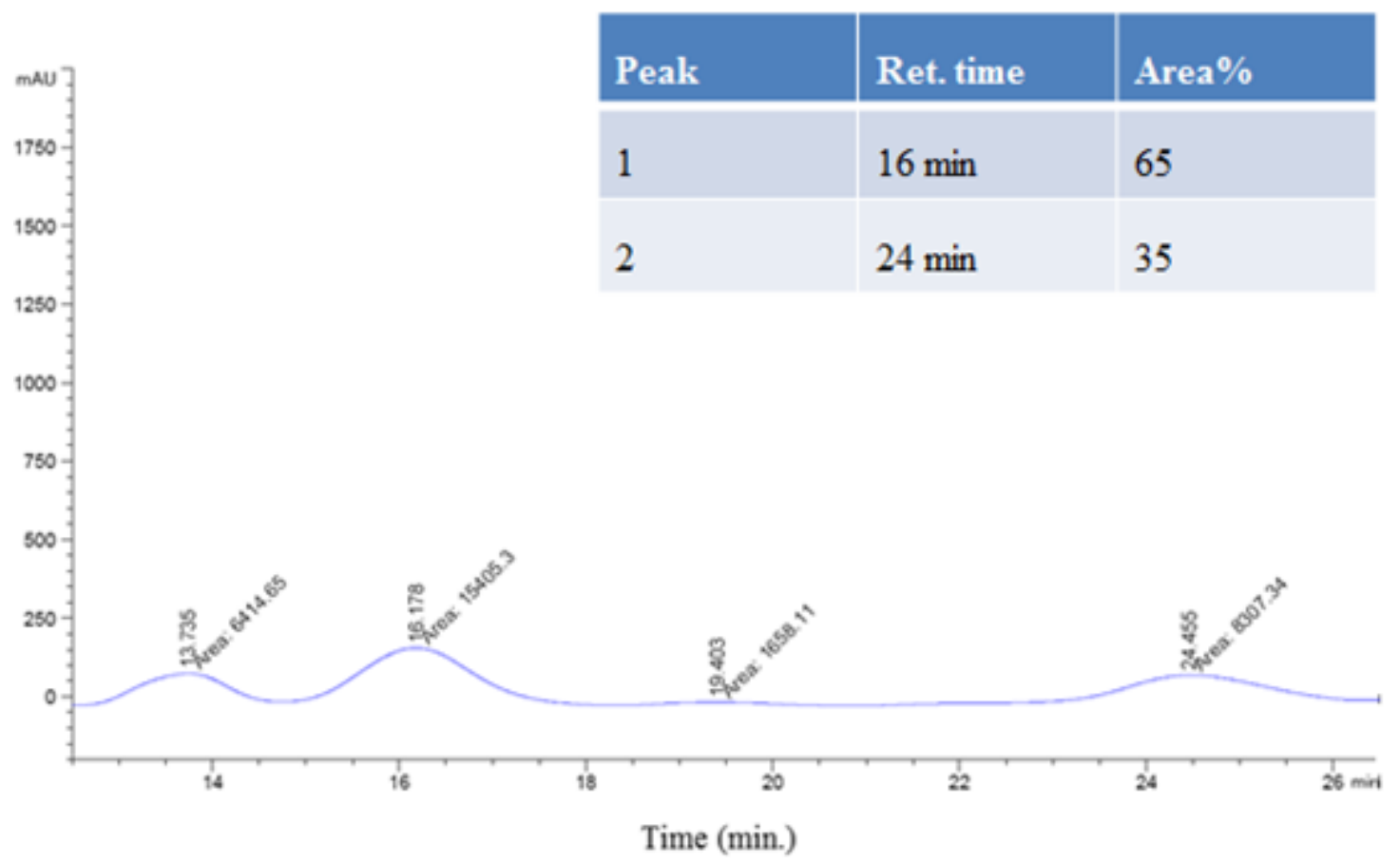

Figure ES 5.6: Diastreomers obtained by cascade reaction catalyzed by ProValDoc, inset showing area distribution. 


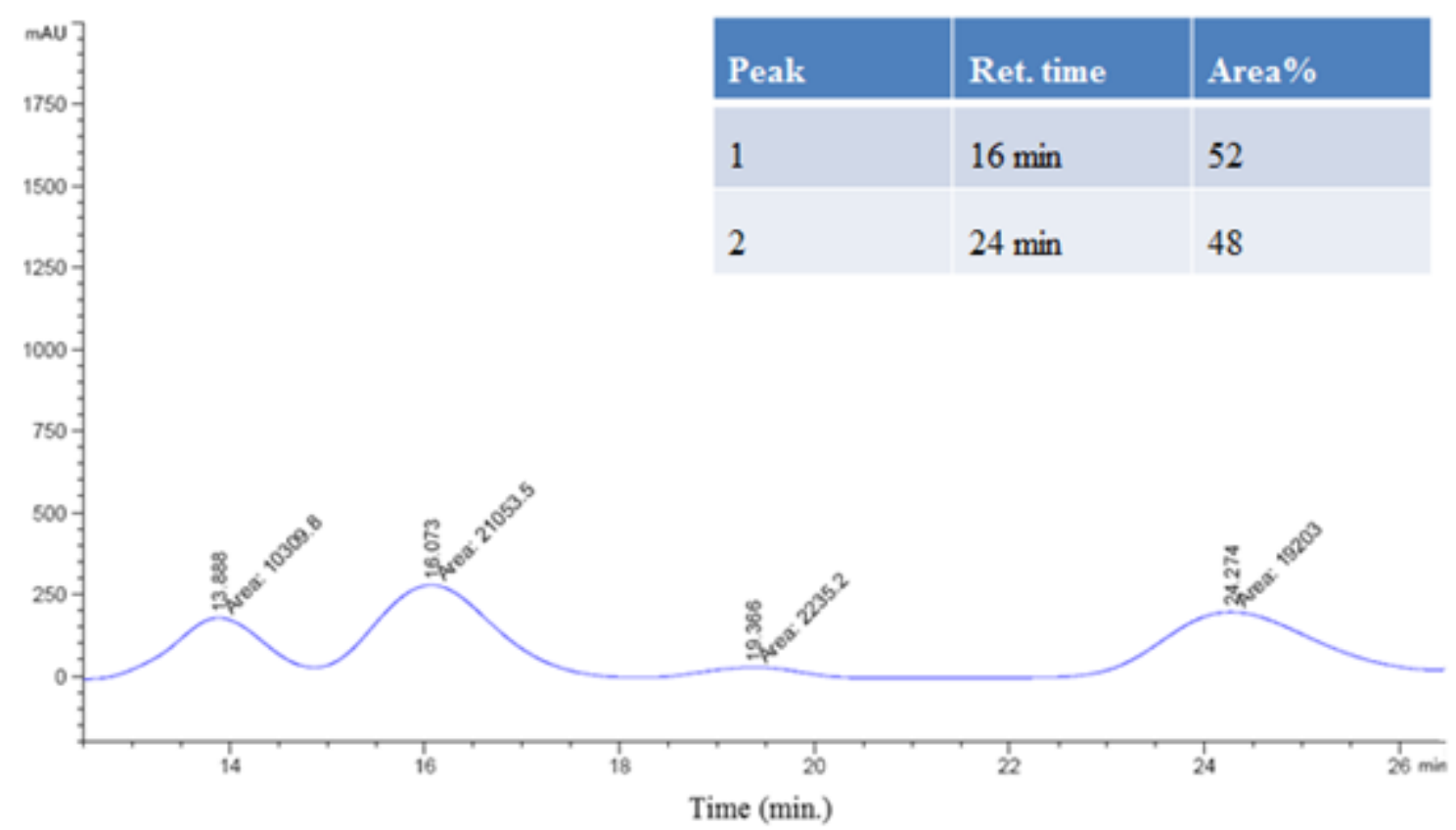

Figure ES 5.7: Diastreomers obtained by cascade reaction catalyzed by SucVal8, inset showing area distribution

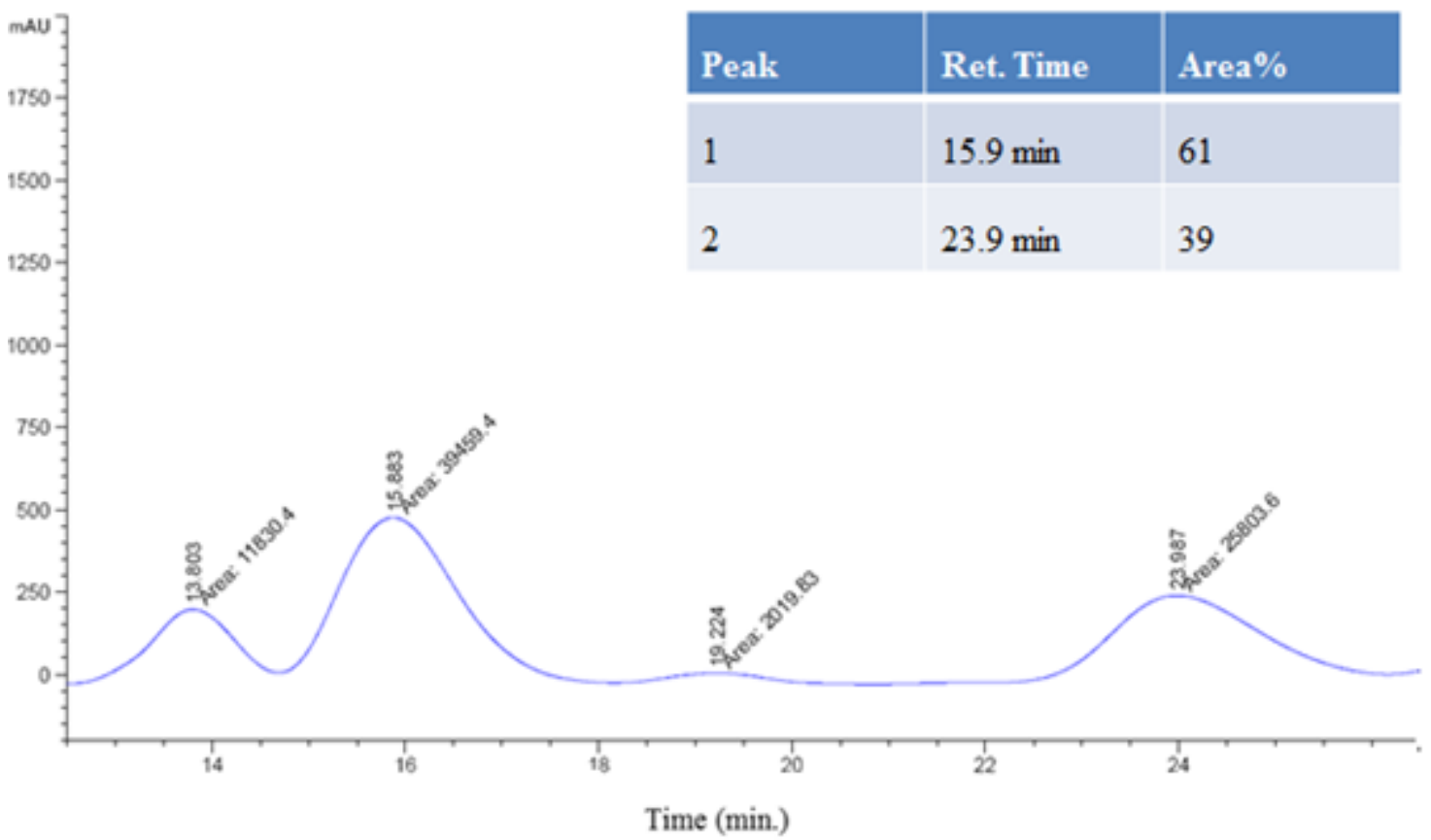

Figure ES 5.8: Diastreomers obtained by cascade-tandem reaction catalyzed by SucVal8+ProValDoc, inset showing area distribution. 


\subsection{References}

1. F. A. F. da Rosa, R. A. Rebelo, M.G. Naschimento, J. Braz. Chem. Soc., 2003, $14,11$.

2. J. M. M. Verkade, L. J. C. van Hemert, P. J. L .M. Quaedflieg, F. P. J. T. Rutjes, Chem. Soc. Rev., 2008, 37, 29.

3. W. Sreevalli, G. Ramachandran, W. Madhuri, Sathiyanarayanan, K. Iyer, MiniRev. Org. Chem., 2014, 11, 97.

4. H. Yamamoto (Ed.), Lewis Acids in Organic Synthesis, Vol. 2, Wiley-VCH, Verlag GmbH, 2000.

5. S. J. Jung, Y.-S. Youn, H. Lee, K.-J. Kim, B. S. Kim, S. Kim, J. Am. Chem. Soc., $\mathbf{2 0 0 8}, 130,3288$.

6. M. Ochiai, A. Yoshimura, T. Mori, Y. Nishi, M. Hirobe, J. Am. Chem. Soc., 2008, 130,3742 .

7. T. Ollevier, E. Nadeau, Org. Biomol. Chem., 2007, 5, 3126.

8. R. Qiu, S. Yin, X. Song, Z. Meng, Y. Qiu, N. Tan, X. Xu, S. Luo, F. Dai, C. Au, W. Wong., Dalton Trans., 2011, 40, 9482.

9. A. Cordova, W. Notz, G. F. Zhong, J.M. Betancort and C. F. Barbas, J. Am. Chem. Soc., 2002, 124, 1842.

10. A. J. A. Cobb, D. M. Shaw, S. V. Ley, Synlett, 2004, 558.

11. A. J. A. Cobb, D. M. Shaw, D. A. Longbottom, J. B. Gold, S. V. Ley, Org. Biomol. Chem, 2005, 3, 84 ..

12. D. H. Paull, C. J. Abraham, M.T. Scerba, E. A-Danforth, T. Lectka, Acc. Chem. Res., 2008, 41, 655.

13. M. O. Guler, S. I. Stupp, J. Am. Chem. Soc., 2007, 129, 12082. 
14. N. Singh, M. P. Conte, R. V. Ulijn, J. F. Miravet, B. Escuder, Chem. Commun., 2015, 51, 13213.

15. N. Singh, M. Tena-Solsona, J. F. Miravet, B. Escuder, Isr. J. Chem., 2015, 55, 711.

16. F. Rodríguez-Llansola, B. Escuder, J. F. Miravet, J. Am. Chem. Soc., 2009, 131, 11478.

17. F. Rodríguez-Llansola, J. F. Miravet, B. Escuder, Chem. Commun., 2009, 7303.

18. B. Escuder, F. Rodríguez-Llansola, J. F. Miravet, New J. Chem., 2010, 34, 1044.

19. C. Berdugo, J. F. Miravet, B. Escuder, Chem. Commun., 2013, 49, 10608.

20. N. Singh, K. Zhang, C. A. A-Pachón, E. Mendes, J. H. van Esch, B. Escuder, Chem. Sci., 2016, 7, 5568.

21. A. Cordova, W. Notz, G. Zhong, J. Betancort, C. F. Barbas, J. Am. Chem. Soc., 2002, 124, 1842.

22. N. Chowdari, J. Suri, C. F. Barbas, Org. Lett., 2004, 6, 2507.

23. B. List, J. Am. Chem. Soc., 2000, 122, 9336.

24. W. Zhuang, S. Saaby, K. A. Jorgensen, Angew. Chem. Int. Ed., 2004, 43, 4476.

25. B. Westermann, C. Neuhaus, Angew. Chem., Int. Ed., 2005, 44, 4077.

26. D. Enders, C. Grondal, M. Vrettou, G. Raabe, Angew. Chem., Int. Ed., 2005, 44, 4079.

27. H. Zhang, S. Mitsumori, N. Utsumi, M. Imia, N. Garcia-Delgado, M. Mifsud, K. Albertshofer, P. H.-Y. Cheong, K. N. Houk, F. Tanaka, C. F. Barbas, J. Am. Chem. Soc., 2008, 130, 875.

28. M. Samet, B. E. Sis , M. M. Hashemi, F. Farmad, Synt. Commun., 2009, 39, 4441 .

29. Y.-Y. Chen, Y. J. Yiang, Y. S. Fan, D. Sha, Q. Whang, G. Zhang, L. Zheng, S. Zhang, Tetrahedron Asymmetry, 2012, 23, 904. 
30. M. Barbero, S. Cadamuro, S. Dughera, Tetrahedron Asymmetry., 2015, 26, 1180.

31. Q. Guo, J. C. Zhao, Org. Lett., 2013, 15, 508. 


\section{Chapter 6}

\section{Catalytically controlled formation of a double network hydrogel}

This work has been performed while at a placement at TU Delft, The Netherlands under the supervision of Dr. Jan H. van Esch. 


\subsection{Introduction}

Double network (DN) hydrogels have gained increased attention in the field of material science as they exhibit the combined physical/chemical properties of the individual components with a possibility of synergistic combination of two types of structures giving rise to new materials. ${ }^{1,2}$ Such hybrid systems which can allow the selective tailoring of material properties typically constitute of two distinct molecules which could be (a) two individual chemically cross linked polymers, (b) a synthetic polymer or a macromolecule and a biological macromolecule such as protein or peptide or (c) two different selfassembling gelators based on molecular recognition/non-covalent interactions. ${ }^{1-12,}$ 18-27 However DN hybrid systems based completely on physical interactions can have certain advantages over the systems with chemically cross linked components owing to their responsiveness to larger range of stimuli with the liberty to modulate the kinetics of inter/intra molecular physical interactions finding applications in photo-patterning, drug delivery, cell engraftments/encapsulation etc. ${ }^{1-17}$

To achieve a DN hydrogel based on physical interactions, self-sorting upon assembly of the different components is essential. Self-sorting though well studied in organogels is harder to predict and design in hydrogels owing to their competition for hydrogen bonding with the water molecules. Most of the examples dealing with self-sorting are thermally induced when one molecule assembles at higher temperature than other with assumed vital role of molecular structural differences even though a direct correlation between the molecular structure and the $\mathrm{T}_{\text {gel }}$ is not well established. ${ }^{18-26}$ Recently Adams et. al. could chemically program the self-sorting of dipeptide based hydrogelators by triggering their gelation close to their distinct $\mathrm{pKa}$ values induced by a smooth $\mathrm{pH}$ change through controlled hydrolysis of GdL. ${ }^{27}$ 

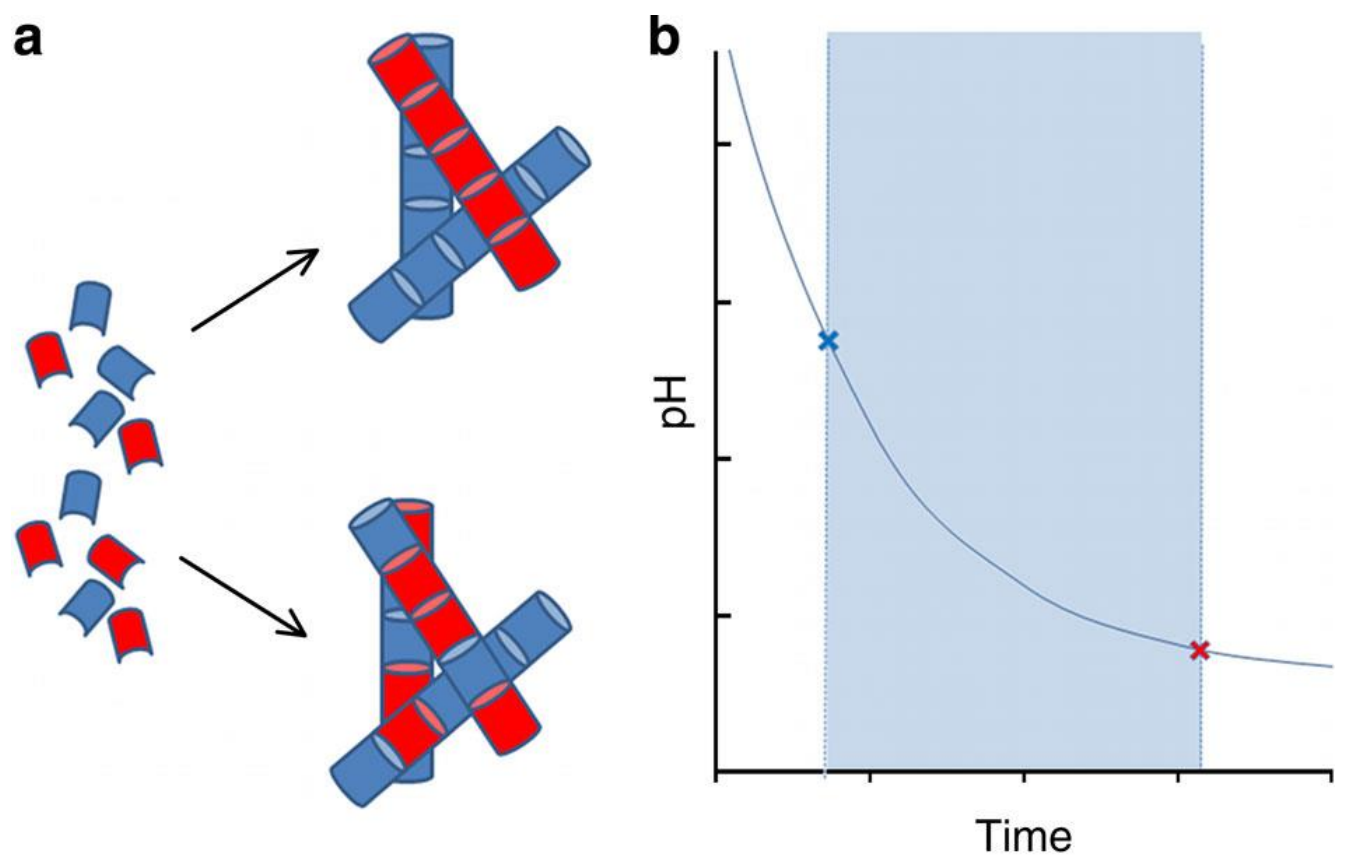

Figure 6.1: (a) Two molecules can either randomly co-assemble (bottom) or self-sort (top) to form aggregated structures. (b) If two molecules have different $p K_{a}$ values, then a slow $\mathrm{pH}$ decrease will lead to the $p K_{a}$ of one molecule being reached first (blue cross). Assembly occurs before the $p K_{a}$ of the second molecule (red cross) is reached. This leads to sequential assembly. ${ }^{27}$

Liu et al. have recently reported a double network based on physical interactions comprising a network formed by DNA hybridisation of complementary DNA-Y scaffold and a DNA linker and another network by host-guest interaction between a phenylalanine functionalised carboxymethyl cellulose and cucurbit[8]uril. This chemical cross linking free double network retains the properties of the individual networks and possesses a high storage modulus finding application in specific enzymatically triggered response from a preselected network. $^{28}$ 


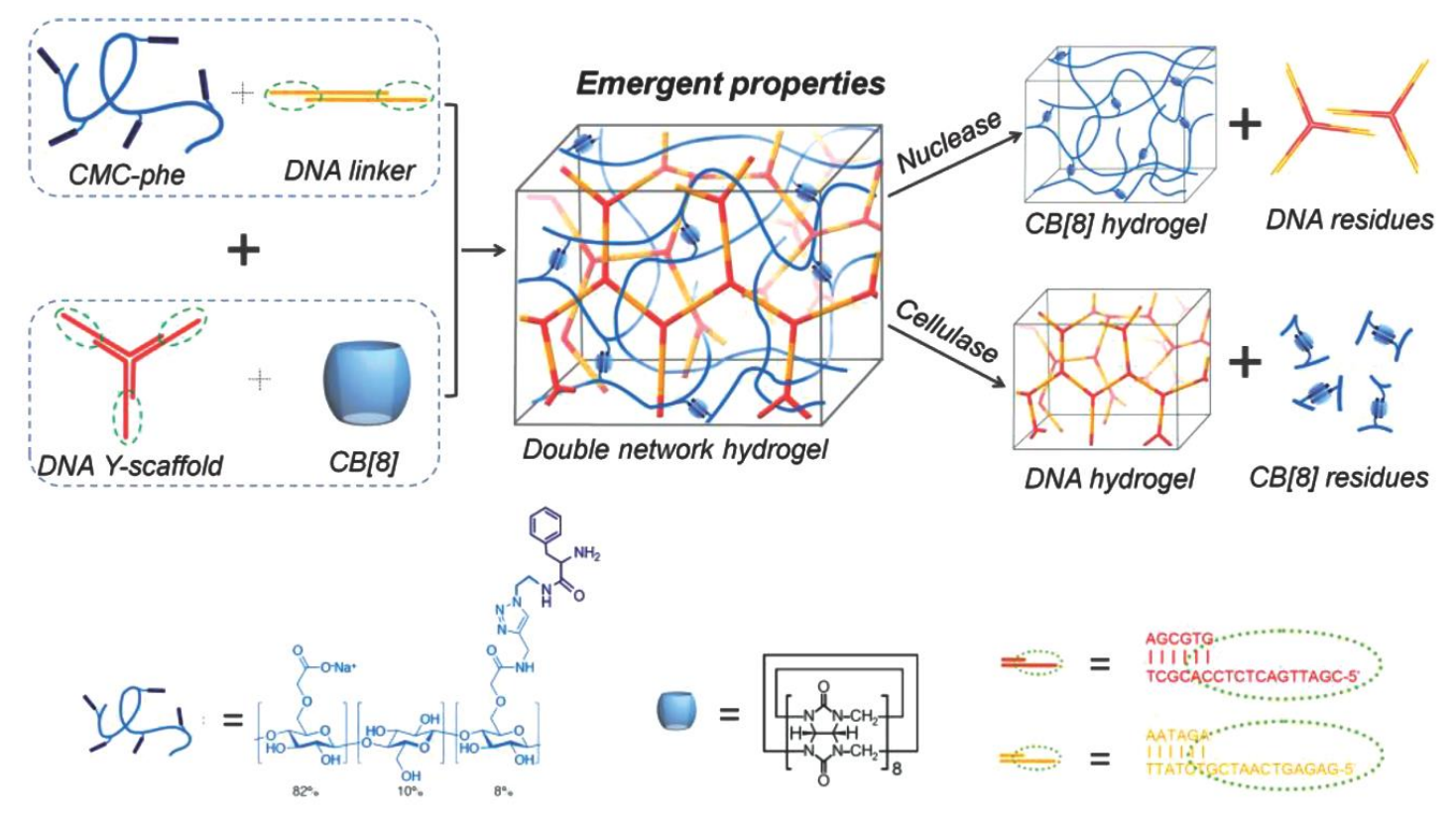

Figure 6.2: The formation process of double network hydrogels through supramolecular interactions. 2:1 homoternary complexation of Phe units pendant from carboxymethyl cellulose to CB[8] affords one macroscopic network. A second network is crosslinked by hybridization of DNA "sticky ends." The resulting double network hydrogel possesses combined properties of each single network hydrogel, such as greater mechanical strength and stimuli responsiveness. ${ }^{28}$

An overlooked way to achieve such DN hydrogels can be the use of a catalytic hydrogel to produce a controlled self-assembly of another hydrogelator. The catalytic control over self-assembly is omnipresent in nature as it allows an on demand site specific temporal control over the supramolecular organisation. It thus presents itself as a very utile tool for the chemists to spatially and temporally control the supramolecular order allowing the nano-fabrication of novel supramolecular structures. Ulijn et. al. have reported the use of subtilisn enzyme for hydrolysis of Fmoc dipeptide methyl esters to obtain a controlled evolution of the supramolecular structures. ${ }^{39}$ By varying the amount of enzyme they could tune the degree of chirality in the nanofibres and the strength of the formed hydrogel. The nucleation and initiation of fibre growth in such enzyme controlled supramolecular structures takes place close to the catalytic enzyme clusters. ${ }^{40}$ 


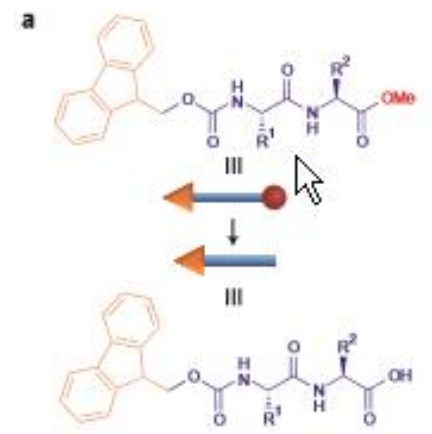

b
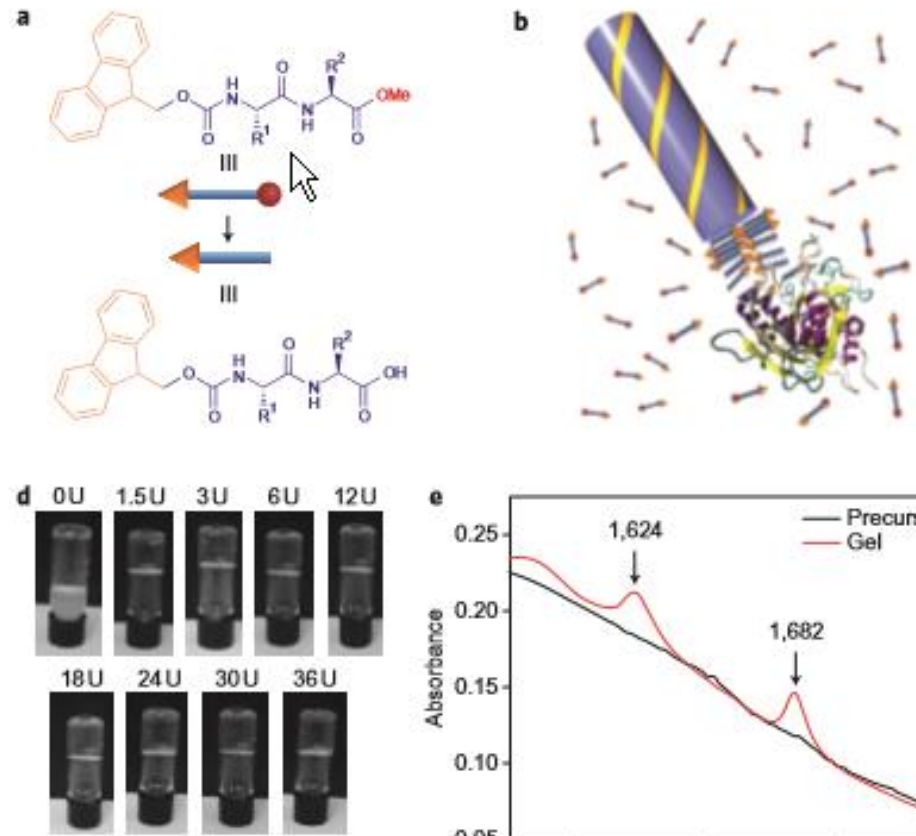

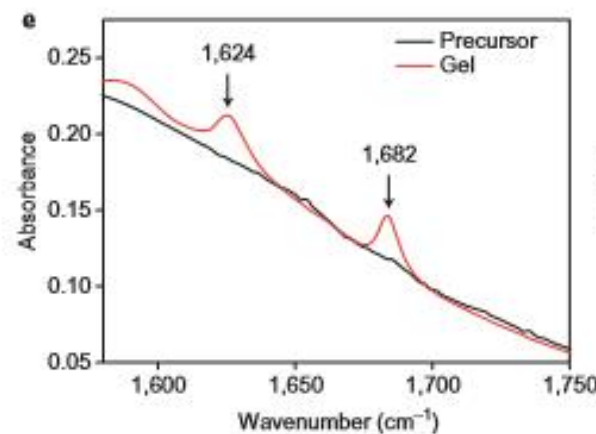

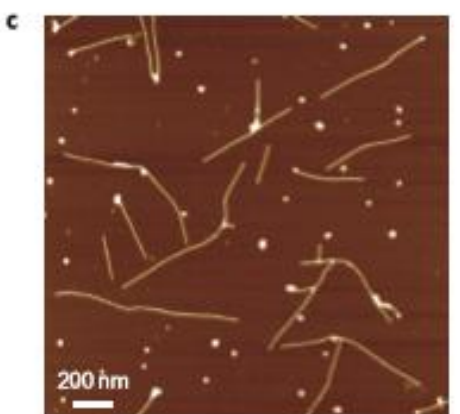

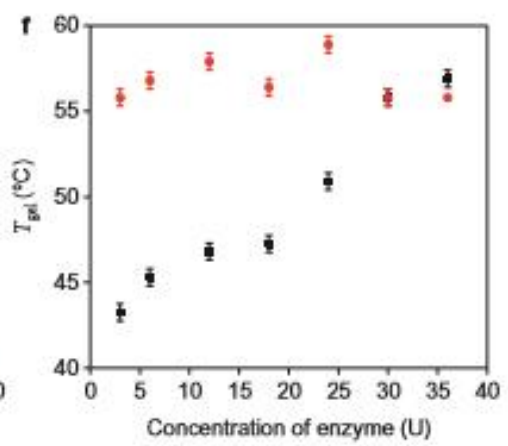

Figure 6.3: Biocatalytic self-assembly and gelation. (a) Chemical structure of the range of Fmoc-dipeptide methyl esters studied here (orange, fluorenyl moiety of the Fmoc group; blue, dipeptide sequence; red, enzyme cleavable methoxy group). Subtilisin catalyses hydrolysis of these esters to Fmoc-peptide gelators. (b), Schematic of nucleation and growth mechanism of self-assembly controlled by subtilisin. (c), AFM analysis of initial stages of the self-assembly process $\left(12 \mathrm{U}, 20 \mathrm{~min}\right.$ at $55^{\circ} \mathrm{C}$, followed by cooling to room temperature and air drying. Here, $1 \mathrm{U}$ is equivalent to the amount of enzyme that hydrolyses casein to produce a colour equivalent to $1 \mathrm{mmol}$ of tyrosine per minute at $\mathrm{pH} 7.5$ at $37^{\circ} \mathrm{C}$ ), showing the formation of clusters and fibres. (d), Self-supporting, optically transparent gels are formed in each case. (e), FTIR spectrum of gel-phase materials showing formation of the antiparallel b-sheet conformation. (f) Melting temperature $\left(\mathrm{T}_{\mathrm{gel}}\right)$ of gels formed catalytically (black) and by a heating-cooling cycle (red) at different enzyme concentrations. The error bars show a standard error corresponding to $+0.5^{\circ} \mathrm{C} .{ }^{39}$

Here we report a double network hydrogel formed by using the catalytic activity of a preformed network to afford the in situ formation of a second interpenetrating self-sorted network (Figure 6.4). The use of catalytic fibres allowed spatially coupled self-assembly of the second network in the vicinity of the first network and with higher resultant mechanical strength. The use of catalytic groups appended hydrogelators to mimic enzyme like catalysis is well known, where the close proximity of the functional groups and formation hydrophobic pockets on self-assembly lead to enhanced catalytic activity. ${ }^{29-35}$ We chose one such catalytic hydrogelator (SucVal8) with acid group 
functionalisation to catalyse the in situ formation of another hydrogel network (hydrogel 16).(Scheme 6.1a)

In situ formation of hydrogelator (SucVal8) was achieved by hydrazone bond formation between its water-soluble trishydrazide (14) and aldehyde (15) building blocks. (Scheme 6.1b) Varying the concentration of the catalytic fibres of SucVal8 allowed having catalytic control over the formation and self-assembly of 16, affecting the final mechanical properties of the self-sorted system. Self-assembly of hydrogelator $\mathbf{1 6}$ upon formation from non-assembling trishydrazide $\mathbf{1 4}$ and aldehyde $\mathbf{1 5}$ through the formation of a hydrazone bond has been described. In aqueous environments, the rate of hydrazone formation could be enhanced by using either acid or aniline catalysis and subsequently producing a pronounced effect on the rate of gelation, fibre morphology, and macroscopic gel properties. ${ }^{36,37}$

The fibres of bola-amphiphilic hydrogelator SucVal8 have the property to perform acid catalysed reactions as reported before for deacetalysation reactions (Chapter 4 and Chapter 5). ${ }^{38}$ The catalytic activity of SucVal8 upon self-assembly is a result of the increase in local concentration of the acid functional groups and the formation of hydrophobic environment by the aliphatic backbone and the valine group easing the approach of the reactants to the catalytic sites. ${ }^{29-33}$ Inspired by enzyme like catalysis reported before for such catalytic hydrogel systems, we expected the fibres of SucVal8 to not only catalyse the formation of $\mathbf{1 6}$, but also to provide a control over the selfassembly by guiding the nucleation and proliferation of the new fibres as observed before. $^{36,37,39}$ The individual networks of the double network hydrogel were envisaged to be orthogonal due to the difference in their structures and more importantly as one 
network dictates the formation of the other network, though hydrogel of SucVal8 could possibly also act as a scaffold for the proliferation of hydrogel $16 .{ }^{18-27}$ (Scheme 6.1a)

(a)<smiles>CC(C)C(NC(=O)CCC(=O)O)C(=O)NCCCCCCCCNC(=O)[C@@H](NC(=O)CCC(=O)O)C(C)C</smiles>

(b)<smiles>NNC(=O)[C@H]1C[C@H](C(=O)NN)C[C@@H](C(=O)NN)C1</smiles>

14

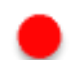<smiles>COCCOCCOc1ccc(C=O)cc1OCCOCCOC</smiles>

SucVal8

15

4

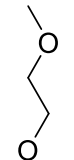

\rangle$^{0}$

6.1: Chemical structure of (a) SucVal8, (b) formation of compound 16 from its hydrazide (14) and aldehyde (15) building blocks using SucVal8.
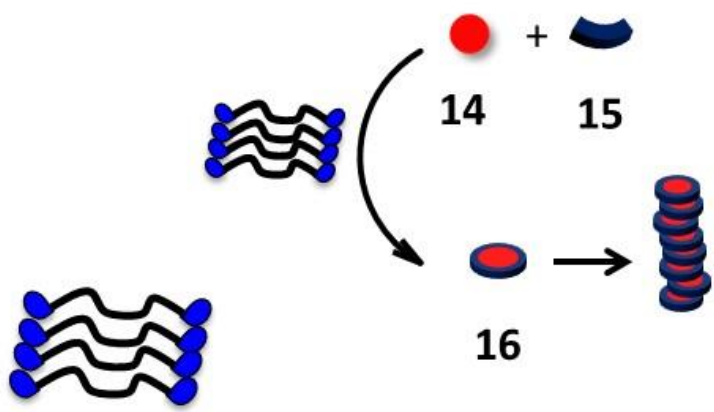

16

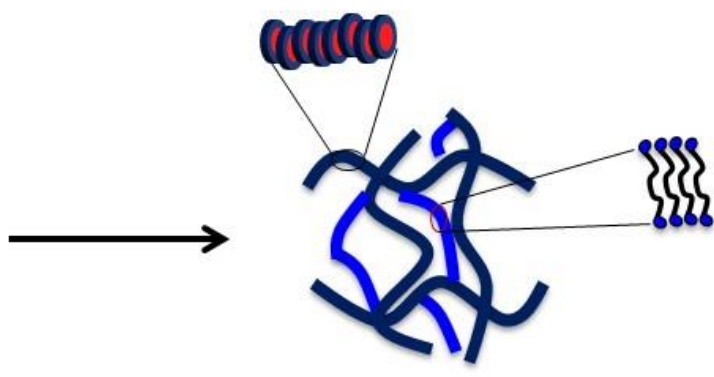

Double Network

\section{SucVal8}

Figure 6.4: Cartoon representation of the formation of hydrogel 16 by using SucVal8 as a catalyst and subsequent orthogonal gelation of two hydrogel network. 


\subsection{Results and discussion}

\subsubsection{Synthesis}

(A)<smiles>O=C(O)c1cc(C(=O)O)cc(C(=O)O)c1</smiles><smiles>CC(C)(C)C(=O)O</smiles><smiles>COC(=O)C1CC(C(=O)OC)CC(C(=O)OC)C1</smiles><smiles>NNC(=O)C1CC(C(=O)NN)CC(C(=O)NN)C1</smiles>

14

(B)

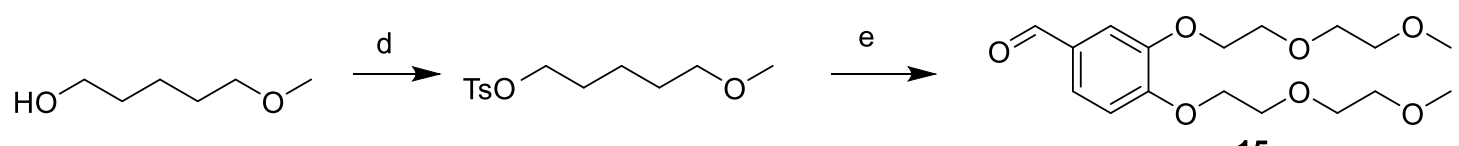

Scheme 6.2: Reagents and conditions: (A) (a) $\mathrm{Pd} / \mathrm{C}, \mathrm{H}_{2} \mathrm{O}, 150{ }^{\circ} \mathrm{C}, 60 \mathrm{bar}, 2 \mathrm{hr}$; (b) $\mathrm{p}-\mathrm{TsOH}, \mathrm{MeOH}$, reflux, $36 \mathrm{~h}, 70 \%$ isolated yield over two steps; (c) $\mathrm{N}_{2} \mathrm{H}_{4}, \mathrm{MeOH}$, room temperature (r.t.), $3 \mathrm{hr}$, quant; (B) (d) $\mathrm{TsCl}$, $\mathrm{Et}_{3} \mathrm{~N}$, THF, $0 \rightarrow$ r.t., $2 \mathrm{hr}$, quant; (e) 3,4-dihydroxybenzaldehyde, $\mathrm{K}_{2} \mathrm{CO}_{3}$, THF, reflux, $18 \mathrm{~h}, 83 \%$.

Synthesis of SucVal8 has already been described in Chapter 4. The precursors 14 and 15 of gelator 16 were synthesised as shown in Scheme 4 following the procedure presented in literature. ${ }^{36,37}$

\subsubsection{Individual and mixed gel system formation}

SucVal8 formed a transparent hydrogel in water at the MGC of $6 \mathrm{mM}$. Desired amount of SucVal8 was dissolved in $0.5 \mathrm{ml}$ water by gentle heating and was allowed to come to room temperature to afford the formation of catalytic fibres/gels. The $\mathrm{pH}$ of these samples was around 6.5. The soluble building blocks 14 and 15 for hydrogelator 16 were introduced into vortexed samples of SucVal8 $(500 \mu \mathrm{L})$ to get the final volume of $1 \mathrm{~mL}$ (the final concentrations of $\mathbf{1 4}$ and $\mathbf{1 5}$ was always $10 \mathrm{mM}$ and $60 \mathrm{mM}$ respectively in all the experiments) and subsequent formation of double network hydrogel was checked by inverted vial method and rheology. No gel but a turbid suspension was obtained when to a diluted solution of $1 \mathrm{mM}(0.5 \mathrm{~mL})$ of SucVal8 were added the soluble building blocks 
14 and 15 (final volume $1 \mathrm{~mL}$ ). This indicates the low catalytic activity of molecules of SucVal8 in solution and not being able to catalyse the reaction between 14 and $\mathbf{1 5}$ at a high rate. For higher initial concentration of SucVal8 with the formation of catalytic fibres the mixed system started forming self-supporting double network hydrogels.

\subsubsection{Rheological experiments}

The maximum storage modulus $\left(\mathrm{G}^{\prime}{ }_{\max }\right)$ of hydrogel SucVal8 at MGC was $0.01 \mathrm{kPa}$ but upon formation of the second interpenetrating network the $\mathrm{G}^{\prime}{ }_{\max }$ value of the system increased drastically. With higher initial concentrations $(1 \mathrm{mM}<$ [SucVal8] $\leq 6 \mathrm{mM})$ of the catalytic fibres, upon addition of soluble precursors the $\mathrm{G}^{\prime}$ max value of the obtained DN system increased linearly. Higher concentrations of fibres of SucVal8 resulted in higher amount of catalytic sites giving higher rates of formation of hydrogel 16 (Figure 6.5). As reported before obtaining high rate of formation of $\mathbf{1 6}$ due to catalysis can lead to a kinetically trapped self-assembled state whose maximum storage modulus is directly proportional to the rate of catalysis. ${ }^{36,37}$ The $\mathrm{G}^{\prime}$ max value of the mixed system of $\mathbf{1 4}$ and 15 without any catalyst was $5 \mathrm{kPa}$ while that for hydrogel of SucVal8 was only $0.01 \mathrm{kPa}$ (Figure ES 6.1). The highest $\mathrm{G}^{\prime}$ max value for the $\mathrm{DN}$ hydrogel of $55 \mathrm{kPa}$ was obtained when SucVal8 was present initially at its MGC. This value is $10 \%$ higher than the summed value of individual $\mathrm{G}^{\prime}$ max values of hydrogel of SucVal8 (MGC) and hydrogel $16(50 \mathrm{kPa}$ at $\mathrm{pH} 5){ }^{36,37}$

Interestingly when hydrogels of SucVal8 above the MGC were used for catalysis, a quick gel formation was observed, but maximum $\mathrm{G}^{\prime}$ values were lower than that observed for the mixed system when hydrogel of SucVal8 was used at the MGC (Figure 6.5 a, b). Comparing the TEM images of hydrogel of SucVal8 at MGC and twice the MGC we could see a change in aspect ratio of the fibres (Figure 6.9). At MGC the twisted several 
micrometres long fibres of SucVal8 were 8-9 $\mathrm{nm}$ in width whereas the fibres obtained at the higher concentration were around $15 \mathrm{~nm}$ in width. This alludes that the aspect ratio of fibres formed at the MGC have most optimal distribution of exposed catalytic sites on the surface when compared to the thicker fibres formed at higher concentrations, yielding a higher rate of conversion and thus greater $\mathrm{G}^{\prime} \max$ value.
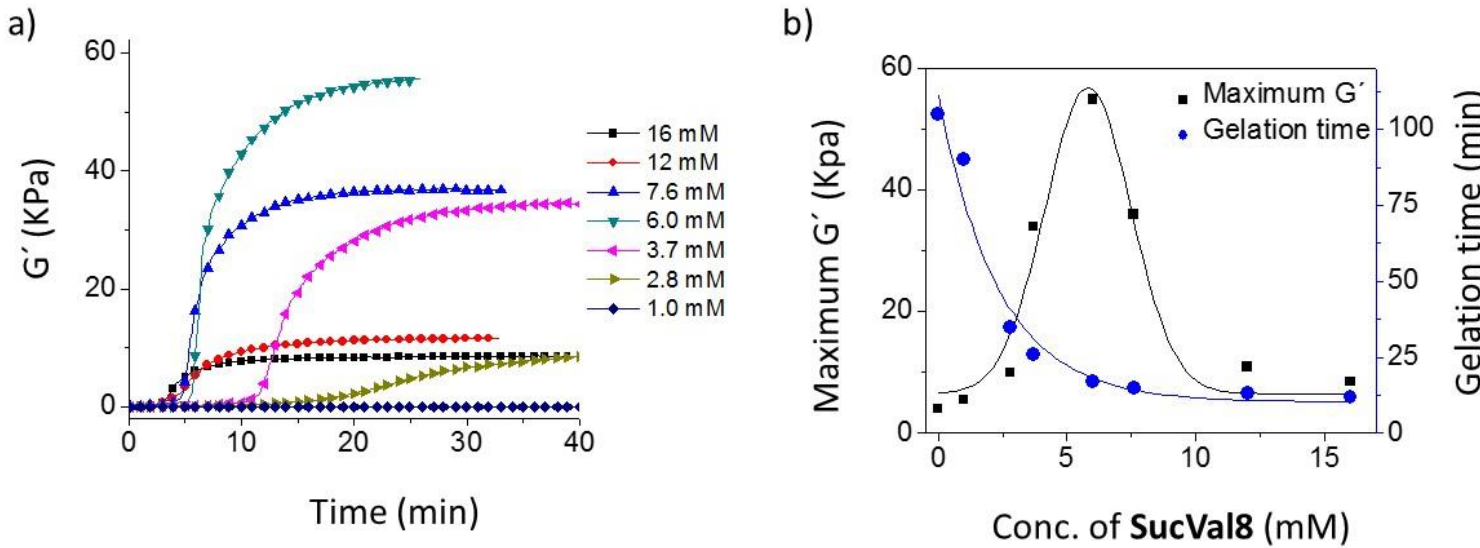

Figure 6.5: DN hydrogel formation measured by rheology: (a) evolution of $\mathrm{G}^{\prime}$ over time employing different concentration of SucVal8. Final concentration of 14 and 15 was $10 \mathrm{mM}$ and $60 \mathrm{Mm}$ respectively for all the experiments. (b) Evolution of maximum storage modulus $\left(\mathrm{G}^{\prime}{ }_{\text {max }}\right)$ and gelation time with different concentrations of SucVal8. The gelation time was defined as the moment that G' measures $95 \%$ of this plateau value. The lines are guide to the eyes.

\subsubsection{Kinetics studies}

By ${ }^{1} \mathrm{H}$ NMR spectroscopy, the consumption rate of the aldehyde building block (15) due to the formation of $\mathbf{1 6}$ with trishydrazide precursor $\mathbf{1 4}$ was monitored over time using two different concentrations of SucVal8 (6.0 mM at MGC and 12.0 mM ) (Figure ES 6.2). 14 and 15 were added to the NMR tubes with $0.25 \mathrm{~mL}$ of hydrogel of SucVal8 at $6 \mathrm{mM}$ and $12 \mathrm{mM}$ to obtain $0.5 \mathrm{~mL}$ final volume (final [14] and [15]:10 $\mathrm{mM}$ and $60 \mathrm{mM}$ respectively). The rate constant for catalysis $\left(k_{\text {cat }}\right)$ was obtained as $1.0 \times 10^{-2} \mathrm{~s}^{-1}$ at MGC 
and $0.5 \times 10^{-2} \mathrm{~s}^{-1}$ for $12 \mathrm{mM}$ implying that not all the catalytic sites at higher concentration were active or available (Figure 6.6).

a)

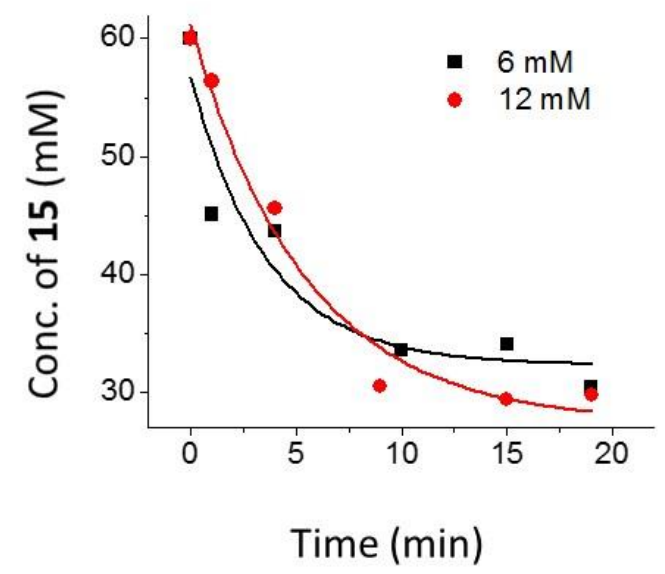

b)

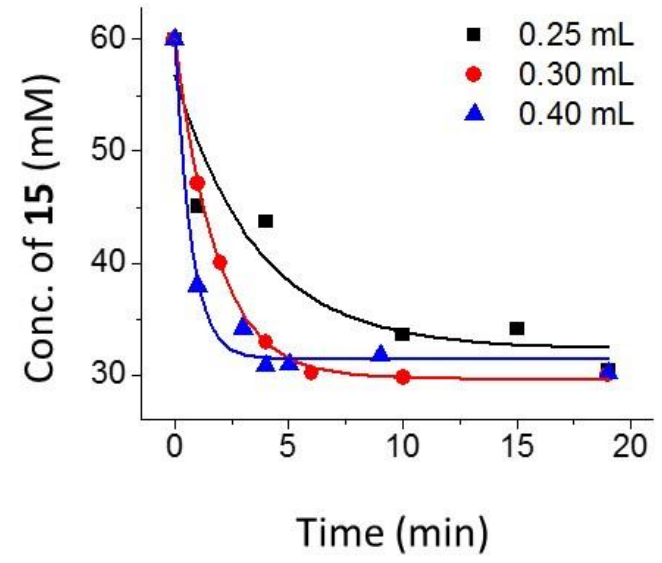

Figure 6.6: Consumption of benzaldehyde derivative 15 as observed in ${ }^{1} \mathrm{H}$ NMR spectroscopy with time (a) using two different concentration of hydrogelator of SucVal8, (b) using different volume of hydrogelator SucVal8, prepared at MGC (6.0 mM). Final volume of DN system for NMR experiments was kept constant $(0.5 \mathrm{~mL})$. Concentration of $\mathbf{1 4}$ and 15 were $10 \mathrm{mM}$ and $60 \mathrm{mM}$ respectively in all the samples. The lines are fitted with an exponential decay equation.

To further substantiate this, another experiment with three different samples of volume $0.25 \mathrm{~mL}, 0.30 \mathrm{~mL}$ and $0.40 \mathrm{~mL}$ with hydrogel of SucVal8 at MGC were prepared. 14 and 15 were added to these samples to attain a final volume of $0.5 \mathrm{~mL}$ and their respective final concentrations as before. With increasing amount of fibres of SucVal8 higher rate of catalysis was observed with $\mathrm{k}_{\text {cat }}$ values as $1.0 \times 10^{-2} \mathrm{~s}^{-1}, 1.5 \times 10^{-2} \mathrm{~s}^{-1}$ and $3.8 \times 10^{-2} \mathrm{~s}^{-1}$ with increasing concentration of SucVal8. Thus we could say that increasing concentration of SucVal8 above MGC gave lower $\mathrm{G}^{\prime}$ max value due to the lower conversion rate probably due to lesser number of available catalytic sites. 


\subsubsection{Confocal laser scanning florescence microscopy}

Hydrogel of SucVal8 was prepared with Nile red so that the formation of fibres could be monitored using confocal laser scanning fluorescence microscopy. Nile red upon selfassembly -of SucVal8 became fluorescent thus enabling the visualisation of fibres of SucVal8, shown in red fluorescence (Figure 6.5 and 6.6). Precursor 14 and 15 with a known amount of precursor aldehyde functionalised with fluorescein was added to this. Upon self-assembly the fluorescein functionalised aldehyde gets incorporated in the fibres of $\mathbf{1 6}$ and allows the visualisation of the fibres of 16. Figure 6.7 depicts the evolution of fibres of hydrogel 16 in the presence of fibres of SucVal8. From Figure 6.7 and 6.8 it is clear that the formation of the new network was orthogonal to the first network and the nucleation of the second network starts in the vicinity of the fibres of SucVal8. Co-localization of the fluorescence of both gel networks indicated the fibre formation of compound 16 in and around the network of hydrogel of SucVal8 (Figure

\section{7 and Figure 6.8).}
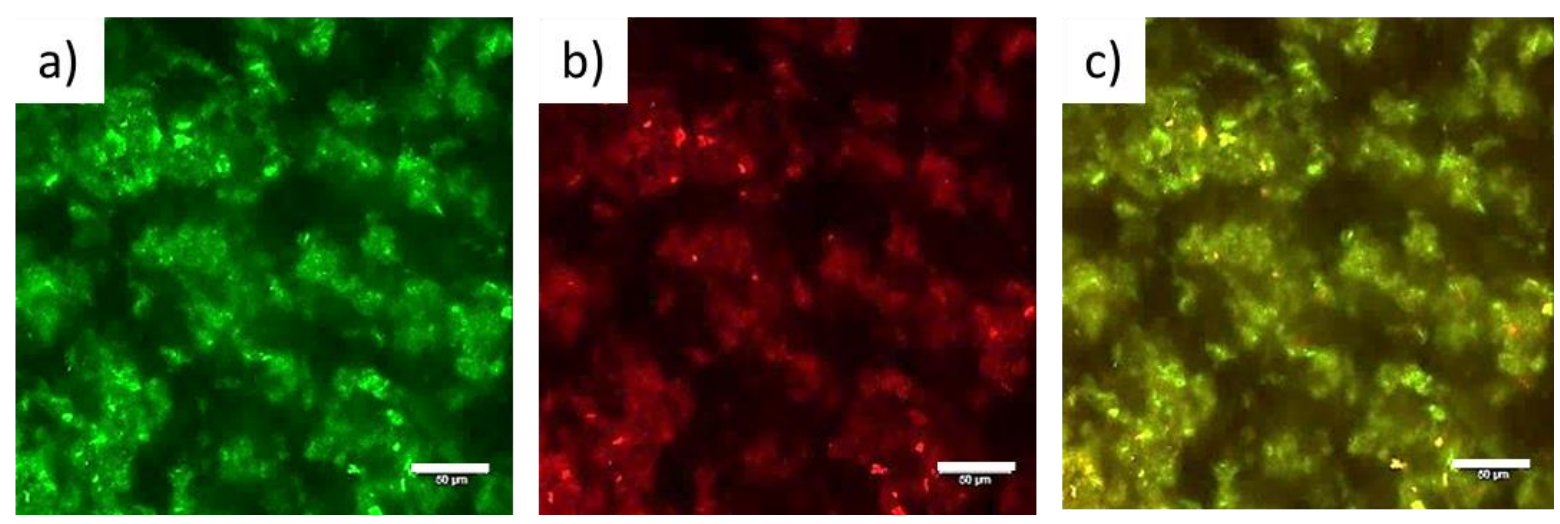

Figure 6.7: CLSFM (Scale bar - $50 \mu \mathrm{m}$ ) of the obtained DN hydrogel. In situ formation of 16 by the catalysis of SucVal8 which was prepared at MGC. (a) Network for hydrogelator SucVal8 $\left(\lambda_{\text {exc }}=488 \mathrm{~nm}\right)$, (b) network for hydrogelator SucVal8 $\left(\lambda_{\mathrm{exc}}=543 \mathrm{~nm}\right)$ and (c) overlapped images $\left(\lambda_{\mathrm{exc}}=488 \mathrm{~nm}\right.$ and 543 $\mathrm{nm})$. 


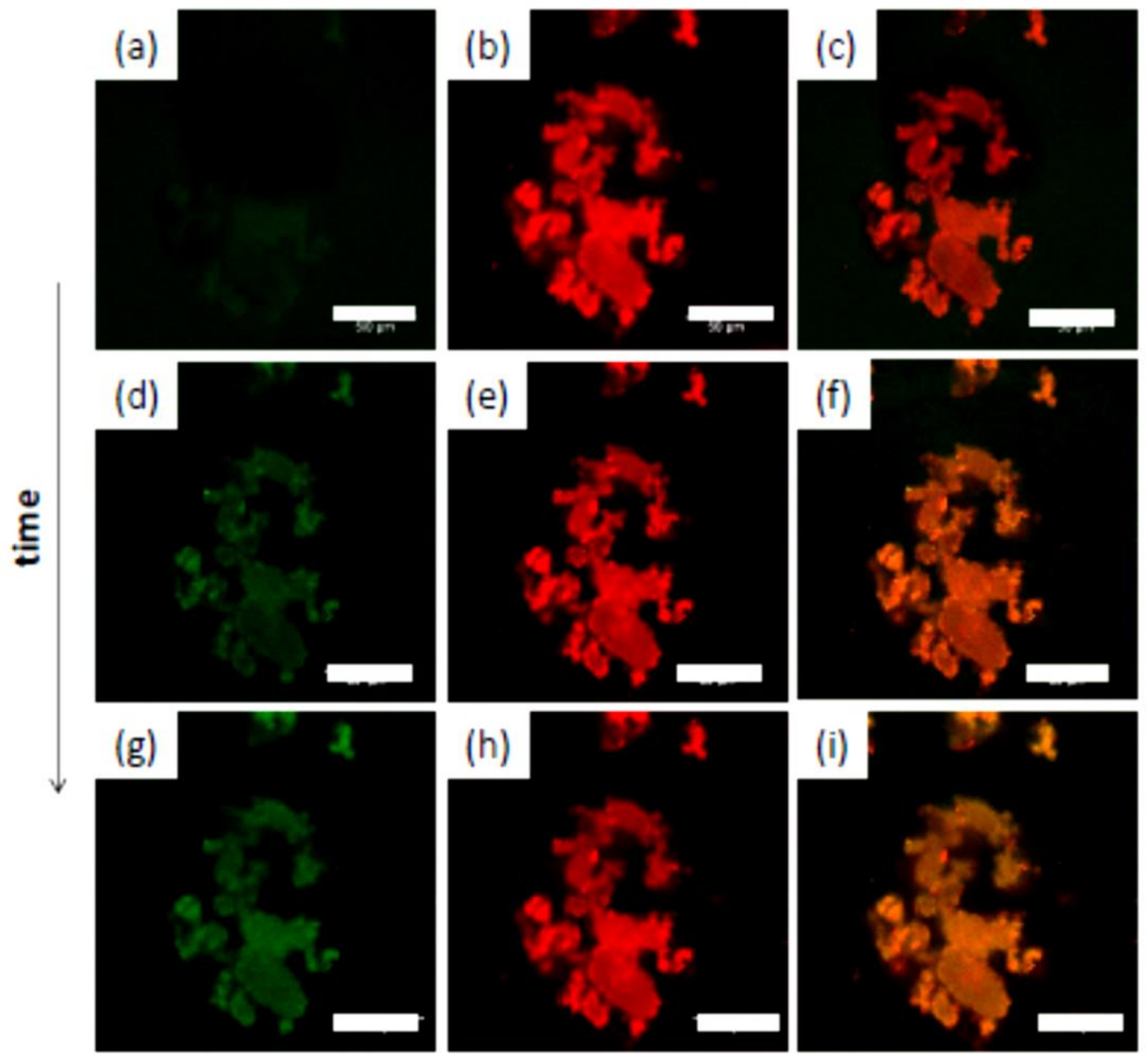

Figure 6.8: Time evolution of hydrogel network of $\mathbf{1 6}$ (in green a, d, g) by catalysis of SucVal8 (in red b, $\mathrm{e}, \mathrm{h}$ ) and overlapped images of the networks (in orange $\mathrm{c}, \mathrm{f}, \mathrm{i}$ ).

\subsubsection{Atomic force and transmmission electron microscopy}

The AFM and TEM images of the mixed system also showed co-existence of two different kinds of fibres. Twisted fibres several micrometres in length and $8 \mathrm{~nm}$ in width could be assigned to hydrogel SucVal8 whereas straighter more branched fibres up to 1 $\mu \mathrm{m}$ in length and 8-9 $\mathrm{nm}$ in width could be assigned to compound $\mathbf{1 6}$ (Figure 6.10). The fibres of compound $\mathbf{1 6}$ seemed to be emerging from several nucleation points in a bouquet like formation from the vicinity of fibres of SucVal8 (Figure 6.10 c, d). This confinement of nucleation points and bundles of fibres close to catalytic sites can be attributed to the high catalytic activity by fibres of SucVal8, very similar to that observed by Hirst et al. using enzymes for catalytically controlled self-assembly of dipeptides. ${ }^{39}$ 

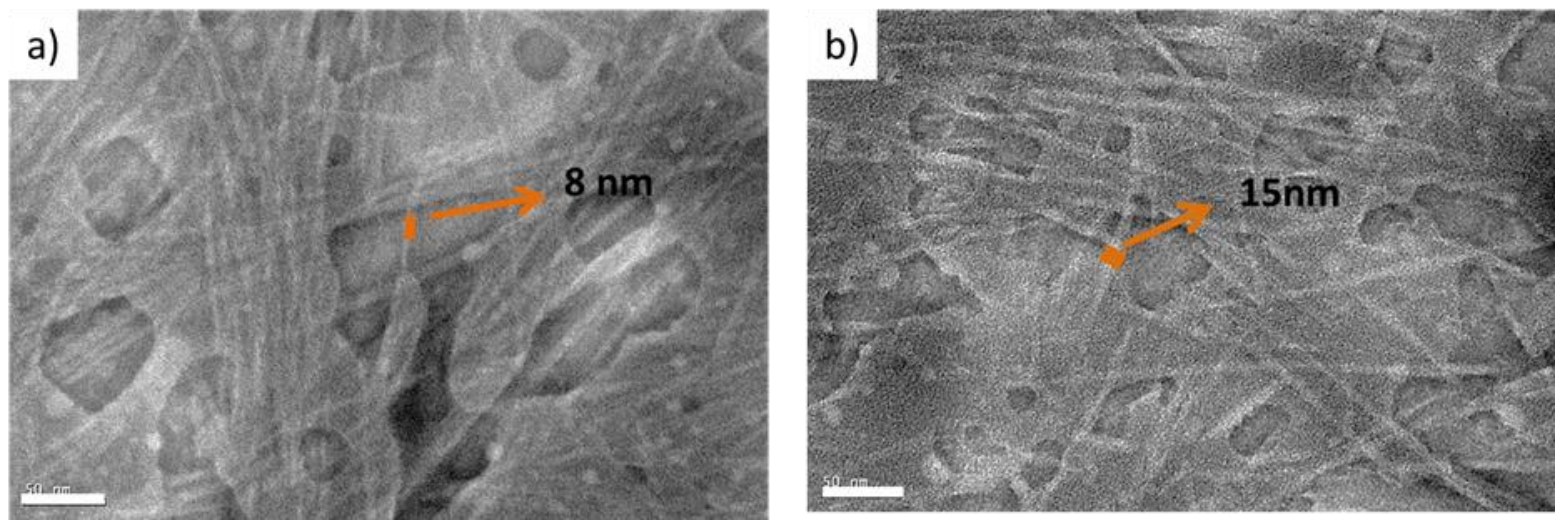

Figure 6.9: TEM images (scale bar $50 \mathrm{~nm}$ ) reflecting the difference in the aspect ratio of the fibres of hydrogelator SucVal8 (a) at MGC (6mM), fibre with $8 \mathrm{~nm}$ width, and (b) at $12 \mathrm{mM}$, fibre with $15 \mathrm{~nm}$ width.

a)

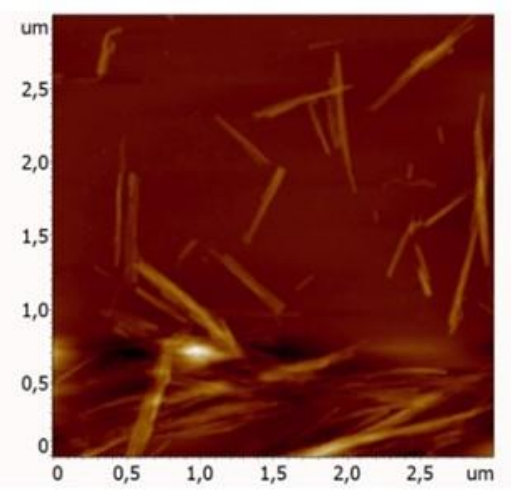

c)

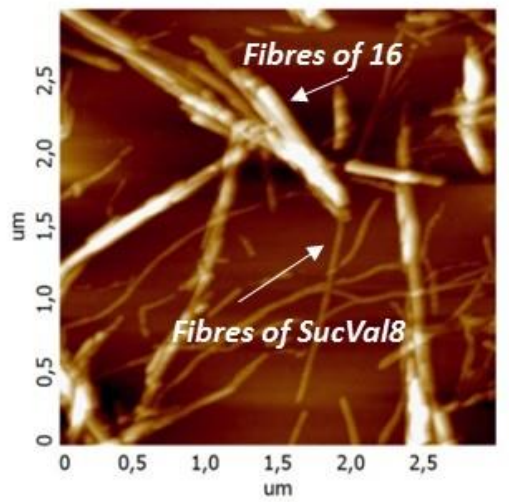

b)
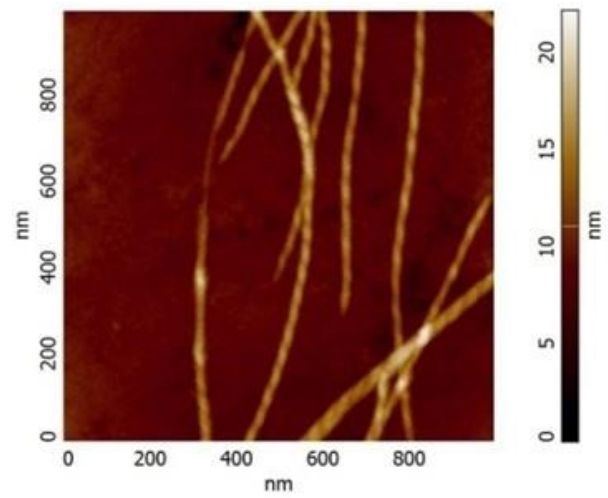

d)
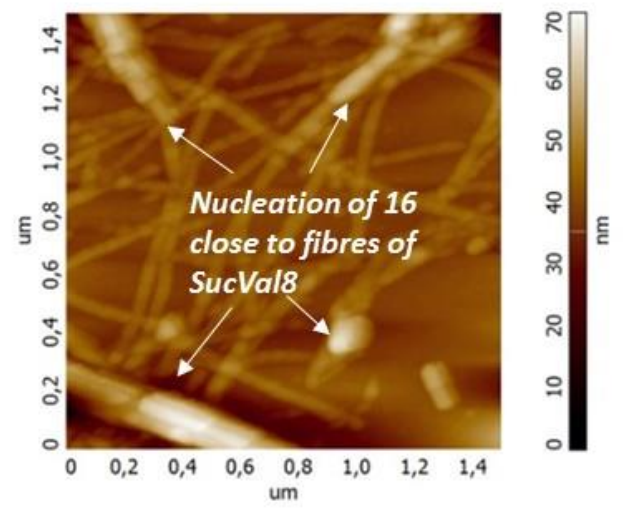

Figure 6.10: AFM images of the gel fibres. (a) Straight fibres for 16, (b) twisted fibres for SucVal8,, (c) presence of two coexisting fibres in the DN system, and (d) closer look at the fibres showing emergence of fibres of $\mathbf{1 6}$ from close vicinity of the catalytic twisted fibres of SucVal8. 


\subsubsection{Wide angle $X$-ray diffraction studies}

The orthogonality of the system was also confirmed by WAXD. The WAXD pattern of hydrogel of SucVal8 was amorphous, whereas that of compound $\mathbf{1 6}$ showed main reflection at 27.0 and $4.1 \AA .^{36,37}$ The pattern of the mixed system was an overlap of the two individual systems without any emergence of new peaks, indicating the orthogonality of the two fibres in the mixed system (Figure 6.11).

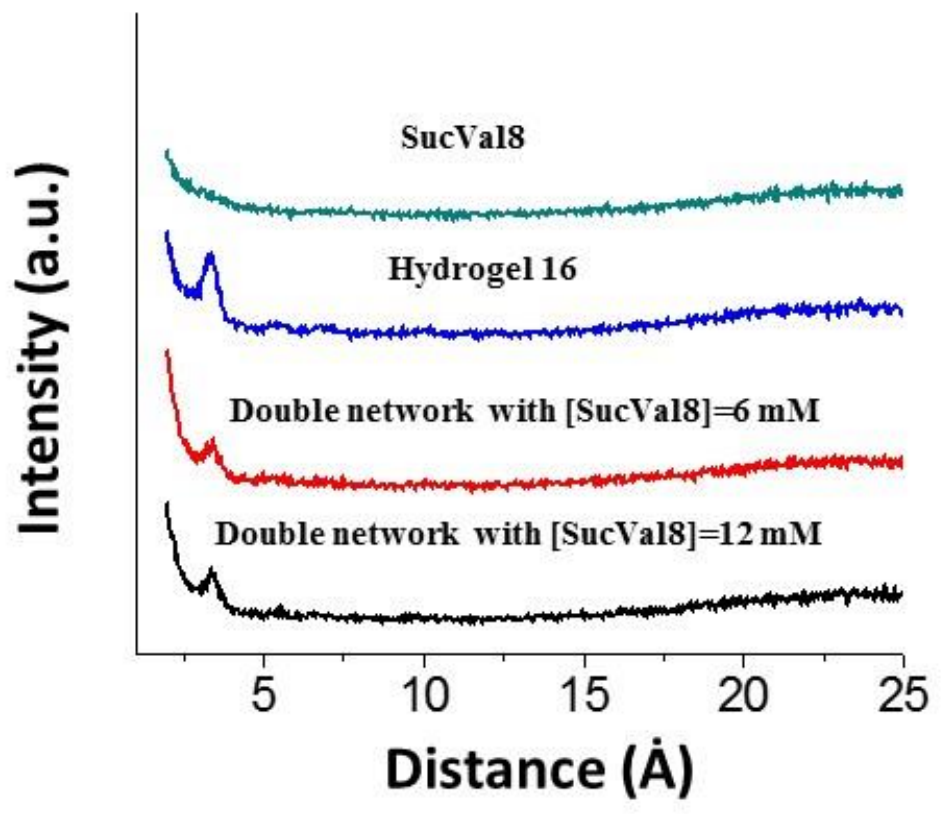

Figure 6.11: WAXD patterns of hydrogelators SucVal8 and 16 and mixed gel system with SucVal8 at MGC (6 mM) and $12 \mathrm{mM}$.

\subsection{Conclusion}

In conclusion we have presented a new way to form a self-sorted double network hydrogel completely based on physical interactions and catalysis. We were able to demonstrate the formation of a DN hydrogel by catalytic activity of one network for in situ formation of an interpenetrating network. The catalytic activity of the SucVal8 could be controlled 
depending on the amount of compound added, this allowed to control the kinetics of formation of second network. The formation of the second network had their nucleation points in the vicinity of the first network. We could thus attain a temporal and spatial control over the formation of the second network.

\subsection{Experimental section}

\subsubsection{Preparation of gels}

Trishydrazide (14) $(10.3 \mathrm{mg})$ was dissolved in $1 \mathrm{ml}$ of MilliQ water to obtain a $40 \mathrm{mM}$ stock solution. $82.2 \mathrm{mg}$ of aldehyde (15) was dissolved in $1 \mathrm{ml}$ of MilliQ water to obtain a $240 \mathrm{mM}$ stock solution. The $\mathrm{pH}$ of the aqueous aldehyde solution was adjusted to 7 via addition of minimal amount of sodium hydroxide solution. A hydrogel of SucVal8 was prepared via dissolving SucVal8 in MilliQ water by gentle heating and subsequently allowing the mixture to reachambient temperature by slowly cooling. A colourless gel was obtained in due course upon cooling. The mixed gel systems were prepared via mixing an aqueous solution of hydrazide (14), aldehyde (15) and hydrogel SucVal8 to give same final concentration of $\mathbf{1 4}$ and $\mathbf{1 5}$ in all the cases and fixed final volume. After rapid mixing, it was kept at ambient temperature to obtain a stable gel. Hydrazone gel was prepared in a 1:2 functional group molar ratio of the hydrazide and aldehyde, which means that there is an initial 1:6 molar ratio between hydrazide and aldehyde. For example, mixing an aqueous solution of hydrazide $14(250 \mu \mathrm{L}, 40 \mathrm{mM}, \mathrm{pH} 7.4)$, aldehyde $15(250 \mu \mathrm{L}, 240 \mathrm{mM}, \mathrm{pH} 7.0)$ and Hydrogel of SucVal8 (500 $\mu \mathrm{L}, \mathrm{pH} 5.5,6 \mathrm{mM})$ provided a mixture $(1000 \mu \mathrm{L})$ of $10 \mathrm{mM}$ hydrazone hydrogelator with final concentration of SucVal8 as $3 \mathrm{mM}$. The 1:2 functional group ratio between $\mathbf{1 4}$ and $\mathbf{1 5}$ is to ensure complete conversion of all hydrazide groups. 


\subsubsection{Rheology}

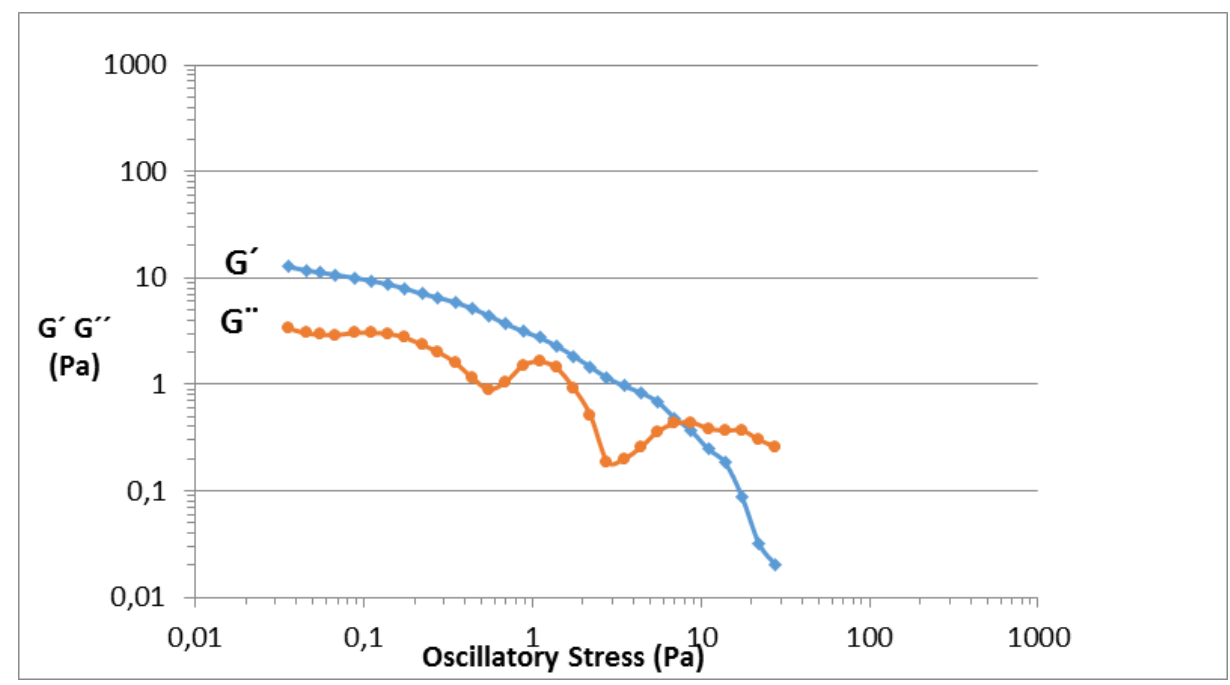

Figure ES 6.1: Contours of G'and G" by rheology for SucVal8 at MGC.

Rheological experiments were performed using a rheometer (AR G2, TA instruments) with a steel bottom plate and a top plate. The experiments were done in a strain controlled mode equipped with plate and plate geometry of $40 \mathrm{~mm}$ in diameter at $25 \pm 0.2{ }^{\circ} \mathrm{C}$. The approximate plate-plate distance is $1000 \mu \mathrm{m}$ and approximate sample volume between the plates is $1000 \mu \mathrm{L}$. The sample was prepared in a glass vial via addition of hydrazide, followed by addition of aldehyde to the solution/gel of SucVal8. After vigorous shaking, the sample mixture was immediately positioned onto the bottom rheometer plate. The sample was distributed evenly via rotating the top glass plate upon descending. Measurements were performed at a frequency of $1 \mathrm{~Hz}$ while applying $0.05 \%$ of strain. During the measurement, the storage and loss moduli ( $G^{\prime}$ and $G^{\prime \prime}$ respectively) were followed as a function of time (time sweep). The strain percentage is in the linear strain regime which was determined by a strain sweep. Upon reaching a plateau value of G', the gel strength was determined based on the average value of the plateau region. We define the gelation time as the moment that $\mathrm{G}^{\prime}$ measures $95 \%$ of this plateau value. Here, $\mathrm{G}^{\prime}$ is 
typically two orders of magnitude higher than $\mathrm{G}^{\prime \prime}$ upon completion of the reaction, and $\mathrm{G}^{\prime}$ typically exceeds G" (the "gel point") early in the reaction.

\subsubsection{Confocal laser scanning fluorescence microscopy (CLSFM)}

Confocal laser scanning fluorescence micrographs were obtained with a Zeiss LSM 700 confocal laser scanning microscope equipped with a Zeiss Axio Observer inverted microscope, 40 x PlanFluor oil immersion objective lens (NA 1.3) using an incident laser. The confocal pinhole was set to 1.0 airy unit and the data files were processed using ZEN 2011 software. Image dimensions were $95.35 \mu \mathrm{m}$ x $95.35 \mu \mathrm{m}$ with a resolution of $1024 \mathrm{x}$ 1024 pixels. Exposition time per pixel was $1.58 \mu \mathrm{s}$. Using confocal laser scanning fluorescence microscopy, the hydrogel of SucVal8 network was imaged via incorporating nile red $(9 \mu \mathrm{M})$ during the gel preparation process, whereas the hydrazone gel networks were imaged via incorporating an aldehyde functionalized fluorescein derivative into the fibre formation process. The hydrazone gelsamples were prepared as before, but now including $30 \mu \mathrm{M}$ (replacing that amount of aldehyde) to the aldehyde functionalized fluorescent probe. By covalent binding to the hydrazide, the probe allowed imaging of the gel and its composing fibres without disrupting its native state.

\subsubsection{NMR Experiment}

Three different samples of hydrogel of SucVal8 at MGC $(250 \mu \mathrm{L}, 300 \mu \mathrm{L}$, and $400 \mu \mathrm{L})$ were prepared in NMR tubes. Aqueous solution of 14 and 15 of different concentrations were added to the hydrogel sample of SucVal8 to achieve the final volume of $500 \mu \mathrm{L}$ in water for the mixed system. Final concentration of $\mathbf{1 4}$ and $\mathbf{1 5}$ were same as before in all the cases. A concentric tube with a known concentration of hydroquinone dissolved in $\mathrm{D}_{2} \mathrm{O}$ was introduced in this system and the consumption of aldehyde with time was 
monitored with respect to the constant peak of hydroquinone at $6.7 \mathrm{ppm}$ (integrated as 100).To determine the initial amount of aldehyde $\mathbf{1 5}$, same system with similar volume was used but without any hydrazide 14 . For sample at twice the MGC, $250 \mu \mathrm{L}$ hydrogel of SucVal8 $(12 \mathrm{mM})$ was prepared, following the addition of $\mathbf{1 4}$ and $\mathbf{1 5}$ to get the final volume of $500 \mathrm{~mL}$ with same final concentration of $\mathbf{1 4}$ and $\mathbf{1 5}$ as before.

(a)
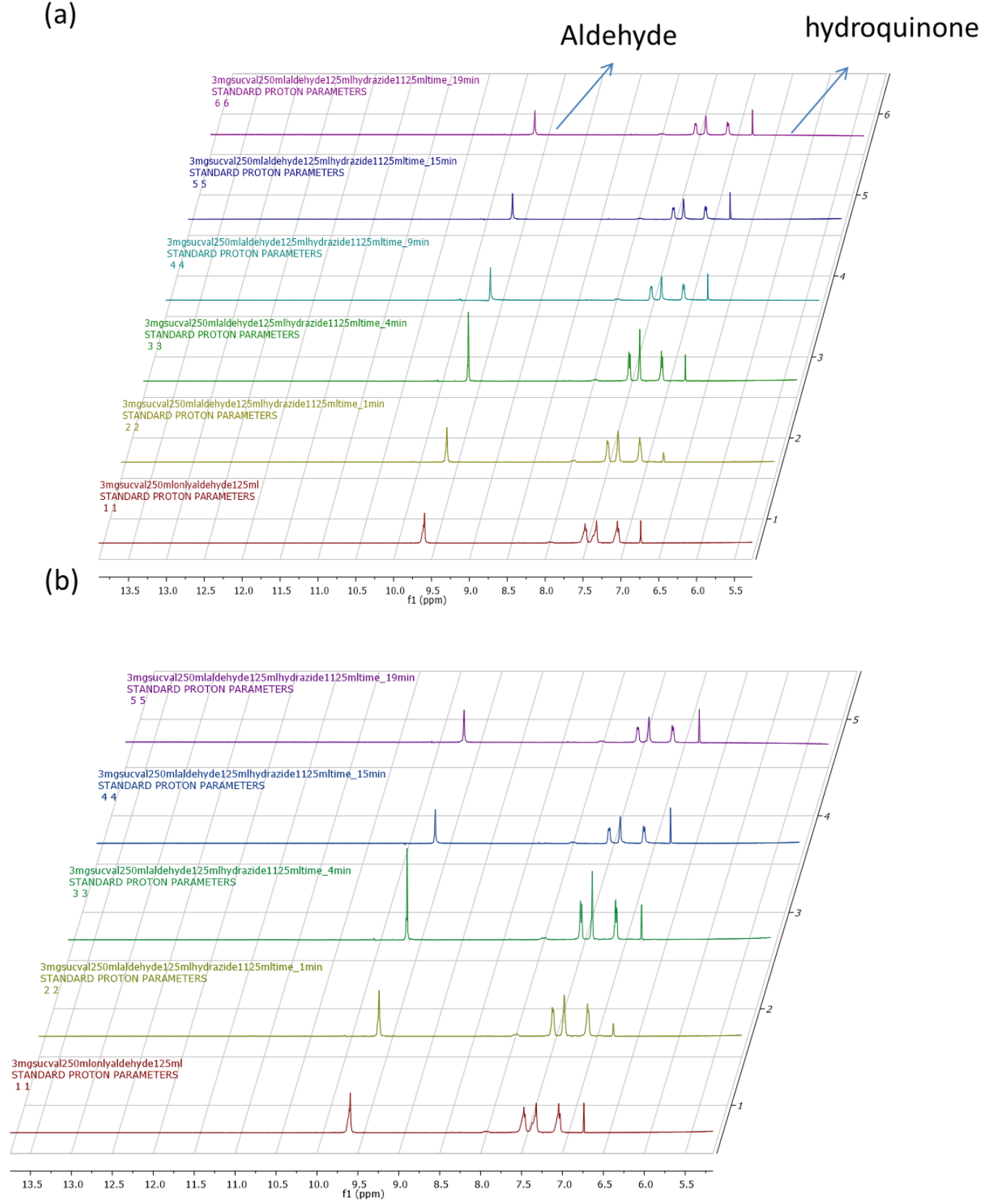

Figure ES 6.2: Kinetics of the consumption of aldehyde (15) with respect to constant hydroquinone peak with hydrogel of SucVal8 prepared (a) at MGC, final concentration of compound SucVal8 is $3.0 \mathrm{mM}$ (b) at double MGC, final concentration of SucVal8 is $6.0 \mathrm{mM}$, 


\section{(c)}

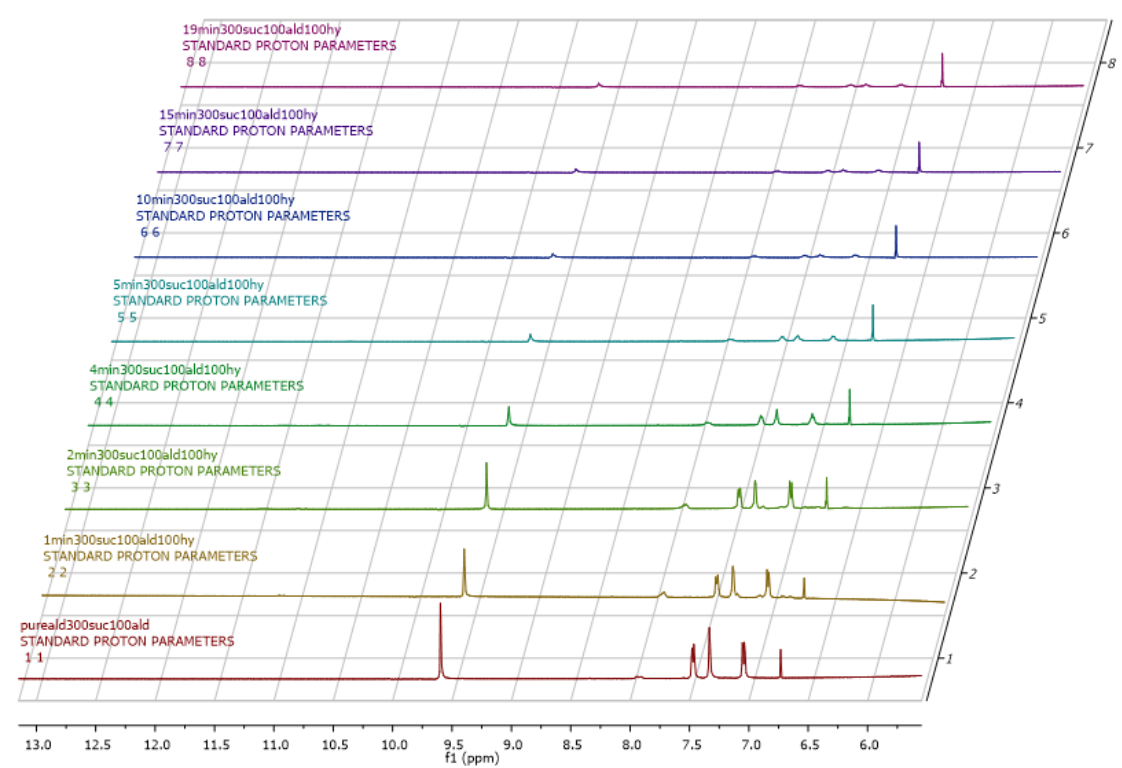

(d)

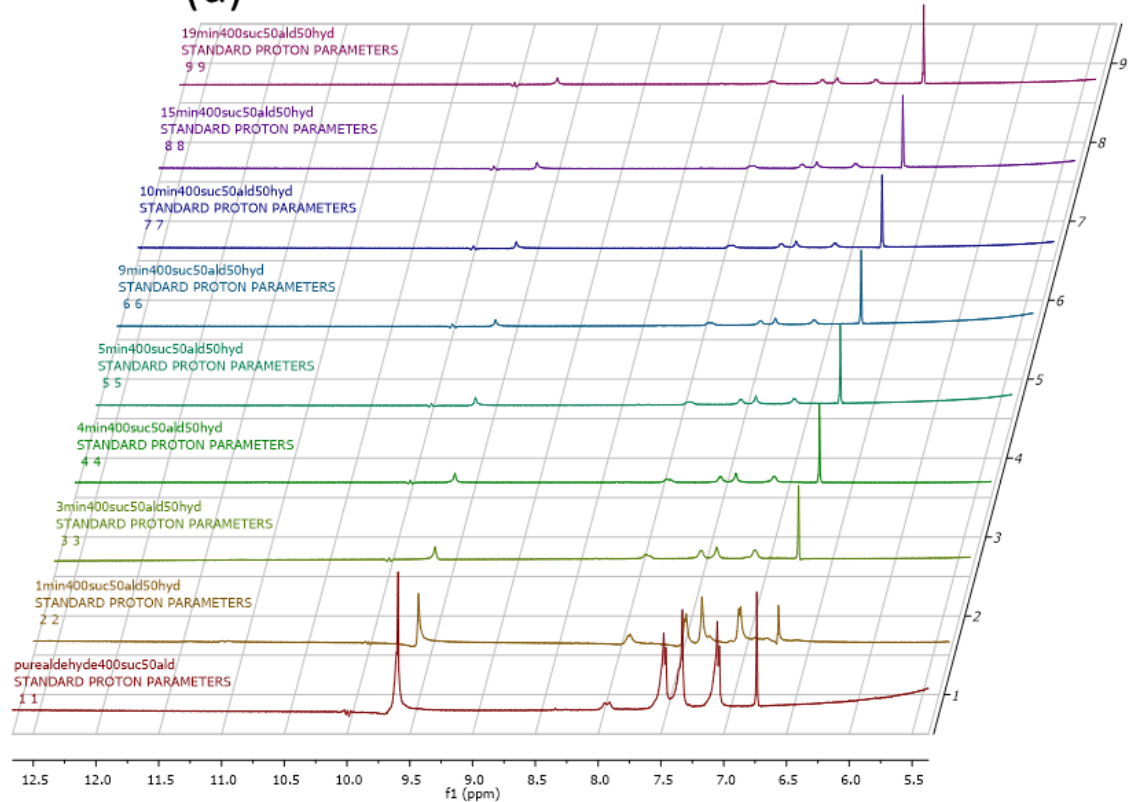

Figure ES 6.2: Kinetics of the consumption of aldehyde (15) with respect to constant hydroquinone peak with hydrogel of SucVal8 prepared (c) at MGC, final concentration of SucVal8 is $3.6 \mathrm{mM}$ and (d) at MGC, final concentration of SucVal8 is $4.8 \mathrm{mM}$. 


\subsubsection{Wide angle $X$-ray diffraction}

Data collection was performed at room temperature with a BrukerD4 Endeavor X-ray powder diffractometer by using $\mathrm{Cu} \mathrm{K} \alpha$ radiation. Xerogels were obtained by lyophilization.

\subsubsection{Transmission electron microscopy}

TEM micrographs were obtained using a JEOL 2100 transmission electron microscope. The TEM samples were prepared by directly applying gels at MGC on formvar-carbon coated TEM grids. A $5 \mu \mathrm{L}$ droplet of purified water was used to remove the salts and the excess solution was wicked off using filter paper. The samples were immediately stained using $5 \mu 1$ droplet of $1 \%$ phosphotungstic acid and was allowed to stand for 5 min. The excess solution was removed using a filter paper. The grids were then left under covered petri dish to dry before obtaining images.

\subsubsection{Atomic force microscopy}

AFM measurements were performed in the tapping mode using a commercial instrument (NTEGRA Prima, NT-MDT Co., Moscow, Russia). Topographic and phase images were recorded simultaneously at scanning rate of $0.4 \mathrm{~Hz}$ using a rectangular silicon cantilever (NSG03 series) with a resonant frequency of $100 \mathrm{kHz}$ (in the air) and force constant of $6.566 \mathrm{~N} / \mathrm{m}$, which was determined by the thermal fluctuation method. ${ }^{41}$ For sample preparation, diluted gel solution was spin-coated on the surface of silicon wafers $(5 \times 7 \mathrm{~mm})$. Before spin coating, these small pieces of silicon wafers were cleaned by water, ethanol, and sonication in acetone followed by plasma treatment for $2.5 \mathrm{~min}$. 


\section{AFM and TEM images.}

a)

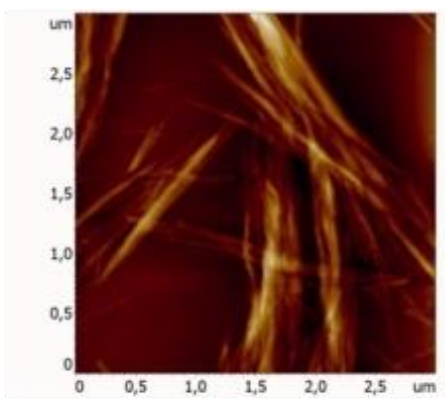

c)
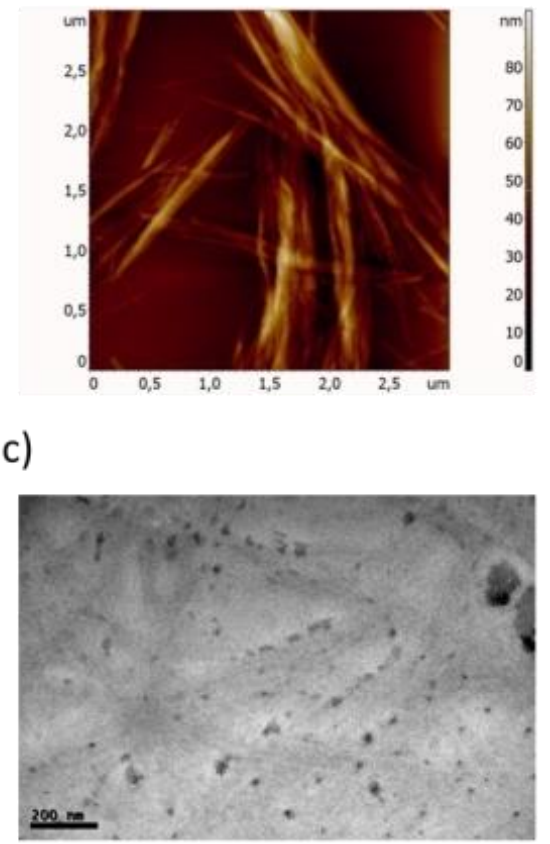

b)

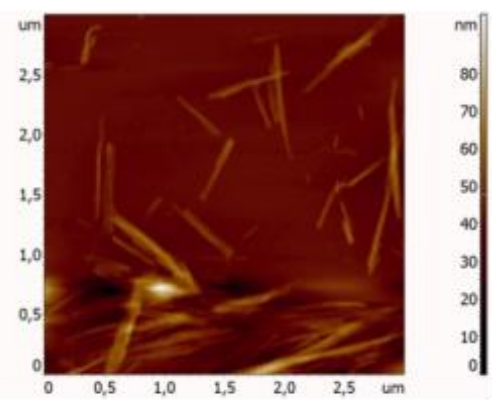

d)

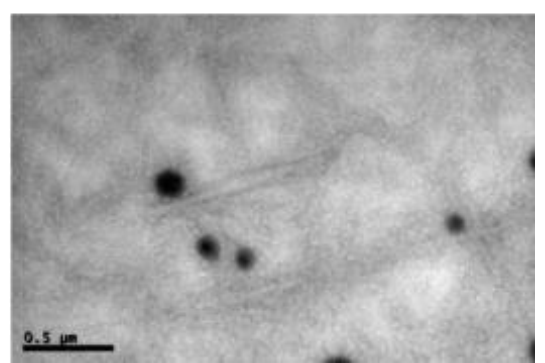

Figure ES 6.3: AFM (a, b) and TEM (c, d) images of fibres of hydrogel 16.

a)

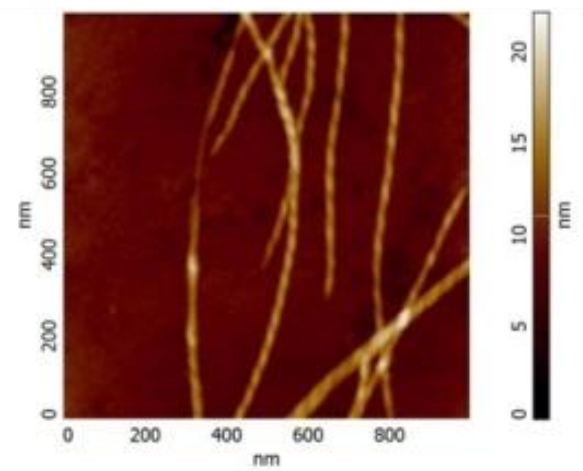

c)

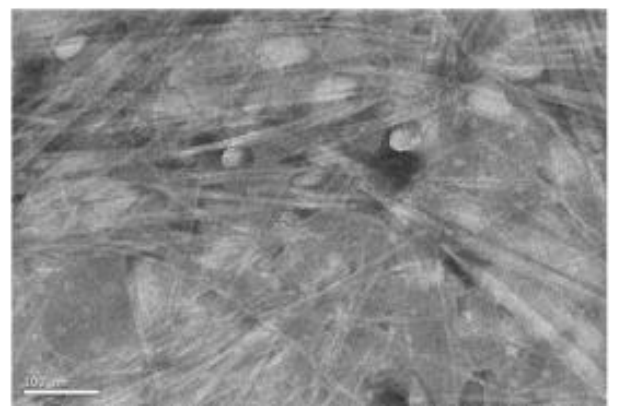

b)

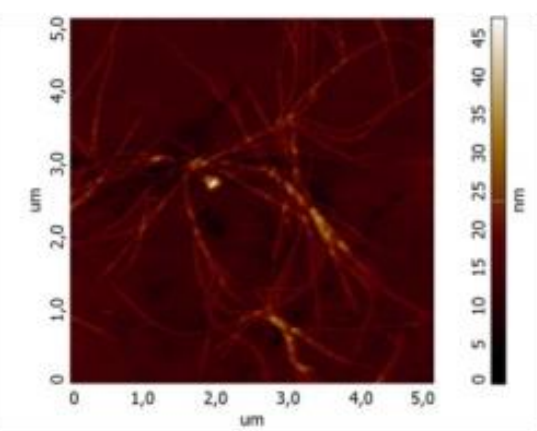

d)

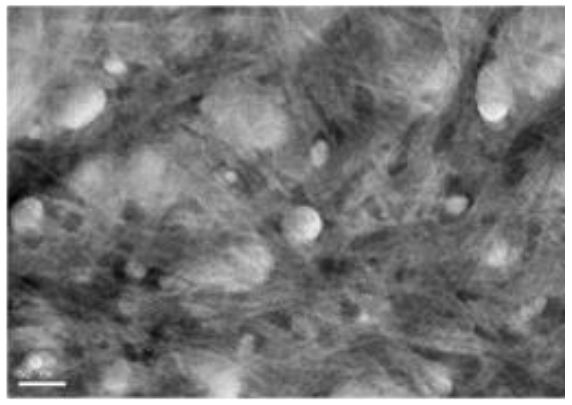

Figure ES 6.4: AFM (a, b) and TEM (c, d) images of SucVal8 gel 
a)

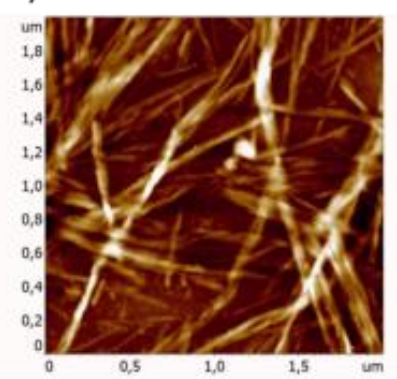

d)

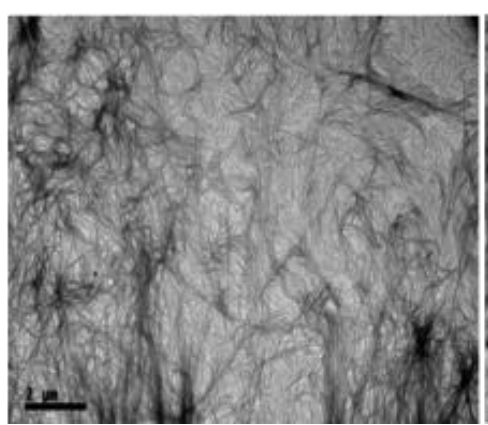

b)

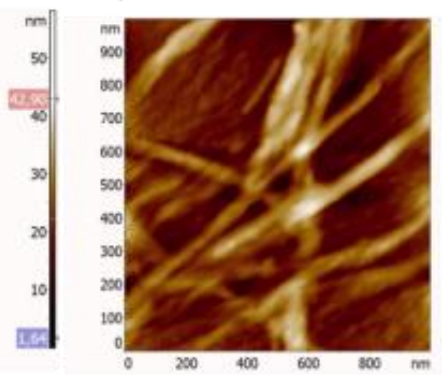

e)

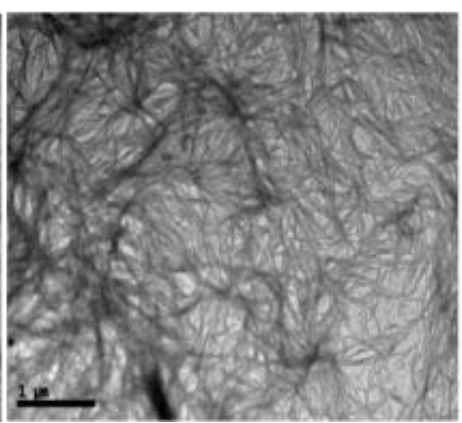

c)

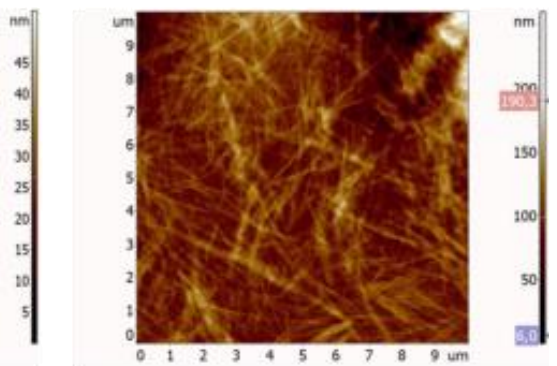

f)

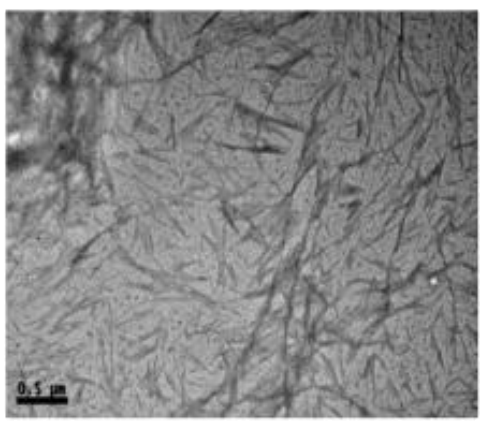

Figure ES 6.5: AFM (a-c) and TEM (d-f) images of the mixed system with SucVal8 at 12 mM. Dark patches in TEM and brighter spots in AFM can be assigned to sites of nucleation of high density branched fibres of hydrogel 16.

a)

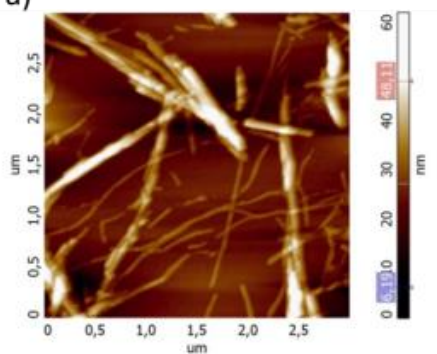

d)

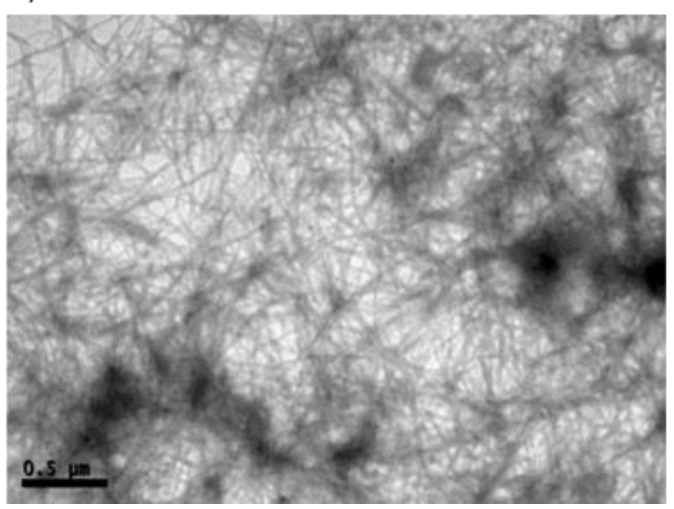

b)

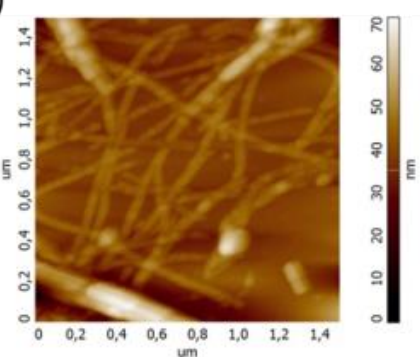

e) c)

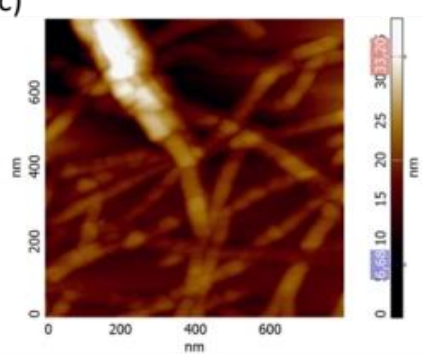

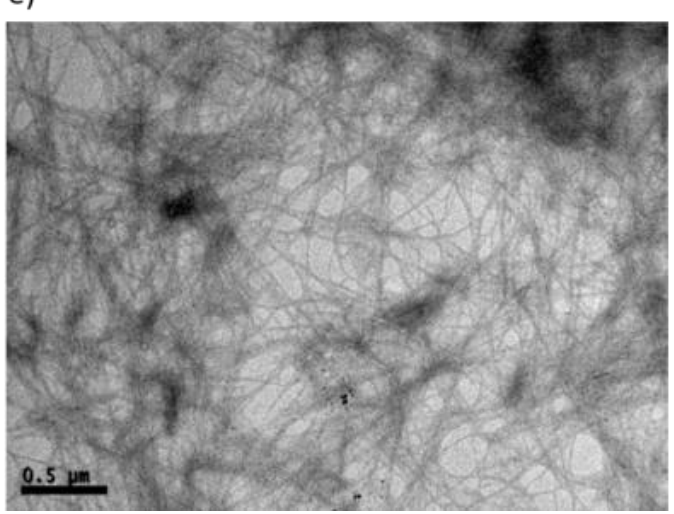

Figure ES 6.6: AFM (a-c) and TEM (d, e) images of the mixed system with SucVal8 at MGC (6.0 mM). Dark patches in TEM can be assigned to sites of nucleation of high density branched fibres of hydrogel 16. 


\subsection{References}

1. C. Wang, R. J. Stewart, J. Kopecek, Nature, 1999, 397,417.

2. J. Kopec`ek, J. Yang, Angew. Chem. Int. Ed., 2012, 51, 7396.

3. H. K. Lau, K. L. Kiick, Biomacromolecules., 2014, 16, 28.

4. Md. A. Haque, T. Kurokawa, J. P. Gong, Polymer, 2012, 53, 1805.

5. T. Gilbert, N. M. B. Smeets, T. Hoare, ACS Macro Lett., 2015, 4, 1104.

6. J.-Y. Sun, X. Zhao , W. R. K. Illeperuma, O. Chaudhuri, K. H. Oh, D. J. Mooney, J. J. Vlassak, Z. Suo, Nature, 2012, 489, 133.

7. M. A. Haque, T. Kurokawa, J. P. Gong, Polymer, 2012, 53, 1805.

8. T. Nakajima, H. Sato, Y. Zhao, S. Kawahara, T. Kurokawa, K. Sugahara, J. P. Gong, Adv. Funct. Mater., 2012, 22, 4426.

9. J. P. Gong, Soft Matter, 2010, 6, 2583.

10. M. Shibayama, Soft Matter, 2012, 8, 8030.

11. X. Zhao, Soft Matter, 2014, 10, 672.

12. E. Ducrot, Y. Chen, M. Bulters, R. P. Sijbesma, C. Creton, Science, 2014, 344, 186.

13. V. X. Truong, M. P. Ablett, S. M. Richardson, J. A. Hoyland, and A. P. Dove, J. Am. Chem. Soc., 2015, 137, 1618.

14. M. Guo, L. M. Pitet, H. M. Wyss, M. Vos, P. Y. W. Dankers, E. W. Meijer, J. Am. Chem. Soc., 2014, 136, 6969.

15. J. Li, NPG Asia Mater., 2010, 2, 112.

16. J. P. Gong, Y. Katsuyama, T. Kurokawa, Y. Osada, Adv. Mater., 2003, 15, 1155.

17. J. P. Gong, Science, 2014, 344, 161.

18. M. M. Smith, D. K. Smith, Soft Matter, 2011, 7, 4856.

19. J. R. Moffat, D. K. Smith, Chem. Commun., 2009, 316. 
20. D. G. Velazquez, R. Luque, Chem. Eur. J., 2011, 17, 3847.

21. A. Das, S. Ghosh, Chem. Commun., 2011, 47, 8922.

22. B. Adhikari, J. Nanda, A. Banerjee, Soft Matter, 2011, 7, 8913.

23. A. R. Hirst, B. Q. Huang, V. Castelletto, I. W. Hamley, D. K. Smith, Chem. Eur. J., 2007, 13, 2180.

24. S. Ghosh, X. Q. Li, V. Stepanenko, F. Wurthner, Chem. Eur. J., 2008, 14, 11343.

25. A. Heeres, C. van der Pol, M. Stuart, A. Friggeri, B. L. Feringa, J. van Esch, J. Am. Chem. Soc., 2003, 125, 14252.

26. A. Brizard, M. Stuart, K. V. Bommel, A. Friggeri, M. de Jong, J. H van Esch, Angew. Chem. Int. Ed., 2008, 47, 2063.

27. K. L. Morris, L. C., J. Raeburn, O. R. Sellick, P. Cotanda, A. Paul, P. C. Griffiths, S. M. King, R. K. O’Reilly, L. C. Serpell, D. J. Adams, Nat. Commun., 2013, 4, 1480. doi: $10.1038 /$ ncomms2499.

28. C. Li, M. J. Rowland, Y. Shao, T. Cao, C. Chen, H. Jia, X. Zhou, Z. Yang, O. A. Scherman, D. Liu, Adv Mater., 2015, 3, 27, 3298.

29. M. O. Guler, S. I. Stupp, J. Am. Chem. Soc., 2007, 129, 12082.

30. N. Singh, M. P. Conte, R. V. Ulijn, J. F. Miravet, B. Escuder, Chem. Commun., $\mathbf{2 0 1 5}, 51,13213$.

31. F. Rodríguez-Llansola, B. Escuder, J. F. Miravet, J. Am. Chem. Soc., 2009, 131, 11478.

32. F. Rodríguez-Llansola, J. F. Miravet, B. Escuder, Chem. Commun., 2009, 7303.

33. B. Escuder, F. Rodríguez-Llansola, J. F. Miravet, New J. Chem.,2010, 34, 1044.

34. C. Berdugo, J. F. Miravet, B. Escuder, Chem. Commun., 2013, 49, 10608.

35. N. Singh, M. Tena-Solsona, J. F. Miravet, B. Escuder, Isr. J. Chem., 2015, 55, 711. 
36. J. Boekhoven, J. M. Poolman, C. Maity, F. Li, L. van der Mee, C. B. Minkenberg, E. Mendes, J. H. van Esch, R. Eelkema, Nat. Chem., 2013, 5, 433.

37. J. M. Poolman, J. Boekhoven, A. Besselink, A. G. L. Olive, J. H. van Esch, R. Eelkema, Nat. Protoc., 2014, 9, 977.

38. N. Singh, K. Zhang, C. A. A. Pachon,E. Mendes, J. H. Van Esch, B. Escuder, Chem. Sci., 2016, 7, 5568.

39. A. R. Hirst, S. Roy, M. Arora, A. K. Das, N. Hodson, P. Murray, S. Marshall, N. Javid, J. Sefcik, J. Boekhoven, J. H. van Esch, S. Santabarbara, N. T. Hunt, R. V. Ulijn, Nat. Chem., 2010, 2, 1089.

40. R. J. Williams, A. M. Smith, R. Collins, A. K. Das, R. V. Ulijn, Nat. Nanotechnol., 2009, 4, 19.

41. J. L. Hutter, J. Bechhoefer, Rev. Sci. Instr., 1993, 64, 1868. 
Summary 


\section{Summary:}

Low molecular weight hydrogelators appended with catalytic groups are known to show enhanced catalytic activities. These self-assembling catalytic molecules demonstrate better catalytic efficacy when compared to their analogues which are unable to aggregate. The enhanced activity has been correlated with several properties such as cooperativity, increased acidity/basicity, pKa shifts, hydrophobic pockets, etc. that come in to play upon aggregation of these molecules.

Based on the previous reports of histidine incorporated molecules we have synthesized ImVal8, a metal free low molecular gelator which was able to hydrolyze the model ester para nitro phenyl acetate demonstrating enzyme like catalysis following MichaelisMenten model. The hydrolysis could be carried out at pHs ranging from 6 to 8 . At lower pHs 6 and 6.5 high catalytic activity was recorded which could be linked to the cooperation of protonated and deprotonated imidazole groups work together. The enhanced catalytic activity also allowed the hydrogelator to hydrolyze $L$ - and $D$ phenylalanine methyl ester into corresponding amino acids at physiological $\mathrm{pH}$. On the other hand a soluble analogue Im8 was able to hydrolise the $p$ NPA ester but at a considerably lower rate and no binding phenomenon was seen. This further proved the role of self-aggregation to achieve high catalytic activity.

As seen in Chapter 3 and various other reports have so far been about using either one catalytic hydrogelator or more hydrogelators working together in cooperation to perform a single reaction. The hydrogelators when mixed together have an inclination of coassembling rather than self-sorting. We have taken advantage of the structural dissimilarity of two hydrogelators for their orthogonal assembly. These hydrogelators ProValDoc and SucVal8 were appended with mutually incompatible groups namely 
proline and acid group respectively. Thanks to the self-sorting, the two functional groups were spatially separated and thus were utilized to perform tandem reaction in one pot. SucVal8 was able to deprotect benzaldimethyl acetaldehyde into benzaldehyde which was used by ProValDoc to perform aldol reaction with cyclohexanone in the same pot giving the final aldol adduct in high yield and enantiomeric ratio. Whereas ProVal8 another bolaamphilic gelator with proline group structurally similar to SucVal8 when used together with SucVal8 showed a co-assembling tendency and no final aldol product was achieved in this case. Proline and acid group in this case formed a salt bridge neutralizing each other rendering them catalytically inactive.

This idea of orthogonal assembly to achieve tandem reactions was extended to a more complex reaction system-Mannich reaction. Mannich reaction is known to be catalyzed by both acidic and proline functional units. In case of acidic catalysis the reported diastreoselectivity and enantiomeric ratio have always been below par even though the reaction rates are on the higher sides. Whereas proline molecules can give high diastreo and enantioselectivity but at lower reaction rates and come with a disadvantage of using toxic organic solvents due to their low solubility. Both SucVal8 and ProValDoc were able to catalyze direct three component Mannich reaction between aniline, benzaldehyde and cyclohexanone. SucVal8 as catalyst showed very poor streoselectivity. Whereas ProValDoc showed considerably higher diastreoselectivity and enantiomeric ratio. When both the gelators were mixed the final selectivity was intermediate but considerably higher than SucVal8 alone. Knowing this we used these hydrogelators to a more complex reaction system in which benzaldehyde was replaced by benzaldehyde dimethyl acetal. We wanted to form a complex cascade-tandem system using SucVal8 and ProValDoc. We expected SucVal8 to perform deacetalisation to give benzaldehyde and subsequently perform the next step of Mannich reaction. But since the selectivity of SucVal8 for the 
final Mannich reaction is not good we expected that presence of ProValDoc will assist in getting higher streo and enantiomeric ratio. In the end we were able to attain to final diastreomeric ratio of anti:syn (75:25) for the mixture of ProValDoc and SucVal8 for the cascade-tandem system while SucVal8 alone showed a diastreoselctivity of 66:34 (anti:syn).

The use of catalysts for on demand control of supramolecular organization in ubiquitous in nature. Inspired by a previous report where different amounts of enzymes where used to catalytically control the supramolecular organization of dipeptide gelators we decide to check one of the catalytic gelators for the same. SucVal8 was used to control the formation and subsequent self-assembly of a new hydrogelator $\mathbf{1 6}$ based on the formation of hydrazone catalyzed by SucVal8 between the precursors 14 and 15. Use of various concentrations of SucVal8 allowed to have a control over the rate of formation of $\mathbf{1 6}$ and thus allowed to fine tune the kinetic of the self-assembly. Thus we were able to attain a double network system of SucVal8 and 16 in the same pot. The kinetics of formation of 16 allowed to have the final double network hydrogelator of varying storage modulus. Higher rate of formation resulted in increased rate of self-assembly of $\mathbf{1 6}$ giving a kinetically trapped mechanically stronger double network gel system. 


\section{Resumen}




\section{Resumen:}

Los hidrogelantes de bajo peso molecular funcionalizados con grupos catalíticos son conocidos por mostrar actividades catalíticas mejoradas. Estas moléculas catalíticas que se auto-ensamblan muestran mejor eficiencia catalítica cuando se comparan con sus análogos solubles que son incapaces de agregar. La mejora de la actividad catalítica ha sido atribuida a diferentes propiedades que aparecen cuando las moléculas agregan como son la cooperatividad, el aumento de basicidad/acidez, creación de superficies hidrofóbicas etc.

Basados en trabajos anteriores de moléculas que incorporaban histidinas, se ha sintetizado el ImVal8, un gelante de bajo peso molecular que fue capaz de hidrolizar el acetato de $p$ nitrofenilo (pNPA) en ausencia de metales demostrando una catálisis parecida a la enzimática siguiendo un modelo Michaelis-Menten. La hidrólisis puede ser llevada a cabo a pH desde 6 a 8 . A valores de $\mathrm{pH}$ de 6 y 6,5 mayor actividad catalítica fue observada lo cual puede ser debid a la cooperación de los grupos imidazol protonados y desprotonados. La mejora de la actividad catalítica también permitió al hidrogelante hidrolizar los ésteres metílicos de la $L$ - y $D$-fenilalanina en sus correspondientes aminoácidos a pH fisiológico. Por otra parte, el análogo soluble Im8 fue capaz de hidrolizar el $p$ NPA pero a una velocidad considerablemente inferior y no se observó fenómeno de interacción alguno. Todo esto prueba el rol de la auto-agregación para conseguir actividades catalíticas elevadas.

El uso de uno o más hidrogelantes catalíticos trabajando cooperativamente para llevar a cabo una única reacción ha sido ampliamente descrito en el capítulo 3 y en otros trabajos. La mezcla de hidrogelantes tiene tendencia a co-ensamblarse (formando agregados mixtos) más que a formar agregados ortogonales (cada gelante formando agregados por 
su lado). Se ha aprovechado la diferencia estructural de dos hidrogelantes, ProValDoc y SucVal8 para formar redes fibrilares ortogonales. Estos hidrogelantes contienen grupos intrínsecamente incompatibles, como son la prolina y un grupo ácido succínico respectivamente. Gracias a la ortogonalidad de los dos hidrogelantes, los dos grupos funcionales están separados espacialmente, siendo esto aprovechado para llevar a cabo reacciones tándem en un solo paso. El compuesto SucVal8 fue capaz de desproteger el benzaldihido dimetilacetal a benzaldehído, que a su vez fue usado por el ProValDoc para llevar a cabo una reacción aldólica con ciclohexanona en el mismo paso, dando el aducto aldólico con un elevado rendimiento y alto ratio enantiomérico. Además, cuando otro gelante bolaamfifílico ProVal8 se combina con el estructuralmente similar SucVal8 se observa una clara tendencia de ambos a presentar estructuras co-ensambladas, en este caso no se observó la producción de aducto aldólico debido a que la prolina y el grupo ácido forman un puente salino neutralizando el uno al otro y haciendo que sean catalíticamente inactivos.

La idea del ensamblaje ortogonal para conseguir reacciones en tándem fue extendida a sistemas de reacciones más complejas como es la reacción de Mannich. Se conoce que la reacción de Mannich es catalizada por prolina y unidades funcionales ácidas. En el caso de la catálisis ácida la estereoselectividad previamente descrito en la bibliografía ha sido siempre menor o igual sin embargo las velocidades de reacción son altas. Los residuos de prolina pueden dar alta diaestereoselectividad y enantioselectividad sin embargo, suelen presentar baja solubilidad (lo que obliga al uso de disolventes orgánicos) y menores velocidades de reacción. SucVal8 y ProValDoc fueron capaces de catalizar directamente la reacción de Mannich entre la anilina, el benzaldehído y la ciclohexanona. Como catalizador, el SucVal8 presentó una muy baja estereoselectividad. No obstante ProValDoc mostró una elevada diastereoselectividad y un ratio enentiomérico elevado. 
Cuando ambos gelantes fueron mezclados, la selectividad final fue intermedia pero considerablemente mayor al SucVal8 solo. Sabiendo esto, se usaron estos hidrogelantes para un Sistema de reacciones más complejo en el que el benzaldehído fue sustituido por el benzaldihido dimetilacetal. Se buscaba formar un sistema complejo cascada-tándem usando SucVal8 y ProValDoc. Se esperaba que el SucVal8 llevara a cabo la desacetilación para dar el benzaldehído y a continuación, que se produjera el paso siguiente de la reacción de Mannich. Sin embargo, como la selectividad del SucVal8 para la reacción de Mannich final no es buena, se esperaba que la presencia del ProValDoc ayudara en conseguir mayor estereoselectividad. Finalmente se consiguió una ratio diastereoisomérico de anti:sin de 75:25 para la mezcla de ProValDoc y SucVal8 para el Sistema de reacciones en cascada-tándem mientras que el SucVal8 solo mostró una diastereoselectividad anti:sin de 66:34.

El uso de catalizadores para el control a voluntad de la organización supramolecular es omnipresente en la naturaleza. Inspirados por un trabajo anterior donde diferentes cantidades de enzimas fueron utilizadas para controlar catalíticamente la organización supramolecular de gelantes dipeptídicos se decidió probar uno de los gelantes catalíticos para lo mismo. El producto SucVal8 fue utilizado para controlar la formación y posterior auto-agregación de un nuevo hidrogelante $\mathbf{1 6}$ basado en la formación de un enlace hidrazona entre los precursores 14 y 15. El uso de diferentes concentraciones de SucVal8 permitieron tener un control sobre la velocidad de formación de 16, además permitió modular de forma precisa la cinética de auto-agregación. De esta manera hemos sido capaces de obtener sistema formado por una doble red fibrilar de SucVal8 y el hidrogel 16. Las cinéticas de formación de $\mathbf{1 6}$ permitieron tener una red fibrilar doble de $\mathrm{G}^{\prime}$ variable. Una mayor velocidad de formación resultó en una mayor velocidad de 
autoensamblaje de $\mathbf{1 6}$ dando una red doble mecánicamente más fuerte y atrapada cinéticamente. 
Annex 


\section{Selected Spectra:}

ImVal8: ${ }^{1} \mathrm{H}$ NMR, $500 \mathrm{MHz}, \mathrm{DMSO}-\mathrm{d}_{6}$

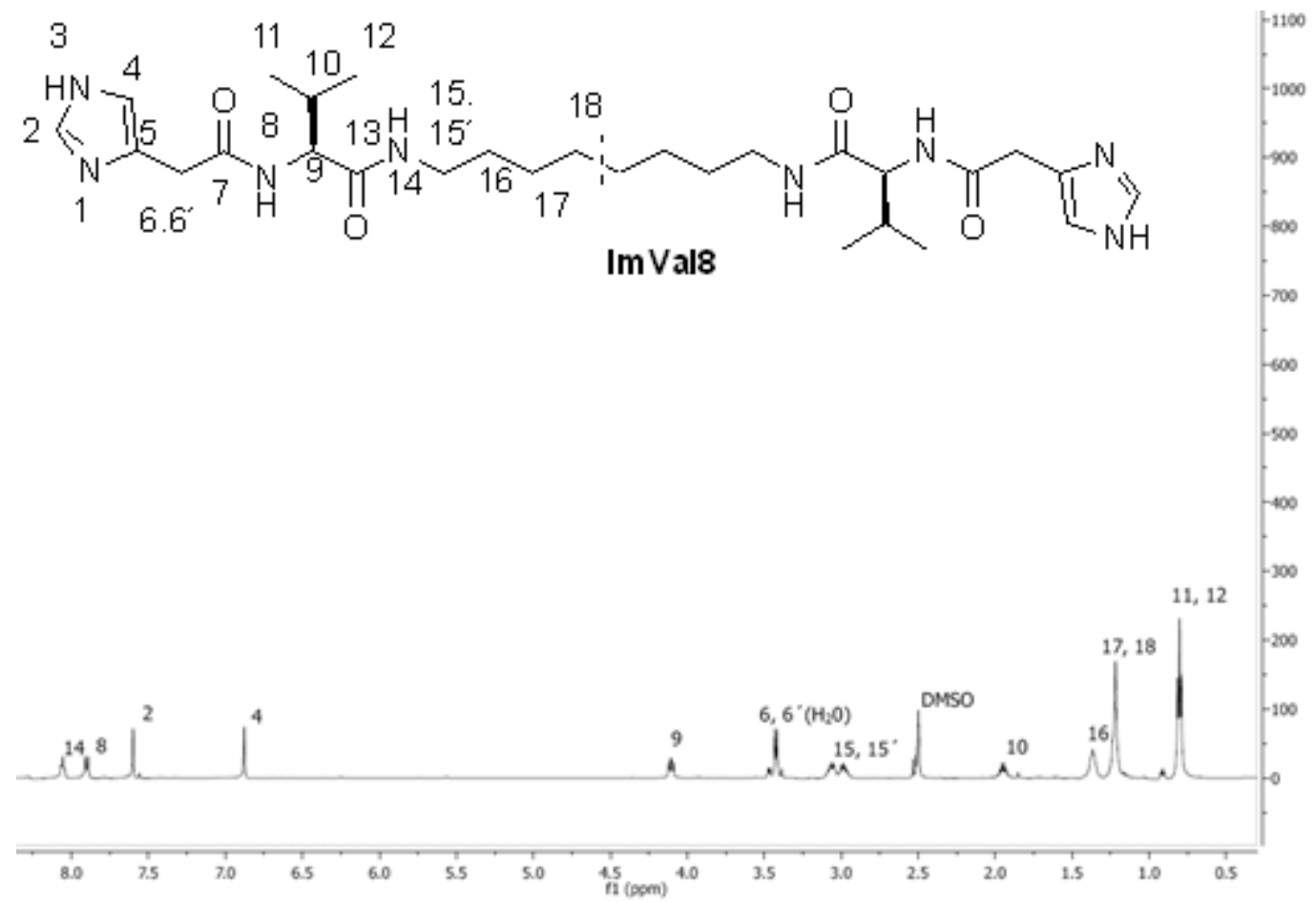

ImVal8: ${ }^{13} \mathrm{C}$ NMR, $500 \mathrm{MHz}, \mathrm{DMSO}-\mathrm{d}_{6}$

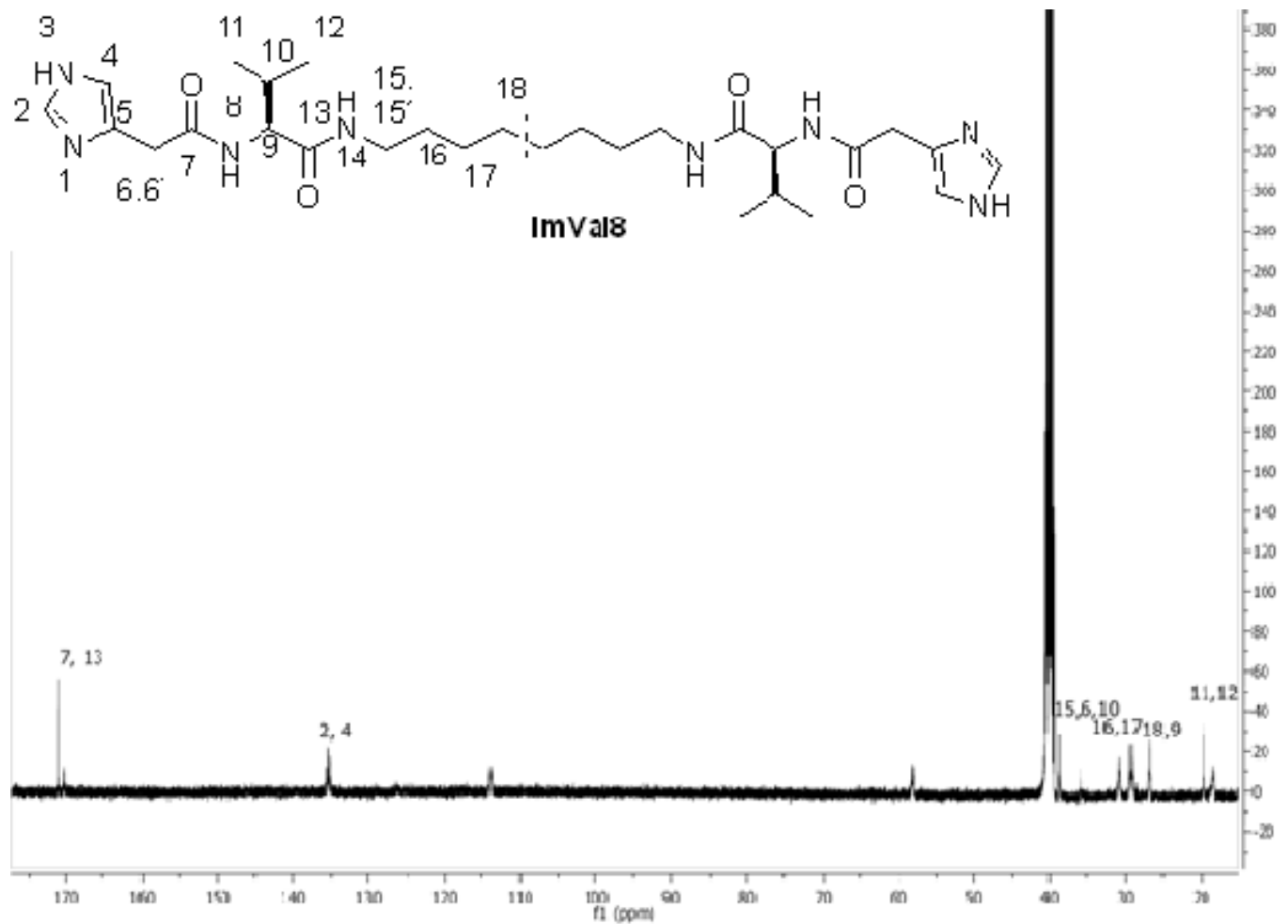


Im8: ${ }^{1} \mathrm{H}$ NMR, 500MHz, DMSO-d 6

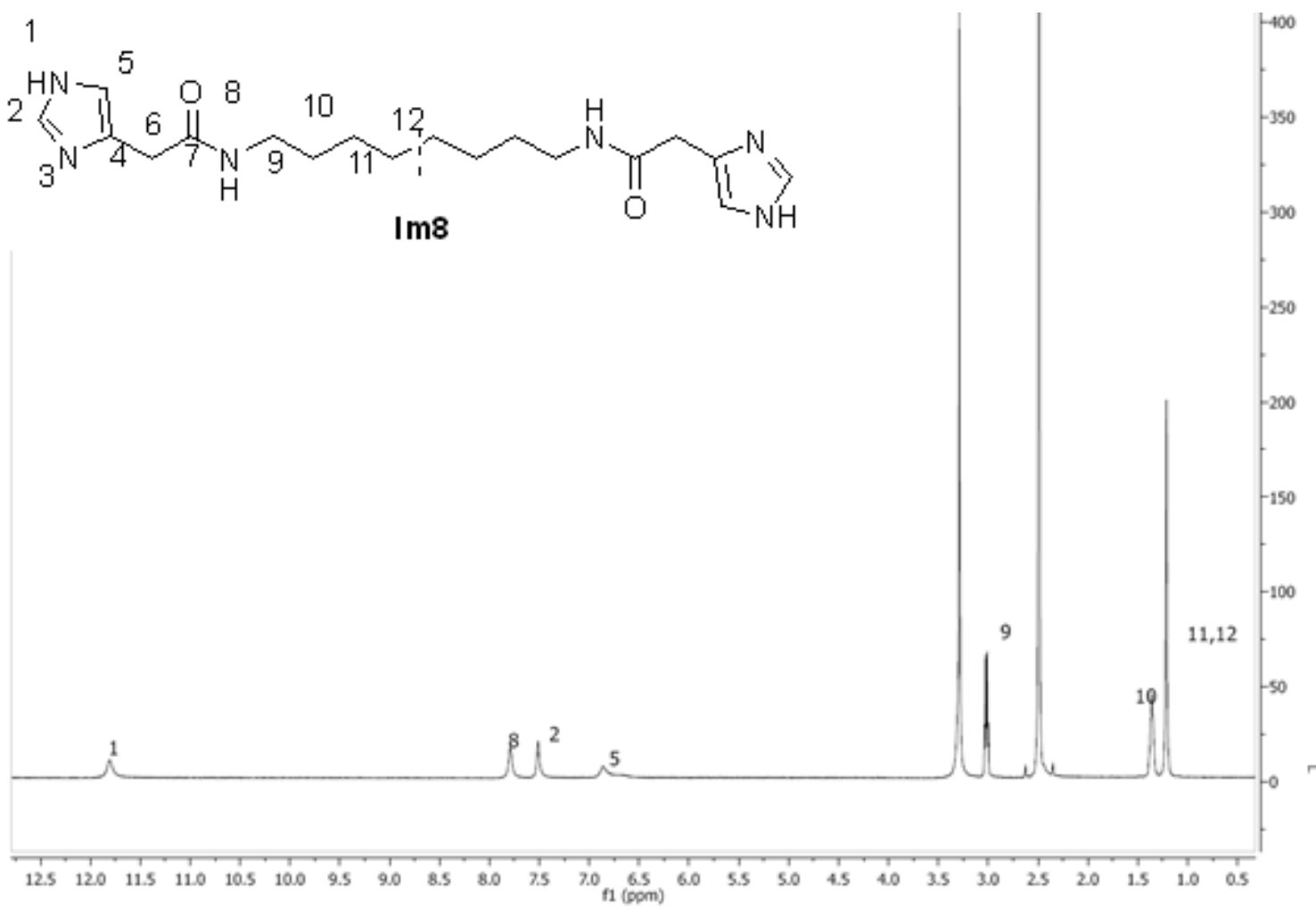

Im8: ${ }^{13} \mathrm{C}$ NMR, $500 \mathrm{MHz}$, DMSO-d6

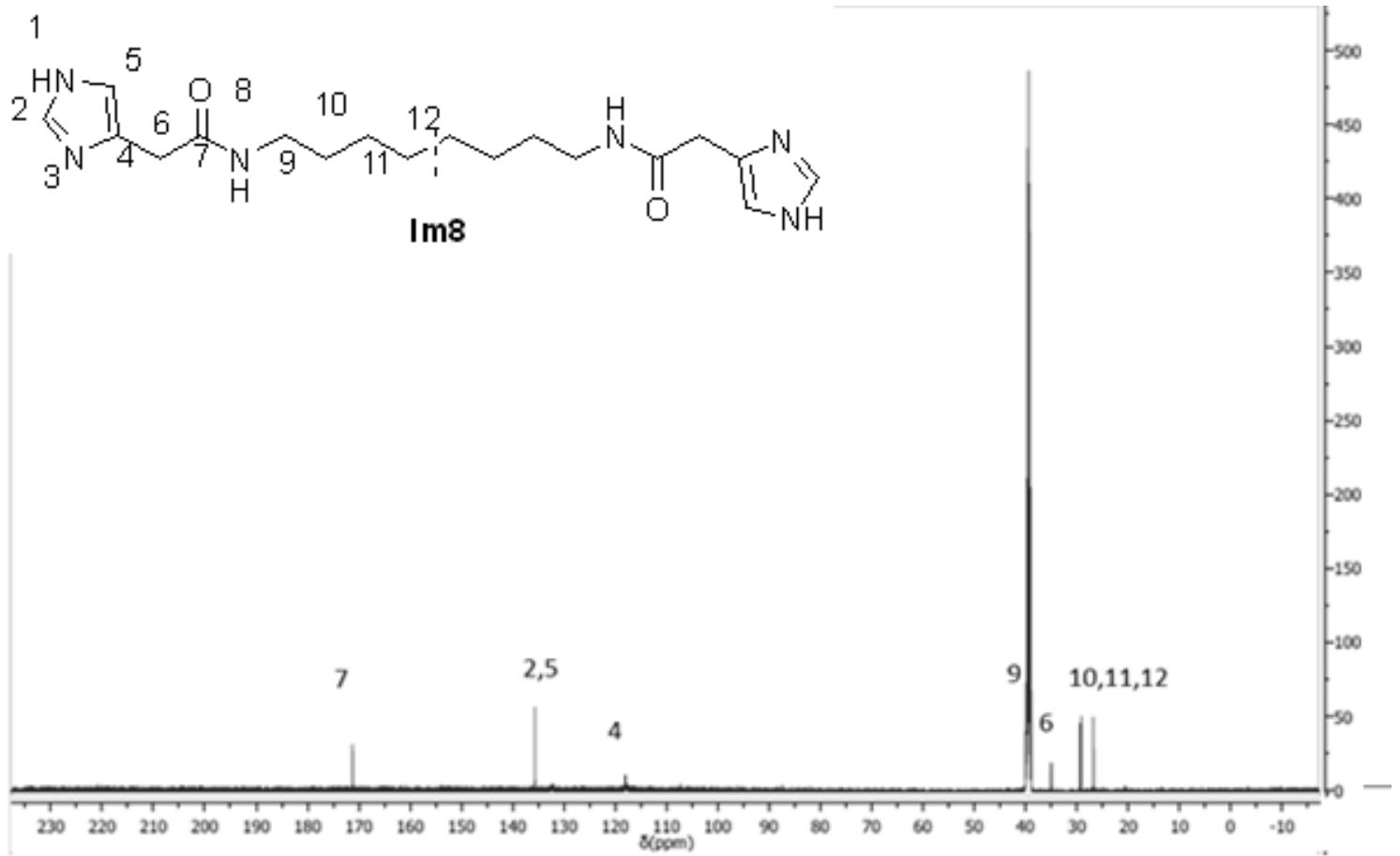


SucVal8 : ${ }^{1} \mathrm{H}$ NMR, $500 \mathrm{MHz}, \mathrm{DMSO}-\mathrm{d}_{6}$<smiles>[Z7]C(C)[C@H](NC(=O)CCC(=O)O)C(=O)NCC[Y]=[V]CCCCCNC(=O)[C@H](NC(=O)CCC(=O)O)C(C)C</smiles>

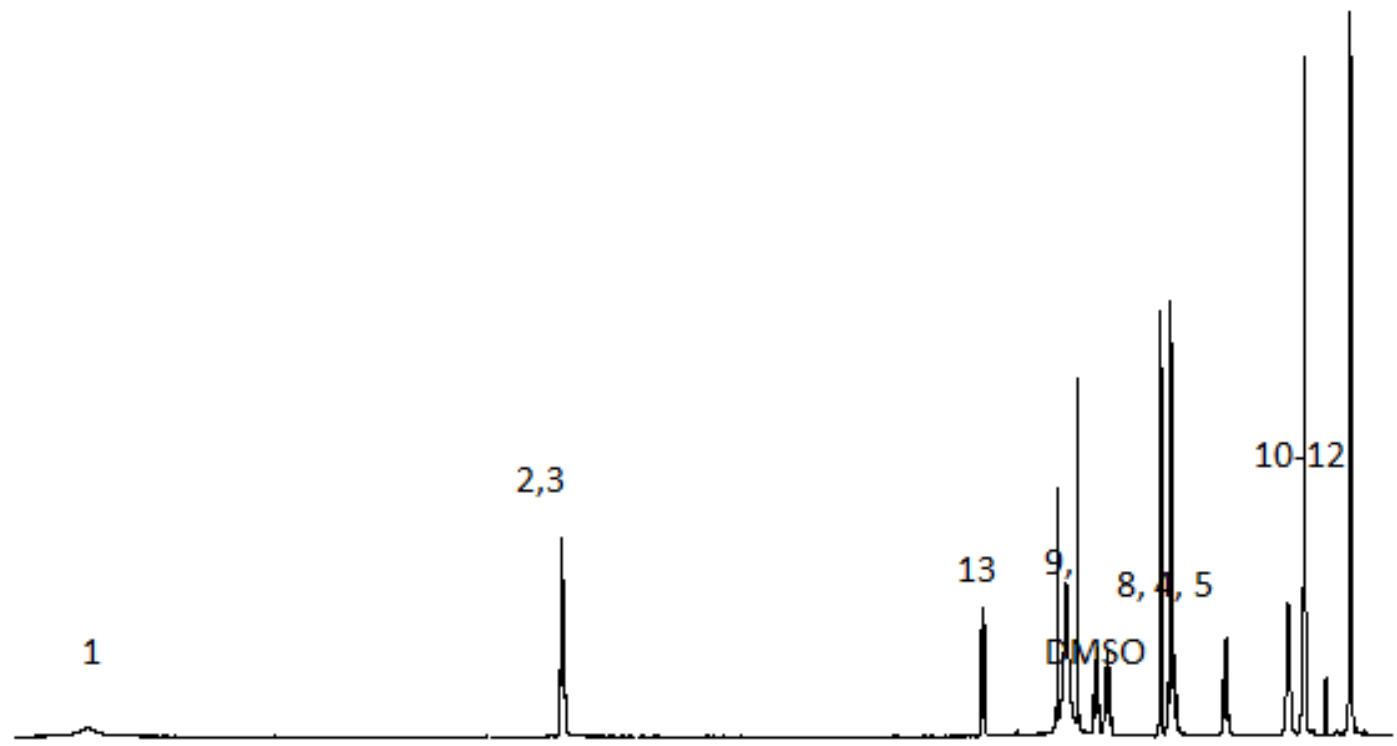
$\begin{array}{llllllllllllllllllllllllll}12.5 & 12.0 & 11.5 & 11.0 & 10.5 & 10.0 & 9.5 & 9.0 & 8.5 & 8.0 & 7.5 & 7.0 & 6.5 & 6.0 & 5.5 & 5.0 & 4.5 & 4.0 & 3.5 & 3.0 & 2.5 & 2.0 & 1.5 & 1.0 & 0.5\end{array}$

SucVal8: ${ }^{13} \mathrm{C}$ NMR, $126 \mathrm{MHz}, \mathrm{DMSO}-\mathrm{d}_{6}$

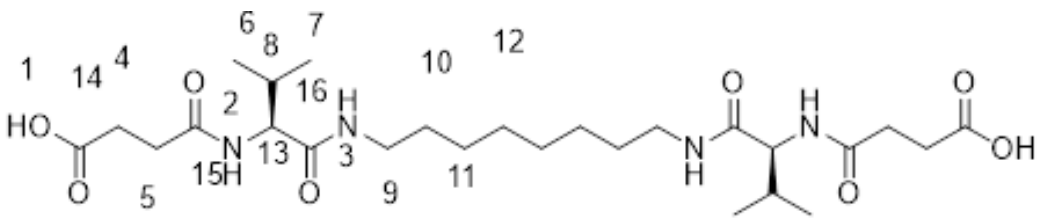

$14-16$

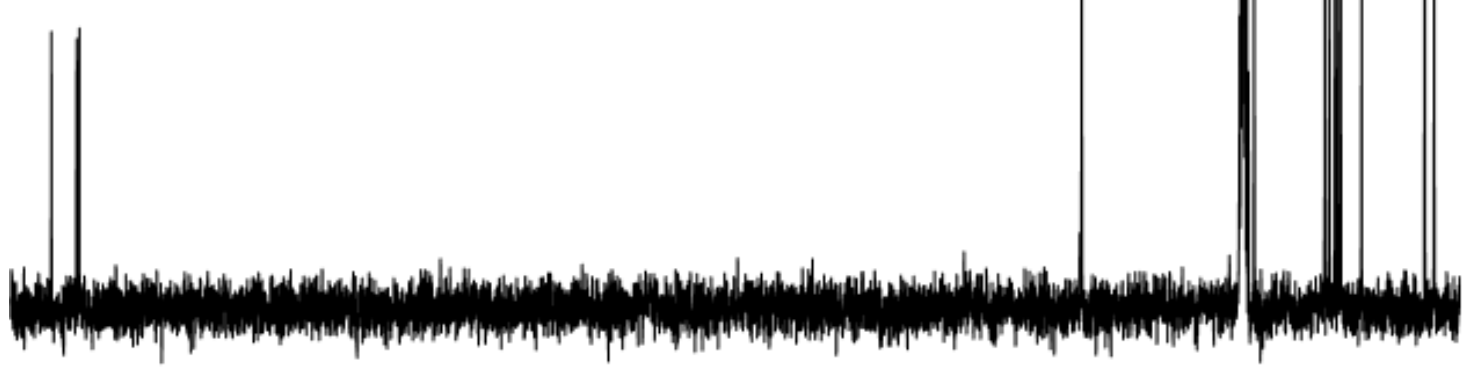

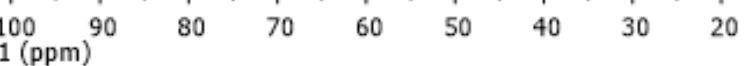


ProVal8: ${ }^{1} \mathrm{H} \mathrm{NMR}, 500 \mathrm{MHz}, \mathrm{CD}_{3} \mathrm{CN}$
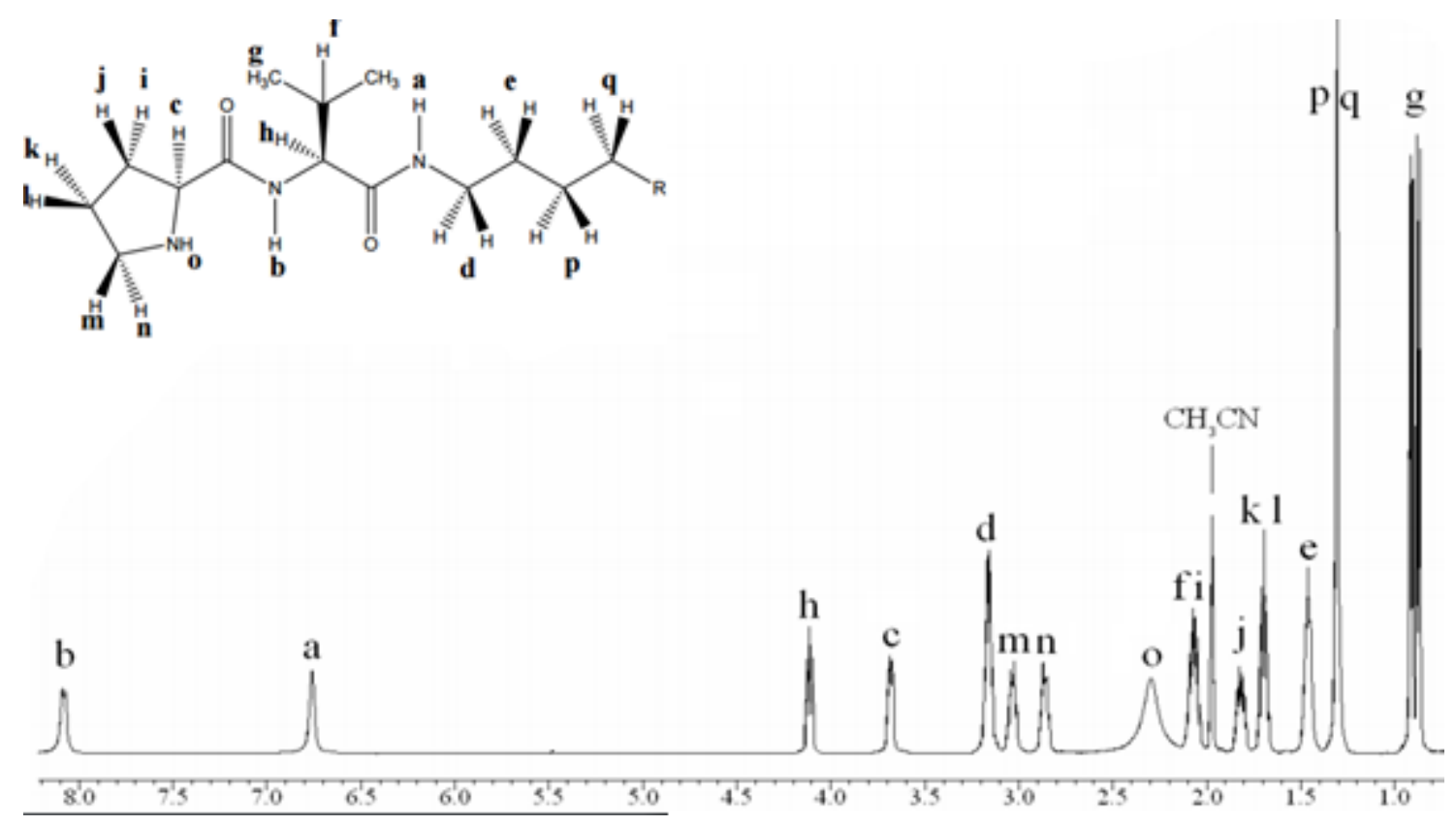

ProVal8: ${ }^{13} \mathrm{C} \mathrm{NMR}, 126 \mathrm{MHz}, \mathrm{CD}_{3} \mathrm{CN}$

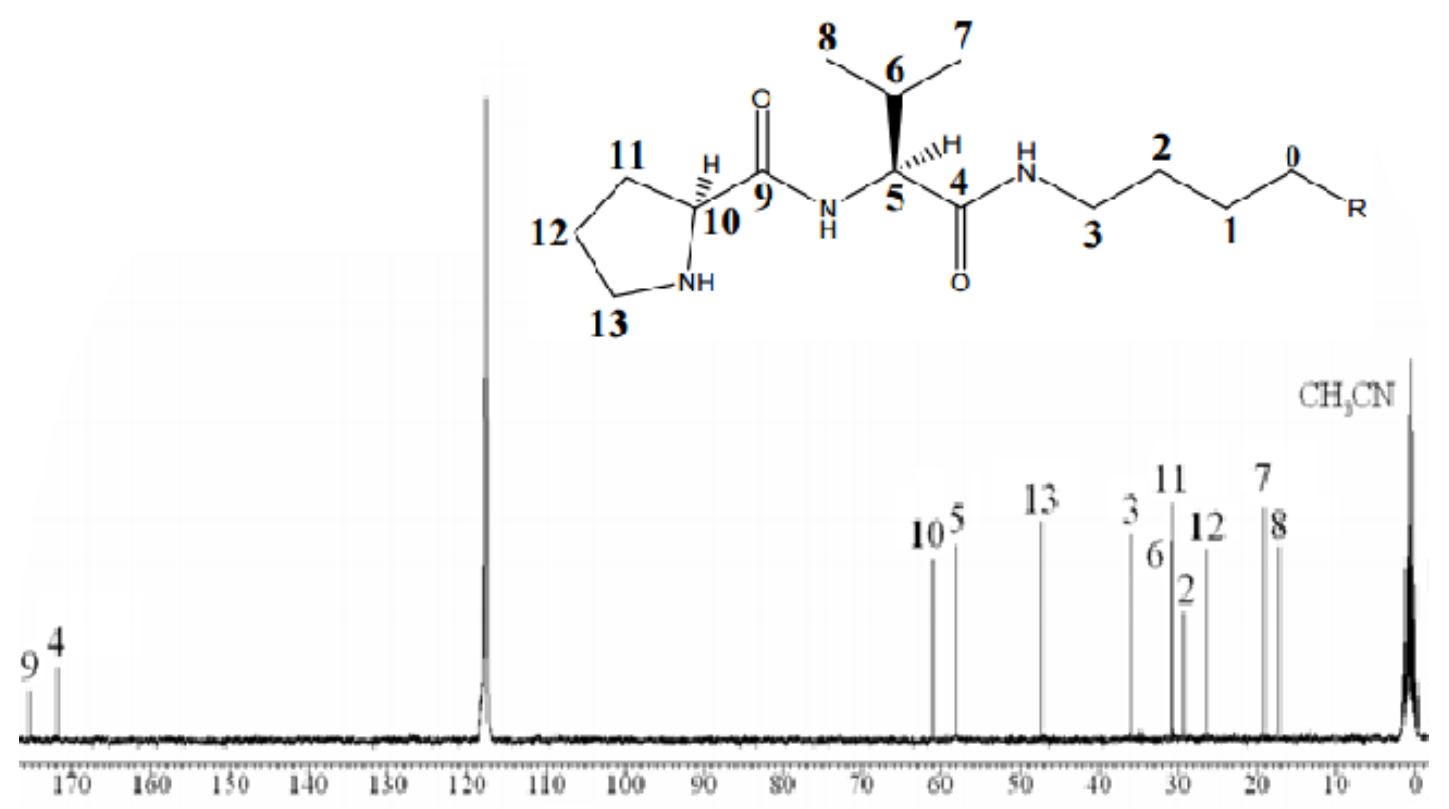


ProValDoc: ${ }^{1} \mathrm{H}$ NMR, $500 \mathrm{MHz}$, DMSO-d 6

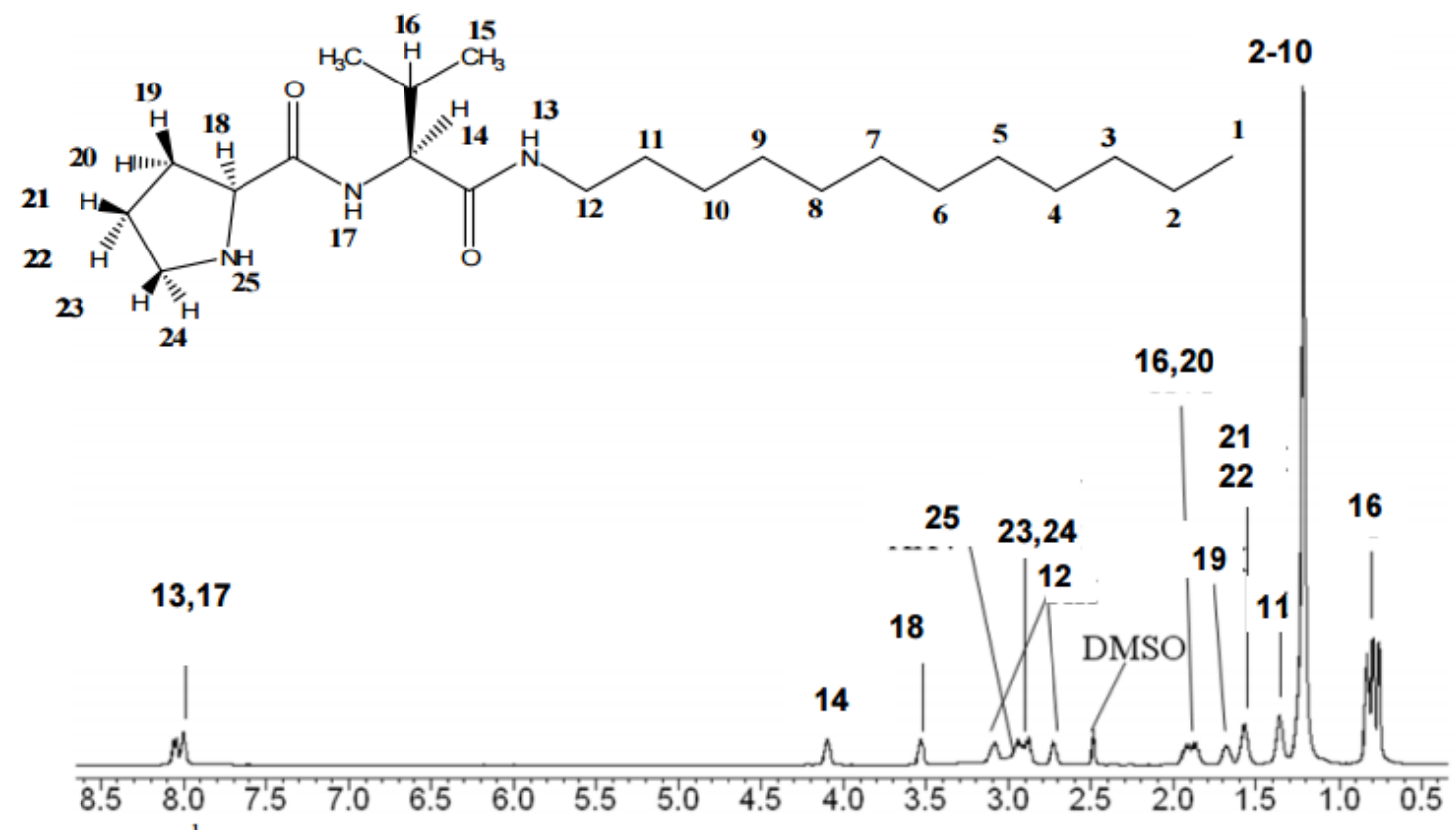

ProValDoc: ${ }^{13 \mathrm{C}} \mathrm{NMR}, 126 \mathrm{MHz}$, DMSO-d 6

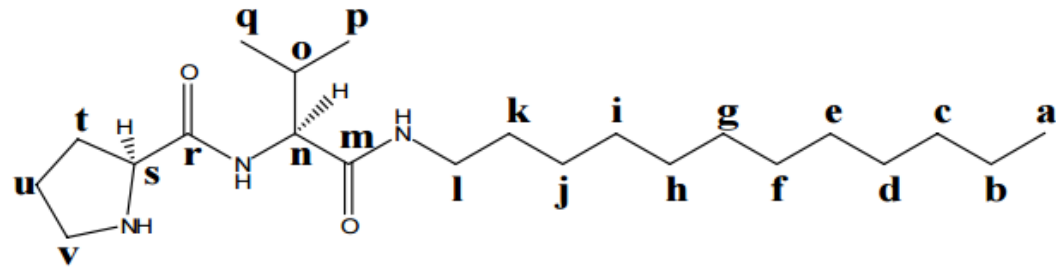

